\title{
The adaptation process after acquired brain injury : Pieces of the puzzle
}

Citation for published version (APA):

Brands, I. M. H. (2015). The adaptation process after acquired brain injury : Pieces of the puzzle.

[Doctoral Thesis, Maastricht University]. Maastricht University. https://doi.org/10.26481/dis.20150123ib

Document status and date:

Published: 01/01/2015

DOI:

10.26481/dis.20150123ib

Document Version:

Publisher's PDF, also known as Version of record

\section{Please check the document version of this publication:}

- A submitted manuscript is the version of the article upon submission and before peer-review. There can be important differences between the submitted version and the official published version of record.

People interested in the research are advised to contact the author for the final version of the publication, or visit the DOI to the publisher's website.

- The final author version and the galley proof are versions of the publication after peer review.

- The final published version features the final layout of the paper including the volume, issue and page numbers.

Link to publication

\footnotetext{
General rights rights.

- You may freely distribute the URL identifying the publication in the public portal. please follow below link for the End User Agreement:

www.umlib.nl/taverne-license

Take down policy

If you believe that this document breaches copyright please contact us at:

repository@maastrichtuniversity.nl

providing details and we will investigate your claim.
}

Copyright and moral rights for the publications made accessible in the public portal are retained by the authors and/or other copyright owners and it is a condition of accessing publications that users recognise and abide by the legal requirements associated with these

- Users may download and print one copy of any publication from the public portal for the purpose of private study or research.

- You may not further distribute the material or use it for any profit-making activity or commercial gain

If the publication is distributed under the terms of Article $25 \mathrm{fa}$ of the Dutch Copyright Act, indicated by the "Taverne" license above, 
The adaptation process after acquired brain injury Pieces of the puzzle

Ingrid Brands 


\section{Colophon}

ISBN: 978-94-6108-849-9

Cover photo and design: Linde Raedschelders

Layout and printing: Gildeprint 


\section{The adaptation process after acquired brain injury Pieces of the puzzle}

\section{PROEFSCHRIFT}

ter verkrijging van de graad van doctor aan de Universiteit Maastricht, op gezag van de Rector Magnificus, Prof. dr. L.L.G. Soete,

volgens het besluit van het College van Decanen, in het openbaar te verdedigen op vrijdag 23 januari 2015 om 12.00 uur

door

Ingrid Maria Henri Brands 


\section{Promotores}

Prof. dr. C.M. van Heugten

Prof. dr. D.T. Wade, Oxford Centre for Enablement, United Kingdom

\section{Copromotores}

Dr. S.Z. Stapert

Dr. S. Köhler

\section{Beoordelingscommissie}

Prof. dr. R.J.E.M Smeets (voorzitter)

Prof. dr. A. Boonen

Prof. dr. R.W.H.M. Ponds

Prof. dr. M.W.M. Post (Rijksuniversiteit Groningen)

Prof. dr. G.M. Ribbers (Erasmus Universiteit Rotterdam)

The research presented in this thesis was conducted at the School for Mental Health and Neuroscience (MHeNS), at the Department of Rehabilitation Medicine of the School for Public Health and Primary Care (CAPHRI), and at the Department of Neuropsychology and Psychopharmacology of the Faculty of Psychology and Neuroscience of Maastricht University. MHeNS and CAPHRI are part of the Faculty of Health, Medicine and Life Sciences of Maastricht University.

This research was financially supported by Libra Rehabilitation Medicine \& Audiology. 
"We must not cease from exploration. And the end of all our exploring will be to arrive where we began and to know the place for the first time."

— T.S. Eliot 



\section{Table of contents}

Chapter 1

General introduction

\section{Chapter 2}

The adaptation process following acute onset disability: an interactive two-dimensional approach applied to acquired brain injury.

\section{Chapter 3}

Assessments of coping after acquired brain injury: a systematic review of instrument conceptualization, feasibility, and psychometric properties.

\section{Chapter 4}

Psychometric properties of the Coping Inventory for Stressful Situations (CISS)

in patients with acquired brain injury.

\section{Chapter 5}

How flexible is coping after acquired brain injury? A one-year prospective study investigating coping patterns and influence of self-efficacy, executive functioning and self-awareness.

\section{Chapter 6}

Influence of self-efficacy and coping on quality of life and social participation after acquired brain injury: a one-year follow-up study.

\section{Chapter 7}

Life goal attainment in the adaptation process after acquired brain injury: the influence of self-efficacy and of flexibility and tenacity in goal pursuit.

\section{Chapter 8}

General Discussion

Summary

Samenvatting

Valorization 



\section{Chapter 1}

General introduction 
Chapter 1 


\section{Adaptation after acquired brain injury}

Acquired brain injury (ABI) refers to any non-progressive injury to the brain caused after birth. The two most common forms of acquired brain injury are strokes and traumatic brain injuries (TBI). Other forms of acquired brain injury include, for example, encephalitis, and hypoxic encephalopathy.

The overall annual incidence rate worldwide of stroke is around $0.20-0.25 \%$, the total annual prevalence rate is around $0.5 \% .{ }^{1}$ After discharge from hospital, more than $50 \%$ of stroke survivors return to their home environment. ${ }^{2}$ For traumatic brain injury, the incidence rate for the European population is $0.24 \%$ with 66000 deaths per year. ${ }^{3,4}$

Physical, cognitive, emotional and behavioural problems are frequently present in patients with acquired brain injury and are often followed by long-lasting impairment and disability. ${ }^{5-8}$ In addition, sustaining a brain injury is usually a disruptive event and may cause major changes, not only in the life course of patients but also in their families' lives. ${ }^{9,10}$ The process of adjustment to these various changes caused by the injury is often difficult and shows an unfavourable course. ${ }^{11}$ Even long after the occurrence of acquired brain injury, large groups of patients report symptoms of anxiety and depression ${ }^{12-14}$, restrictions in their level of social participation ${ }^{8}$ and worse quality of life $^{15}$ and well-being ${ }^{16}$ compared with the general population.

The substantial clinical burden of acquired brain injury also involves considerable health care costs ${ }^{17,18}$, e.g. in Western society approximately 3-4\% of total health care expenditures are spent on stroke. ${ }^{19}$ So, from a clinical perspective it is important to gain insight into the determinants of successful adaptation to the consequences of acquired brain injury, which would enable us to detect patients at risk for worse outcome and to develop interventions to optimize the adjustment process. In addition, this knowledge serves economical interests as, for example identification of risk factors for unfavourable adjustment might be helpful in reducing long-term health care costs.

\section{Models explaining the adaptation process after acquired brain injury}

The 'theory of stress and coping' by Lazarus and Folkman, ${ }^{20-22}$ that has been developed to explain how people deal with acute stress in general, is commonly used as a theoretical background for explaining the process of adaptation after brain injury. ${ }^{23-25}$ 
An essential theme in this 'theory of stress and coping' is the 'transactional' perspective, which means that there is a continuous interplay between the individual and the environment. The basic assumption is that an event is defined as stressful by the individual's subjective appraisal of the event rather than by the objective characteristics of it. Through primary appraisal the person evaluates what is at stake for him. This concerns emotions of threat, harm or challenge. In the secondary appraisal process the person evaluates what can or cannot be done to overcome or prevent harm or to improve the prospects for benefit. This concerns the aspect of controllability of the event.

The process of appraisal results in 'coping', i.e. the cognitive and behavioural efforts used to deal with the event and with one's emotional reactions to the event. Effective coping will be facilitated through access to sufficient personal and environmental resources such as family support, financial security, and self-esteem.

Building on the Lazarus and Folkman theory, Kendall et al. ${ }^{23}$ have proposed an elaborate and complex theoretical model, comprising both neurological and non-neurological variables, for explaining psychosocial outcome in traumatic brain injury. The central assumption is that personal resources (self-esteem and locus of control), environmental resources (social support, family style and financial status) and situational factors (non-brain injury related stressors, age and physical disability) will predict emotional well-being through their impact on appraisal and coping. ${ }^{23}$ This means that the effect of these resources on adjustment is fully mediated by appraisal and coping. So, appraisal and coping have a central mediating role in this model. Furthermore a direct effect of neurological factors (severity of injury, lesion location) and cognitive impairment on psychosocial outcome is assumed in this model. ${ }^{23}$

Kendall et al. ${ }^{26}$ have tested their model in patients with traumatic brain injury in their first year after injury, and have found only limited support for the central mediating role of appraisal and coping in explaining psychosocial outcome. Only higher self-esteem and financial security predicted both greater short-term and long-term emotional wellbeing through their effect on perceived threat (the appraisal component, which has a mediating role) ${ }^{26}$ In patients with traumatic brain injury who were more than ten years post-injury, no evidence was found for a mediating role of appraisal and coping in explaining the nature of predictive relationships between psychosocial variables (cognitive functioning, personality and self-efficacy) and outcome. ${ }^{27,28}$

Also Godfrey et al. ${ }^{24}$ proposed, in line with the 'theory of stress and coping' from Lazarus and Folkman, a 'stress-appraisal-coping' model of emotional adjustment to traumatic brain injury. However, these authors did not test their model. Strom et al. ${ }^{25}$ tested a part of the 
model by Godfrey et al. in patients who were on average four years after having sustained mild traumatic brain injury, but they found no evidence for a mediating role of coping in explaining psychosocial outcome.

So, the 'theory of stress and coping' seems only partially sufficient as a theoretical basis for explaining the adaptation process after acquired brain injury. The central mediating role of appraisal and coping is only partially supported.

\section{Why do we need a new model?}

A better model is needed to explain the adaptation process after acquired brain injury. Model development is important, as knowledge about the relationships between key factors involved in the process of adaptation to brain injury is still lacking. A theoretical understanding of the likely process of change and an understanding of causal mechanisms is essential as a first step in the development of interventions directed at optimizing adjustment and adaptation to brain injury. ${ }^{11,29,30}$ A nice example of the importance of theory-driven research is the progress made in the understanding and treatment of anxiety disorders. ${ }^{31}$ The development of theoretical models in understanding anxiety disorders during the last decades has contributed extensively to the design of successful and effective treatment procedures derived from this theoretical models. ${ }^{31}$

In the process of adjustment to the consequences of acquired brain injury, the physical, psychological, emotional and social aspects involved are all interlinked. This is the basis of the biopsychosocial model of human functioning in the context of disease or illness. So, a prerequisite for the new model to develop, is being consistent with the biopsychosocial model. ${ }^{11,32}$ The biopsychosocial model emphasizes the importance of understanding the consequences of a health condition in terms of interactions between biological factors (e.g., the pathology that causes specific deficits), psychological factors (e.g., cognition and emotion), and social factors (implications for a person's ability to participate in usual activities of daily life, including work, leisure, and developing and maintaining social relationships). ${ }^{11,32}$ The biopsychosocial model is the theoretical basis underpinning the international classification of functioning, disability and health (WHO ICF).

As adaptation to brain injury is about making major adjustments in various domains of functioning and participation, we think it is essential to incorporate theories about human behaviour and behavioural change in the new model, e.g. the theory on self-regulation of behaviour by Carver and Scheier ${ }^{33}$ and the theory on self-efficacy by Bandura ${ }^{34}$. Gracey et al. ${ }^{11}$ also emphasized the importance of using input from behavioural sciences. Gracey et al. ${ }^{11}$ 
developed the 'Y-shaped model of rehabilitation interventions' in which a cycle of behavioural experiments is proposed aiming at facilitating the process of adaptation and reintegration into society. A first step involves gradually reducing the social, interpersonal and personal discrepancies between the experienced self post-injury and the pre-injury or aspired self. Next steps involve identifying new adaptive meanings and identities and supporting generalization, social participation and psychological growth.

\section{General aims of this thesis}

The first main objective of this thesis is to develop a new theoretical model that describes the process of adaptation to acquired brain injury within the framework of the biopsychosocial model of illness.

The second main objective is to test our theoretical model and to investigate if theoretically assumed relations between the core concepts in our new model do indeed contribute to adaptation defined in terms of quality of life, social participation and emotional distress.

\section{Outline of this thesis}

\section{Part I. An interactive two-dimensional model on adaptation after acquired brain injury}

Chapter 2 describes the rationale for and development of our new model on the adaptation process following acquired brain injury. Core elements of this model are depicted in Figure 1. The new model has three theoretical bases that are integrated:

- The transactional perspective, which is present in the 'theory of stress and coping' of Lazarus and Folkman, implies the continuous interplay between individual and environment,

- Elements central to the theory of Carver and Scheier on self-regulation,

- The self-efficacy theory of Bandura.

In our new model we suggest two dimensions. On the one hand, there is the temporal dimension, which comprises the interaction of the short-term and long-term perspective in goal pursuit and/or goal revision, and on the other hand, there is the dimension covering the interaction between behaviour and emotion. 


\section{Part II. The measurement of coping}

Coping, in our new model defined as the way people deal with their day-to-day problems, has a role in the adaptation process to the consequences of acquired brain injury. For testing the role of coping in our new model reliable and valid measurement instruments are needed. Yet, only in stroke a systematic review has been performed to assess the use of coping instruments revealing that information on the psychometric properties of these instruments for use in stroke was lacking. ${ }^{35}$

So, Chapter 3 provides a systematic overview of coping instruments that have been used to measure coping after acquired brain injury, as well as information about their conceptualization, their psychometric properties and feasibility.

Chapter 4 investigates the psychometric properties of the Coping Inventory for Stressful Situations (CISS) in patients with acquired brain injury, as this was the instrument we preferred to use in testing our model. Our choice was based on the feasibility of the CISS (easy wording of the items and suitable for measurement of situation-specific coping) and on the fact that the CISS is widely used in the general population and has been reported to have excellent psychometric properties. ${ }^{36-39}$

\section{Part III. Testing the new interactive two-dimensional model on adaptation following acquired brain injury}

To test our model, we had to operationalize the core concepts mentioned in our model and choose a timeframe in which the evolution of the process was assessed. As our model consists of many interacting components, we isolated meaningful parts of the model (see Figure 1) and choose to assess patients at two points in time.

Baseline measurement was set at discharge home from hospital or inpatient rehabilitation, since we expected that experiencing the impact of the impairments associated with acquired brain injury on daily living and community re-entry and adjusting to the altered reality starts upon return to the home environment.

As adaptation is a process that takes time, we planned the follow-up assessment one year later. The rationale for this choice is that most motor recovery is completed within 10 weeks. ${ }^{40}$ For aphasia, the major part of recovery occurs in the first three months. ${ }^{41}$ For cognitive, impairments no information is available concerning the course of spontaneous recovery. So, we assumed that over the course of one year spontaneous recovery would have been completed and the extent of long(er)-lasting consequences would become apparent. ${ }^{42}$ Yet, it must be noted that adaptation to the consequences of brain injury is not a pure linear timedependent process, but rather a cyclical process embedded in a certain social context. ${ }^{42}$ 


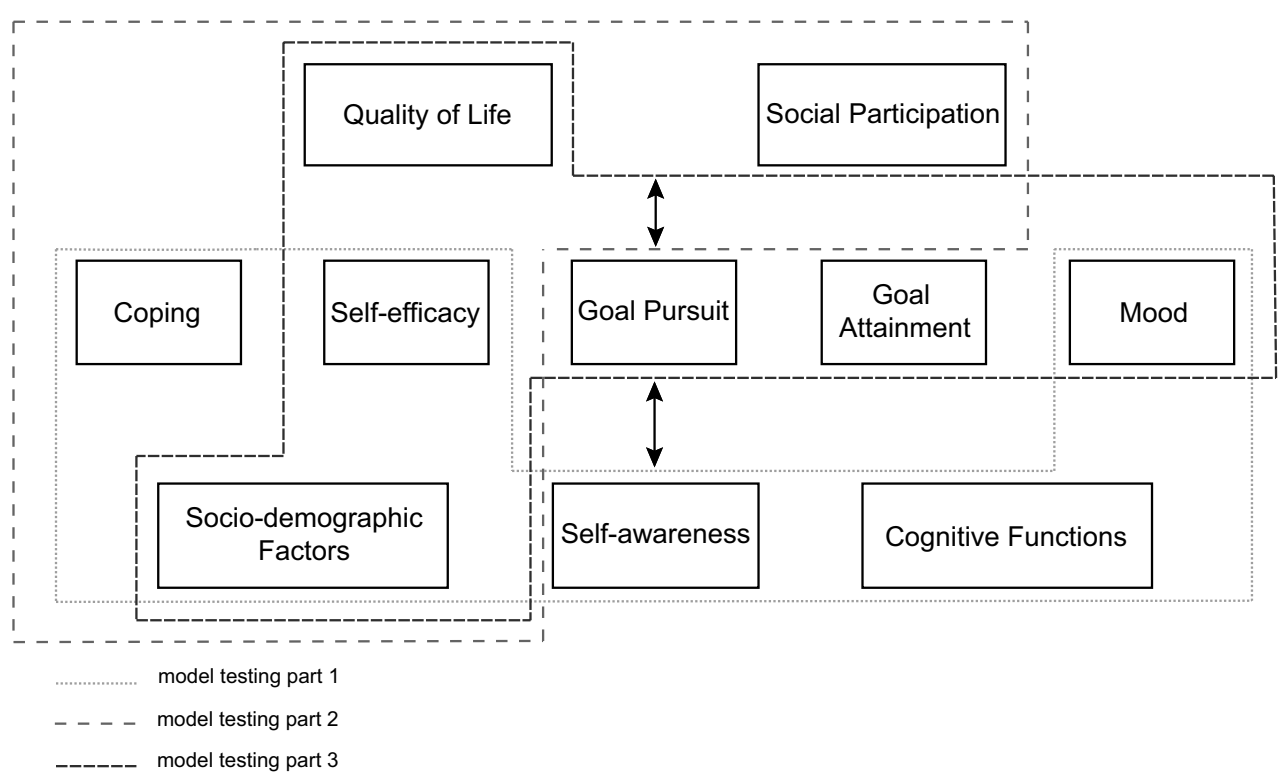

Figure 1. Components of the interactive two-dimensional model

As a first part, we isolated elements essential to the short-term perspective of the model representing the day-to-day adjustment and application of strategies to manage the various problems associated with acquired brain injury. How do patients cope with various stressful situations due to their injury and what is the influence of self-efficacy, mood and brain injuryspecific factors such as self-awareness and subjective executive functioning?

As a second part, we isolated the relationship between coping and self-efficacy and its relation to quality of life and social participation. In our model we assume that higher self-efficacy is associated with a more effective selection of available coping strategies. Furthermore, we assume that higher self-efficacy will positively influence both restoration-oriented and lossoriented behaviour as it determines the level of effort people spent, their perseverance in the face of difficulties and their emotional resiliency, their ability to overcome and manage emotional distress.

As a third part, we shifted the focus towards elements concerning the long-term perspective of the model, which concerns the process of building a new perspective on life and altering expectations about the future. In our model, we assume a continuous, on-going interaction between self-efficacy, goal attainment (which is the inverse of goal-performance discrepancy) and the extent to which one will be tenacious in goal pursuit or more prone to disengagement. In this part we focused on the relationships in the model at one year post-discharge. We 
were interested in how successful patients had been in attainment of their self-set important and valuable goals in life after one year and how they adjusted to non-attained life goals. We looked at the relations between life goal attainment and self-efficacy, tenacity in goal pursuit and flexibility in goal adjustment and its relations to emotional distress and quality of life.

So, the testing of our model is reflected in three chapters. Chapter 5 investigates how flexible coping is in patients with acquired brain injury and investigates the influence of the type of problem encountered, self-efficacy, self-awareness and self-reported executive functions on coping and coping flexibility. Chapter 6 explores the relationships linking self-efficacy and coping to quality of life and social participation and investigates what influence selfefficacy, changes in self-efficacy and coping style have on long-term quality of life and social participation. Chapter 7 investigates the attainment of important life goals and examines whether self-efficacy, tenacity in goal pursuit and flexibility in goal adjustment contribute to adaptation by affecting levels of emotional distress and quality of life.

To conclude, chapter 8 is the general discussion of this thesis in which overall reflections are made, implications for clinical practice are discussed and ideas for future research are presented. 


\section{References}

1. Wolfe CD. The impact of stroke. Br Med Bull. 2000;56(2):275-286.

2. Scholte op Reimer W. Proceedings of the Mixed Methods Symposium. November 28, 2008; Amsterdam.

3. Andlin-Sobocki P, Jonsson B, Wittchen HU, Olesen J. Cost of disorders of the brain in Europe. Eur J Neurol. 2005;12(S1):1-27.

4. Tagliaferri F, Compagnone C, Korsic M, Servadei F, Kraus J. A systematic review of brain injury epidemiology in Europe. Acta Neurochir (Wien). 2006;148(3):255-268.

5. Dikmen S, Machamer J, Temkin N. Psychosocial outcome in patients with moderate to severe head injury: 2-year follow-up. Brain Inj. 1993;7(2):113-124.

6. Dikmen SS, Machamer JE, Powell JM, Temkin NR. Outcome 3 to 5 years after moderate to severe traumatic brain injury. Arch Phys Med Rehabil. 2003;84(10):1449-1457.

7. McCarthy ML, Dikmen SS, Langlois JA, Selassie AW, Gu JK, Horner MD. Self-reported psychosocial health among adults with traumatic brain injury. Arch Phys Med Rehabil. 2006;87(7):953-961.

8. Gadidi V, Katz-Leurer M, Carmeli E, Bornstein NM. Long-term outcome poststroke: predictors of activity limitation and participation restriction. Arch Phys Med Rehabil. 2011;92(11):18021808.

9. Visser-Meily A, Post M, Schepers V, Lindeman E. Spouses' quality of life 1 year after stroke: prediction at the start of clinical rehabilitation. Cerebrovasc Dis. 2005;20(6):443-448.

10. Peters LC, Stambrook M, Moore AD, Esses L. Psychosocial sequelae of closed head injury: effects on the marital relationship. Brain Inj. 1990;4(1):39-47.

11. Gracey F, Evans JJ, Malley D. Capturing process and outcome in complex rehabilitation interventions: a "Y-shaped" model. Neuropsychol Rehabil. 2009;19(6):867-890.

12. Bergersen H, Frøslie KF, Stibrant Sunnerhagen K, Schanke A-K. Anxiety, depression, and psychological well-being 2 to 5 years poststroke. J Stroke Cerebrovasc Dis. 2010;19(5):364-369.

13. Gould KR, Ponsford JL, Johnston L, Schönberger M. Course of psychiatric disorders following traumatic brain injury. Brain Inj. 2010;24(3):337.

14. Whelan-Goodinson R, Ponsford J, Johnston L, Grant F. Psychiatric disorders following traumatic brain injury: their nature and frequency. J Head Trauma Rehabil. 2009;24(5):324-332.

15. Andelic N, Hammergren N, Bautz-Holter E, Sveen U, Brunborg C, Roe C. Functional outcome and health-related quality of life 10 years after moderate-to-severe traumatic brain injury. Acta Neurol Scand. 2009;120(1):16-23.

16. Clarke P, Marshall V, Black SE, Colantonio A. Well-being after stroke in Canadian seniors. Findings from the Canadian Study of Health and Aging. Stroke. 2002;33:1016-1021.

17. Evers SM, Struijs JN, Ament AJ, Van Genugten ML, Jager JH, Van Den Bos GA. International comparison of stroke cost studies. Stroke 2004;35:1209-1215.

18. Berg J, Tagliaferri F, Servadei F. Cost of trauma in Europe. Eur J Neurol 2005;12(S1):85-90.

19. Struijs JN, Van Genugten ML, Evers SMA, Ament AJ, Baan CA, Van Den Bos GA. Future costs of stroke in the Netherlands: the impact of stroke services. Int J Technol Assess Health Care. 2006;22:518-524.

20. Folkman S, Lazarus RS. If it changes it must be a process: study of emotion and coping during three stages of a college examination. J Pers Soc Psychol. 1985;48(1):150-170.

21. Folkman S, Lazarus RS, Gruen RJ, DeLongis A. Appraisal, coping, health status, and psychological symptoms. J Pers Soc Psychol. 1986;50(3):571-579.

22. Lazarus RS. Coping theory and research: past, present, and future. Psychosom Med. 1993;55(3):234247. 
23. Kendall E. Psychosocial adjustment following closed head injury: a model for understanding individual differences and predicting outcome. Neuropsychol Rehabil. 1996;6(2):101-132.

24. Godfrey H, Knight R, Partridge F. Emotional adjustment following traumatic brain injury; a stress-appraisal-coping formulation. J Head Trauma Rehabil. 1996;11(6):29-40.

25. Strom TQ, Kosciulek J. Stress, appraisal and coping following mild traumatic brain injury. Brain Inj. 2007;21(11):1137-1145.

26. Kendall E, Terry D. Predicting emotional well-being following traumatic brain injury: a test of mediated and moderated models. Soc Sci Med. 2009;69(6):947-954.

27. Rutterford NA, Wood RL. Evaluating a theory of stress and adjustment when predicting longterm psychosocial outcome after brain injury. J Int Neuropsychol Soc. 2006;12(3):359-367.

28. Wood RL, Rutterford NA. Demographic and cognitive predictors of long-term psychosocial outcome following traumatic brain injury. J Int Neuropsychol Soc. 2006;12(3):350-358.

29. Whyte J, Hart T. It's more than a black box; it's a russian doll: defining rehabilitation treatments. Am J Phys Med Rehabil. 2003;82(8):639-652.

30. Craig P, Dieppe P, Macintyre S, Michie S, Nazareth I, Petticrew M. Developing and evaluating complex interventions: the new Medical Research Council guidance. BMJ. 2008:337:a1655.

31. Clark DM. Anxiety disorders: why they persist and how to treat them. Behav Res Ther. 1999;37(S1):S5-S27.

32. Wade DT. Applying the WHO ICF framework to the rehabilitation of patients with cognitive deficits. In: Halligan PW, Wade DT, eds. Effectiveness of rehabilitation for cognitive deficits. Oxford: Oxford University Press; 2005.

33. Carver CS, Scheier MF. On the self-regulation of behaviour. 2005 ed. Cambridge: Cambridge university Press; 1998.

34. Bandura A. Self-efficacy: the exercise of control. New York: W.H. Freeman and Company; 1997.

35. Donnellan C, Hevey D, Hickey A, O’Neill D. Defining and quantifying coping strategies after stroke: a review. J Neurol Neurosurg Psychiatry. 2006;77(11):1208-1218.

36. Cook SW, Heppner PP. A psychometric study of three coping measures. Educ Psychol Meas. 1997;57(6):906-923.

37. De Ridder DTD, Van Heck GL. Coping inventory for stressful situations. CISS Handleiding. Lisse: Swets Test Publishers; 2004.

38. Endler NS, Parker JD. Assessment of multidimensional coping: task, emotion, and avoidance strategies. Psychol Assess. 1994;6(1):50-60.

39. McWilliams LA, Cox BJ, Enns MW. Use of the Coping Inventory for Stressful Situations in a clinically depressed sample: factor structure, personality correlates, and prediction of distress. $J$ Clin Psychol. 2003;59(4):423-437.

40. Kwakkel G, Kollen BJ, Twisk J. Impact of time on improvement of outcome after stroke. Stroke. 2006;37:2348-2353.

41. El Hachiouia H, van de Sandt-Koenderman MW, Dippela DW, Peter J., Visch-Brinka EG. A 3-year evolution of linguistic disorders in aphasia after stroke. J Rehabil Res 2011;34(3):214-221.

42. Kendall E, Catalano T, Kuipers P, Posner N, Buys N, Charker J. Recovery following stroke: the role of self-management education. Soc Sci Med. 2007;64(3):735-746. 



\section{Chapter 2}

\section{The adaptation process following acute onset disability:}

an interactive two-dimensional approach applied to acquired brain injury

Brands I, Wade D, Stapert S, van Heugten C. The adaptation process following acute onset disability: an interactive two-dimensional approach applied to acquired brain injury. Clinical Rehabilitation 2012;26(9):840-852. 


\section{Abstract}

Objective: To describe a new model of the adaptation process following acquired brain injury, based on the patient's goals, the patient's abilities, and the emotional response to the changes and the possible discrepancy between goals and achievements.

Background: The process of adaptation after acquired brain injury (ABI) is characterized by a continuous interaction of two processes: achieving maximal restoration of function; and adjusting to the alterations and losses that occur in the various domains of functioning. Consequently, adaptation requires a balanced mix of restoration-oriented coping and lossoriented coping. The commonly used framework to explain adaptation and coping, 'the theory of stress and coping' by Lazarus and Folkman, does not capture this interactive duality.

Relevant theories: This model additionally considers theories concerned with self-regulation of behaviour, self-awareness and self-efficacy, and with the setting and achievement of goals.

The two-dimensional model: Our model proposes the simultaneous and continuous interaction of two pathways; goal pursuit (short-term and long-term) or revision as a result of success and failure in reducing distance between current state and expected future state and an affective response that is generated by the experienced goal-performance discrepancies. This affective response, in turn, influences the goals set. This two-dimensional representation covers the processes mentioned above; restoration of function and consideration of long-term limitations. We propose that adaptation centres on readjustment of long-term goals to new achievable but desired and important goals, and that this adjustment underlies re-establishing emotional stability. We discuss how the proposed model is related to actual rehabilitation practice. 


\section{Introduction}

The process of adjustment to acquired brain injury is often divided into a biomedical process and a psychosocial adaptation process. ${ }^{1-3}$ The biomedical pathway focuses on medical diagnosis, treatment and functional outcome. The psychosocial or emotional pathway concerns the way people perceive their circumstances and how others perceive them ${ }^{2}$ and how they deal with, overcome and manage the emotional consequences of brain injury.

Although this dual approach is widely used, it is based on two isolated linear models of the processes involved. In practice the physical, psychosocial and emotional aspects of the adaptation process to injury are obviously interlinked. The general adjustment process usually starts with the (re-) learning of skills to manage the wide array of physical, cognitive and communication impairments. Then, when the patient begins to realize that the premorbid level of functioning is not going to be completely regained despite hard work, the process of building an entirely new perspective on life starts, which includes making adjustments of expectations about the future to restore and /or rebuild self-concept or self-image.

So, the global process of adaptation is characterized by a continuous and complex interaction between two processes: achieving maximal restoration of function; and adjusting to the alterations and losses that occur in the various domains of physical and psychosocial functioning.

Although clinicians and researchers regularly use the term 'coping' in this context, the content of coping is ill defined. The recent literature suggests it is used to cover several different aspects of adaptation. Some authors use 'coping' to describe the way people with brain injury deal with any problem or stressor they encounter. ${ }^{4-7}$ Others conceptualize coping as the way of managing all symptoms and problems related to brain injury (considering brain injury as a unitary stressor). ${ }^{1,8-11}$ Yet, other authors use a situation-specific approach and focus on particular problems due to brain injury to identify specific coping efforts. ${ }^{12-14}$

We think there is a need to reconsider the classical view on coping and adaptation. In this article we will therefore present a new model for explaining the adaptation process after acquired brain injury based on theories, developed out of the field of rehabilitation, concerning behavioural change and self-regulation and self-efficacy. We will briefly explain these theories first. We will discuss how our model can help to solve the knowledge gaps in the existing literature although the purpose of this article is not to undertake a full review on coping. Finally, we discuss how this new model is related to actual clinical practice in rehabilitation. 


\section{The stress-coping model and critique}

Despite the diversity in the conceptualization of coping, almost all authors rely on 'The Transactional Theory of Stress and Coping' of Lazarus and Folkman as the theoretical foundation for explaining 'problem management. ${ }^{15-17}$ An essential theme in this theory is the 'transactional' perspective, which means that there is a continuous interplay between the individual and the environment.

The basic assumption is that an event is defined as stressful by the individual's subjective appraisal of the event rather than by its objective characteristics. Through primary appraisal the person evaluates what is at stake for him. This concerns emotions such as threat, harm, loss or challenge. In the secondary appraisal process the person evaluates what can or cannot be done to overcome or prevent harm or to improve the prospects for benefit; this concerns the controllability of the event.

In this theory, the process of appraisal results in 'coping', which are the cognitive and behavioural efforts used to deal with the event and with one's emotional reactions to the event. The process of appraisal and coping is influenced by a range of personal (e.g. self-esteem) and environmental (e.g. social support) resources.

Within this theoretical model, coping has been classified in many ways. One very common division concerns the 'style' of coping, separating problem-focused coping processes (i.e. resolving the problem by altering the situation itself) from emotion-focused coping (i.e. regulating and managing the emotional response associated with the situation). ${ }^{15,18-21}$

The Lazarus and Folkman model is a serial model where the result of one stress-coping cycle is the possible starting point of a new cycle. This model incorporates the possibility that different stressors coexist but it does not describe a process of concurrent appraisal and coping with different stressors ${ }^{22}$ nor a description of the interaction that takes places when coping with different stressors occurs simultaneously, which is always the case in patients with recent brain damage.

The published research into coping can be summarized as showing that certain kinds of escapist strategies (which simply do not try to resolve either the practical or the emotional problems generated) are consistently associated with poor mental health outcomes, while other kinds of coping - such as the seeking of social support or instrumental, problemfocused forms of coping - are sometimes associated with negative outcomes, sometimes with positive ones, and sometimes with neither, usually depending on characteristics of the appraised stressful encounter. ${ }^{17}$ 
A similar conclusion can be drawn from the literature concerning acquired brain injury. A few specific coping styles such as passive emotion-focused coping and coping characterized by wishful thinking, avoidance, worry, self-blame and using drugs and alcohol are consistently associated with poor quality of life. ${ }^{5,23}$ In contrast, the relation between outcome and other styles of coping, both problem-oriented and emotion-oriented, are diverse and complex., ${ }^{5,6,12,24-28}$ We cannot infer from the existing literature what determines the adaptive quality of a coping style and why one coping strategy should be (or is) used in favour of another.

Within their theory on stress and coping, Lazarus and Folkman formulated the goodness-offit hypothesis. This hypothesis suggests that the nature and success of coping strategies will be associated with the controllability of the event. ${ }^{17}$ If an event is relatively uncontrollable, then emotion-focused or perception-focused (reappraising the meaning of a situation) coping may be more effective than problem-focused coping. In contrast, a controllable event may be best managed through problem-focused coping. In the normal population, there is only mixed support for this hypothesis. ${ }^{17}$ Kendall found no support for the goodness-of-fit hypothesis in a traumatic brain injury population. ${ }^{9}$

Furthermore, very few researchers have tried to develop a model to explain adaptation after recent brain injury. ${ }^{1,24,29}$ The work of Kendall and Terry ${ }^{8}$ and Rutterford and Wood ${ }^{4}$ has shown that the theory of Lazarus and Folkman only partially fits as a framework for explaining adaptation both in the early and late stage after acute brain damage.

In summary, the model of Lazarus and Folkman is a widely used and valuable model but it has weaknesses when applied to the adaptation process after brain injury. The theory offers a description and a classification of how people cope with stress but it does not provide a complete explanation, or a framework to elucidate why people cope as they do, what determines the choices people make and what makes coping adaptive. Lastly, the available evidence only partially supports the validity or utility of this model to explain the adaptation process after recent brain damage.

As we stated earlier, the process of adaptation to brain injury is better considered as having at least two contemporaneous tracks: an interaction of striving towards maximal restoration of function while also adjusting to the alterations and losses that occur in the domains of physical and psychosocial functioning. Thus, adaptation requires a balanced mix of restorationoriented coping and loss-oriented coping ${ }^{22}$ and the commonly used division of coping styles in the model of Lazarus and Folkman into emotion-focused and problem-focused styles does not fit this model very well. Both emotion-focused and problem-focused styles are in play simultaneously. 
We think that the reality of adapting to brain injury is better represented by a model that allows parallel and interactive processing; people deal with different problems or stressors simultaneously and these parallel processes influence and interact with each other.

\section{Definitions of adaptation and coping}

When introducing a new model, it is important to start with clear definitions of the core concepts. The words 'coping' and 'adaptation' are regularly used in the literature, sometimes as unique concepts, sometimes as interchangeable notions, but for the most part their meaning is open to many interpretations. To avoid confusion and for a clear reading of this article, we propose the following distinction between coping and adaptation.

- Adaptation, in our definition, refers to the general and overall process of change in emotions, actions and thoughts that arise from the changes and limitations imposed by the injury in any and all domains. Adaptation is a process, an evolution that takes place over time in response to on-going challenges.

- Coping, in our definition, is a more restricted concept and refers to the way people are responding to the problems and emotional turmoil associated with brain injury. It is a description of the adaptation process in relation to a specified problem at a certain moment in time.

The contrast between the two is illustrated by 'Mr Jones is adapting poorly to his brain injury' and 'Mrs Smith is coping well with her poor communication'.

Table 1 gives an overview and explanation of the terminology concerning coping used in this article.

\section{Additional theories used}

Before introducing our model we will first explain two influential behavioural theories - the theory on self-regulation of behaviour from Carver and Scheier ${ }^{30}$ and the concept of selfefficacy from Bandura ${ }^{31}$ - that served as a general theoretical basis for our model of adaptation after brain injury. 
Table 1. Explanation of the coping terminology used in this article

\begin{tabular}{ll}
\hline Coping Style & Explanation \\
\hline Emotion-focused & $\begin{array}{l}\text { Regulating and managing the emotional response associated with the } \\
\text { situation }\end{array}$ \\
$\begin{array}{l}\text { Problem-focused } \\
\text { Perception-focused } \\
\text { Escapist }\end{array}$ & $\begin{array}{l}\text { Reappraising the meaning of a situation } \\
\text { Turning away from problems }\end{array}$ \\
$\begin{array}{l}\text { Avoidant } \\
\text { Restoration-oriented }\end{array}$ & $\begin{array}{l}\text { Keeping oneself busy with other things to avoid thinking about the problem } \\
\text { Applying all kinds of necessary strategies to rebuild one's situation }\end{array}$ \\
Loss-oriented & $\begin{array}{l}\text { Applying all kinds of necessary strategies to deal with aspects of the loss } \\
\text { experience itself }\end{array}$ \\
Adaptive & $\begin{array}{l}\text { Actively working on the problem and using humour and enjoyable activities } \\
\text { to manage stress (subscale of the Coping Scale for Adults) }\end{array}$ \\
Non-productive & $\begin{array}{l}\text { Avoidance, worry, wishful thinking, self-blame, and using } \\
\text { drugs and alcohol (subscale of the Coping Scale for Adults) }\end{array}$ \\
Accommodative & $\begin{array}{l}\text { Attempting to accept the consequences by adjusting personal goals and } \\
\text { preferences } \\
\text { Actively adjusting circumstances to personal preferences, striving to maintain }\end{array}$ \\
Assimilative & life as it was before
\end{tabular}

\section{Self-regulation of behaviour}

Goals are central to some very influential theories developed to explain human behaviour. ${ }^{30,32,33}$ The common principle is that achieving goals generates feedback processes that are involved in creating and adapting our behaviour through affecting thoughts, actions and emotions. These theories have been the subject of extensive research and are also used in rehabilitation to develop interventions directed towards self-regulation and self-management in brain injury. ${ }^{34-38}$

We will focus on the theory on self-regulation of behaviour from Carver and Scheier. ${ }^{30}$ Described in brief, the core construct in this theory is the 'discrepancy feedback loop'. The theory argues that the normal adaptive self-regulation constitutes of the following cycle:

- The perception of the current condition (input) is compared to a reference value, which is equivalent to a goal.

- If the comparison yields 'discrepancy', a process of creating conformity between input and reference starts, attempting to attain valued or desired goals. This output is behaviour.

- At some late point the comparison is made again, and the cycle continues until the goal is met, or until the goal is changed or abandoned. 
Furthermore this theory suggests that, parallel to this behaviour-guiding loop, an affect-loop operates. The affect-loop has the following cycle:

- It checks how well the behaviour-loop is doing in terms of discrepancy reduction over time, the rate of progress.

- This rate of progress is compared to an internally generated expected rate of change, a reference standard.

- The result of this comparison is affect, a sense of positiveness or negativeness, which in turn has an influence on subsequent behaviour. Negative feelings may lead to efforts to catch up or, alternatively, to a sense of hopelessness and giving up. Positive feelings lead to coasting.

- The normal effect of this adjustment is to return affect to neutral but constant failure may lead to frustration, or hopelessness.

In this theory, when people encounter adversity in trying to move towards their goals, they monitor their efforts to assess the likelihood of success. Their outcome expectancy depends on memories of prior outcomes, the availability of additional resources or alternative approaches, and influences subsequent behaviour. If expectancies are favourable, the result is renewed goal-directed effort. If doubts are strong enough, the result is reduced effort or even complete disengagement. Research shows that confident people take a goal-engaged approach to coping, whereas doubtful people respond in ways that imply disengagement. ${ }^{39,40}$ Goals that people engage in are derived from core aspects of the self, a system of beliefs and values with a hierarchical structure.

Furthermore, in this theory, when one is confronted with continuing adversity (as is the case in brain injury) an additional mechanism can occur. As mentioned before, the first response to discrepancy is to change the present conditions. One tries very hard to correct things. If, for a long enough period, all these efforts fail, feelings of distress increase. In this perspective, one has to acknowledge that persistence is a very important quality but the ability to give up at an appropriate time is an equally important quality.

One way that both cycles can respond is to alter (usually to scale back) the reference point against which current conditions are compared. ${ }^{41}$ In the context of goals, this slower-acting feedback mechanism has the effect of recalibrating the person's subjective reality (behavioural aspirations), which may alter the affective response and the choice of goals to pursue. This shift in reference point, if appropriate in size, may enable the person to experience the same range of positive and negative feelings again instead of an overwhelming amount of negative emotions associated with the original reference point. 
In this way the person's quality of life is maintained. As some goals become unattainable, they are substituted but not indiscriminately; new wanted goals are set. The substitute goals typically represent alternative paths to core values of the self. This scaling back of aspirations prevents people from complete disengagement. Consequently, purpose in life is sustained, albeit different from before, which is crucial to well-being.

In quality of life research, this is termed 'response shift' and it is an important methodological issue, dealing with discrimination between 'true' changes in quality of life scores and changes based upon the recalibration of internal standards, reprioritization of values and reconceptualization. ${ }^{42-44}$ Conceptually though, these three types of change fit into the theory of Carver and Scheier. ${ }^{41}$

\section{Self-efficacy}

The theory of 'self-efficacy' from Albert Bandura ${ }^{31}$ can also shed some light on the process of adaptation. Perceived self-efficacy refers to beliefs in one's capabilities to organise and execute the courses of action required to achieve goals; it is not a measure of skills one has. Self-efficacy is not an omnibus trait but a differentiated set of self-beliefs linked to distinct realms of functioning. Efficacy beliefs are concerned not only with the exercise of control over action but also with the self-regulation of thought processes, motivation and affective and physiological states.

Self-efficacy beliefs are constructed from four principal sources of information:

- Mastery experiences, which serve as indicators of capability (e.g. success in specific activity performance);

- Vicarious experiences, which alter efficacy beliefs through transmission of competencies and comparison with the attainment of others (e.g. the performance of a sports teammate);

- Verbal persuasions that one possesses certain capabilities (e.g. constructive feedback);

- Physiological and affective states, from which people partly judge their capabilities, strength and vulnerability to dysfunction (e.g. stress, fatigue).

Efficacy beliefs vary on several dimensions. They differ in level or magnitude (the level of a task demand from easy to taxing), strength (the stronger, the more resistant to disconfirming evidence) and generality (specific to one task or more general). Efficacy beliefs influence the type of activity people choose to engage in, the level of effort they spend and their perseverance in the face of difficulties. Among other factors, cognitive processes are an important mediator through which efficacy beliefs produce their effects. Both the conception of ability (as either an acquirable skill or an inherent aptitude) and people's beliefs about the extent to which 
their environment can be influenced and controlled are strong belief systems that affect how efficacy information is cognitively processed.

People with a strong sense of self-efficacy are less burdened by negative thoughts, they set themselves challenging goals and maintain strong commitment to them, and they are more resilient in the face of failure and setbacks.

Looking at coping and adjustment from the self-efficacy perspective, one could hypothesise again that the widely used dichotomisation into problem-focused and emotion-focused coping becomes less important because these concepts are simply different means by which one exerts self-control. Of importance is to develop a strong sense of self-efficacy in one's coping abilities, whatever processes are used.

In the medical field self-efficacy is widely studied in relation to interventions and disease self-management. High self-efficacy predicts better psychological functioning, improved functional status and improved health behaviour and disease management. ${ }^{45-49}$ Also in numerous other fields (e.g. sports, organisational decision making) the role of self-efficacy is acknowledged. ${ }^{31}$

\section{Our proposed model}

We propose an alternative approach to adaptation after acquired brain injury, based on an interactive model with two dimensions or axes. The model, which is shown schematically in Figure 1, will now be explained. It has been developed in response to the limitations of the current theory on stress and coping already discussed, and it specifically incorporates the selfregulation and self-efficacy theories just reviewed.

After brain injury the person has to deal with various problems or stressors, many being long-term. As a result, problems must be considered both in a short-term perspective and in a long-term perspective. This time perspective is inevitably closely related to the goals that are set in relation to the problems because goal setting is highly influenced by future expectations. What seems impossible in the short term may be judged as achievable in the long term. When setting goals to manage problems with a long-term character, it is usual to set short- and longterm goals simultaneously. ${ }^{50,51}$ 


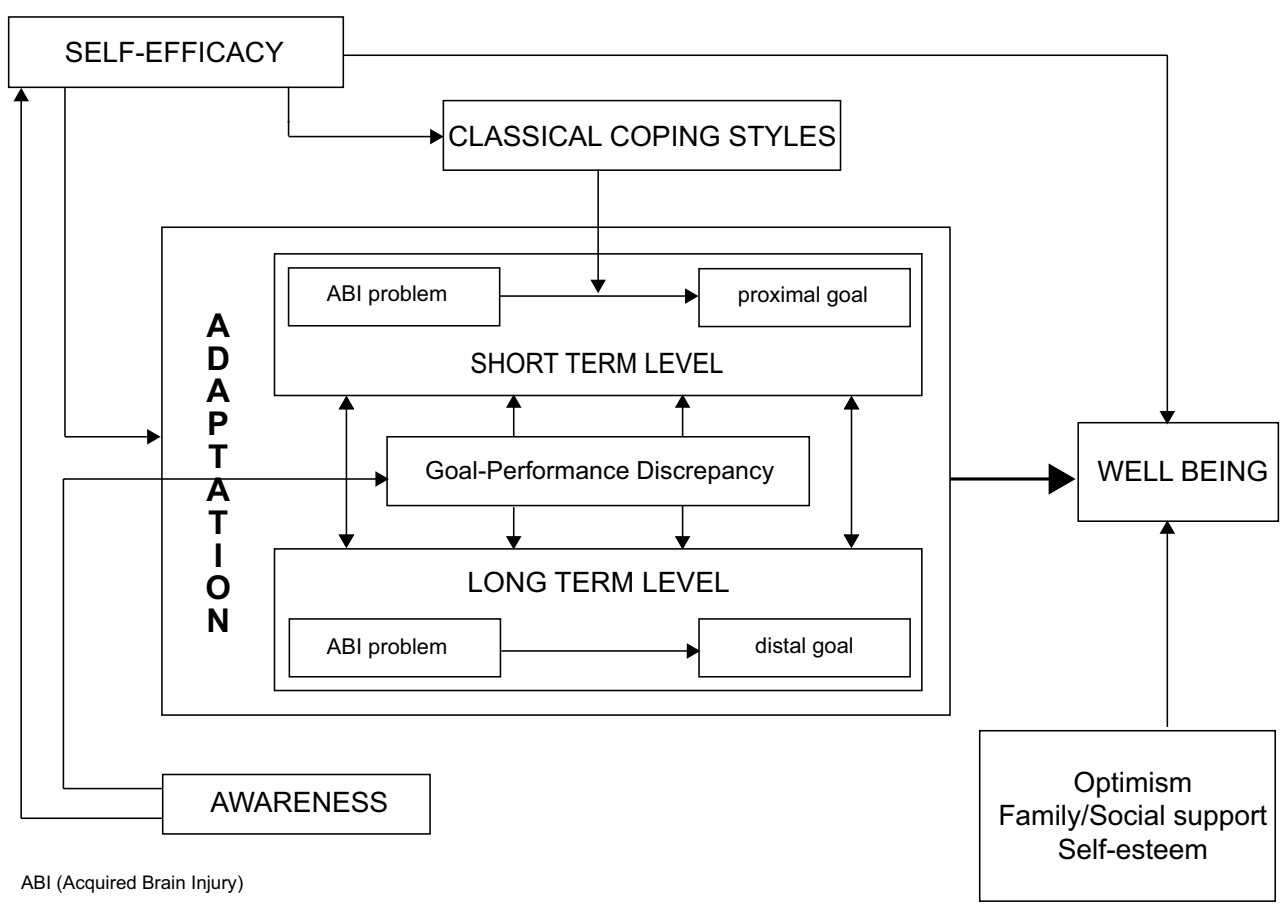

Figure 1. Schematic of the model

Consequently, coping with or adjusting to a chronic problem reflects the simultaneous interaction of two levels. On the one hand, there is the short term level, representing the dayto-day adjustment and application of strategies to manage the various problems associated with brain injury. In this perspective proximal goals are set. For example, Mr Peters wants to walk around the house and in the garden and learn to use a notebook to overcome memory problems.

On the other hand, there is the long term level, where the same problems/stressors are related and integrated into a broader perspective and oriented towards the long term. This level concerns the process of building a new perspective about life and altering expectations about the future. In this perspective, distal goals are set. In our example: Mr Peters wants to regain his former job as an engineer and he wants to make a long low budget trip around the world on his own.

Both levels interact continuously and simultaneously. With the passage of time, one learns if one's short-term goals can be attained. This is an important indicator for possible success in attaining one's long-term goals. This process of judging and evaluating what one has reached and what one wishes to achieve in the future is continuous. In our example: eight months post 
injury, Mr Peters still experiences poor walking ability and problems to manage his memory problems. He no longer is planning a world trip but wants to take a hotel vacation at the seaside together with his family.

Everyone, not only people with brain injury, has to answer questions such as: do I stick to my original goal of regaining fulltime employment or do I switch towards voluntary work? Both the short term and the long term level mutually influence each other in this process of appraisal of possibilities and difficulties.

This continuous interplay, which is here described for the more behavioural oriented aspects, operates analogously for the emotional aspects (Figure 2). So, finally the process of adaptation will be influenced by the emotional state that the process itself engenders.

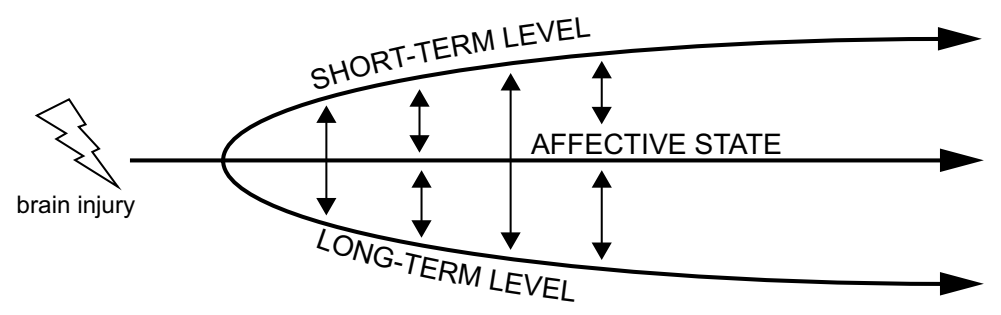

Figure 2. Influence of the emotional state on the adaptation process following brain injury.

A major determinant of goal revision is the size of the discrepancy between one's performance and goal. These goal-performance discrepancies are powerful motivational forces towards action. When people recognise goal-performance discrepancies, they make adjustments to either their goal, or their behaviour or both when they are attempting to reduce the discrepancy ${ }^{30,32,52}$ At the same time, there is an effect on the emotional state. The experienced discrepancy is compared to an expected rate of progress (an internally generated standard, see self-regulation theory), which engenders positive or negative emotions (affect). Achieving goals create feelings of satisfaction. Negative emotions arise when the actual performance is far from what one is striving for. This in turn can lead to re-engagement and efforts to catch up but also to frustration when the anticipated goal cannot be reached.

Thus, a balance must be found between persistence - important in preventing people from giving up too quickly - and partial disengagement when goals are unattainable. The proper balance between tenacious goal pursuit and flexible goal adjustment ${ }^{33}$ reflects the ability to sustain effort or to disengage based on the size of experienced goal-performance discrepancies. 
Finding this balance is crucial in regaining emotional stability and preventing striving towards the unattainable ending up in frustration.

Research shows that individuals often respond to large negative goal-performance discrepancy feedback (performance < goal) by revising their goals in such a way that they become easier. ${ }^{53,54}$ Individuals who come close to their goals or even exceed their goals have been found to increase their goals. ${ }^{53}$ Donovan showed in athletes that distal goals were revised continuously on the basis of the outcome of proximal goals. ${ }^{50}$

Outside the field of rehabilitation, investigators have shown that goal disengagement and goal re-engagement are important factors when people face challenging and normatively less-expected life circumstances that might require them to adjust important life goals. Disengagement from unattainable goals shows beneficial effects on subjective well being. ${ }^{55,56}$ Also re-engaging in new pursuits predicts well being above and beyond a person's ease of abandoning unachievable goals. ${ }^{55}$

In brain injury, not only the importance of life goals has shown to influence subjective well being but both attainability and success of life goals are also found to play important intermediate roles. ${ }^{38}$

We suggest that optimal adjustment is reached if an individual is able, based on the accomplishments and failures experienced in the day-to-day struggle with the different problems associated with their injury, to adapt their long-term perspective by choosing a set of realistic goals, which will create feelings of well-being and satisfaction with life when attained. Finding a balance and adjusting previously set goals towards a more achievable level of goals is a process that takes time..$^{30,41}$

A range of personal and environmental resources will enable individuals to resist to the deleterious effects of stress and adjust with less effort to a range of situations. Self-esteem, optimism and perceived family and social support are shown to be important. ${ }^{1,4,5,8,19,57-64}$

In summary, as we stated in the introduction, the process of adaptation is an interplay between achieving maximal restoration of function; and adjusting to the alterations and losses that occur in the various domains of physical and psychosocial functioning. Both components are represented and incorporated in the proposed model.

Adaptation is an iterative process. This iterative character fits well into the proposed model because of its time independency. The model is applicable independent of time since injury. 
Either being confronted with problems in the acute stage after brain injury or facing a stressful major life event in the chronic phase, starts the same kind of adaptation process.

\section{The role of self-efficacy in the new model}

Little research into the role of self-efficacy in the process of coping and the prediction of adjustment has been published. ${ }^{4,8,9,65}$ Most authors consider self-efficacy only in relation to the secondary appraisal process (i.e. the aspect of controllability of the stressful situation). However, Cicerone et al. ${ }^{66,67}$ showed that self-efficacy, conceptualized in a multi-dimensional way and linked to specific domains of functioning, is an important contributor to life satisfaction. More specifically, participants' self-efficacy for the management of cognitive symptoms made the single greatest contribution to prediction of quality of life. ${ }^{67}$

In our opinion, self-efficacy is an important contributor to successful adaptation. ${ }^{68}$ Perceived self-efficacy will act directly upon well being. ${ }^{67}$ We hypothesize that the better one's perceived self-efficacy is in several domains, the greater the range of available response strategies and the better the selection of strategies in relation to the demands of the situation. A higher level of self-efficacy will influence both restoration-oriented behaviours, because it determines the level of effort people spend and their perseverance in the face of difficulties, and also lossoriented coping and goal changing because it influences emotional resiliency and the ability to overcome and manage emotional distress.

\section{The role of awareness in the new model}

Impaired awareness will interfere with problem perception and the ability to assess goalperformance discrepancies. We hypothesize that impaired awareness will inflate perceived self-efficacy. The assumption is that in the presence of impaired awareness, the person feels little urge to adapt because relatively few problems and small goal-performance discrepancies are perceived. Satisfaction with life and quality of life could be fairly good as a direct consequence of the absence of problem perception and goal-performance discrepancy and a high-perceived self-efficacy.

Little is known about the relation between awareness of deficits and coping or adaptation. Anson and Ponsford ${ }^{5}$ did not find an association between the level of adaptive coping and self-awareness, but did find that greater use of non-productive coping strategies (coping characterized by avoidance, worry, wishful thinking, self-blame and using drugs and alcohol) was significantly associated with greater awareness of deficits. Kortte et al. ${ }^{69}$ showed that lower levels of awareness were associated with an increased reliance on avoidance strategies. Interestingly she found that psychological denial was a stronger predictor of an avoidant coping style than organic awareness deficits. ${ }^{69}$ Medley et al. ${ }^{70}$ found that patients with 
impaired awareness showed a relatively lower reliance on wishful thinking and emotionfocused coping. The group with better awareness reported a greater overall use of a variety of coping strategies. ${ }^{70}$

In the long term, Ownsworth et al. ${ }^{11}$ did not find differences in emotional adjustment between groups with good and poor awareness. However, the poor awareness group scored significantly lower on independent living skills. ${ }^{71}$

\section{The role of coping styles in the new model}

In our model coping styles, defined and described in the classical way using the dichotomisation into problem- and emotion- oriented styles, are only relevant to the day-to-day, short-term adjustment to problems (short term level). They reflect which strategies people are currently using to attain the short-term goals that are related to the daily problems they have to overcome.

The description of coping styles in terms of accommodation (attempting to accept the consequences by adjusting personal goals and preferences) versus assimilation (actively adjusting circumstances to personal preferences, striving to maintain life as it was before $)^{33}$ is more appropriate to reflect aspects of the general process of adaptation (see definition) which is characterized by the simultaneous interaction of achieving maximal restoration of function and adjusting to losses in the various domains of functioning.

\section{What is new in this model?}

This model differs from existing models in several ways:

- There is an emphasis on the importance of goal setting, which is crucial in understanding behavioural change and adaptation.

- It has three theoretical bases that are integrated:

- the transactional perspective, which is present in the theory of stress and coping of Lazarus and Folkman, implies the continuous interplay between individual and environment,

- $\quad$ elements central to the theory of Carver and Scheier on self-regulation, and

- the self-efficacy theory of Bandura.

- It integrates two processes that are occurring and interacting simultaneously: attempts to recover lost skills and abilities and consideration of (perceived) longterm limitations, by the interaction of:

- goal revision as a result of success and failure in reducing distance between current state and expected future state. 
- the affective responses that are generated as a result of the experienced goal-performance discrepancies.

These affective responses, in turn, may influence both functional performances and the goals set.

- It proposes that adaptation centres on readjustment of long-term goals to new achievable but desired and important goals, and that this adjustment underlies reestablishing emotional stability

\section{Discussion}

The basic principle in the proposed model is the parallel processing and simultaneous interaction of two processes: attempts to recover lost skills and abilities and adjusting longterm goals in response to (perceived) long-term limitations. The model suggests that the patient's emotional state arises from the search for equilibrium between persistence, which is necessary to progress successfully towards long-term goals and partial disengagement, which is necessary to prevent frustration when goals turn out to be unattainable.

Although research, using the classical approach on coping, shows that coping styles and appraisals contribute in the prediction of well being and functional outcome ${ }^{8,27,72-74}$, it remains very difficult to determine what distinguishes the adaptive quality of coping. The classical theory of stress and coping does not provide a framework of motivational patterns and belief systems that guides the process of appraisal and coping, especially in long-term illness.

Furthermore the theory of stress and coping of Lazarus and Folkman is a mediated model; resources (predictors) influence adjustment through their impact on appraisal and coping (mediators). In the early stage after brain injury, partial evidence was found for mediated relationships ${ }^{8}$ but in the late stage no mediated effects occurred. ${ }^{4}$

We have developed this interactive two-dimensional model because we think it reflects the iterative character of the adaptation process. It is applicable both in the acute and chronic stage after brain injury. In our opinion, this model helps to solve the existing knowledge gaps concerning the effectiveness of coping and adaptation by adding elements such as success in goal pursuit, goal revision and self-efficacy.

We suggest that goals play a central role in guiding and adapting behaviour ${ }^{30,32}$ and our model is based on this premise. We believe that describing adaptation in the proposed two dimensional goal-oriented way provides a link to the general rehabilitation practice where 
systems of goal setting and goal planning are considered to be essential and are widely implemented in therapyschemes. Moreover, there is a trend to develop interventions directed towards self-regulation and self-management in people with adult-onset brain damage. In these interventions short-term goal setting, self-evaluation and use of feedback from proximal goal setting are core concepts. ${ }^{75-77}$

As the goal-oriented approach is already common practice in rehabilitation, describing the adaptation process in a similar way facilitates the integration and evaluation of adaptation processes into the whole process of rehabilitation.

This model is entirely consistent with the biopsychosocial model of illness that underlies the World Health Organisations International Classification of Functioning (WHO ICF). ${ }^{78,79}$ All the concepts described in the model (see figure 1) can be classified, following the ICF terminology, as body functions, activities and participation, personal or environmental factors. ${ }^{80,81}$

Data are now being collected to test this model of adjustment after brain injury. We hope to increase our understanding of this complex but intriguing topic and we hope to contribute to a more solid theoretical background from which predictions about the adaptation process can be made and interventions can be designed to facilitate this process.

\section{Clinical messages}

- Adaptation to brain injury is an interactive and iterative process.

- A serial model does not illustrate the complex process of adaptation in brain injury well.

- Focussing on goals, their pursuit and their revision, helps in understanding adaptation.

- Considering adaptation in terms of goals facilitates its integration into the whole rehabilitation process. 


\section{References}

1. Kendall E. Psychosocial adjustment following closed head injury: a model for understanding individual differences and predicting outcome. Neuropsychol Rehabil. 1996;6(2):101-132.

2. Kendall E, Catalano T, Kuipers P, Posner N, Buys N, Charker J. Recovery following stroke: the role of self-management education. Soc Sci Med. 2007;64(3):735-746.

3. Wood RL, Rutterford NA. Demographic and cognitive predictors of long-term psychosocial outcome following traumatic brain injury. J Int Neuropsychol Soc. 2006;12(3):350-358.

4. Rutterford NA, Wood RL. Evaluating a theory of stress and adjustment when predicting longterm psychosocial outcome after brain injury. J Int Neuropsychol Soc. 2006;12(3):359-367.

5. Anson K, Ponsford J. Coping and emotional adjustment following traumatic brain injury. J Head Trauma Rehabil. 2006;21(3):248-259.

6. Moore AD, Stambrook M. Coping strategies and locus of control following traumatic brain injury: relationship to long-term outcome. Brain Inj. 1992;6(1):89-94.

7. Darlington A-S, Dippel DW, Ribbers GM, van Balen R, Passchier J, Busschbach JJ. Coping strategies as determinants of quality of life in stroke patients: a longitudinal study. Cerebrovasc Dis. 2007;23(5-6):401-407.

8. Kendall E, Terry D. Predicting emotional well-being following traumatic brain injury: a test of mediated and moderated models. Soc Sci Med. 2009;69(6):947-954.

9. Kendall E, Terry DJ. Understanding adjustment following traumatic brain injury: is the Goodnessof-Fit coping hypothesis useful? Soc Sci Med. 2008;67(8):1217-1224.

10. Herrmann M, Curio N, Petz T, et al. Coping with illness after brain diseases: a comparison between patients with malignant brain tumors, stroke, Parkinson's disease and traumatic brain injury. Disabil Rehabil. 2000;22(12):539-546.

11. Smout S, Koudstaal PJ, Ribbers GM, Janssen WG, Passchier J. Struck by stroke: a pilot study exploring quality of life and coping patterns in younger patients and spouses. Int J Rehabil Res. 2001;24(4):261-268.

12. Kendall E, Shum D, Lack B, Bull S, Fee C. Coping following traumatic brain injury: the need for contextually sensitive assessment. Brain Impair. 2001;2(2):81-96.

13. Karlovits T, McColl MA. Coping with community reintegration after severe brain injury: a description of stresses and coping strategies. Brain Inj. 1999;13(11):845-861.

14. Shotton L, Simpson J, Smith M. The experience of appraisal, coping and adaptive psychosocial adjustment following traumatic brain injury: a qualitative investigation. Brain Inj. 2007;21(8):857869.

15. Lazarus RS. Coping theory and research: past, present, and future. Psychosom Med. 1993;55(3):234247.

16. Lazarus RS. Theory-based stress measurement. Psychol Inq. 1990;1(1):3-13.

17. Folkman S, Moskowitz JT. Coping: pitfalls and promise. Annu Rev Psychol. 2004;55(1):745-774.

18. Folkman S, Lazarus RS, Gruen RJ, DeLongis A. Appraisal, coping, health status, and psychological symptoms. J Pers Soc Psychol. 1986;50(3):571-579.

19. Carver CS, Scheier MF, Weintraub JK. Assessing coping strategies: a theoretically based approach. J Pers Soc Psychol. 1989;56(2):267-283.

20. Stone AA, Greenberg MA, Kennedy-Moore E, Newman MG. Self-report, situation-specific coping questionnaires: what are they measuring? J Pers Soc Psychol. 1991;61(4):648-658.

21. Cook SW, Heppner PP. A psychometric study of three coping measures. Educ Psychol Meas. 1997;57(6):906-923. 
22. Stroebe M, Schut H. The dual process model of coping with bereavement: rationale and description. Death Stud. 1999;23(3):197 - 224.

23. Moore AD, Stambrook M. Coping following traumatic brain injury (TBI): derivation and validation of TBI sample Ways of Coping-Revised subscales. Can J Rehabil. 1994;4:122-129.

24. Moore AD, Stambrook M. Cognitive moderators of outcome following traumatic brain injury: a conceptual model and implications for rehabilitation. Brain Inj. 1995;9(2):109-130.

25. Moore AD, Stambrook M, Peters LC. Coping strategies and adjustment after closed-head injury: a cluster analytical approach. Brain Inj. 1989;3(2):171-175.

26. Hepp U, Moergeli H, Büchi S, Wittmann L, Schnyder U. Coping with serious accidental injury: a one-year follow-up study. Psychother Psychosom. 2005;74(6):379-386.

27. Wolters G, Stapert S, Brands I, Van Heugten C. Coping styles in relation to cognitive rehabilitation and quality of life after brain injury. Neuropsychol Rehabil. 2010;20(4):587-600.

28. Tomberg T, Toomela A, Pulver A, Tikk A. Coping strategies, social support, life orientation and health-related quality of life following traumatic brain injury. Brain Inj. 2005;19(14):1181-1190.

29. Godfrey H, Knight R, Partridge F. Emotional adjustment following traumatic brain injury; a stress-appraisal-coping formulation. J Head Trauma Rehabil. 1996;11(6):29-40.

30. Carver CS, Scheier MF. On the self-regulation of behaviour. 2005 ed. Cambridge: Cambridge university Press; 1998.

31. Bandura A. Self-efficacy: the exercise of control. New York: W.H. Freeman and Company; 1997.

32. Bandura A. Social Foundations of Thought and Action. Englewood Cliffs, NJ: Prentice-Hall; 1986.

33. Brandtstadter J, Renner G. Tenacious goal pursuit and flexible goal adjustment: explication and age-related analysis of assimilative and accommodative strategies of coping. Psychol Aging. 1990;5(1):58-67.

34. Webb PM, Glueckauf RL. The effects of direct involvement in goal setting on rehabilitation outcome for persons with traumatic brain injuries. Rehabil Psychol. 1994;39(3):179-188.

35. Novakovic-Agopian T, Chen AJ, Rome S, et al. Rehabilitation of executive functioning with training in attention regulation applied to individually defined goals: a pilot study bridging theory, assessment, and treatment. J Head Trauma Rehabil. 2011;26(5):325-338.

36. McPherson KM, Kayes N, Weatherall M. A pilot study of self-regulation informed goal setting in people with traumatic brain injury. Clin Rehabil. 2009;23(4):296-309.

37. Ertzgaard P, Ward AB, Wissel J, Borg J. Practical considerations for goal attainment scaling during rehabilitation following acquired brain injury. J Rehabil Med. 2011;43(1):8-14.

38. Conrad N, Doering BK, Rief W, Exner C. Looking beyond the importance of life goals. The personal goal model of subjective well-being in neuropsychological rehabilitation. Clin Rehabil. 2010;24(5):431-443.

39. Scheier MF, Matthews KA, Owens JF, et al. Dispositional optimism and recovery from coronary artery bypass surgery: The beneficial effects on physical and psychological well-being. J Pers Soc Psychol. 1989;57(6):1024-1040.

40. Carver CS, Scheier MF. Origins and functions of positive and negative affect: a control-process view. Psychol Rev. 1990;97(1):19-35.

41. Carver CS, Scheier MF. Scaling back goals and recalibration of the affect system are processes in normal adaptive self-regulation: understanding 'response shift' phenomena. Soc Sci Med. 2000;50(12):1715-1722.

42. Sprangers MA, Schwartz CE. Integrating response shift into health-related quality of life research: a theoretical model. Soc Sci Med. 1999;48(11):1507-1515.

43. Rapkin B, Schwartz C. Toward a theoretical model of quality-of-life appraisal: implications of findings from studies of response shift Health Qual Life Outcomes. 2004;2(1):14. 
44. Schwartz CE, Bode R, Repucci N, Becker J, Sprangers MA, Fayers PM. The clinical significance of adaptation to changing health: a meta-analysis of response shift. Qual Life Res. 2006;15(9):15331550 .

45. Hellstrom K, Lindmark B, Wahlberg B, Fugl-Meyer AR. Self-efficacy in relation to impairments and activities of daily living disability in elderly patients with stroke: a prospective investigation. $J$ Rehabil Med. Sep 2003;35(5):202-207.

46. Marks R, Allegrante JP. A review and synthesis of research evidence for self-efficacy-enhancing interventions for reducing chronic disability: implications for health education practice (Part II). Health Promot Pract. 2005 2005;6(2):148-156.

47. Lorig K, Holman H. Self-management education: history, definition, outcomes, and mechanisms. Ann Behav Med. 2003;26(1):1-7.

48. Lorig KR, Ritter P, Stewart AL, et al. Chronic disease self-management program: 2-year health status and health care utilization outcomes. Med Care. 2001;39(11):1217-1223.

49. O'Leary A. Self-efficacy and health: behavioral and stress-physiological mediation. Cognit Ther Res. 1992;16(2):229-245.

50. Donovan JJ, Williams KJ. Missing the mark: effects of time and causal attributions on goal revision in response to goal-performance discrepancies. J Appl Psychol. 2003;88(3):379-390.

51. Bandura A, Simon KM. The role of proximal intentions in self regulation of refractory behavior. Cognit Ther Res. 1977;1(3):177-193.

52. Carver CS, Scheier MF. Attention and self-regulation: a control theory approach to human behavior. New York: Springer-Verlag; 1981.

53. Campion MA, Lord RG. A control systems conceptualization of the goal-setting and changing process. Organ Behav Hum Perf. 1982;30(2):265-287.

54. Williams KJ, Donovan JJ, Dodge TL. Self-Regulation of performance: goal establishment and goal revision processes in athletes. Hum Perf. 2000;13(2):159-180.

55. Wrosch C, Scheier MF, Miller GE, Schulz R, Carver CS. Adaptive self-regulation of unattainable goals: goal disengagement, goal reengagement, and subjective well-being. Pers Soc Psychol Bull. 2003;29(12):1494-1508.

56. Heckhausen J, Wrosch C, Fleeson W. Developmental regulation before and after a developmental deadline: the sample case of "biological clock" for childbearing. Psychol Aging. 2001;16(3):400413.

57. Friedman LC, Nelson DV, Baer PE, Lane M, Smith FE, Dworkin RJ. The relationship of dispositional optimism, daily life stress, and domestic environment to coping methods used by cancer patients. J Behav Med. 1992;15(2):127-141.

58. Mailhan L, Azouvi P, Dazord A. Life satisfaction and disability after severe traumatic brain injury. Brain Inj. 2005;19(4):227-238.

59. Scheier MF, Carver CS. Optimism, coping, and health: assessment and implications of generalized outcome expectancies. Health Psychol. 1985;4(3):219-247.

60. Scheier MF, Carver CS. Effects of optimism on psychological and physical well-being: theoretical overview and empirical update. Cognit Ther Res. 1992;16(2):201-228.

61. Scheier MF, Weintraub JK, Carver CS. Coping with stress: divergent strategies of optimists and pessimists. J Pers Soc Psychol. 1986;51(6):1257-1264.

62. Stalnacke BM. Community integration, social support and life satisfaction in relation to symptoms 3 years after mild traumatic brain injury. Brain Inj. 2007;21(9):933-942.

63. Taylor SE, Kemeny ME, Aspinwall LG, Schneider SG, Rodriguez R, Herbert M. Optimism, coping, psychological distress, and high-risk sexual behavior among men at risk for acquired immunodeficiency syndrome (AIDS). J Pers Soc Psychol. 1992;63(3):460-473. 
64. Terry DJ. Coping resources and situational appraisals as predictors of coping behavior. Pers Indiv Diff. 1991;12(10):1031-1047.

65. Strom TQ, Kosciulek J. Stress, appraisal and coping following mild traumatic brain injury. Brain Inj. 2007;21(11):1137-1145.

66. Cicerone KD, Mott T, Azulay J, Friel JC. Community integration and satisfaction with functioning after intensive cognitive rehabilitation for traumatic brain injury. Arch Phys Med Rehabil. 2004;85(6):943-950.

67. Cicerone KD, Azulay J. Perceived self-efficacy and life satisfaction after traumatic brain injury. $J$ Head Trauma Rehabil. 2007;22(5):257-266.

68. Smith RE. Effects of coping skills training on generalized self-efficacy and locus of control. J Pers Soc Psychol. 1989;56(2):228-233.

69. Kortte KB, Wegener ST, Chwalisz K. Anosognosia and denial: their relationship to coping and depression in acquired brain injury. Rehabil Psychol. 2003;48(3):131-136.

70. Medley AR, Powell T, Worthington A, Chohan G, Jones C. Brain injury beliefs, self-awareness, and coping: a preliminary cluster analytic study based within the self-regulatory model. Neuropsychol Rehabil. 2010;20(6):899 - 921.

71. Ownsworth T, Fleming J, Strong J, Radel M, Chan W, Clare L. Awareness typologies, long-term emotional adjustment and psychosocial outcomes following acquired brain injury. Neuropsychol Rehabil. 2007;17(2):129-150.

72. Rochette A, Bravo G, Desrosiers J, St-Cyr/Tribble D, Bourget A. Adaptation process, participation and depression over six months in first-stroke individuals and spouses. Clin Rehabil. 2007;21(6):554-562.

73. Wolters G, Stapert S, Brands I, Van Heugten C. Coping following acquired brain injury: predictors and correlates. J Head Trauma Rehabil. 2011;26(2):150-157.

74. Kennedy P, Smithson E, McClelland M, Short D, Royle J, Wilson C. Life satisfaction, appraisals and functional outcomes in spinal cord-injured people living in the community. Spinal Cord. 2009;48(2):144-148.

75. Hart T, Evans J. Self-regulation and goal theories in brain injury rehabilitation. J Head Trauma Rehabil. 2006;21(2):142-155.

76. Muenchberger H, Kendall E, Kennedy A, Charker J. Living with brain injury in the community: outcomes from a community-based self-management support (CB-SMS) programme in Australia. Brain Inj. 2011;25(1):23-34.

77. Scobbie L, Dixon D, Wyke S. Goal setting and action planning in the rehabilitation setting: development of a theoretically informed practice framework. Clin Rehabil. 2011;25(5):468-482.

78. Wade DT, Halligan P. New wine in old bottles: the WHO ICF as an explanatory model of human behaviour. Clin Rehabil. 2003;17(4):349-354.

79. WHO. International classification of functioning, disability and health. 2001; http://www3.who. int/icf/icftemplate.cfm.

80. Svestkova O, Angerova Y, Sladkova P, Bickenbach JE, Raggi A. Functioning and disability in traumatic brain injury. Disabil Rehabil. 2010;32(S1):S68-S77.

81. Goljar N, Burger H, Vidmar G, et al. Functioning and disability in stroke. Disabil Rehabil. 2010;32(S1):S50-S58. 



\section{Chapter 3}

\section{Assessments of coping after acquired brain injury:}

a systematic review of instrument conceptualization, feasibility, and psychometric properties

Published in Journal of Head Trauma Rehabilitation as:

Wolters Gregório G, Brands I, Stapert S, Verhey F, van Heugten C. Assessments of coping after acquired brain injury: a systematic review of instrument conceptualization, feasibility, and psychometric properties. Journal of Head Trauma Rehabilitation. 2014;29(3):E30-E42. 


\section{Abstract}

Objective: To identify instruments used to measure coping styles in patients with acquired brain injury ( $\mathrm{ABI}$ ); to evaluate the conceptualization, feasibility, and psychometric properties of the instruments; and to provide guidance for researchers and clinicians in the choice of a suitable instrument.

Design: Systematic review.

Results: The search identified 47 instruments, of which 14 were selected. The instruments focused on dispositional coping, situation-specific coping, or domain-specific coping. Psychometric properties were scarcely investigated. The COPE stood out in terms of psychometric properties, but had low feasibility. The Coping Scale for Adults-short form (CSA-s), Utrecht Coping List (UCL), and brief COPE stood out in terms of feasibility, and the available psychometric properties of these instruments were good. Only the Coping with Health Injuries and Problems (CHIP) was used as other-report.

Conclusion: Information on psychometric properties of coping instruments in acquired brain injury is scarcely available and limits the strength of our recommendations. For patients with mild injuries, we cautiously recommend the COPE and for patients with more severe injuries the brief COPE, Coping Scale for Adults-short form, Utrecht Coping List, and Coping With Health Injuries and Problems-other-report. Other instruments may be used to address particular issues such as coping with a specific stressful situation or illness. 


\section{Introduction}

Acquired brain injury (ABI) refers to any non-progressive injury to the brain caused after birth. The two most common forms of acquired brain injury are strokes and traumatic brain injuries (TBI). Other forms of acquired brain injury include, for example, brain tumours, encephalitis, and hydrocephalus. ${ }^{1}$ After acquired brain injury, patients can suffer from longlasting cognitive, behavioural, and emotional deficits that interfere with many aspects of daily life and psychosocial functioning. In the last two decades, many studies have explored the factors associated with and predictive of psychosocial outcomes after acquired brain injury. ${ }^{2-5}$ Coping style has been suggested as a key concept, helping to explain the effects of stress on productivity, social activity, emotional stability, and quality of life after acquired brain injury. Although the important role of coping after acquired brain injury has been widely accepted, the coping construct itself is complex and vague. ${ }^{6}$ Therefore, its assessment is problematic, and several issues in measuring coping must be acknowledged.

The use of different theoretical backgrounds, definitions, and classifications of coping are complicating factors. In the conceptualization of coping, the focus can be on dispositional, situation-specific, or domain-specific coping. Furthermore, it has been suggested that these three foci are interrelated. ${ }^{7}$ Situation-specific (transactional) coping is the most dominant view. In this view, coping is regarded as a dynamic and situation-dependent process, defined as 'the person's cognitive and behavioural efforts to manage (reduce, minimize, master, or tolerate) the internal and external demands of the person-environment transaction that is appraised as taxing or exceeding the person's resources. ${ }^{8(p 993)}$ Coping can also be conceptualized as a style or disposition. ${ }^{9}$ This view does not consider coping as a stable trait but assumes that people prefer certain coping styles over others. Moreover, this preference may change over time, for example, after a major life event or behavioural treatment. ${ }^{10}$ Domain-specific coping resembles the dispositional view: it is relatively stable across stressors within a single domain. However, for different domains the coping repertoire used may vary. A specific medical condition, such as brain injury, may define a domain. ${ }^{7}$ Compounding the lack of consensus on the conceptualization of coping is that the terms coping actions, strategies, styles, and efforts are used interchangeably ${ }^{11}$ both in clinical practice and in scientific writing. It is, however important to distinguish among coping styles (e.g. active problem solving, avoidance, and reassuring thoughts) and coping resources (e.g. optimism, mastery, self-esteem, and social support). It has been suggested that coping styles mediate the relation among these resources and psychosocial functioning, explaining unique variations in outcomes. ${ }^{12}$ 
While some coping instruments have been constructed using factor analysis, other instruments have been formulated by more theoretical approaches. ${ }^{13}$ Consequently, these approaches differentially influence the number and content of the factors, complicating comparison of results obtained with different coping instruments. Furthermore, when comparing subscales of different instruments, similarity in terminology does not necessarily translate to similarity in conceptualization or meaning. For example, problem-focused coping can imply actively searching for more information but could also refer to seeking social support. Even subscales with similar names, which arose from different factor analyses, can contain different items. ${ }^{14}$

Although a sizeable number of coping instruments exist, ${ }^{6}$ appropriate instrument selection for use with patients with acquired brain injury remains difficult. Cognitive and behavioural deficits can interfere with a patient's ability to complete the questionnaires. Aphasia, even in subtle cases, can interfere with the ability to understand the questions. Inattentiveness, memory deficits, or mental fatigue could also prevent patients from completing an assessment in a reliable and valid fashion.

To facilitate and optimize the selection of coping instruments in acquired brain injury, three separate aspects must be considered. The first consideration is the focus of coping, that is, dispositional, situation-specific, or domain-specific. ${ }^{7}$ The second consideration should be an instrument's feasibility, for example, administration duration. The third consideration is the available psychometric data on the given population, in our case, individuals with acquired brain injury. In this review, we define coping as the cognitive and behavioural efforts to deal with stressful events, including daily problems or life events (e.g. illness), as well as dispositional, situation-specific, or domain-specific coping. ${ }^{8}$

In the area of acquired brain injury, a critical overview of coping instruments and their properties is lacking. Most coping instruments were standardized for use in general settings; consequently, reviews and surveys have not focused specifically on coping in patients with acquired brain injury. ${ }^{6,15,16}$ The only published systematic review on coping assessment after brain injury was limited to patients with stroke and focused on the conceptualization of coping in the studies, psychometric properties of the instruments identified, the domains assessed, and the coping styles used by the patients. ${ }^{17}$ The literature search was valid to early 2006 , but information about the focus of the coping instruments and their feasibility was not provided.

Therefore, the goal of this systematic review was to broaden the search criteria and review methods previously used by Donnellan et al. ${ }^{17}$ We attempted to answer the following research questions: (1) Which instruments have been used in empirical studies investigating coping after acquired brain injury? (2) What is known about the conceptualization of coping on 
which the instruments are based, their feasibility, and psychometric properties in patients with acquired brain injury? (3) Which coping instruments can be recommended for use with patients with acquired brain injury?

\section{Method}

\section{Selection procedure of articles and instruments}

Coping measures were identified using a systematic computerized literature search in PubMed, PsycINFO, and CINAHL from January 1970 to November 2011. Free-text words as well as MeSH terms specifying each of the two components of the search question - coping and brain injury - were combined. Details of the search can be found in Appendix 1. Articles were included if they described an empirical study assessing coping after acquired brain injury in adults (aged 18 years or older) and if they were written in English. Reviews and case studies were excluded.

Measures were identified as coping instruments by the description of the measure's concept, with coping defined as cognitively and behaviourally dealing with stressful situations. ${ }^{8}$ The stressful situations can include daily problems or life events such as illnesses. Instruments were excluded if they were utilized in one patient sample and if they were unavailable. Also excluded were instruments in which (1) coping with a specific symptom of acquired brain injury was measured, for example, pain or vertigo; (2) the coping assessment was limited to the general capacity to solve problems or to either cognitive or behavioural coping; (3) coping usefulness, effectiveness, or capacity was investigated (e.g. instances in which someone had been able to cope with a problem in general, but specific coping styles that had been used were not mentioned); (4) only one aspect of coping was measured (e.g. avoidance); (5) coping was investigated using an unstructured or semi-structured assessment (e.g. an unstructured interview).

Two authors (GWG and IB) performed the selection procedure independently. The first selection of articles was based on the title and abstract, and the definitive selection was then made on the basis of the full text of the article. We also reviewed the reference lists of the identified articles. After the selection procedure, any disagreements about inclusion or exclusion (which typically arose from vague descriptions of coping) were resolved by discussion until consensus was reached. A third reviewer $(\mathrm{CvH})$ was consulted when no initial consensus could be reached. 


\section{Properties of instruments}

After the selection process, GWG and IB searched the articles for information about the conceptualization, feasibility, reliability, validity, and responsiveness of the instruments. We contacted the authors who developed the instruments for copies and manuals of the instruments.

\section{Evaluation of conceptualization and feasibility}

The conceptualization of the instruments was rated according to four aspects, based on information obtained from the selected article, the manual, or the instrument. First, the focus of the coping instrument (e.g. dispositional) was identified. Second, the time frame in which the stressful situation appeared was noted, where applicable. Third, the number and content of the domains were reported. Fourth, the response format was identified.

Similarly, the feasibility, or utility, of the instruments was rated according to four aspects: availability of the instrument, the different languages used in the selected studies, the number of items, and the administration duration, that is, the burden for the respondent. ${ }^{18}$

\section{Evaluation of reliability, validity, and responsiveness}

The psychometric properties were evaluated according to the criteria used in the systematic review of Visser-Meily et al. ${ }^{19}$ Internal consistency was considered to be good if the available Cronbach's a was more than 0.8 , moderate if it was between 0.7 and 0.8 , or poor if it was less than 0.7 . Test-retest reliability was considered to be good if the reported intraclass correlation coefficient or $\kappa$ was more than 0.6 , moderate if it was between 0.3 and 0.6 , and poor if it was less than 0.3 . Construct validity was investigated by comparing subscales of the selected coping instruments to similar subscales of other coping instruments (convergent validity) and by comparing the obtained factor structure with the original factor structure (factorial validity). Convergent validity was considered to be good if the correlation coefficients between similar coping subscales were more than 0.6 , moderate if the coefficients were between 0.3 and 0.6 , and poor if the coefficients were less than 0.3 . Factorial validity was considered positive if the multidimensional structure was confirmed by factor or principal components analysis and negative if it was not confirmed. Finally, instrument responsiveness was interpreted as positive if the changes in a clinical trial or follow-up study were significant $(p<0.05)$. Responsiveness was interpreted as unknown when there were no changes in coping, as it is possible that coping had not changed. 


\section{Results}

The literature search identified 1245 articles, of which 293 articles were duplicates. The remaining 952 articles were evaluated according to our inclusion and exclusion criteria. In addition, we found 6 potentially pertinent articles after reviewing the reference lists. ${ }^{20-25}$ However, one could not be retrieved despite numerous efforts to obtain it and was therefore excluded. ${ }^{21}$ Ultimately, 58 articles met the inclusion and exclusion criteria (Figure 1). We reviewed the psychometric properties of 14 instruments (Table 1). The articles that were excluded after reviewing the full texts included 33 instruments. The excluded instruments and reasons for exclusion are described in Appendix 2.

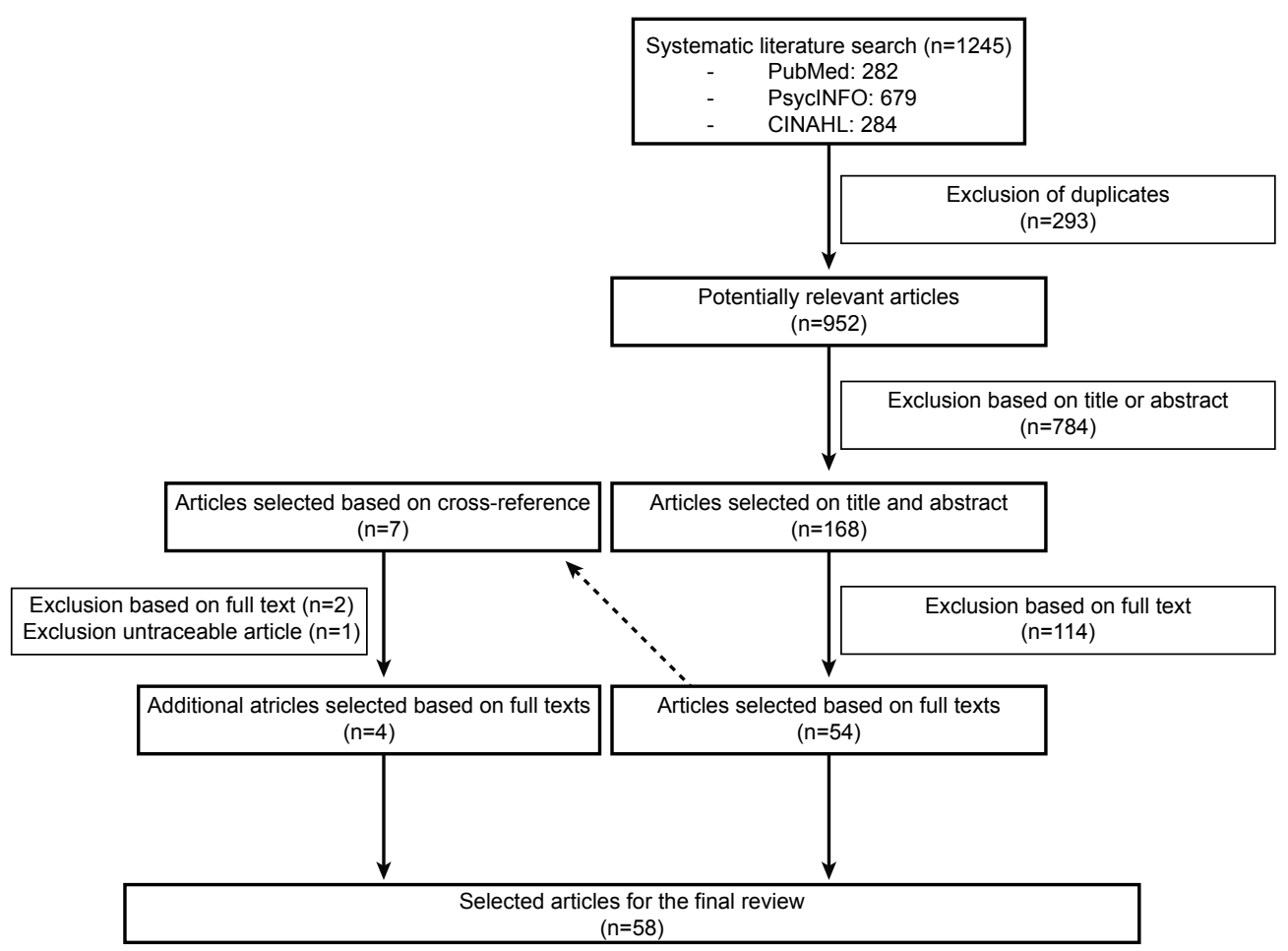

Figure 1. Flow chart of selected articles 


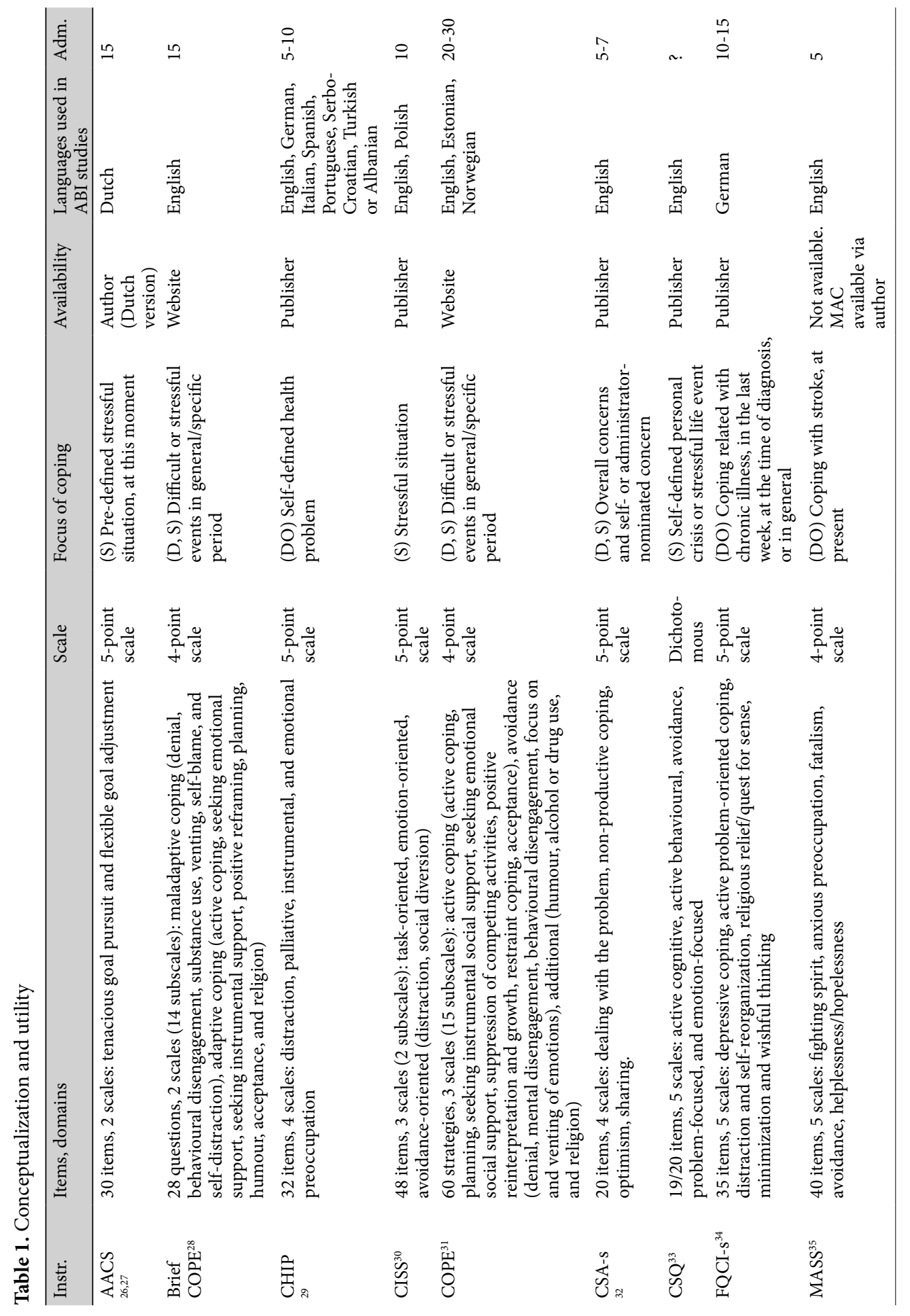




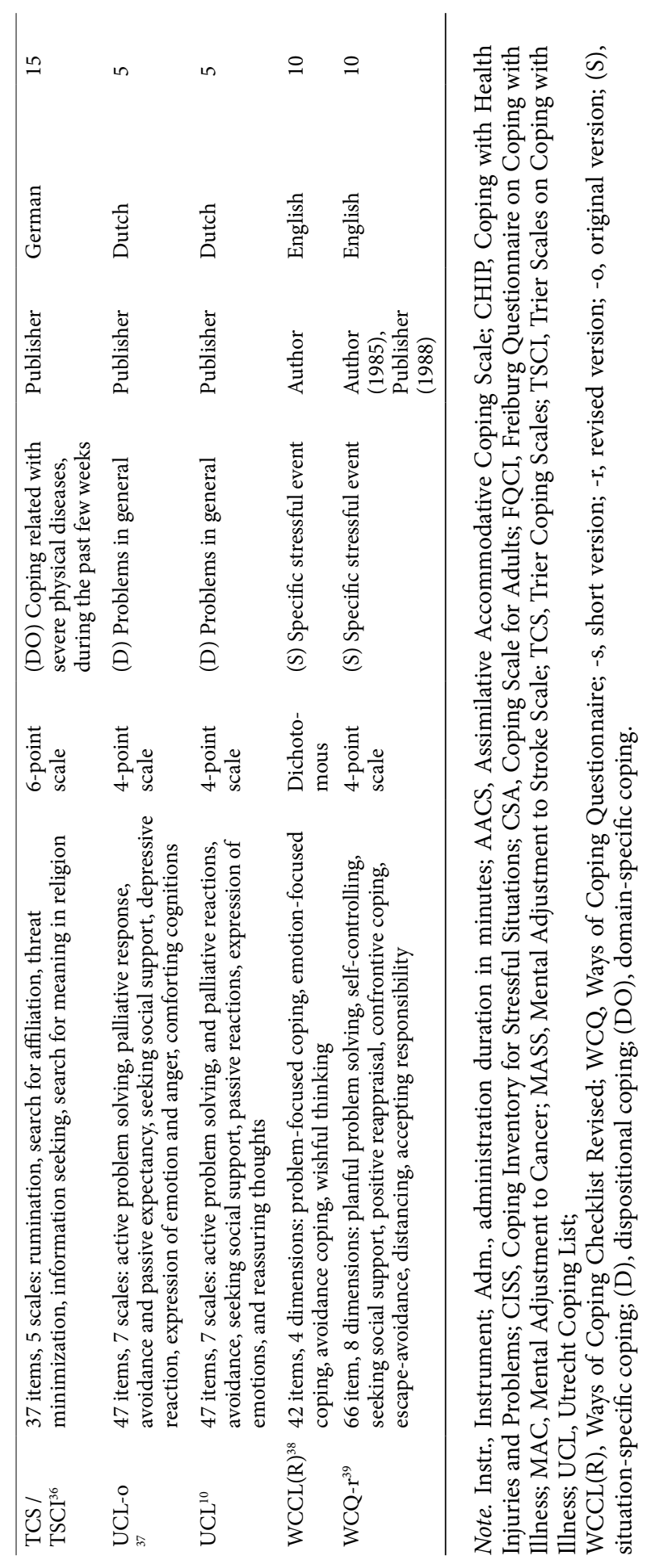




\section{Conceptualization and feasibility}

Table 1 displays descriptions of instrument conceptualization and feasibility. Instruments were primarily self-report measures with the exception of the Coping with Health Injuries and Problems (CHIP), which was also used as an other-report measure. ${ }^{40}$ Most instruments measured situation-specific coping. These included the Assimilative Accommodative Coping Scale (AACS), the Coping Inventory for Stressful Situations (CISS), the Coping Style Questionnaire (CSQ), the Ways of Coping Checklist Revised (WCCL(R)), and the Ways of Coping Questionnaire-revised (WCQ-r). Instruments that measured dispositional coping included the Utrecht Coping List original and revised version (UCL-o and UCL). Some instruments had both a dispositional and a situation-specific version available; these were the COPE, the brief COPE, and the Coping Scale for Adults-short (CSA-s; an adapted version of the Adolescent Coping Scale ${ }^{27}$ ). Domain-specific coping instruments reviewed were the CHIP, the Freiburg Questionnaire on Coping with Illness-short (FQCI-s), the Mental Adjustment to Stroke Scale (MASS), and the Trier Scales on Coping with Illness (TSCI). The temporal aspect of the specific stressful situation was reported only for the situation-specific coping instruments and was either vague (a situation in the past) or in the 12 months prior to the time of assessment. The number of domains ranged from 2 to 15 subscales, and almost all instruments used a Likert-scale ranging from 3 to 5 responses. Two instruments used a dichotomous answer format (yes/no), the CSQ and the WCCL(R).

Examination of feasibility showed that most instruments were available through the publisher. Only the AACS (Dutch version), COPE, brief COPE, WCCL(R), and WCQ-r (1985 version) were freely available via the Internet or by contacting the author. The MASS is a minor modification of the Mental Adjustment to Cancer (MAC) scale with the word cancer changed to stroke. ${ }^{41}$ The instruments varied in the number of items and administration duration. The number of items ranged from 19 to 66 , and administration time was between 5 and 30 minutes. Most instruments had either a German, Dutch, or English version. Different versions in other languages exist for many of the measures in the non-acquired brain injury specific literature (for more information, please contact the corresponding author).

\section{Psychometric properties}

Table 2 contains a summary of the reliability, validity, and responsiveness of the coping instruments. Detailed information about the patient characteristics and psychometric properties is provided in Supplement Digital Content Table 1, available at: http://links.lww. com/JHTR/A75. The brief COPE and WCCL(R) stood out in terms of internal consistency. ${ }^{25,38}$ However, most scales and subscales had moderate-to-low internal consistencies as indicated by Cronbach's a values of less than $0.80,{ }^{4,42-44}$ with the CHIP, COPE, MASS, TSCI and WCQ-r having one or more a values higher than $0.80 . .^{23,25,38,45-49}$ In 6 of 14 instruments, information 
about internal consistency was not provided. Only the test-retest reliability was calculated for the MASS, which had reasonable reliability $(\kappa=0.18-0.89) .{ }^{23}$

Because each study only used one instrument to assess coping, information about convergent validity was unavailable. Studies using the brief COPE, the COPE, WCCL(R), and WCQ-r reported information about factor structure. ${ }^{4,25,38,49-52}$ Only the factor structure of the Brief COPE was confirmed. Finally, 7 instruments demonstrated responsiveness to change, that is, the CHIP, COPE, CSA-s, FQCI-s, TSCI, UCL, and WCQ-r. ${ }^{5,40,43,47,48,53-58}$ The responsiveness of other instruments was either not investigated or unclear.

Table 2. Summary of psychometric properties of instruments

\begin{tabular}{llllll}
\hline & $\begin{array}{l}\text { Internal } \\
\text { consistency }\end{array}$ & $\begin{array}{l}\text { Test retest } \\
\text { reliability }\end{array}$ & $\begin{array}{l}\text { Convergent } \\
\text { validity }^{\mathrm{c}}\end{array}$ & $\begin{array}{l}\text { Factorial } \\
\text { validity }^{\mathrm{d}}\end{array}$ & Responsiveness $^{\mathrm{e}}$ \\
\hline AACS & $?$ & $?$ & $?$ & $?$ & $\pm ?$ \\
Brief COPE & + & $?$ & $?$ & + & $?$ \\
CHIP & \pm & $?$ & $?$ & $?$ & + \\
CISS & $?$ & $?$ & $?$ & $?$ & $?$ \\
COPE & \pm & $?$ & $?$ & \pm & + \\
CSA-s & $?$ & $?$ & $?$ & $?$ & + \\
CSQ & $?$ & $?$ & $?$ & $?$ & $?$ \\
FQCI-s & - & $?$ & $?$ & $?$ & + \\
MASS & \pm & \pm & $?$ & $?$ & $?$ \\
TCS/TSCI & \pm & $?$ & $?$ & $?$ & + \\
UCL-o & $?$ & $?$ & $?$ & $?$ & $?$ \\
UCL & $?$ & $?$ & $?$ & $?$ & + \\
WCCL(R) & + & $?$ & $?$ & \pm & $?$ \\
WCQ-r & \pm & $?$ & $?$ & - & + \\
\hline
\end{tabular}

Note. AACS, Assimilative Accommodative Coping Scale; CHIP, Coping with Health Injuries and Problems; CISS, Coping Inventory for Stressful Situations; CSA, Coping Scale for Adults; CSQ, Coping Style Questionnaire; FQCI, Freiburg Questionnaire on Coping with Illness; MASS, Mental Adjustment to Stroke Scale; TCS, Trier Coping Scales; TSCI, Trier Scales on Coping with Illness; UCL, Utrecht Coping List; WCCL(R), Ways of Coping Checklist Revised; WCQ, Ways of Coping Questionnaire; -s, short version; -r, revised version; -o, original version

+ , sufficient; \pm , moderate; - , insufficient; ?, unknown; \pm ?, ambiguous

${ }^{a}$ Cronbach's $\alpha:-,<0.70 ; \pm, 0.70-0.80 ;+,>0.80$

${ }^{\mathrm{b}} \kappa$, ICC:,$-<0.70 ; \pm, 0.70-0.80 ;+,>0.80$

${ }^{\mathrm{c}}$ Correlation coefficients (Pearson, Spearman) with other coping instruments, other clinical variables or between subscales:,$-<0.30$ no correlation;, \pm 0.30 - 0.60 moderate correlation;

,$+>0.60$ strong correlation

d + , Multidimensional structure confirmed by factor or principal component analysis;

\pm ?, ambiguous evidence for confirmation of factor structure by factor or principal component analysis; -, structure not confirmed by factor or principal component analysis

${ }^{\mathrm{e}}$ Changes in coping demonstrated in clinical trials or follow up studies, \pm ?, non-significant;

+ , significant $(\mathrm{p}<0.05$ or effect size $>0.4)$ 


\section{Discussion}

The purpose of this systematic review was to examine instruments used to assess coping after acquired brain injury; describe their conceptualization, feasibility, and psychometric properties; and provide guidance in selecting the most appropriate instrument for use in populations with acquired brain injury. Fourteen instruments met the inclusion and exclusion criteria. All were questionnaires, and most were self-report instruments, except for the CHIP which has also been used as an other-report instrument in patients with traumatic brain injury. ${ }^{40}$

As mentioned previously, three primary factors should be considered when choosing a coping instrument for use in the acquired brain injury population: the focus of the coping instrument (dispositional, situation-specific, or domain-specific coping), its feasibility in patients with acquired brain injury, and the psychometric properties as reported in acquired brain injury populations.

First, the conceptualization of coping, that is, the focus of the clinician or researcher is important. To measure an individual's coping with a specific stressful situation, a questionnaire that measures situation-specific coping is most appropriate. Although situation-specific coping questionnaires are appealing because of their simplicity, they should be administered more than once in order to determine a patient's generally preferred coping style or explore the variability in coping preferences when facing different situations or problems. This manner of assessment requires additional administration time. For this purpose, a questionnaire of limited length would be preferable, especially when cognitive deficits are present. In addition, it has been suggested that requiring self-generation of stressful situations is difficult for patients with acquired brain injury, and consequently less valid. ${ }^{59}$ Assessing domain-specific coping is useful when the focus is on coping with health problems such as a specific illness or disease. ${ }^{6}$ However, to understand one's general coping preferences, we recommend using disposition-specific questionnaires, including the COPE, brief COPE, UCL, and CSA-s. These questionnaires can also be used to examine changes in preferred style when confronted with a major life event such as acquired brain injury.

Second, patients can suffer from a wide array of symptoms and levels of disability after acquired brain injury. The frequent presence of cognitive deficits along with language and communication problems after acquired brain injury necessitates careful consideration when choosing assessment instruments. Because of cognitive impairments such as inattentiveness or mental fatigue, patients with acquired brain injury may need more time than the normal population to complete coping instruments. In the presence of cognitive deficits, an instrument 
with a shorter duration of administration would be preferable. The instruments having the shortest administration time (maximum 10 minutes) are the CHIP, CISS, CSA-s, MASS, UCL, and WCQ-r. Patients with language and communication problems (often observed after stroke) might struggle with the self-report format of many questionnaires. Patients with limited self-awareness (often observed after traumatic brain injury because of the greater risk for frontal lobe damage) might not actually experience problems and consequently will not employ and report coping strategies. As an alternative to self-report, only the CHIP is being used as an other-report tool for patients with acquired brain injury. However, other reports also suffer from limitations; for example, they may be influenced by emotional factors, and reports of internal efforts may be unreliable. Therefore, we cannot conclude that one means of assessment is preferable to another to evaluate coping after acquired brain injury. ${ }^{60}$

A trade-off between feasibility and psychometric properties may exist. Fewer items could reduce reliability and validity. Unfortunately, detailed information regarding psychometric properties was often unavailable, and psychometric properties that were investigated were often only poor-to-moderate. These weaknesses are at least partially caused by the absence of consensus regarding the conceptualization of coping. ${ }^{6}$ The identified coping instruments contained different dimensions, reflecting the various underlying theoretical concepts. In addition, because coping is often considered to be variable, problems are generated regarding reliability and validity.

Although test-retest reliability is important in conducting research and in clinical practice, it has rarely been investigated in measures of coping of patients with acquired brain injury. Coping is often conceptualized as situation-specific and changing over time in response to situational demands and to feedback from earlier coping attempts. ${ }^{61}$ These changes in coping between testing administrations complicate the assessment of test-retest reliability. Measuring the test-retest reliability of dispositional coping questionnaires appears more straightforward because dispositional coping can be measured at multiple time points. However, it is important to control for any events that might have changed the use of coping styles (e.g. life events and treatment).

Because information regarding test-retest reliability was generally absent, evaluation of the responsiveness of the instruments should be interpreted with caution. Several studies investigated changes in coping over time, with many instruments showing good responsiveness, for example references 5 and 53.

Convergent validity has not been studied in patients with acquired brain injury because none of the studies used more than one coping instrument to assess coping. Notably, in other 
populations, such as students and patients with multiple sclerosis or cancer, these relationships have been investigated. In general, moderate to strong correlations have been found between similar scales of coping, such as the COPE, WCQ-r, and CHIP, showing evidence for good convergent validity in these populations. ${ }^{62-67}$

Evidence for the multidimensional structure of coping is scarce. Only the factor structure of the brief COPE was replicated. Some support was found for the COPE and WCCL(R), whereas most studies could not replicate the factor structure of the WCQ-r, for example references 49 and 52 . This is consistent with coping research in other populations showing that the WCQ-r has an unstable non-replicable factor structure. ${ }^{68}$ Therefore, Tennen and Herzberger ${ }^{68}$ recommended that factor analyses be conducted for every study population, which naturally complicates the comparison of outcomes even across studies that used the same coping instrument. Moreover, we noticed that many studies changed the quantity or phrasing of certain items, further complicating comparisons across studies and questioning the methodological adequacy of the instrument. ${ }^{69}$

\section{Strengths and limitations}

This study is unique regarding several aspects. It provides a comprehensive overview of coping instruments used in the acquired brain injury population. Moreover, it is the first study to simultaneously review information about conceptualization, feasibility, and psychometric properties of coping instruments used after acquired brain injury, on which we base our recommendations for instrument selection.

We might have excluded some potentially useful coping instruments for the acquired brain injury population. For example, we excluded instruments in which coping was defined as a general capacity to solve problems (Problem Solving Inventory) or as dealing with stress in a laboratory setting (Baycrest Psychosocial Stress Test). ${ }^{70-72}$ Depending on these excluded definitions of coping, these instruments could be used in studies measuring coping after acquired brain injury. We further excluded coping instruments in which only one domain of coping was measured. While these instruments are useful for measuring a particular coping domain, because coping is a complex and multi-domain construct, we focused on instruments with a broader focus. Finally, our search strategy may have overlooked some coping instruments. For example, we only searched three databases for articles written in English. Nevertheless, by scanning the reference lists of selected articles, we believe that the risk of missing relevant articles was minimal. 


\section{Implications and future research}

Based on psychometric properties alone, no single questionnaire excelled, nor was any questionnaire judged completely negative. This was primarily due to the lack of information about psychometric properties in the reviewed articles. Implications should therefore be interpreted with caution. In persons with mild injuries, less cognitive impairment, and who are not easily fatigued, we suggest that the COPE is most suitable. The COPE is the questionnaire that was investigated most comprehensively, is freely available, and showed sufficient-to-good psychometric properties. However, because many people with acquired brain injury report fatigue and cognitive impairments, we believe that the feasibility of an instrument is also very important. Unfortunately, administration of the COPE is time consuming. Unless the goal is to study the use of coping in a specific situation, measuring preferred, dispositional coping styles precludes multiple assessments and is therefore less time consuming. In particular, the brief COPE is promising, shows good internal consistency and factorial validity, and consists of only 28 items; thus it may be used with more severely injured patients. The UCL and CSA-s stood out in terms of feasibility while also showing good responsiveness. The CHIP may be recommended in instances when patients cannot complete the questionnaires themselves for example, when patients suffer from language, communication, or awareness deficits because it can be completed by informed others.

In future research, it will be important to investigate the psychometric properties of coping instruments used in acquired brain injury populations. Specifically, the COPE and brief COPE showed promise so far, as well as the UCL, CSA-s, and CHIP, although their properties are less well studied. Furthermore, increased clarity in the conceptualization of coping may lead to improvements to the psychometric properties of the coping instruments. ${ }^{6}$ In addition, almost all of the reviewed instruments utilized retrospective reports that are subject to memory decay because of the elapsed time between the reported stressful events and the time of the coping assessment and they may also be influenced by the success of the coping strategy. ${ }^{73}$ No daily or moment-to-moment assessment procedures have been used in the evaluation of persons with acquired brain injury, although these procedures have sometimes been recommended in the general literature. ${ }^{7}$ The development and use of momentary assessments of coping are important avenues for future research.

\section{Conclusions}

Although coping is a widely used concept, its operational definition and assessment are complex. In the field of acquired brain injury, researchers and clinicians regularly use the term coping, but no consensus exists on what this actually entails. The lack of an agreedupon operationalized definition of coping partly explains why psychometric properties of coping instruments have generally been poor to moderate and are rarely investigated. 
After synthesizing and reviewing information about the conceptualization, feasibility, and psychometric properties, we recommend the use of the COPE for patients with mild injuries; the brief COPE, CSA-s, and UCL for patients with moderate to severe cognitive deficits; and the CHIP other report for patients who are severely injured and struggle with commonly used self-report formats. Other instruments may be used when researchers or clinicians have specific questions, such as how an individual is coping with a specific stressful situation or illness. This systematic review can guide clinicians and researchers in selecting the most suitable coping instrument for use with individual survivors of acquired brain injury. 
Appendix 1. Details of the literature search 'Instruments of coping after acquired brain injury

\begin{tabular}{|c|c|}
\hline \multicolumn{2}{|l|}{ PubMed } \\
\hline Set 1 & coping $[\mathrm{tw}]$ \\
\hline Set 2 & 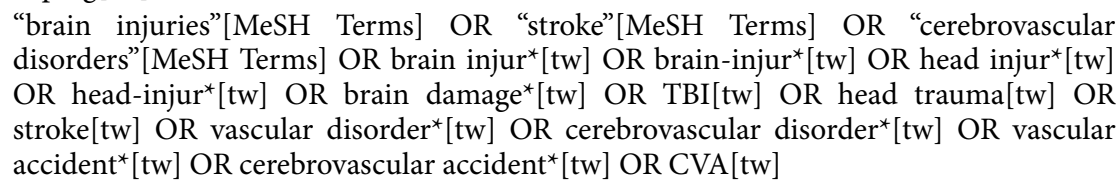 \\
\hline Set 3 & $\begin{array}{l}\text { "humans"[MeSH Terms] AND Journal Article[ptyp] AND English[lang] AND } \\
\text { "adult"[MeSH Terms] AND ("1970/01/01"[PDAT]: "2011/10/31"[PDAT]) }\end{array}$ \\
\hline \multicolumn{2}{|l|}{ PsycINFO } \\
\hline Set 1 & TX (“coping”) \\
\hline Set 2 & 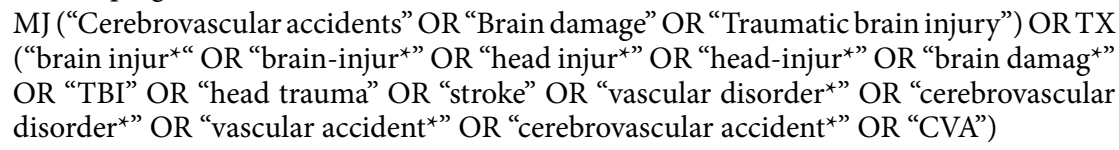 \\
\hline Set 3 & $\begin{array}{l}\text { Published Date from: 19700101-20111031; Publication Type: All Journals; English; } \\
\text { Age Groups: Adulthood (18 yrs \& older); Population Group: Human; Document Type: } \\
\text { Journal Article }\end{array}$ \\
\hline \multicolumn{2}{|l|}{ CINAHL } \\
\hline Set 1 & TX (“coping”) \\
\hline Set 2 & 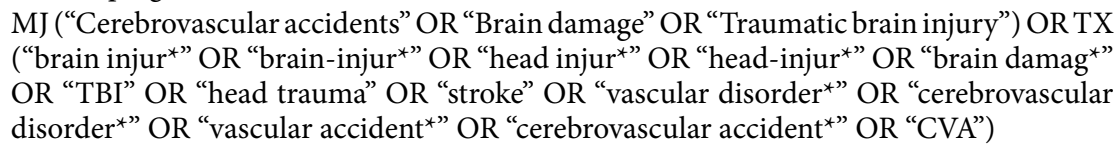 \\
\hline Set 3 & $\begin{array}{l}\text { Limiters - Published Date from: 19700101-20111031; Human; Publication Type: Journal } \\
\text { Article; Language: English; Age Groups: Adult: 19-44 years, Middle Aged: 45-64 years, } \\
\text { Aged: } 65+\text { years, Aged, } 80 \text { and over }\end{array}$ \\
\hline Result sets & Combination of set 1 AND set 2 AND set 3 per search engine \\
\hline
\end{tabular}


Appendix 2. Excluded articles based on full text

\begin{tabular}{|c|c|c|}
\hline Exclusion criteria & Measure & References \\
\hline Not available & Ways of Coping Checklist & 74 \\
\hline No adult coping scale & Adolescent Coping Scale & 75 \\
\hline \multirow[t]{8}{*}{ No coping instrument: No coping ${ }^{\star}$} & Perceived Self-Regulatory Ability Inventory & 76 \\
\hline & Optimization in Primary and Secondary Control & 77 \\
\hline & Problem Solving Inventory & 72 \\
\hline & Social Problem Solving Inventory & 78 \\
\hline & Baycrest Psychosocial Stress Test & 70,71 \\
\hline & Sense of Coherence & $44,45,79-84$ \\
\hline & Coping Resources Inventory for Stress & 85,86 \\
\hline & Coping Resources Questionnaire & 87 \\
\hline \multirow[t]{2}{*}{ Efectiveness } & Acceptance of Disability Scale & 88 \\
\hline & McNett Coping Effectiveness Questionnaire & 74 \\
\hline Skilfulness & Adaptive Skills Battery & 89 \\
\hline \multirow{4}{*}{ Specific consequence/ functioning } & Vertigo Coping Questionnaire & 90 \\
\hline & Coping Strategies Questionnaire & 91 \\
\hline & F-COPES- family functioning & 92 \\
\hline & Family Coping Behavior & 93 \\
\hline \multirow[t]{9}{*}{ One subscale } & Health and Daily Living Form & 94,95 \\
\hline & Preference Based Stroke Index & 96 \\
\hline & General Health Questionnaire & 97 \\
\hline & Millon Behavioral Medicine Diagnostic & 98 \\
\hline & Brain Injury Grief Inventory & 99 \\
\hline & Impact of Event Scale & 100 \\
\hline & National Health Interview Survey & 101 \\
\hline & Acceptance and Action Questionnaire & 102 \\
\hline & Symptom Expectancy Checklist & 103,104 \\
\hline \multirow{7}{*}{ Used in one sample } & Strategies for Handling Stress & 81 \\
\hline & ABI Distress and Coping Scale & 105 \\
\hline & Coping Scale for Adults & 106 \\
\hline & Coping Response Inventory & 107 \\
\hline & Ways of Coping Questionnaire-short versions & $108-110$ \\
\hline & Ways of Coping Questionnaire-revised versions & $111-114$ \\
\hline & Ways of Coping Questionnaire-Cardiovascular Accident & 22 \\
\hline
\end{tabular}

Note. ${ }^{*}$, as defined as cognitively and behaviourally dealing with problem; ABI, acquired brain injury 


\section{References}

1. Ponsford JL, Sloan S, Snow P. Traumatic brain injury: Rehabilitation for everyday adaptive living. 2nd ed. Hove and New York: Psychology Press (Taylor and Francis Group); 2012.

2. Anson K, Ponsford J. Coping and emotional adjustment following traumatic brain injury. J. Head Trauma Rehabil. 2006;21(3):248-259.

3. Dawson DR, Schwartz ML, Winocur G, Stuss DT. Return to productivity following traumatic brain injury: cognitive, psychological, physical, spiritual, and environmental correlates. Disabil. Rehabil. 2007;29:301-313.

4. Finset A, Andersson S. Coping strategies in patients with acquired brain injury: relationships between coping, apathy, depression and lesion location. Brain Inj. 2000;14(10):887-905.

5. Wolters G, Stapert S, Brands I, van Heugten C. Coping styles in relation to cognitive rehabilitation and quality of life after brain injury. Neuropsychol Rehabil. 2010;20(4):587-600.

6. de Ridder D. What is wrong with coping assessment? A review of conceptual and methodological issues. Psychol Health. 1997;12(3):417-431.

7. Ptacek JT, Pierce GR. Issues in the study of stress and coping in rehabilitation settings. Rehabil Psychol. 2003;48(2):113-124.

8. Folkman S. Dynamics of a stressful encounter: cognitive appraisal, coping, and encounter outcomes. J Pers Soc Psychol. 1986;50(5):992-1003.

9. Schreurs PJG, Tellegen B, Willige GV. [Health, stress and coping: the development of the Utrecht Coping Scale]. Gedrag: Tijdschrift voor Psychologie. 1984(1-2):101-117.

10. Schreurs PJ, van de Willege G, Brosschot JF, Tellegen B, Graus GM. [The Utrecht Coping List: UCL. Dealing with problems and events]. Utrecht: Swets en Zeitlinger; 1993.

11. Frydenberg E, Lewis R. The Coping Scale for Adults: correlates of productive and nonproductive coping. Australian Educational and Developmental Psychologist. 2002;19(1):5-17.

12. Taylor MM, Schaeffer JN, Blumenthal FS, Grisell JL. Perceptual training in patients with left hemiplegia. Arch Phys Med Rehabil. 1971;52(4):163.

13. Zuckerman M, Gagne M. The COPE revised: proposing a 5-factor model of coping strategies. J Res Pers. 2003;37(3):169-204.

14. Parker JD, Endler NS, Bagby RM. If it changes, it might be unstable: examining the factor structure of the Ways of Coping Questionnaire. Psychol Assess. 1993;5(3):361-368.

15. Martz E, Livneh H, eds. Coping with chronic illness and disability. Theoretical, empirical, and clinical aspects. New York: Springer; 2007.

16. Schwarzer R, Schwarzer C. A critical survey of coping instruments. In: Zeidner M, Endler NS, eds. Handbook of coping: Theory, research and applications. New York: Wiley; 1996:107-132.

17. Donnellan C, Hevey D, Hickey A, O’Neill D. Defining and quantifying coping strategies after stroke: a review. J Neurol Neurosurg Psychiatry. 2006;77(11):1208-1218.

18. Smeets SM, Ponds RW, Verhey FR, van Heugten CM. Psychometric properties and feasibility of instruments used to assess awareness of deficits after acquired brain injury: a systematic review. $J$ Head Trauma Rehabil. 2012;93(5):834-841.

19. Visser-Meily JM, Post MW, Riphagen II, Lindeman E. Measures used to assess burden among caregivers of stroke patients: a review. Clin Rehabil. 2004;18(6):601-623.

20. Dennis M, O’Rourke S, Slattery J, Staniforth T, Warlow C. Evaluation of a stroke family care worker: results of a randomised controlled trial. BMJ. 1997;314(7087):1071-1076.

21. Easton KL, Rawl SM, Zemen D, Kwiatkowski S, Burczyk B. The effects of nursing follow-up on the coping strategies used by rehabilitation patients after discharge. Rehabil Nurs Res. 1995;4(4):119127. 
22. Johnson J, Pearson V. The effects of a structured education course on stroke survivors living in the community. Rehabil Nurs. 2000;25(2):79-65.

23. Lewis SC, Dennis MS, O’Rourke SJ, Sharpe M. Negative attitudes among short-term stroke survivors predict worse long-term survival. Stroke. 2001;32(7):1640-1645.

24. Sinyor D, Amato P, Kaloupek DG, Becker R, Goldenberg M, Coopersmith H. Post-stroke depression: relationships to functional impairment, coping strategies, and rehabilitation outcome. Stroke. 1986;17(6):1102-1107.

25. Snell DL, Siegert RJ, C, Surgenor LJ. Factor structure of the brief COPE in people with mild traumatic brain injury. J Head Trauma Rehabil. 2011;26(6):468-477.

26. Brandtstädter J, Renner G. Tenacious goal pursuit and flexible goal adjustment: explication and age-related analysis of assimilative and accommodative strategies of coping. Psychol Aging. 1990;5(1):58-67.

27. Slangen-de Kort YA, van Wagenberg AF, Midden CJ. Adaptive problem solving processes of older persons in their homes. Stud Health Technol Inform. 1998;48:340-346.

28. Carver CS. You want to measure coping but your protocol's too long: consider the brief COPE. Int J Behav Med. 1997;4(1):92-100.

29. Endler NS, Parker JD. CHIP: Coping with Health Injuries and Problems. Toronto: Multi-Health Systems; 1992.

30. Endler NS, Parker JD. Coping Inventory for Stressful Situations (CISS): manual. Toronto: MultiHealth Systems; 1990.

31. Carver CS, Scheier MF, Weintraub JK. Assessing coping strategies: a theoretically based approach. J Pers Soc Psychol. 1989;56(2):267-283.

32. Frydenberg E, Lewis R. Coping Scale for Adults. Melbourne: The Australian Council for Educational Research; 1997.

33. Billings AG, Moos RH. The role of coping responses and social resources in attenuating the stress of life events. J Behav Med. 1981;4(2):139-157.

34. Muthny FA. [Freiburg coping questionnaire: manual]. Weinheim: Beltz; 1989.

35. Watson M, Greer S, Bliss JM. Mental Adjustment to Cancer (MAC) Scale Users' Manual. 1989.

36. Klauer T, Filipp SH. [Trier scales for coping (TSK)]. Göttingen, Germany: Hogrefe; 1993.

37. Schreurs PJ, van de Willige G, Tellegen B, Brosschot JF. [The Utrecht Coping List: Manual of the UCL]. Lisse, Netherlands: Swets \& Zeitlinger; 1988.

38. Malia K, Powell G, Torode S. Coping and psychosocial function after brain injury. Brain Inj. 1995;9(6):607-618.

39. Folkman S, Lazarus R. Ways of Coping Questionnaire manual. Palo Alto, CA: Consulting Psychologists Press, Inc.; 1988.

40. Dawson DR, Catanzaro AM, Firestone J, Schwartz M, Stuss DT. Changes in coping style following traumatic brain injury and their relationship to productivity status. Brain Cogn. 2006;60(2):214216.

41. Watson M, Greer S, Young J, Inayat Q, Burgess C, Robertson B. Development of a questionnaire measure of adjustment to cancer: the MAC scale. Psychol Med. 1988;18(1):203-209.

42. Boynton De Sepulveda LI, Chang B. Effective coping with stroke disability in a community setting: the development of a causal model. J Neurosci Nurs. 1994;26(4):193-203.

43. Hepp U, Moergeli H, Büchi S, Wittmann L, Schnyder U. Coping with serious accidental injury: a one-year follow-up study. Psychother Psychosom. 2005;74(6):379-386.

44. Schnyder U, Morgeli H, Nigg C, et al. Early psychological reactions to life-threatening injuries. Crit Care Med. 2000;28(1):86-92. 
45. Schnyder U, Wittmann L, Friedrich-Perez J, Hepp U, Moergeli H. Posttraumatic stress disorder following accidental injury: rule or exception in Switzerland? Psychother Psychosom. 2008;77(2):111-118.

46. Kortte KB, Wegener ST, Chwalisz K. Anosognosia and denial: their relationship to coping and depression in acquired brain injury. Rehabil Psychol. 2003;48(3):131-136.

47. Wahl HW, Martin P, Minnemann E, Martin S, Oster P. Predictors of well-being and autonomy before and after geriatric rehabilitation. J Health Psychol. 2001;6(3):339-354.

48. King RB, Shade-Zeldow Y, Carlson CE, Feldman JL, Philip M. Adaptation to stroke: a longitudinal study of depressive symptoms, physical health, and coping process. Top Stroke Rehabil. 2002;9(1):46-66.

49. Rochette A, Bravo G, Desrosiers J, St-Cyr/Tribble D, Bourget A. Adaptation process, participation and depression over six months in first-stroke individuals and spouses. Clin Rehabil. 2007;21(6):554-562.

50. Wood RL, Rutterford NA. Demographic and cognitive predictors of long-term psychosocial outcome following traumatic brain injury. J Int Neuropsychol Soc. 2006;12(3):350-358.

51. Rutterford NA, Wood RL. Evaluating a theory of stress and adjustment when predicting longterm psychosocial outcome after brain injury. J Int Neuropsychol Soc. 2006;12(3):359-367.

52. Moore AD, Stambrook M. Coping following traumatic brain injury (TBI): derivation and validation of TBI sample Ways of Coping-Revised subscales. Can J Rehabil. 1994;7(3):193-200.

53. Sinnakaruppan I, Downey B, Morrison S. Head injury and family carers: a pilot study to investigate an innovative community-based educational programme for family carers and patients. Brain Inj. 2005;19(4):283-308.

54. Hofer H, Holtforth MG, Frischknecht E, Znoj H-J. Fostering adjustment to acquired brain injury by psychotherapeutic interventions: a preliminary study. Appl Neuropsychol. 2010;17(1):18-26.

55. Wolters G, Stapert S, Brands I, van Heugten C. Coping following acquired brain injury: predictors and correlates. J. Head Trauma Rehabil. 2011;26(2):150-157.

56. Bradbury CL, Christensen BK, Lau MA, Ruttan LA, Arundine AL, Green RE. The efficacy of cognitive behavior therapy in the treatment of emotional distress after acquired brain injury. Arch Phys Med Rehabil. 2008;89(12 Suppl):S61-68.

57. Tomberg T, Toomela A, Ennok M, Tikk A. Changes in coping strategies, social support, optimism and health-related quality of life following traumatic brain injury: a longitudinal study. Brain Inj. 2007;21(5):479-488.

58. Anson K, Ponsford J. Evaluation of a coping skills group following traumatic brain injury. Brain Inj. 2006;20(2):167-178.

59. Moore AD, Stambrook M. Cognitive moderators of outcome following traumatic brain injury: a conceptual model and implications for rehabilitation. Brain Inj. 1995;9(2):109-130.

60. Sveinbjornsdottir S, Thorsteinsson EB. Adolescent coping scales: a critical psychometric review. Scand J Psychol. 2008;49(6):533-548.

61. Folkman S, Lazarus RS. If it changes it must be a process: study of emotion and coping during three stages of a college examination. J Pers Soc Psychol. 1985;48(1):150-170.

62. Bouchard G, Guillemette A, Landry-Léger N. Situational and dispositional coping: an examination of their relation to personality, cognitive appraisals, and psychological distress. Eur J Pers. 2004;18(3):221-238.

63. Carver CS, Scheier MF, Weintraub JK. Assessing coping strategies - a theoretically based approach. J Pers Soc Psychol. 1989;56(2):267-283.

64. Clark KK, Bormann CA, Cropanzano RS, James K. Validation evidence for three coping measures. J Pers Assess. 1995;65(3):434-455. 
65. Endler NS, Courbasson CM, Fillion L. Coping with cancer: the evidence for the temporal stability of the French-Canadian version of the Coping with Health Injuries and Problems (CHIP). Pers Individ Diff. 1998;25(4):711-717.

66. Fillion L, Kovacs AH, Gagnon P, Endler NS. Validation of the shortened COPE for use with breast cancer patients undergoing radiation therapy. Curr Psychol. 2002;21(1):17-34.

67. Pakenham KI. Coping with multiple sclerosis: development of a measure. Psychol Health Med. 2001;6(4):411-428.

68. Tennen H, Herzberger S. The Ways of Coping Scale. In: Keyser DJ, Sweetland RC, eds. Test Critiques. Vol 3. Kansas City: Test Corporation of America; 1985:686-697.

69. Parker JDA, Endler NS. Coping with coping assessment: a critical review. Eur J Pers. 1992;6(5):321344.

70. Krpan KM, Stuss DT, Anderson ND. Planful versus avoidant coping: behavior of individuals with moderate-to-severe traumatic brain injury during a psychosocial stress test. J Int Neuropsychol Soc. 2011;17(2):248-255.

71. Krpan KM, Stuss DT, Anderson ND. Coping behaviour following traumatic brain injury: what makes a planner plan and an avoider avoid? Brain Inj. 2011;25(10):989-996.

72. Strom TQ, Kosciulek J. Stress, appraisal and coping following mild traumatic brain injury. Brain Inj. 2007;21(11):1137-1145.

73. Coyne JC, Gottlieb BH. The mismeasure of coping by checklist. J. Pers. 1996;64(4):959-991.

74. McNett SC. Social support, threat, and coping responses and effectiveness in the functionally disabled. Nurs Res. 1987;36(2):98-103.

75. Reeve DK, Lincoln NB. Coping with the challenge of transition in older adolescents with epilepsy. Seizure. 2002;11(1):33-39.

76. Armengol CG. A multimodal support group with Hispanic traumatic brain injury survivors. $J$ Head Trauma Rehabil. 1999;14(3):233-246.

77. Chipperfield JG, Perry RP, Bailis DS, Ruthig JC, Loring PC. Gender differences in use of primary and secondary control strategies in older adults with major health problem. Psychol Health. 2007;22(1):83-105.

78. Backhaus SL, Ibarra SL, Klyce D, Trexler LE, Malec JF. Brain injury coping skills group: a preventative intervention for patients with brain injury and their caregivers. Arch Phys Med Rehabil. 2010;91(6):840-848.

79. Abjornsson GL, Karlson BA, Orbaek PH. Education for men with solvent-induced chronic toxic encephalopathy and their spouses. Patient Educ Couns. 2005;58(1):88-95.

80. Feigin R. The relationship between the sense of coherence and adjustment to disability studied in the context of marital interrelations. Marriage Fam Rev. 1998;27(1-2):71-90.

81. Karlson B, Seger L, Osterberg K, Abjornsson G, Orbaek P. Stress management in men with solvent-induced chronic toxic encephalopathy. J Occup Environ Med. 2000;42(6):670-675.

82. Nilsson B, Holmgren L, Westman G. Sense of coherence in different stages of health and disease in northern Sweden: Gender and psychosocial differences. Scand J Prim Health Care. 2000;18(1):1420.

83. Nilsson I, Axelsson K, Gustafson Y, Lundman B, Norberg A. Well-being, sense of coherence, and burnout in stroke victims and spouses during the first few months after stroke. Scand J Caring Sci. 2001;15(3):203-214.

84. Rena F, Moshe S, Abraham O. Couples' adjustment to one partner's disability: the relationship between sense of coherence and adjustment. Soc Sci Med. 1996;43(2):163-171.

85. DuBay MF, Laures-Gore JS, Matheny K, Romski MA. Coping resources in individuals with aphasia. Aphasiology. 2011;25(9):1016-1029. 
86. Laures-Gore J, Hamilton A, Matheny K. Coping resources, perceived stress, and recent life experiences in individuals with aphasia. J Med Speech Lang Pathol. 2007;15(4):423-431.

87. Riley GA, Dennis RK, Powell T. Evaluation of coping resources and self-esteem as moderators of the relationship between threat appraisals and avoidance of activities after traumatic brain injury. Neuropsychol Rehabil. 2010;20(6):869-882.

88. Rosenbaum M, Palmon N. Helplessness and resourcefulness in coping with epilepsy. J Consult Clin Psychol. 1984;52(2):244-253.

89. Vungkhanching M, Heinemann AW, Langley MJ, Ridgely M, Kramer KM. Feasibility of a skillsbased substance abuse prevention program following traumatic brain injury. J Head Trauma Rehabil. 2007;22(3):167-176.

90. Gurr B, Moffat N. Psychological consequences of vertigo and the effectiveness of vestibular rehabilitation for brain injury patients. Brain Inj. 2001;15(5):387-400.

91. Iezzi T, Duckworth MP, Mercer V, Vuong L. Chronic pain and head injury following motor vehicle collisions: a double whammy or different sides of a coin. Psychol Health Med. 2007;12(2):197-212.

92. Leach LR, Frank RG, Bouman DE, Farmer J. Family functioning, social support and depression after traumatic brain injury. Brain Inj. 1994;8(7):599-606.

93. Hibbard MR, Cantor J, Charatz H, et al. Peer support in the community: initial findings of a mentoring program for individuals with traumatic brain injury and their families. J Head Trauma Rehabil. 2002;17(2):112-131.

94. Douglas JM, Spellacy FJ. Indicators of long-term family functioning following severe traumatic brain injury in adults. Brain Inj. 1996;10(11):819-839.

95. Hinkeldey NS, Corrigan JD. The structure of head-injured patients' neurobehavioural complaints: a preliminary study. Brain Inj. 1990;4(2):115-133.

96. Poissant L, Mayo NE, Wood-Dauphinee S, Clarke AE. The development and preliminary validation of a Preference-Based Stroke Index (PBSI). Health Qual Life Outcomes. 2003;1:43.

97. Sveen U, Thommessen B, Bautz-Holter E, Wyller TB, Laake K. Well-being and instrumental activities of daily living after stroke. Clin Rehabil. 2004;18(3):267-274.

98. Beck KD, Franks SF, Hall JR. Postinjury personality and outcome in acquired brain injury: the Millon Behavioral Medicine Diagnostic. PM R. 2010;2(3):195-201.

99. Coetzer R, Ruddle JA, Mulla F. The Brain Injury Grief Inventory: a follow-up study of emotional and functional outcome following traumatic brain injury. J Cogn Rehabil. 2006;24(2):7-11.

100. Middelboe T, Birket-Smith M, Andersen HS, Friis ML. Personality traits in patients with postconcussional sequelae. J Pers Disord. 1992;6(3):246-255.

101. Badke MB. The Health and Activity Limitation Index: determinants of health-related quality of life in persons with stroke. J Rehabil Outcomes Meas. 2000;4(3):1-16.

102. Kortte KB, Veiel L, Batten SV, Wegener ST. Measuring avoidance in medical rehabilitation. Rehabil Psychol. 2009;54(1):91-98.

103. Ownsworth T, McFarland K. Investigation of psychological and neuropsychological factors associated with clinical outcome following a group rehabilitation programme. Neuropsychol Rehabil. 2004;14(5):535-562.

104. Ownsworth TL, McFarland K, Young RM. The investigation of factors underlying deficits in selfawareness and self-regulation. Brain Inj. 2002;16(4):291-309.

105. Davis JR, Gemeinhardt M, Gan C, Anstey K, Gargaro J. Crisis and its assessment after brain injury. Brain Inj. 2003;17(5):359-376.

106. Curran CA, Ponsford JL, Crowe S. Coping strategies and emotional outcome following traumatic brain injury: a comparison with orthopedic patients. J Head Trauma Rehabil. 2000;15(6):12561274. 
107. Tiersky LA, Anselmi V, Johnston MV, et al. A trial of neuropsychologic rehabilitation in mildspectrum traumatic brain injury. Arch Phys Med Rehabil. 2005;86(8):1565-1574.

108. Brunborg B, Wyller TB. Coping with stressful events during the first six months after a stroke. Norsk Tidsskrift For Sykepleieforskning. 2007;9(1):16-28.

109. Rochette A, Desrosiers J. Coping with the consequences of a stroke. Int J Rehabil Res. 2002;25(1):1724.

110. Blais MC, Boisvert JM. Psychological adjustment and marital satisfaction following head injury. Which critical personal characteristics should both partners develop? Brain Inj. 2007;21:357-372.

111. Wheeler G, Krausher R, Cumming C, Jung V, Steadward R, Cumming D. Personal styles and ways of coping in individuals who use wheelchairs. Spinal Cord. 1996;34(6):351-357.

112. Kendall E, Terry D. Predicting emotional well-being following traumatic brain injury: a test of mediated and moderated models. Soc Sci Med. 2009;69(6):947-954.

113. Kendall E, Terry DJ. Understanding adjustment following traumatic brain injury: is the goodnessof-fit coping hypothesis useful? Soc Sci Med. 2008;67(8):1217-1224.

114. Gillespie DC. Poststroke anxiety and its relationship to coping and stage of recovery. Psychol Rep. 1997;80(3):1059-1064. 


\section{Chapter 4}

\section{Psychometric properties of the Coping Inventory for Stressful Situations (CISS) in patients with acquired brain injury}

Published in Psychological Assessment as:

Brands I, Köhler S, Stapert S, Wade D, van Heugten C. Psychometric properties of the Coping Inventory for Stressful Situations (CISS) in patients with acquired brain injury. Psychological Assessment. 2014;26(3):848-856. 


\begin{abstract}
Information on the psychometric properties of the Coping Inventory for Stressful Situations (CISS) in acquired brain injury (ABI) is currently unavailable. Therefore, we investigated the construct and discriminant, convergent and divergent validity of the CISS in a Dutch adult sample with newly acquired brain injury $(\mathrm{N}=139)$. Patients were recruited at the start of outpatient neurorehabilitation (time since diagnosis $\leq 4$ months) or after discharge home from hospital or inpatient neurorehabilitation. The original three-factor solution of the CISS (Task-oriented, Emotion-oriented, Avoidance) showed a borderline fit, which slightly improved after removal of three problematic items. We found borderline support for a fourfactor model. Internal consistency was good. Discriminant validity was only partial as we found a moderate correlation between the Task-oriented and Avoidance scale. Emotionoriented coping correlated strongly with the Anxiety and Depression subscale of the Hospital Anxiety and Depression Scale. Of the two scales of the Assimilative/Accommodative Coping Questionnaire, Tenacious Goal Pursuit correlated strongest with Task-oriented coping whereas Flexible Goal Adjustment correlated negatively with Emotion-oriented coping. In summary, the psychometric properties of the CISS in patients with acquired brain injury ranged from acceptable to good. The classical three-factor structure is appropriate, but some items might be problematic in patients with acquired brain injury. Replication of the restricted three-factor model in larger samples is needed, together with further exploration of discriminant validity and the relationship of the CISS with other coping measures, but for now we recommend using the original CISS in patients with acquired brain injury.
\end{abstract}




\section{Introduction}

Acquired brain injury (ABI) refers to any non-progressive injury to the brain caused after birth. The two most common forms of acquired brain injury are strokes and traumatic brain injuries (TBI). Other forms of acquired brain injury include, for example, brain tumours, encephalitis, and hypoxic encephalopathy. A growing body of evidence suggests that coping style is an important determinant of psychosocial outcome in acquired brain injury. Coping style is associated with levels of productivity, emotional stability, quality of life and societal participation after acquired brain injury. ${ }^{1-4}$

Despite its wide use, the exact meaning of the term 'coping' is open to many interpretations. The definition, conceptualization and classification of coping depend on the theoretical foundation that serves as background. From the transactional (situation-specific) perspective, coping is considered as a dynamic and situation-dependent process and is defined as 'the person's cognitive and behavioural efforts to manage (reduce, minimize, master, or tolerate) the internal and external demands of the person-environment transaction that is appraised as taxing or exceeding the person's resources. ${ }^{5(\mathrm{p} 572)}$ In the disposition-oriented view coping is conceptualized as a personality trait or style, which assumes that people, across different situations, have preferences for certain coping styles. ${ }^{6}$ Coping can also be regarded as domainspecific. In this view coping is considered to be relatively stable across different stressors within one domain, but coping styles can differ between different domains. ${ }^{7}$ Different instruments for measuring coping will reflect different theoretical backgrounds.

In the general population, the Coping Inventory for Stressful Situations (CISS) developed by Endler and Parker ${ }^{8}$ is widely used and has been reported to have excellent psychometric properties. ${ }^{9-12}$ The dispositional approach was used in the development of the CISS, focusing on identification and comparison of basic coping strategies used by different individuals across different types of stressful situations. ${ }^{13}$

The CISS is a 48-item instrument that distinguishes three basic coping strategies with 16 items per scale: Task-oriented ( $\mathrm{T}$ scale), Emotion-oriented (E scale) and Avoidance (A scale).9,14 Exploratory factor analysis of the 48-item inventory has shown that these three subscales correspond to separate factors. Additionally, the T, E and A scales were factor analysed separately. For the $\mathrm{T}$ and $\mathrm{E}$ scale only one factor was produced. The A scale yielded two factors: a five-item Social Diversion scale and an eight-item Distraction scale, with three items loading on both or neither factor. ${ }^{13}$ Some authors have found stronger support for a fourfactor model (task-oriented, emotion-oriented, distraction and social diversion). ${ }^{10,12,15}$ 
Internal reliability scores (Cronbach's $\alpha$ ) of the CISS are reported to be good, ranging from .72 to $.92 .{ }^{9} 10,12,13,16$ Concerning convergent and divergent validity, the Beck Depression Inventory $(\mathrm{BDI})^{17}$ and the Depression subscale of the Hospital Anxiety and Depression Scale (HADS $)^{18}$ have shown significant positive correlations with the Emotion-oriented CISS scale $(\mathrm{r}=$ $.50-.61)$ and significant negative correlations with the Task-oriented CISS scale ( $\mathrm{r}=-.20$ - -.43). ${ }^{12,13,15,19}$ Diverse anxiety measures have been positively correlated with the Emotionoriented CISS scale. ${ }^{12,13,15,20}$

A Dutch version of the CISS scale was developed by de Ridder and van Heck ${ }^{11}$ and showed, in a similar fashion to the original version, a three-factor structure and good internal reliability.

Information on the internal and external validity of the CISS for use in the acquired brain injury population is currently not available. Two systematic reviews have assessed the use of coping instruments in acquired brain injury, and both showed a need for information on the psychometric properties of these instruments. ${ }^{21,22}$ Only two of the reviewed studies used the CISS to measure coping behaviours. ${ }^{23,24}$ Backhaus et al. ${ }^{23}$ showed that coping self-efficacy improved significantly in patients with traumatic brain injury who received coping skills training compared with a non-treated control group. Coping styles, measured at baseline only, did not differ between groups. Jaracz et al. ${ }^{24}$ investigated coping in patients with poststroke fatigue to find that high levels of fatigue were associated with high use of emotionoriented coping and low use of task-oriented coping.

Physical, cognitive, emotional and behavioural problems are frequently present in patients with brain injury and typically have a chronic character. ${ }^{25}$ Adaptation to these consequences of acquired brain injury is characterized by the simultaneous interaction of two processes: achieving maximal restoration of function and adjusting to the alterations and losses that occur in the various domains of functioning. In this process, not only coping with actual 'every day' problems is involved, which can be measured by the CISS, but also the pursuit of longterm goals. In the process of goal pursuit, persistence is needed to progress successfully. Yet the ability to (partially) disengage and adapt goals is equally important to prevent frustration when goals turn out to be unattainable. ${ }^{26}$

Both tendencies, tenacity as the reflection of assimilative coping and flexibility in goal pursuit as the reflection of accommodative coping, can be measured by the Assimilative/ Accommodative Coping Questionnaire (AACQ) developed by Brandtstadter and Renner. ${ }^{27}$ So, to measure the different aspects of coping that are simultaneously involved in the process of adaptation after brain injury, the CISS and the AACQ are complementary. 
As the CISS is widely used in the general population and good psychometric properties have been reported, it might be a promising instrument for use in patients with acquired brain injury, in whom it has been hardly used so far. The presence of cognitive deficits and mental fatigue in this patient population make the CISS an attractive clinical instrument because of its relatively short administration time (10 to 15 minutes). ${ }^{22}$ Information on the psychometric properties of the CISS in the acquired brain injury population is needed.

Therefore, the aims of this study were (1) to examine the factor structure of the CISS, (2) to study internal consistency and (3) discriminant validity, and (4) to examine the associations (convergent and divergent validity) of the CISS with the HADS and the Assimilative/ Accommodative Coping Questionnaire in a sample of patients with acquired brain injury.

\section{Method}

\section{Patients}

Between January 2011 and January 2012, rehabilitation physicians and neurologists of the participating institutes (two rehabilitation centres and two hospitals in the South of the Netherlands) recruited patients eligible for participation in this study in which coping flexibility after acquired brain injury was investigated. The patients were included consecutively upon return to the home environment, either at the start of an outpatient neurorehabilitation programme or at discharge home from hospital or from an inpatient neurorehabilitation setting.

The inclusion criteria were (1) being older than age 18 years, (2) having newly acquired, nonprogressive brain injury of any aetiology confirmed by neurological and/or neuroimaging data, and (3) being a patient recruited at the start of an outpatient rehabilitation programme: having sustained the injury in the previous 4 months.

The exclusion criteria were (1) the presence of any premorbid progressive brain disease, (2) having insufficient command of the Dutch language, and (3) lacking the ability to complete questionnaires based on clinical judgement (aphasia, severe cognitive impairment).

The medical ethics committees of Maastricht University Medical Centre and all participating hospitals and rehabilitation centres approved this study. All patients gave their written informed consent. 


\section{Measures}

\section{Coping Inventory for Stressful Situations (CISS)}

The CISS is a 48-item instrument used to measure three basic coping strategies with 16 items per scale: Task-oriented (T), Emotion-oriented (E), and Avoidance (A). ${ }^{9,14}$. The Avoidance scale contains two subscales: Distraction (D) and Social Diversion (SD). Items are scored on a 5 -point Likert scale (from $1=$ not at all to $5=$ very much). Scores for all items per scale are summed to form scale scores; higher scores indicate a greater use of that particular coping strategy. We used the Dutch version of the CISS that was developed by De Ridder and van $\mathrm{Heck}^{11}$ and has been validated in healthy adults and students. Internal consistency scores (Cronbach's $\alpha$ ) were good ranging from .75 to .88 . Factor analysis revealed a three-factor structure (Task, Emotion, Avoidance). Discriminant validity was shown to be sufficient for the three main scales with non-significant or low correlations $(r<.25)$. Correlations between the Avoidance subscales (Social Diversion and Distraction) were higher but sufficiently low to distinguish two separate subscales $(\mathrm{r}=.36-.46)$. Test-retest reliability was measured over a period of 6 weeks, and test-retest correlations were found to be high $(r=.78-.90)$, except for the Distraction subscale that showed a lower value $(r=.66)$.

\section{The Assimilative/Accommodative Coping Questionnaire (AACQ)}

The AACQ measures the dispositions of tenacity and flexibility. The Flexibility scale (Flexible Goal Adjustment, or FGA) consists of facets of accommodative processes related to disengagement, reorientation, and acceptance. The Tenacity scale (Tenacious Goal Pursuit, or TGP) refers to assimilative tendencies: maintaining a chosen course of action even under difficulty or increasing the valence of blocked goal perspectives. Both scales, TGP and FGA, consist of 15 items, measured on 5-point scales $(0=$ completely agree to $4=$ completely disagree). Mean scores are calculated for each subscale and higher scores indicate better use of that particular coping strategy. The internal consistency of both scales has been found good (FGA: Cronbach's $\alpha=.83$, TGP: Cronbach's $\alpha=.80$ ) as was the discriminant validity between the two scales $(\mathrm{r}=.06, \mathrm{~ns}) .{ }^{27}$ We used the Dutch translation ${ }^{28}$ of the original German version of the questionnaire. ${ }^{27}$ This translation was done in a formal way and consisted of several independent forward (by the two German speaking native Dutch researchers) and backward translations (by two native German researchers speaking Dutch fluently) and a check on comprehension by three lay subjects. ${ }^{28}$ An informally translated Dutch version has been used in stroke. ${ }^{29,30}$. There is no information available on the psychometric properties of any of the Dutch versions. 


\section{Hospital Anxiety and Depression Scale (HADS)}

The HADS is a 14-item self-report measure with two subscales: Anxiety and Depression. ${ }^{18}$ Items are scored on a 4-point scale. Subscale scores range from $0-21$; higher scores indicate a greater amount of complaints. The HADS is widely used in traumatic brain injury ${ }^{31}$ and stroke ${ }^{32}$. A Dutch version was validated by Spinhoven et al. $^{33}$ in adults, older adults, general practice patients, general medical outpatients with unexplained medical symptoms, and psychiatric outpatients. Internal consistency of the Dutch version showed to be good with Cronbach's $\alpha$ for the total scale and subscales ranging from .71 to .90. Factor analysis revealed that the two-factor solution was superior to a single factor model although subscale intercorrelations appeared to be high $(\mathrm{r}=.42-.73)$. Test-retest correlations, measured over a period of 3 weeks, were high $(r=.86-.91)$.

\section{Modified Frenchay Activities Index (Modi-FAI)}

The FAI is a 15-item measure, developed for stroke patients, assessing the frequency of performance of activities such as housekeeping, recreation, transportation and work during the last 3-6 months. ${ }^{34}$ The FAI has also been used in traumatic brain injury. ${ }^{35}$ We used the Dutch adapted version, Modi-FAI, which covers a period of four weeks with answering categories adapted correspondingly. ${ }^{36}$ Items are scored on a 4-point scale (from 0 to 3), and all scores are added to form a total score ranging from 0 to 45 . Higher scores indicate a higher level of activity. The Dutch version has been validated in patients with stroke and older adults (> 65 years).$^{37}$ Schuling et al. ${ }^{37}$ reported good internal consistency of the total scale with Cronbach's a ranging from .78 to .87 . They found, as expected, a substantial convergent relation with the Barthel Index ${ }^{38}$, which measures activities of daily living $(r=.66)$. Interrater reliability was found to be $\operatorname{good}(\mathrm{r}=.90) \cdot{ }^{36}$

\section{Procedure}

At the start of outpatient rehabilitation or at discharge from hospital or inpatient rehabilitation, eligible patients were invited to participate in the study by their rehabilitation physician or neurologist. After obtaining consent, the first author or research assistant interviewed all participants by telephone. The telephone interview took place when patients had been at home for at least 2-4 weeks. They were asked about the three most stressful problems or situations-attributed by them to their brain injury-that they had encountered the previous 2 weeks. As a second part of the telephone interview, the patients completed the modified FAI.

For each of the three situations listed during the interview a separate CISS questionnaire was prepared in which the instruction for completion was made specific: 'How much do you engage in these types of activities when you are confronted with... (one of the three situations mentioned)'. So this procedure resulted in three situation-specific CISS questionnaires per 
participant, which were sent to each participant by post, along with the HADS and the Assimilative/Accommodative Coping Questionnaire.

If a participant preferred a live interview or needed assistance to complete the questionnaires, a face-to-face interview with the research assistant or first author was arranged $(n=19,14$ $\%$ of the cases). The three brain injury-specific situations mentioned by each participant were categorized based on type of impairment: physical, cognitive, emotional, behavioural, communication and other. Categorization was done by the research assistant and verified by the first author.

Demographic data and lesion characteristics (gender, level of educational attainment, date of birth, date of brain injury, type of lesion) were collected from the medical files.

\section{Data analysis}

In order to determine patient characteristics, we carried out independent sample t-tests to investigate differences in CISS subscale scores between our study sample and the Dutch norm group of working adults ${ }^{11}$ and to compare means between men and women for all CISS subscale scores and for scores on AACQ, HADS and Modi-FAI. Alpha level was set at .05 (two-sided) for all analyses.

Level of educational attainment was classified according to a three-level system often used in the Netherlands: primary education (low), junior vocational training (medium) and senior vocational or academic training (high), corresponding to $8.6 \pm 1.9,11.4 \pm 2.5$, and $15.2 \pm 3.3$ years of full-time education, respectively. ${ }^{39}$

The CISS completed for the first problem was used in all analyses reported in this article. The CISS results for the second and third problem were not included in the analyses to avoid the problem of intercorrelation, as these measurements were not collected independently.

In order to determine the construct validity of the theoretical three- and four-factor model of coping proposed in the original CISS, we performed confirmatory factor analyses using Mplus Version 6.12 (Muthén \& Muthén, 2012). For the three-factor solution, three continuous latent variables were regressed on the 48 CISS items, as suggested by Endler and Parker. ${ }^{8}$ For the four-factor solution, four latent variables were regressed on 45 items (three items do not contribute: item 2, 23, 32) as suggested by Cook and Heppner. ${ }^{10}$ Model fit was assessed by the Root Mean Square Error of Approximation (RMSEA) ranging from 0 to 1 ( $\leq .05$ indicates good fit, $\leq .08$ indicates acceptable fit), the Comparative Fit Index (CFI) ranging from 0 to 1 ( $\geq .95$ indicates good fit, $\geq .90$ indicates acceptable fit), and the Tucker Lewis Index (TLI) 
ranging from 0 to 1 ( $\geq .95$ indicates good fit, $\geq .90$ indicates acceptable fit). Modification indices (MI) were inspected to explore item cross-loadings (items loading on more than one factor) and residual interitem and interfactor correlations. Since CISS items form an ordinal scale, a mean- and variance-corrected weighted least squares estimator was used.

The internal consistency of the scale was assessed using Cronbach's $\alpha$. Pearson's correlations were used to examine discriminant validity and to examine convergent and divergent validity by correlating the CISS with the Assimilative/Accommodative Coping Questionnaire and the Hospital Anxiety and Depression Scale (HADS), respectively. Alpha level was set at .05 (twosided) for all analyses. All analyses, except the confirmatory factor analysis, were performed using SPSS 20 for Mac.

\section{Results}

Of the 190 patients asked to participate, 148 (78\%) consented and fulfilled all criteria. For this particular study, we only used data of the patients that completed the CISS for the first problem $(\mathrm{N}=139)$. Table 1 shows demographic and injury-related characteristics of the study sample. Most participants had suffered a stroke (81\%) and $65 \%$ of the study sample were men.

Table 1. Patient characteristics

\begin{tabular}{llcc}
\hline & & Mean & SD \\
\hline $\begin{array}{l}\text { Age (years) } \\
\text { Time since injury (weeks) }\end{array}$ & & 55 & 12 \\
\hline & & 12.8 & 8.7 \\
\hline Male gender & & $\mathrm{n}$ & $\%$ \\
Educational level & Low & 90 & 64.7 \\
& Medium & 39 & 28.1 \\
& High & 57 & 41.0 \\
Type of lesion & Infarction & 43 & 30.9 \\
& SAH & 91 & 65.5 \\
& ICH & 10 & 7.2 \\
& Diffuse vascular lesions & 9 & 6.5 \\
& TBI & 2 & 1.4 \\
& Anoxic encephalopathy & 12 & 8.6 \\
& Tumour benign & 3 & 2.2 \\
& Meningitis/encephalitis & 5 & 3.6 \\
& Other & 1 & 0.7 \\
& & 6 & 4.3 \\
\hline
\end{tabular}

Note. $\mathrm{N}=139$. $\mathrm{SAH}$, subarachnoid haemorrhage; $\mathrm{ICH}$, intracerebral haemorrhage; $\mathrm{TBI}$, traumatic brain injury 
In Table 2, descriptive statistics for all study variables are displayed and all CISS scale scores have been compared with those of a Dutch norm group composed of 386 working adults with a mean age of 40 years $(\mathrm{SD}=9.5) .{ }^{11}$ Compared with the total norm group, our total sample of patients with acquired brain injury made significantly less use of all coping strategies (Table 2). Only HADS Anxiety and Modi-FAI scores showed significant differences between women and men in our sample $(\mathrm{t}(135)=2.09, \mathrm{p}=.04$ and $\mathrm{t}(137)=3.79, \mathrm{p}<.001$ respectively). No significant differences were found in CISS subscale scores between women and men (Table 2). Mean HADS Anxiety and Depression scores were below cut-off score (score $\geq 8$ is an indication for the presence of depression or anxiety; Table 2).

\section{Construct validity: confirmatory factor analysis}

All items significantly loaded onto their hypothesized factors at $\mathrm{p}<.001$ in both the threeand four-factor models. Fit indices provided acceptable (RMSEA) to borderline (CFI, TLI) support for the classical three-factor model (Table 3). Inspection of standardized factor loadings showed that these were low (i.e. <.40) for items 3 and 11 (both loading on Avoidance) and item 6 (loading on Task). Despite significant associations, the factors explained little of the items' variances. We therefore ran a restricted model that excluded the three problematic items. This model showed acceptable model fit (Table 3). In addition, fit indices provided borderline support for the four-factor model (Table 3). Table 4 shows the standardized factor loadings for all the models.

Table 3. Confirmatory Factor Analysis (Model Fit Indices) of the Coping Inventory for Stressful Situations

\begin{tabular}{lcccc}
\hline & RMSEA & CFI & TLI & Overall \\
\hline Three-factor model $_{\text {Restricted three-factor model }}^{\mathrm{a}}$ & .062 & .894 & .889 & Borderline \\
Four-factor model $^{\mathrm{b}}$ & .061 & .910 & .906 & Acceptable \\
\hline
\end{tabular}

Note. RMSEA, Root Mean Square Error of Approximation (good fit $\leq .05$, acceptable $\leq .08$ ); CFI, Comparative Fit Index (good fit $\geq .95$, acceptable $\geq .90$ ); TLI, Tucker Lewis Index (good fit $\geq .95$, acceptable $\geq .90$ )

${ }^{a}$ items $3,6,11$ removed; ${ }^{b}$ items $3,23,32$ removed 


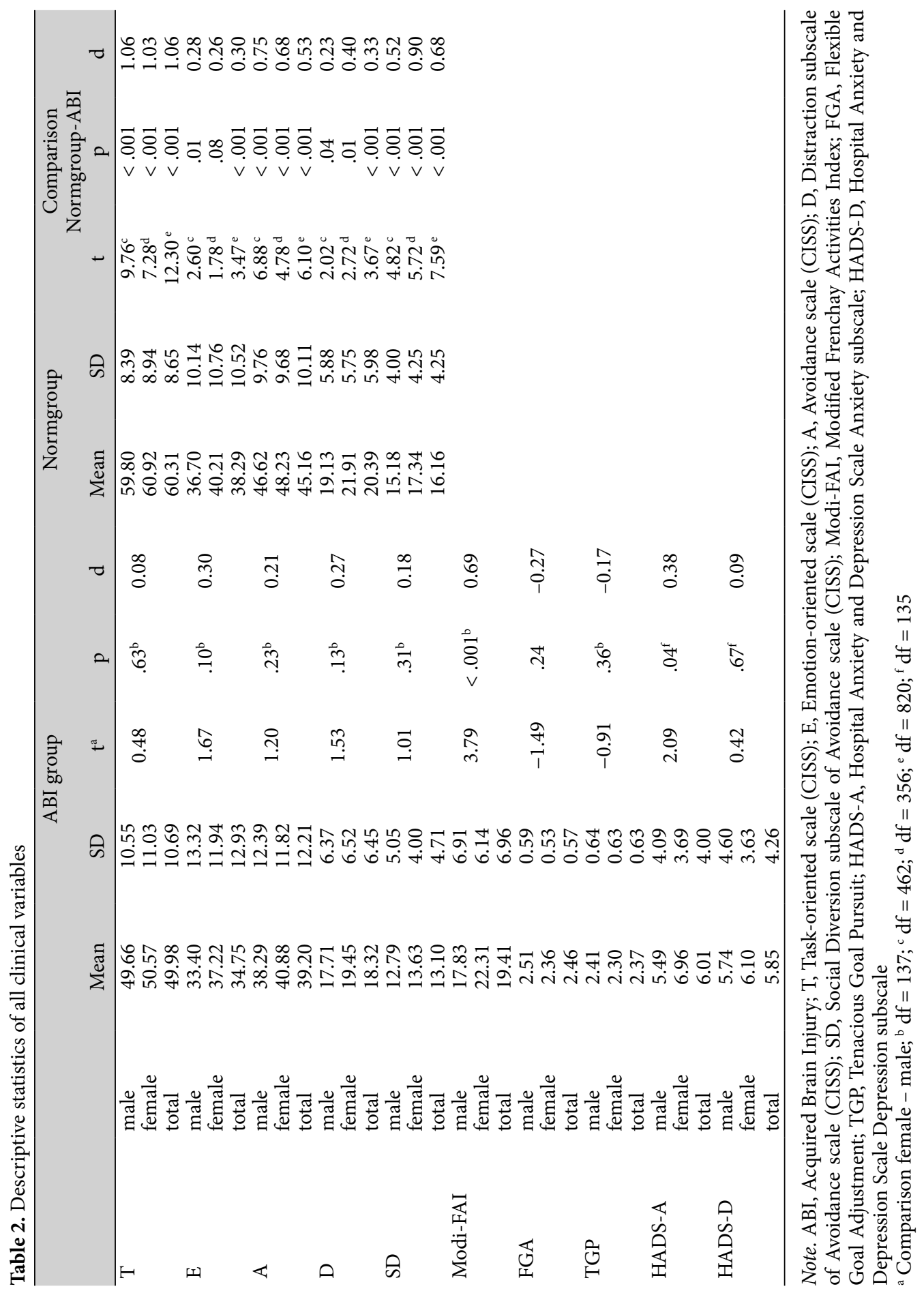


Table 4. Standardized factor loadings of the Coping Inventory for Stressful Situations (CISS): three- and four-factor solutions

\begin{tabular}{|c|c|c|c|c|c|c|c|c|c|c|}
\hline \multirow[b]{2}{*}{ CISS item } & \multicolumn{3}{|c|}{ Three-factor model } & \multicolumn{3}{|c|}{ Restricted Three-factor model } & \multicolumn{4}{|c|}{ Four-factor model ${ }^{\mathrm{b}}$} \\
\hline & $\mathrm{T}$ & E & A & $\mathrm{T}$ & E & A & $\mathrm{T}$ & $\mathrm{E}$ & D & SD \\
\hline 1 & .4 & & & .47 & & & .47 & & & \\
\hline 2 & .5 & & & .57 & & & .57 & & & \\
\hline 6 & .3 & & & $/ / / /$ & & & .36 & & & \\
\hline 10 & .7 & & & .72 & & & .72 & & & \\
\hline 15 & .4 & & & .47 & & & .46 & & & \\
\hline 21 & .5 & & & .58 & & & .59 & & & \\
\hline 24 & .6 & & & .60 & & & .60 & & & \\
\hline 26 & .7 & & & .72 & & & .72 & & & \\
\hline 27 & .5 & & & .55 & & & .55 & & & \\
\hline 36 & .6 & & & .65 & & & .64 & & & \\
\hline 39 & .5 & & & .49 & & & .49 & & & \\
\hline 41 & .6 & & & .62 & & & .61 & & & \\
\hline 42 & .7 & & & .70 & & & .70 & & & \\
\hline 43 & .7 & & & .78 & & & .77 & & & \\
\hline 46 & .6 & & & .69 & & & .68 & & & \\
\hline 47 & .6 & & & .68 & & & .69 & & & \\
\hline 5 & & .70 & & & .70 & & & .70 & & \\
\hline 7 & & .65 & & & .64 & & & .65 & & \\
\hline 8 & & .61 & & & .61 & & & .62 & & \\
\hline 13 & & .75 & & & .75 & & & .75 & & \\
\hline 14 & & .90 & & & .89 & & & .90 & & \\
\hline 16 & & .57 & & & .57 & & & .57 & & \\
\hline 17 & & .73 & & & .73 & & & .73 & & \\
\hline 19 & & .80 & & & .80 & & & .80 & & \\
\hline 22 & & .77 & & & .77 & & & .78 & & \\
\hline 25 & & .78 & & & .78 & & & .78 & & \\
\hline 28 & & .71 & & & .71 & & & .71 & & \\
\hline 30 & & .81 & & & .81 & & & .81 & & \\
\hline 33 & & .53 & & & .53 & & & .52 & & \\
\hline 34 & & .72 & & & .72 & & & .71 & & \\
\hline 38 & & .82 & & & .82 & & & .82 & & \\
\hline 45 & & .83 & & & .83 & & & .83 & & \\
\hline 3 & & & .30 & & & ///// & & & ///// & $/ / / / /$ \\
\hline 4 & & & .69 & & & .69 & & & & .70 \\
\hline 9 & & & .61 & & & .61 & & & .61 & \\
\hline 11 & & & .39 & & & ///// & & & .46 & \\
\hline 12 & & & .84 & & & .84 & & & .86 & \\
\hline 18 & & & .86 & & & .86 & & & .88 & \\
\hline 20 & & & .82 & & & .82 & & & .85 & \\
\hline 23 & & & .74 & & & .75 & & & $/ / / / /$ & $/ / / / /$ \\
\hline 29 & & & .79 & & & .80 & & & & .80 \\
\hline 31 & & & .71 & & & .71 & & & & .75 \\
\hline 32 & & & .56 & & & .56 & & & $/ / / / /$ & $/ / / / /$ \\
\hline 35 & & & .69 & & & .68 & & & & .72 \\
\hline 37 & & & .81 & & & .81 & & & & .85 \\
\hline 40 & & & .65 & & & .66 & & & .66 & \\
\hline 44 & & & .64 & & & .64 & & & .67 & \\
\hline 48 & & & .56 & & & .56 & & & .60 & \\
\hline
\end{tabular}

Note. Standardized factor loadings $<.40$ are indicated in bold. CISS, Coping Inventory for Stressful Situations; T, Task-oriented scale (CISS); E, Emotion-oriented scale (CISS); A, Avoidance scale (CISS); D, Distraction subscale of Avoidance scale (CISS); SD, Social Diversion subscale of Avoidance scale (CISS)

//I/I = removed

a items 3, 6, 11 removed; bitems 3, 23, 32 removed 


\section{Internal consistency}

The subscales in the original three-factor model (Task, Emotion, Avoidance) showed good internal reliability with Cronbach's a varying between .88 and .92 (Table 5). For the restricted three-factor model, results were similar (Table 5).

Table 5. Internal consistency (Cronbach's $\alpha$ ) of the Coping Inventory for Stressful Situations (CISS) factors

\begin{tabular}{lccccc}
\hline & T & E & A & D & SD \\
\hline 3-factor model & .88 & .92 & .90 & & \\
Restricted 3-factor model & .88 & .92 & .91 & & \\
4-factor model & .88 & .92 & & .82 & .83 \\
\hline
\end{tabular}

Note. T, Task-oriented scale (CISS); E, Emotion-oriented scale (CISS); A, Avoidance scale (CISS); D, Distraction subscale of Avoidance scale (CISS); SD, Social Diversion subscale of Avoidance scale (CISS)

\section{Discriminant validity}

In Table 6, intersubscale correlations are presented. Intersubscale correlations were low between Task and Emotion and Avoidance and Emotion. Task was moderately correlated with Avoidance ( $\mathrm{r}=.51, \mathrm{p} \leq .001)$. Intersubscale correlations were strong between Avoidance, Distraction and Social Diversion.

Table 6. Coping Inventory for Stressful Situations (CISS) intersubscale correlations

\begin{tabular}{lcccc}
\hline & $\mathrm{E}$ & $\mathrm{A}$ & $\mathrm{D}$ & $\mathrm{SD}$ \\
\hline $\mathrm{T}$ & $.17^{\star}$ & $.51^{* *}$ & $.38^{\star *}$ & $.52^{\star *}$ \\
$\mathrm{E}$ & & $.29^{* *}$ & $.35^{\star *}$ & $.21^{\star}$ \\
$\mathrm{A}$ & & & $.93^{\star *}$ & $.90^{\star *}$ \\
$\mathrm{D}$ & & & & $.73^{\star *}$ \\
\hline
\end{tabular}

Note. T, Task-oriented scale (CISS); E, Emotion-oriented scale (CISS); A, Avoidance scale (CISS); D, Distraction subscale of Avoidance scale (CISS); SD, Social Diversion subscale of Avoidance scale (CISS) ${ }^{\star} \mathrm{p}<.05 ;{ }^{* *} \mathrm{p} \leq .001$

\section{Convergent and divergent validity}

For the Task scale, a stronger positive correlation was found with Tenacious Goal Pursuit $(\mathrm{r}=.34, \mathrm{p}<.005)$ compared with Flexible Goal Adjustment $(\mathrm{r}=.19, \mathrm{p}<.05$; Table 7$)$. For the Emotion scale, the strongest negative correlation was found with FGA $(r=-.51, p<.005$; Table 7). Strong significant positive correlations were found between the Emotion scale and both the HADS Depression and Anxiety subscale (Table 7). 
Table 7. Correlations between Coping Inventory for Stressful Situations (CISS) subscales and the subscales of the Assimilative/Accommodative Coping Questionnaire (FGA, FGP) and subscales of the Hospital Anxiety and Depression Scale (HADS)

\begin{tabular}{lccccc}
\hline & $\mathrm{T}$ & $\mathrm{E}$ & $\mathrm{A}$ & $\mathrm{D}$ & $\mathrm{SD}$ \\
\hline FGA & $.19^{\star}$ & $-.51^{\star *}$ & .16 & .08 & .15 \\
TGP & $.34^{\star *}$ & $-.25^{\star *}$ & .11 & .04 & .18 \\
HADS-A & .05 & $.73^{\star *}$ & .09 & .14 & .04 \\
HADS-D & -.09 & $.56^{\star * *}$ & -.27 & .01 & -.01 \\
\hline
\end{tabular}

Note. T, Task-oriented scale (CISS); E, Emotion-oriented scale (CISS); A, Avoidance scale (CISS); D, Distraction subscale of Avoidance scale (CISS); SD, Social Diversion subscale of Avoidance scale (CISS); FGA, Flexible Goal Adjustment; TGP, Tenacious Goal Pursuit; HADS-A, Hospital Anxiety and Depression Scale Anxiety subscale; HADS-D, Hospital Anxiety and Depression Scale Depression subscale

${ }^{\star} \mathrm{p}<.05 ;{ }^{* *} \mathrm{p}<.005 ;{ }^{* * *} \mathrm{p}<.001$

\section{Discussion}

In the present study, we evaluated the psychometric properties of the CISS in a sample of patients with acquired brain injury. The construct validity of the CISS in patients with acquired brain injury was acceptable and suggested that the CISS measures the same three coping styles that have been reported before in different populations: Task-oriented, Emotion-oriented and Avoidance coping. ${ }^{11-13,20}$ The confirmatory factor analysis, however, slightly favoured a restricted three-factor model and a more complex four-factor model.

So far, only a limited number of studies have investigated the factor structure of the CISS. In the general population and in patients with depression, exploratory factor analysis has confirmed the original three-factor solution. ${ }^{11,12,20}$ Confirmatory factor analysis performed on the CISS in the general population and in patients with Parkinson's disease, however, showed results slightly in favour of the four-factor model. ${ }^{10,15,40}$ In the Parkinson's disease sample the strongest model-fit indices were found for a restricted four-factor solution in which items 11, 44 and 48 were removed. ${ }^{15}$ These and our findings suggest that the CISS has a replicable factor structure. Together with the high internal consistency (Cronbach's $\alpha=.88-.92$ ), the CISS might thus be regarded to have good internal validity in an acquired brain injury population.

In our restricted three-factor model, items 3 and 11 (Avoidance) and item 6 (Task) were removed based on their low standardized factor loadings, suggesting that they contributed relatively little to the stability of the factor. The content and specific wording of these items might play a role in this. Item 11 refers to sleep, a strategy that is often influenced by acquired brain injury itself, as mental fatigue is a very common complaint after acquired brain injury. 
The wording of items 3 (which refers to the respondent's thinking of the good times he or she has had) and 6 (which refers to the respondent's relying on his or her own judgement) is more abstract than that of most other items of the CISS. The cognitive problems that are characteristic for acquired brain injury may interfere with understanding and interpretation of these questions. Also the fact that we choose a situation-specific approach (asking for the coping strategies a person used for a specific problem related to brain injury) might have reinforced the preference for less abstract formulated strategies.

Earlier studies have also provided evidence for inconsistency of these items. In patients with depression, exploratory factor analysis of the CISS showed that item 3 did not saliently load on Avoidance but on Task, and item 11 did not load on any factor. ${ }^{12}$ In patients with Parkinson's disease, construct validity of the CISS was examined using interitem correlations, which was low for item 11 , indicating item redundancy. ${ }^{15,41}$ However, our study results need to be confirmed in larger acquired brain injury samples before recommendations can be made concerning the use of an adapted version of the CISS in the acquired brain injury population. Given the relatively modest difference in model fit for the restricted three-factor model and the more complex four-factor model, it seems reasonable to apply Occam's razor and stick with the more parsimonious classical three-factor solution when using the CISS in the acquired brain injury population. Our findings also suggest that the factors arise from the items included and are intrinsic to the questionnaire and are not specific to an acquired brain injury population.

Our findings concerning discriminant validity are in certain aspects different from the original findings by Endler and Parker ${ }^{13}$ and studies published since. ${ }^{11,15,40}$ Correlations between Task and Avoidance are generally reported to be low. In our acquired brain injury sample, a moderate correlation was found $(\mathrm{r}=.51)$, which indicates that the CISS is only partially effective in discriminating between these major coping styles. We found high correlations between Avoidance and Distraction and Avoidance and Social Diversion, which correspond to earlier findings. However, the correlation between Distraction and Social Diversion is markedly higher than usually reported $(r=.73)$, suggesting that these subscales measure more or less the same dimension, which again is in line with a three-factor model.

The correlations between the CISS and the Assimilative/Accommodative Coping Questionnaire were consistent with theoretical predictions. For the Task scale, a stronger positive correlation was found with Tenacious Goal Pursuit $(r=.34)$ compared with Flexible Goal Adjustment $(\mathrm{r}=.19)$. TGP refers to actively adjusting circumstances to personal preferences and, as such, a greater involvement of task-oriented strategies is expected compared with FGA, where the focus is on accepting consequences and adjusting goals. For the Emotion scale, the strongest 
negative correlation was found with FGA $(\mathrm{r}=-.51)$ compared with TGP. This is expected, as the Emotion scale contains many negatively formulated emotions, which are oppositional to issues of acceptance and reorientation. Intercorrelations of the CISS subscales with the HADS followed expected patterns. ${ }^{15}$ The HADS Depression and Anxiety subscales showed high positive correlations with the Emotion scale of the CISS.

Several other findings in this study are worth mentioning. Compared with the general population, our study sample of patients with acquired brain injury differs in some coping characteristics. They make less use of all coping strategies than a working adult norm group. Similar results are found in people with Parkinson's disease and multiple sclerosis. ${ }^{11,15}$ No gender differences in use of any coping style were detected in this acquired brain injury sample. Generally, in healthy people, men and women use task-oriented strategies equally as much, but women make greater use of other strategies. In acquired brain injury, Herrmann et $\mathrm{al}^{42}$ reported no gender differences, whereas Wolters et al. ${ }^{4}$ found greater use of palliative strategies and seeking of social support in women.

Our choice not to limit inclusion criteria for this study to one specific diagnosis was to increase generalizability and recognize that severity and type of brain injury do not influence coping. ${ }^{1,3,42,43}$ We think our study sample is representative of the population of acquired brain injury patients that return home after discharge, not requiring long-term residential care.

The sample size of our study $(\mathrm{N}=139)$ might be considered as low for confirmatory factor analysis, and this has to be acknowledged as a weakness of this study. However, the reported fit indices such as the CFI are known to be relatively unaffected by sample size. ${ }^{44}$ In addition, it has been shown that even in samples as small as 50 confirmatory factor analysis behaves well if factor loadings are reasonably high and the number of variables per factor is sufficiently $\operatorname{high}^{45}$, as is the case in this study.

A further limitation of this study is the fact that we did not use the original instruction of the 48-item CISS (how to deal with 'a' difficult, upsetting situation, which is not further specified). Instead, we used a situation-specific instruction (how to deal with a 'specific' problem). Originally, to suit a situation-specific approach Endler and Parker ${ }^{13}$ developed the CISS-SSC (CISS Situation-Specific Coping) by extracting 21 items out of the original version with 7 items per scale (Task, Emotion, Avoidance). Confirmatory factor analysis of the CISS-SSC showed a three-factor structure. Cohan et al. ${ }^{46}$ suggested a four-factor structure for the CISSSSC. In their study, they used the general instruction (which is the standard instruction on the 48 -item CISS) instead of the original situation-specific instruction of the CISS-SSC. ${ }^{46}$ The consistent finding of a three- to four-factor structure across studies using various versions of 
the questionnaire (either the CISS-SSC or the 48-item CISS) suggests that these versions are measuring the same underlying construct.

We did not investigate test-retest reliability because the subject of coping (a specific situation or problem) in our study is not stable over time. Over the course of six weeks, the timeframe that is classically used to investigate test-retest reliability of the CISS, we expected that several problems or situations initially denoted as stressful would have changed or been appraised differently.

\section{Conclusions}

The present study provides important new insights into the psychometric properties of the CISS in the acquired brain injury population. We found expected associations with other measurement instruments (AACQ and HADS) and good internal consistency. Discriminant validity seems only partially sufficient as we found a moderate correlation between the Task and Avoidance scale. The classical three-factor structure is appropriate, but some items might be problematic in patients with acquired brain injury. However, replication of a restricted three-factor model in larger acquired brain injury samples is needed, together with further exploration of discriminant validity and the relationship of the CISS with other coping measures. Hence, for now, we recommend using the original CISS in the acquired brain injury population. 


\section{References}

1. Anson K, Ponsford J. Coping and emotional adjustment following traumatic brain injury. J Head Trauma Rehabil. 2006;21(3):248-259.

2. Dawson DR, Schwartz ML, Winocur G, Stuss DT. Return to productivity following traumatic brain injury: cognitive, psychological, physical, spiritual, and environmental correlates. Disabil Rehabil. 2007;29(4):301-313.

3. Finset A, Andersson S. Coping strategies in patients with acquired brain injury: relationships between coping, apathy, depression and lesion location. Brain Inj. 2000;14(10):887-905.

4. Wolters G, Stapert S, Brands I, van Heugten C. Coping following acquired brain injury: predictors and correlates. J Head Trauma Rehabil. 2011;26(2):150-157.

5. Folkman S, Lazarus RS, Gruen RJ, DeLongis A. Appraisal, coping, health status, and psychological symptoms. J Pers Soc Psychol. 1986;50(3):571-579.

6. Schreurs PJ, Tellegen B, Willige GV. Health, stress and coping: the development of the Utrechtse Coping Scale. Gedrag: Tijdschrift voor psychologie. 1984;12:101-117.

7. Ptacek JT, Pierce GR. Issues in the study of stress and coping in rehabilitation settings. Rehabil Psychol. 2003;48(2):113-124.

8. Endler NS, Parker JD. Multidimensional assessment of coping: a critical evaluation. J Pers Soc Psychol. 1990;58(5):844-854.

9. Endler NS, Parker JD. Assessment of multidimensional coping: task, emotion, and avoidance strategies. Psychol Assess. 1994;6(1):50-60.

10. Cook SW, Heppner PP. A psychometric study of three coping measures. Educ Psychol Meas. 1997;57(6):906-923.

11. De Ridder DT, Van Heck GL. Coping Inventory for Stressful Situations. CISS Handleiding. Lisse: Swets Test Publishers; 2004.

12. McWilliams LA, Cox BJ, Enns MW. Use of the Coping Inventory for Stressful Situations in a clinically depressed sample: factor structure, personality correlates, and prediction of distress. $J$ Clin Psychol. 2003;59(4):423-437.

13. Endler NS, Parker JD. Coping Inventory for Stressful Situations (CISS): manual. Toronto: MultiHealth Systems; 1999.

14. Endler NS, Parker JD. Coping Inventory for Stressful Situations (CISS): manual. Toronto: MultiHealth Systems; 1990.

15. Hurt CS, Thomas BA, Burn DJ, et al. Coping in Parkinson's disease: an examination of the coping inventory for stressful situations. Int J Geriatr Psychiatry. 2011;26(10):1030-1037.

16. Smari J, Valtysdottir H. Dispositional coping, psychological distress and disease-control in diabetes. Pers Individ Diff. 1997;22(2):151-156.

17. Beck AT, Steer RA, Carbin MG. Psychometric properties of the Beck Depression Inventory: twenty-five years of evaluation. Clin Psychol Rev. 1988;8(1):77-100.

18. Zigmond AS, Snaith RP. The Hospital Anxiety and Depression Scale. Acta Psychiatr Scand. 1983;67(6):361-370.

19. Flett GL, Blankstein KR, Obertynski M. Affect intensity, coping styles, mood regulation expectancies, and depressive symptoms. Pers Individ Diff. 1996;20(2):221-228.

20. Cosway R, Endler NS, Sadler AJ, Deary IJ. The Coping Inventory for Stressful Situations: factorial structure and associations with personality traits and psychological health. J Appl Biobehav Res. 2000;5(2):121-143.

21. Donnellan C, Hevey D, Hickey A, O'Neill D. Defining and quantifying coping strategies after stroke: a review. J Neurol Neurosurg Psychiatry. 2006;77(11):1208-1218. 
22. Wolters Gregório G, Brands I, Stapert S, Verhey FR, van Heugten CM. Assessments of coping after acquired brain injury: a systematic review of instrument conceptualization, feasibility, and psychometric properties. J Head Trauma Rehabil. 2014;29(3):E30-E42.

23. Backhaus SL, Ibarra SL, Klyce D, Trexler LE, Malec JF. Brain injury coping skills group: a preventative intervention for patients with brain injury and their caregivers. Arch Phys Med Rehabil. 2010;91(6):840-848.

24. Jaracz K, Mielcarek L, Kozubski W. Clinical and psychological correlates of poststroke fatigue. Preliminary results. Neurol Neurochir Pol. 2007;41(1):36-43.

25. Dikmen SS, Machamer JE, Powell JM, Temkin NR. Outcome 3 to 5 years after moderate to severe traumatic brain injury. Arch Phys Med Rehabil. 2003;84(10):1449-1457.

26. Brands IM, Wade DT, Stapert SZ, van Heugten CM. The adaptation process following acute onset disability: an interactive two-dimensional approach applied to acquired brain injury. Clin Rehabil. 2012;26(9):840-852.

27. Brandtstadter J, Renner G. Tenacious goal pursuit and flexible goal adjustment: explication and age-related analysis of assimilative and accommodative strategies of coping. Psychol Aging. 1990;5(1):58-67.

28. Aben L, Busschbach JJ. A formal translation of the Assimilation-Accomodation Coping Scale from German to Dutch. 2009 Erasmus MC Report 06.

29. Darlington A-S, Dippel DW, Ribbers GM, van Balen R, Passchier J, Busschbach JJ. A prospective study on coping strategies and quality of life in patients after stroke, assessing prognostic relationships and estimates of cost-effectiveness. J Rehabil Med. 2009;41(4):237-241.

30. Darlington A-S, Dippel DW, Ribbers GM, van Balen R, Passchier J, Busschbach JJ. Coping strategies as determinants of quality of life in stroke patients: a longitudinal study. Cerebrovasc Dis. 2007;23(5-6):401-407.

31. Schonberger M, Ponsford J. The factor structure of the Hospital Anxiety and Depression Scale in individuals with traumatic brain injury. Psychiatry Res. 2010;179(3):342-349.

32. Sagen U, Vik TG, Moum T, Morland T, Finset A, Dammen T. Screening for anxiety and depression after stroke: comparison of the hospital anxiety and depression scale and the Montgomery and Asberg depression rating scale. J Psychosom Res. 2009;67(4):325-332.

33. Spinhoven P, Ormel J, Sloekers PP, Kempen GI, Speckens AE, Hemert AM. A validation study of the Hospital Anxiety and Depression Scale (HADS) in different groups of Dutch subjects. Psychol Med. 1997;27(2):363-370.

34. Holbrook M, Skilbeck CE. An activities index for use with stroke patients. Age Ageing. 1983;12(2):166-170.

35. van Baalen B, Odding E, van Woensel MP, van Kessel MA, Roebroeck ME, Stam HJ. Reliability and sensitivity to change of measurement instruments used in a traumatic brain injury population. Clin Rehabil. 2006;20(8):686-700.

36. Post MW, De Witte LP. Good inter-rater reliability of the Frenchay Activities Index in stroke patients. Clin Rehabil. 2003;17(5):548-552.

37. Schuling J, de Haan R, Limburg M, Groenier KH. The Frenchay Activities Index. Assessment of functional status in stroke patients. Stroke. 1993;24(8):1173-1177.

38. Wade DT, Collin C. The Barthel ADL Index: A standard measure of physical disability? Disabil Rehabil. 1988;10(2):64-67.

39. De Bie SE. Standaardvragen 1987: Voorstellen voor uniformering van vraagstellingen naar achtergrondkenmerken en interviews (Standard questions 1987: Proposal for uniformization of questions regarding background variables and interviews). Leiden: Leiden University Press; 1987.

40. Rafnsson FD, Smari J, Windle M, Mears SA, Endler NS. Factor structure and psychometric characteristics of the Icelandic version of the Coping Inventory for Stressful Situations (CISS). Pers Individ Diff. 2006;40(6):1247-1258. 
41. Briggs SR. The role of factor analysis in the development and evaluation of personality scales. $J$ Pers. 1986;54(1):106-148.

42. Herrmann M, Curio N, Petz T, et al. Coping with illness after brain diseases: a comparison between patients with malignant brain tumors, stroke, Parkinson's disease and traumatic brain injury. Disabil Rehabil. 2000;22(12):539-546.

43. Curran CA, Ponsford JL, Crowe S. Coping strategies and emotional outcome following traumatic brain injury: a comparison with orthopedic patients. J Head Trauma Rehabil. 2000;15(6):12561274.

44. Gagne P, Hancock GR. Measurement model quality, sample size, and solution propriety in confirmatory factor models. Multivariate Behav Res. 2006;41(1):65-83.

45. Marsh HW, Hau K-T, Balla JR, Grayson D. Is more ever too much? The number of indicators per factor in confirmatory factor analysis. Multivariate Behav Res. 1998;33(2):181-220.

46. Cohan SL, Jang KL, Stein MB. Confirmatory factor analysis of a short form of the Coping Inventory for Stressful Situations. J Clin Psychol. 2006;62(3):273-283. 


\section{Chapter 5}

How flexible is coping after acquired brain injury?

A one-year prospective study investigating coping patterns and influence of self-efficacy, executive functioning and self-awareness

Published in Journal of Rehabilitation Medicine as:

Brands I, Köhler S, Stapert S, Wade D, van Heugten C. How flexible is coping after acquired brain injury? A one-year prospective study investigating coping patterns and influence of self-efficacy, executive functioning and self-awareness. Journal of Rehabilitation Medicine. 2014;46(9):869-875. 


\section{Abstract}

Objective: To investigate coping flexibility in patients with newly acquired brain injury (ABI) and to investigate the influence of problem type, self-efficacy, self-awareness and self-reported executive functions on coping flexibility.

Method: Data were collected from a prospective clinical cohort study of 136 patients assessed after discharge home (mean time since injury $=15$ weeks) and one year later. Situationspecific coping was measured by asking patients to complete the Coping Inventory for Stressful Situations (CISS) for three acquired brain injury-related situations, which were then categorized into problem types (physical, cognitive, emotional, behavioural, communication ands other). Coping consistency (number of strategies used throughout every situation) and variability (range in frequency of use of strategies over situations) were measured. Random effects regression analyses were used.

Results: Patients used more task-oriented coping for cognitive compared with physical problems. Coping variability was limited. Reliance on emotion-oriented coping decreased over time. Higher self-efficacy correlated with increased task-oriented and avoidance coping and decreased emotion-oriented coping. Greater self-reported problems in executive function correlated with greater consistency in task-oriented and emotion-oriented strategies.

Conclusion: Patients with acquired brain injury rely on a rather defined and stable set of coping options across situations and time. High self-efficacy increases active coping. Subjective executive dysfunction might hamper effective strategy selection. 


\section{Introduction}

Coping, the cognitive and behavioural efforts made to manage stressful situations ${ }^{1}$, is considered to be an important determinant of psychosocial adaptation after acquired brain injury (ABI). The use of a few specific coping styles, such as passive coping and coping characterized by wishful thinking, avoidance, worry, self-blame and substance abuse, have been consistently associated with poor quality of life. ${ }^{2,3}$ High use of escape-avoidance coping has a negative effect on return to productivity. ${ }^{4}$ Poor executive functioning is the best predictor of escape-avoidant coping. ${ }^{5}$

Furthermore, high self-efficacy has been associated with better psychosocial adjustment and quality of life in traumatic brain injury (TBI). ${ }^{6}$ Self-efficacy refers to the belief in one's capabilities in achieving goals. ${ }^{7}$ Self-efficacy beliefs are domain-specific, but various and numerous experiences of success and failure in different domains of functioning may generate a generalized belief of self-efficacy. In the healthy population, individuals with higher selfefficacy displayed higher use of active and problem-focused coping. ${ }^{8}$ However, it is not known whether the same is true for patients with acquired brain injury.

It has been proposed that access to a flexible repertoire of coping strategies is an important determinant of coping effectiveness and well-being in general. ${ }^{9}$ Coping flexibility means that coping styles can readily be adapted to changing contextual demands. ${ }^{9}$ Lester et al. ${ }^{10}$ have shown, in the healthy population, that individuals who display a greater variability in their coping responses to different situations report greater well-being. Others have found that healthy individuals exhibit higher levels of self-reported coping variability than do chronically ill people. ${ }^{11}$ In patients with rheumatoid arthritis, increased coping flexibility and illness acceptance has been associated with decreased psychological stress. ${ }^{12}$

For patients with acquired brain injury, coping flexibility may be important, yet it has not been studied intensively. Most studies have used a cross-sectional design and measured coping with stress in general or in one particular stressful situation, with largely inconsistent findings. ${ }^{13-15}$ For instance, Moore et al. ${ }^{13}$ and Moore and Stambrook ${ }^{14}$ found that patients with traumatic brain injury who use high levels of a wide variety of coping styles showed worse psychosocial adjustment than patients characterized by either low use of all coping styles or high use of positive reappraisal and social support seeking. Medley et al. ${ }^{15}$ found higher overall strategy use in traumatic brain injury patients with good self-awareness, high levels of emotional distress and high perceived control than in patients with impaired awareness and lower stress levels. 
While studying the overall use of coping styles can identify inter-individual differences in the amount and patterns of strategy use, it does not provide information on an individual patient's ability to use different strategies according to changing situational demands, i.e. intra-individual differences. Coping flexibility might be dependent on problem/stressor characteristics ${ }^{11}$ and specific brain-injury related symptoms ${ }^{16}$ such as dysexecutive functions and impaired self-awareness, resulting in impaired problem-solving and anticipation, decreased mental flexibility and diminished problem perception.

In summary, few studies have investigated coping flexibility in acquired brain injury. In acquired brain injury, self-efficacy, executive functioning and self-awareness have been shown to influence coping but their relation to coping flexibility is unknown.

Coping flexibility has many aspects. The aims of the present study in patients with acquired brain injury, were (1) to explore whether coping responses are adapted across situations, according to the type of problem encountered and over time; (2) to investigate coping variability (the range in frequency of use of strategies across situations) and coping consistency (one's fixed situation-independent coping repertoire) and its evolution over time; and (3) to investigate the influence of self-reported executive functioning, self-awareness and self-efficacy on coping, variability and consistency. We expected to find differences in coping responses based on problem characteristics. We furthermore hypothesized that (1) high self-efficacy is associated with higher use of problem-focused coping and lower coping consistency; (2) impaired selfawareness is associated with low overall use of coping and low variability; (3) self-reported problems in executive functions are associated with greater coping consistency.

\section{Method}

\section{Patients}

Between January 2011 and January 2012, rehabilitation physicians and neurologists of the participating institutes (two rehabilitation centres and two hospitals in the South of the Netherlands) recruited patients who were eligible for participation in this prospective clinical cohort study and, if available, their significant others (spouse, adult child, sibling, parent). Patients were included consecutively upon return to the home environment, either at the start of outpatient neurorehabilitation or at discharge home from hospital or from inpatient neurorehabilitation.

The inclusion criteria were: (1) age $\geq 18$ years; (2) newly acquired, non-progressive brain injury of any aetiology confirmed by neurological and/or neuroimaging data; (3) for patients recruited at the start of outpatient rehabilitation maximum time since injury 4 months. 
Exclusion criteria were: (1) any premorbid progressive brain disease; (2) insufficient command of the Dutch language; (3) inability to complete questionnaires based on clinical judgment (aphasia, severe cognitive impairment).

This study was approved by the medical ethics committees of Maastricht University Medical Centre and all participating hospitals and rehabilitation centres. All patients and significant others provided written informed consent.

\section{Procedure}

Baseline assessment consisted of questionnaire assessments and a telephone interview that took place within 6 weeks after inclusion. Patients were interviewed when they had been at home for at least 2-4 weeks. They were asked about the three most stressful situations that they had encountered as a consequence of their brain injury during the previous two weeks.

The situations mentioned by each participant were categorized into problem types: physical, cognitive, emotional, behavioural, communicative and other. Categorization was done by the research assistant and verified by the first author. For example, the situation 'I am very stressed when I meet people because I cannot remember their names' was classified as a cognitive problem. For each of the three stressful situations, a separate coping questionnaire (CISS, see below) was prepared in which the instruction for completion was made specific: 'How much do you engage in these types of activities when you are confronted with...(one of three situations)?'.

Each patient received three situation-specific coping questionnaires (CISS) by post, together with questionnaires about self-efficacy, self-awareness, executive functioning and emotional distress. The significant other received the 'other' version of the awareness questionnaire by post.

Follow-up assessment took place one year ( \pm 4 weeks) after inclusion. Interviews and questionnaire assessments were repeated. The patient again identified three brain-injury related stressful situations at that time.

If a patient preferred a live interview or needed assistance in completing the questionnaires, a face-to-face interview with the research assistant or first author was arranged ( $n=19,14 \%$ of the cases at baseline; $\mathrm{n}=18,15 \%$ of the cases at follow-up).

For this study, from the patients who consented (148 out of 190 patients who were asked to participate), we only used data of those who completed the coping questionnaires for all three situations. 


\section{Measurements}

\section{Coping}

Basic coping strategies were measured using the Coping Inventory for Stressful Situations (CISS). ${ }^{17,18}$ The 48 -item CISS has three scales (16 items per scale): Task-oriented (T), Emotionoriented (E) and Avoidance (A). The Avoidance scale contains two subscales: Social Diversion (SD) and Distraction (D). Item scores ( $1=$ not at all to $5=$ very much) are summed per scale; higher scores indicate a greater use of that particular coping style.

\section{Coping variability and consisteny}

Coping variability reflects the range in frequency of use of strategies over situations. ${ }^{10}$ For each CISS item, over the three CISS questionnaires, the score range was calculated by extracting the lowest score of the three lists for that particular item from the highest (score range maximum $=4$, minimum $=0)($ Figure 1$)$. The mean of all item score ranges per scale formed CISS scale score ranges.

Figure 1. Coping Inventory for Stressful Situations (CISS) questionnaire (2 out of 48 items are selected)

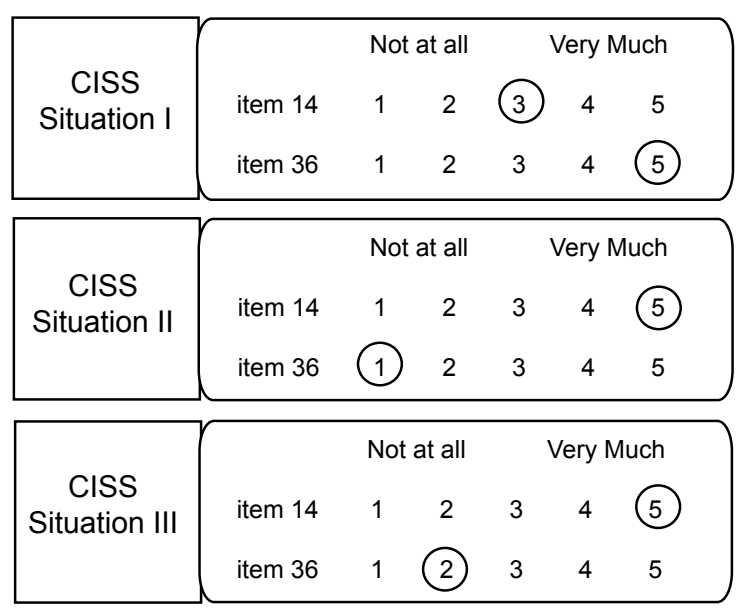

Note. The instruction for completion is: 'How much do you engage in these types of activities when you are confronted with...(one of three stressful situations)'

Example of calculation of item score ranges for a hypothetical subject:

item 14 score range: 5 (highest score) -3 (lowest score) $=2$

item 36 score range: 5 (highest score) -1 (lowest score) $=4$

Example of counting scale fixed scores for a hypothetical subject:

Item 14: score $\geq 2$ in all three CISS questionnaires, thus item 14 is used in every situation and contributes to CISS-E fixed score

Item 36: score in CISS II questionnaire = 1 (not at all), so this strategy is not used in every situation and thus item 36 does not contribute to CISS-T fixed score 
Coping consistency reflects one's fixed coping repertoire, the strategies used invariably throughout every situation. ${ }^{19}$ It is non-judgemental and can refer to desirable (e.g. stable, resilient and systematic) as well as undesirable (e.g. invariable, inflexible and rigid) coping behaviour. To quantify consistency, we counted for each CISS scale (T, E, A) how many of its 16 CISS items (= coping strategies) were used in all three situation-specific CISS questionnaires (item score $\geq 2$ in each questionnaire) (Figure 1). This resulted in CISS scale fixed scores (maximum $=16$, minimum $=0$ ). Higher CISS scale fixed scores mean that more coping strategies of the respective scales (T, E, A) are used throughout every situation.

\section{Self-efficacy}

To measure self-efficacy for managing brain injury-specific symptoms, we used the 13-item TBI Self-efficacy Questionnaire (SEsx) ${ }^{6}$, which contains four subscales: social (4 items), physical (1 item), cognitive (4 items) and emotional (4 items) measuring self-efficacy for obtaining help from community, family and friends to perform everyday activities and obtain emotional support, managing physical symptoms, managing and compensating for cognitive symptoms, and managing emotional symptoms (e.g. feeling frustrated or overwhelmed), respectively. Items scores $(1=$ not at all confident to $10=$ totally confident $)$ are summed per subscale. Subscale scores are summed to a total score. Higher scores indicate greater selfefficacy.

To measure general self-efficacy, we used the 12 -item Dutch version ${ }^{20}$ of the original General Self-efficacy Scale (GSES) ${ }^{21}$ Items are scored on a 5-point Likert scale. Higher scores indicate higher general self-efficacy (maximum score $=60$ ).

\section{Brain injury-specific symptoms}

Self-awareness was measured with the 17-item Awareness Questionnaire (AQ), which assesses how well individuals perform on a variety of activities compared with before their injury ( 1 $=$ much worse to $5=$ much better). All item scores are summed. The AQ consists of 'self' and 'other' versions completed by the participant and family member or significant other. Selfawareness is calculated by subtracting others' rating from the patients' own rating, resulting in a discrepancy score. Positive discrepancy scores indicate that patients underestimate their deficits; higher scores are associated with greater degrees of impaired self-awareness. ${ }^{22,23}$

The patient's subjective executive functioning was measured with the 20-item self-rating form of the Dysexecutive Questionnaire (DEX-P). ${ }^{24}$ Items are rated on a 5-point Likert scale indicating frequency of occurrence of symptoms $(0=$ never to $4=$ very often $)$. Higher patient scores indicate a higher level of self-perceived executive problems. 


\section{Other measures}

The Hospital Anxiety and Depression Scale (HADS) was used as a general measure of emotional distress. The HADS contains 14 items, scored on a 4-point scale (range 0-3), which form two subscales: Anxiety and Depression. ${ }^{25}$ HADS subscale scores $\geq 8$ might indicate the presence of depression or anxiety.

Demographic data and lesion characteristics (gender; age; date of brain injury; type of lesion) were collected from the medical files. The level of educational attainment was recorded during baseline interview and classified according to a three-level system often used in the Netherlands: primary education (low), junior vocational training (medium) and senior vocational or academic training (high), corresponding to $8.6 \pm 1.9,11.4 \pm 2.5$, and $15.2 \pm 3.3$ years of full-time education ${ }^{26}$, respectively.

\section{Statistical analyses}

Independent t-tests and $\chi^{2}$ tests were calculated to detect differences in demographic and clinical characteristics between study completers and patients lost to observation. Pairedsamples t-tests were used to compare baseline and follow-up scores of all clinical variables.

A random effects (mixed model) regression analysis was used to test whether coping styles (CISS scale scores: T, E, A) differed across situations, over time and according to the type of problem (physical, cognitive, emotional, behavioural, communicative and other). The analyses account for the fact that repeated measures were taken from individuals when asking patients to complete the CISS for three different situations and at two time-points (baseline, one-year follow-up). Thus, analyses made full use of all available data, but were adjusted for the fact that repeated measures are correlated within individuals, yielding pooled effect estimates. We also tested whether estimates were further influenced by demographic (age, gender, education) and clinical variables (self-efficacy, self-awareness, self-reported executive functioning, emotional distress).

Model development consisted of several steps. First, all demographic variables and the variables denoting situation (situation $1,2,3$ ) and time (baseline, follow-up) were entered. Then the associations with clinical variables (GSES, SEsx, DEX-P, AQ discrepancy, HADS) were tested separately, and those who showed associations at a p-value $<.10$ were retained. Finally, any clinical variable that was not statistically significant at a p-value of $<.05$ in the full multivariable model was manually removed in a backward selection procedure, thus starting with the variables with the highest $\mathrm{p}$-value.

To investigate the influence of demographic and clinical variables on coping variability and consistency, the analyses noted above were repeated using the CISS scale score ranges 
(variability) and CISS scale fixed scores (consistency) as dependent variables in the random effects regression analyses. All analyses were carried out in Stata 12.1, using two-sided hypothesis testing with an alpha-level of .05.

\section{Results}

At baseline (mean time since injury $=15.3$ weeks) our study sample consisted of 136 patients of whom 118 (87\%) completed all three CISS questionnaires at follow-up (mean time since injury $=66.8$ weeks). Patients lost to observation $(13 \%)$ did not differ significantly in baseline coping or in any of the demographic and clinical variables. Table 1 shows the demographic and injury-related characteristics of the study sample. Description of all clinical variables is summarized in Table 2.

HADS-D scores were above cut-off indicative for depression in $37 \%$ of patients at baseline and in $32 \%$ at follow-up. For HADS-A, at both measurements $32 \%$ of patients scored above cut-off indicative for anxiety. The types of problem that were mentioned most frequently as being highly stressful were physical and cognitive problems (Table 3).

In Table 4, coping variability and consistency scores are presented. CISS scale score ranges (variability) were small $(<1.0)$ for both measurements. CISS scales fixed scores (consistency) were highest for task-oriented coping and lowest for emotion-oriented coping.

Table 1. Patient characteristics at baseline $(\mathrm{N}=136)$

\begin{tabular}{llcc}
\hline & & Mean & SD \\
\hline Age (years) & & 56 & 11.7 \\
Time since injury (weeks) & & 15.3 & 8.6 \\
\hline & & $n$ & $\%$ \\
\hline Gender (male) & & 88 & 64.7 \\
Educational level & Low & 39 & 28.7 \\
& Medium & 54 & 39.7 \\
Type of lesion & High & 43 & 31.6 \\
& Infarction & 89 & 65.4 \\
& SAH & 10 & 7.4 \\
& ICH & 9 & 6.6 \\
& Diffuse vascular lesions & 2 & 1.5 \\
& TBI & 11 & 8.1 \\
& Anoxic encephalopathy & 3 & 2.2 \\
& Tumour benign & 5 & 3.6 \\
& Menigitis/encephalitis & 1 & 0.7 \\
& Other & 6 & 4.4 \\
\hline
\end{tabular}

Note. SAH, subarachnoid haemorrhage; ICH, intracerebral haemorrhage; TBI, traumatic brain injury 


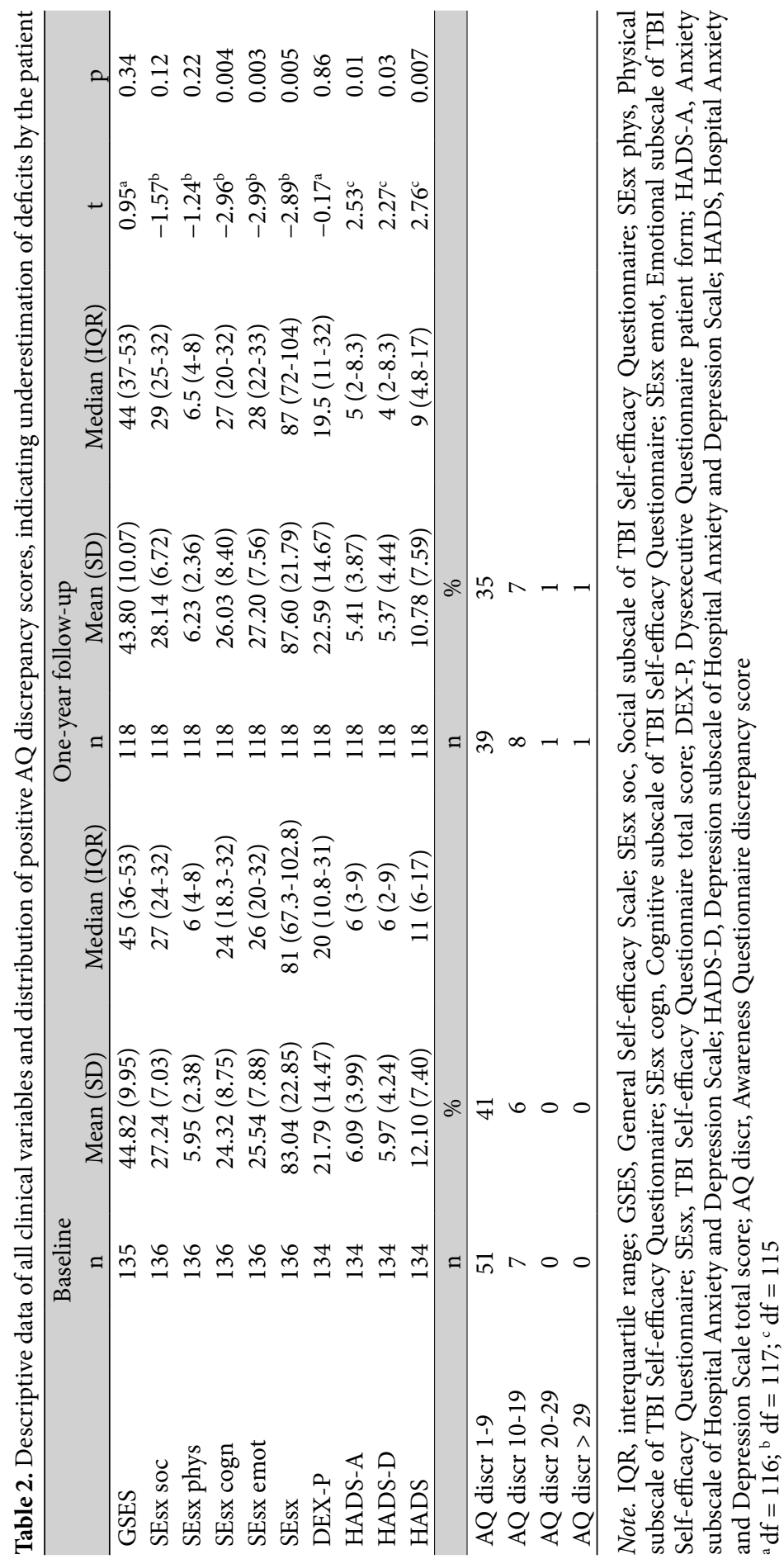


Table 3. Problem types, defined to categorize the stressful situations patients encountered due to their brain injury

\begin{tabular}{lcccc}
\hline & \multicolumn{2}{c}{ Baseline } & \multicolumn{2}{c}{ One-year follow-up } \\
Type of problem & $\mathrm{n}$ & $\%$ & $\mathrm{n}$ & $\%$ \\
\hline Physical & 132 & 32.4 & 111 & 31.4 \\
Cognitive & 161 & 39.5 & 171 & 48.3 \\
Emotional & 18 & 4.4 & 24 & 6.8 \\
Behavioural & 16 & 3.9 & 6 & 1.7 \\
Communication & 42 & 10.3 & 31 & 8.8 \\
Other & 39 & 9.6 & 11 & 3.1 \\
Total problems & 408 & 100.0 & 354 & 100.0 \\
\hline
\end{tabular}

Table 4. CISS scale score ranges and CISS scale fixed scores

\begin{tabular}{lcccc}
\hline & \multicolumn{2}{c}{ Baseline } & \multicolumn{2}{c}{ Follow-up } \\
& Mean & SD & Mean & SD \\
\hline Range CISS-T & 0.95 & 0.52 & 0.96 & 0.54 \\
Range CISS-E & 0.80 & 0.51 & 0.81 & 0.52 \\
Range CISS-A & 0.73 & 0.50 & 0.77 & 0.47 \\
Fixed CISS-T & 12.5 & 4.1 & 12.3 & 4.6 \\
Fixed CISS-E & 7.4 & 5.2 & 6.6 & 5.1 \\
Fixed CISS-A & 9.2 & 5.1 & 8.8 & 5.1 \\
\hline
\end{tabular}

Note. CISS-T, Task scale of the Coping Inventory for Stressful Situations (CISS); CISS-E, CISS Emotion scale; CISS-A, CISS Avoidance scale

\section{Task-oriented coping}

CISS-T scores did not differ significantly over time or over situations. However, patients used more task-oriented coping when faced with cognitive problems than with physical problems $(\mathrm{b}=1.55,95 \% \mathrm{CI} 0.50$ to $2.61, \mathrm{p}=.004)$. From the clinical variables, only GSES scores were significantly associated with CISS-T scores $(b=0.24,95 \%$ CI 0.10 to $0.38, p=.001)$, indicating that reliance on task-oriented coping increased with increasing general self-efficacy. However, differences in self-efficacy did not explain the difference among task-oriented coping with physical versus cognitive problems.

For CISS-T score range, only a significant effect of age was observed $(b=-0.008,95 \%$ CI -0.01 to $-0.002, \mathrm{p}=.013)$, indicating that the variability in the use of task coping decreased modestly with increasing age.

For CISS-T fixed scores, the final model showed a significant effect for DEX-P scores only (b $=0.04,95 \%$ CI 0.0003 to $0.08, \mathrm{p}=.048)$, indicating that the number of task-oriented strategies used consistently in all three situations increased with increasing self-reported executive problems. 


\section{Emotion-oriented coping}

CISS-E scores decreased over time $(b=-2.30,95 \%$ CI -4.12 to $-0.48, \mathrm{p}=.013)$. Emotionoriented coping appeared to be used more often when dealing with behavioural problems compared with physical problems, though differences did not reach statistical significance (b $=1.99,95 \% \mathrm{CI}-0.44$ to $4.42, \mathrm{p}=.11)$. Adding the clinical variables, SEsx scores $(\mathrm{b}=-0.10$, $95 \% \mathrm{CI}-0.17$ to $-0.03, \mathrm{p}=.004)$, DEX-P scores $(\mathrm{b}=0.21,95 \%$ CI 0.10 to $0.31, \mathrm{p}<.001)$ and HADS scores $(\mathrm{b}=0.56,95 \% \mathrm{CI} 0.34$ to $0.77, \mathrm{p}<.001)$ were significantly associated with CISS-E scores, indicating that reliance on emotion-oriented coping decreased with increasing self-efficacy for the management of brain injury-related symptoms and increased with higher levels of emotional distress and self-reported executive problems. CISS-E scores showed a significant association with level of education (high versus low: $b=-7.99,95 \% \mathrm{CI}-12.60$ to $-3.38, \mathrm{p}=.001$ ), indicating that highly educated people made considerably less use of emotion-oriented coping.

CISS-E score range only showed a significant association with SEsx scores $(b=-0.008,95 \%$ $\mathrm{CI}-0.01$ to $-0.005, \mathrm{p}<.001)$, indicating that variability in emotion-oriented coping decreased with increasing self-efficacy for managing brain-injury related symptoms.

CISS-E fixed scores decreased over time $(b=-0.98,95 \% \mathrm{CI}-1.81$ to $-0.15, \mathrm{p}=.02$ ). For the clinical variables, a significant effect of DEX-P scores $(b=0.09,95 \%$ CI 0.04 to $0.14, p=.001)$ and HADS scores $(\mathrm{b}=0.24,95 \%$ CI 0.15 to $0.34, \mathrm{p}<.001)$ was observed. CISS-E fixed scores also showed a significant dose-response effect with level of education (medium versus low: $b$ $=-1.92,95 \% \mathrm{CI}-3.79$ to $-0.05, \mathrm{p}=.04$, high versus low: $\mathrm{b}=-3.04,95 \% \mathrm{CI}-5.00$ to $-1.10, \mathrm{p}=$ $.002)$. Therefore, the number of emotion-oriented strategies used throughout every situation increased with increasing self-reported executive dysfunction and higher emotional distress and decreased with higher education.

\section{Avoidance coping}

CISS-A scores did not differ significantly over time, but showed a significant difference over situations (situation 2 versus $1: \mathrm{b}=-1.21, \mathrm{p}=.002$; situation 3 versus $1: \mathrm{b}=-1.24, \mathrm{p}=.007$ ), indicating intra-individual variability. There was no effect for problem category. Adding the clinical variables, only GSES scores showed a significant association with CISS-A scores $(b=$ $0.20,95 \%$ CI 0.06 to $0.35, \mathrm{p}=.006$ ), indicating that the use of avoidance coping increased with increasing general self-efficacy. A significant association with education (high versus low: $\mathrm{b}=-7.36,95 \% \mathrm{CI}-11.75$ to $-2.96, \mathrm{p}=.001$ ) indicated that, with higher education, the use of avoidance coping decreased substantially. 
No significant effects were found for CISS-A score range. For CISS-A fixed scores, a significant association was observed for level of education, only (high versus low: $b=-3,34,95 \% \mathrm{CI}$ -5.24 to $-1.43, \mathrm{p}=.001$ ), indicating lower consistent reliance on avoidance strategies with higher education.

\section{Discussion}

In this prospective study of a large group of patients over one year after acute disabling brain injury, we tested whether they adapted their coping responses over situations and according to the type of problem encountered. We explored coping variability and consistency and examined whether coping style, variability and consistency were dependent on clinical characteristics.

We found that patients relied on a rather stable set of coping strategies, both over time and across different situations. Contrary to our expectations, the type of problem denoted as most stressful was of limited influence on patients' use of coping styles. Patients only used more task-oriented coping when confronted with cognitive problems compared with physical problems.

In line with previous studies, cognitive problems were the most frequently mentioned cause of major distress. ${ }^{27}$ However, the association between behavioural problems and emotionoriented coping style seems to deserve further research as our analyses were probably underpowered (only $4 \%$ of patients reported behavioural problems). Yet, in patients diagnosed with multiple sclerosis, rheumatoid arthritis or systemic lupus erythematosus, coping responses were not influenced by specific stressor characteristics. ${ }^{11}$

Overall, coping variability (CISS scale score ranges varied from 0.7 to 0.9 ) was small, indicating that patients generally do not make major switches in the frequency of use of strategies over different situations (e.g. from very limited to extensive use). Consistency for task-oriented coping was high (12 of 16 strategies were used in every situation), which is in line with findings of Kendall et al. ${ }^{19}$ Over time, only the use of emotion-oriented coping changed, and it decreased.

Higher self-efficacy in managing brain injury-specific symptoms correlated with lower reliance on emotion-oriented coping and a lower variability in use of emotion-oriented strategies. This stress-buffering effect of self-efficacy is well documented in healthy people ${ }^{28}$ and patients with cancer. ${ }^{29}$ In addition, the association between low self-efficacy and increased use of emotionoriented coping has been reported in other chronic diseases. ${ }^{30,31}$ 
Moreover, as we expected, we found that higher general self-efficacy was associated with higher use of task and avoidance coping. At first glance, the latter association might seem odd, but it must be noted that the CISS avoidance scale contains many items referring to actively seeking social support and distraction, whereas in other coping questionnaires avoidance is frequently associated with a passive, internalizing attitude. Our results suggest that self-efficacy facilitates the use of both restoration-oriented behaviour (task coping) and loss-oriented coping (avoidance). Achieving maximal restoration of function and adjusting to alterations and losses are simultaneous processes involved in the adaptation process after brain injury. ${ }^{32}$ The association between active coping and high self-efficacy has been documented in chronically ill people ${ }^{33}$ and in the healthy population. ${ }^{34}$

Patients reporting greater executive dysfunction used more emotion-oriented coping. Furthermore, in accordance with our hypothesis, greater self-reported executive problems correlated with higher coping consistency for task-oriented and emotion-oriented coping. The invariable deployment of a greater amount of task and emotion strategies throughout situations might reflect problems in effective strategy selection.

A low level of education was consistently related to higher reliance on emotion-oriented and avoidance coping and to higher consistency in use of both styles, mirroring earlier studies showing associations between non-productive coping ${ }^{2}$, social-emotional coping ${ }^{35}$ and low level of education.

Our findings may have implications for clinical practice. To optimize adjustment to the diverse consequences of acquired brain injury, we suggest training patients, especially those who experience problems in executive functioning, to use a small, but effective, set of coping strategies. Furthermore, these findings suggest that therapeutic attempts to enhance selfefficacy during rehabilitation would be appropriate, as this seems to promote active coping. Cognitive behavioural therapy has shown to be effective in increasing the ability to implement adaptive coping strategies ${ }^{36}$ and in improving coping self-efficacy. ${ }^{37}$

In addition, according to Bandura ${ }^{7}$, self-efficacy beliefs are not only developed through direct mastery experiences, but also by vicarious experiences, verbal persuasions and changes in physiological and affective states from which people judge their capabilities. When training skills and strategies, one could think of adding elements such as referential comparison with significant others, positive feedback, reward and providing control over interfering emotions, e.g. stress, anxiety and fatigue, or making use of behavioural experiments. 
This study has several strengths. It is the first study to examine coping flexibility related to real life problems in acquired brain injury using a prospective design. We took multiple approaches to measure coping flexibility, since there is no standardized method, and in our analyses, we controlled for emotional distress. We did not limit our inclusion criteria to a single diagnosis as it has been demonstrated repeatedly that severity and type of brain injury did not influence coping. ${ }^{2,38}$ The fact that our study sample is a mixed composition of patients with acquired brain injury due to stroke, traumatic brain injury, and anoxic encephalopathy, among other causes, enhances the generalizability of our results. Loss to observation was small (13\% of cases) and did not lead to selection bias.

The limitations of the present study should also be acknowledged. As we did not compare our results to a healthy control sample, we cannot determine whether coping variability or consistency in acquired brain injury differs from the healthy population. We did not formally test the executive performance of the subjects. However, in acquired brain injury patients with prominent neuropsychiatric symptoms coping was found to be associated with subjective executive functioning, but not with objective executive performance. ${ }^{39}$ Despite a relatively large sample size, small subgroup sizes might have influenced detection of associations with less frequently mentioned problem categories and self-awareness. According to the criteria by Sherer et al. ${ }^{23}$ only $2 \%$ of our patients at follow-up could be categorized as having moderate and severe impaired self-awareness. The small number of traumatic brain injury patients in our sample ( $8 \%)$ might explain this. In traumatic brain injury, awareness deficits occur more frequently due to the higher incidence of frontal lobe damage. ${ }^{40}$ To measure self-efficacy for managing brain injury-specific symptoms we used the SEsx, which, to date, is only validated for use in traumatic brain injury. ${ }^{6}$

In conclusion, this study showed that patients with acquired brain injury rely on a rather defined and stable set of coping options across situations and time. Coping style is only modestly influenced by problem type. Self-efficacy enhances task and avoidance coping, which are both needed in adapting to the consequences of acquired brain injury. Subjective executive dysfunction increases consistency in task and emotion strategy use, which might suggest problems in effective strategy selection and could be target for rehabilitation therapy. 


\section{References}

1. Folkman S, Lazarus RS, Gruen RJ, DeLongis A. Appraisal, coping, health status, and psychological symptoms. J Pers Soc Psychol. 1986;50(3):571-579.

2. Anson K, Ponsford J. Coping and emotional adjustment following traumatic brain injury. J Head Trauma Rehabil. 2006;21(3):248-259.

3. Wolters G, Stapert S, Brands I, van Heugten C. Coping following acquired brain injury: predictors and correlates. J Head Trauma Rehabil. 2011;26(2):150-157.

4. Dawson DR, Schwartz ML, Winocur G, Stuss DT. Return to productivity following traumatic brain injury: cognitive, psychological, physical, spiritual, and environmental correlates. Disabil Rehabil. 2007;29(4):301-313.

5. Krpan KM, Stuss DT, Anderson ND. Coping behaviour following traumatic brain injury: what makes a planner plan and an avoider avoid? Brain Inj. 2011;25(10):989-996.

6. Cicerone KD, Azulay J. Perceived self-efficacy and life satisfaction after traumatic brain injury. J Head Trauma Rehabil. 2007;22(5):257-266.

7. Bandura A. Self-efficacy : the exercise of control. New York: W.H. Freeman and Company; 1997.

8. Trouillet R, Gana K, Lourel M, Fort I. Predictive value of age for coping: the role of self-efficacy, social support satisfaction and perceived stress. Aging Ment Health. 2009;13(3):357-366.

9. Pearlin LI, Schooler C. The structure of coping. J Health Soc Behav. 1978;19(1):2-21.

10. Lester N, Smart L, Baum A. Measuring coping flexibility. Psychol Health. 1994;9(6):409 - 424.

11. Schwartz CE, Peng CK, Lester N, Daltroy L, Goldberger AL. Self-reported coping behavior in health and disease: assessment with a card sort game. Behav Med. 1998(24):41-44.

12. Vriezekolk JE, Eijsbouts AM, van Lankveld WG, Beenackers H, Geenen R, van den Ende CH. An acceptance-oriented cognitive-behavioral therapy in multimodal rehabilitation: a prepost test evaluation in highly distressed patients with rheumatic diseases. Patient Educ Couns. 2013;91(3):357-363.

13. Moore AD, Stambrook M, Peters LC. Coping strategies and adjustment after closed-head injury: a cluster analytical approach. Brain Inj. 1989;3(2):171-175.

14. Moore AD, Stambrook M. Cognitive moderators of outcome following traumatic brain injury: a conceptual model and implications for rehabilitation. Brain Inj. 1995;9(2):109-130.

15. Medley AR, Powell T, Worthington A, Chohan G, Jones C. Brain injury beliefs, self-awareness, and coping: a preliminary cluster analytic study based within the self-regulatory model. Neuropsychol Rehabil. 2010;20(6):899-921.

16. Schwartz CE, Daltroy LH. Learning from unreliability: the importance of inconsistency in coping dynamics. Soc Sci Med. 1999;48(5):619-631.

17. Endler NS, Parker JDA. Coping Inventory for Stressful Situations (CISS): manual. Toronto: MultiHealth Systems; 1990.

18. Brands IM, Köhler S, Stapert SZ, Wade DT, Van Heugten CM. Psychometric properties of the Coping Inventory for Stressful Situations (CISS) in patients with acquired brain injury. Psychol Assess. 2014;26(3):848-856.

19. Kendall E, Shum D, Lack B, Bull S, Fee C. Coping following traumatic brain injury: the need for contextually sensitive assessment. Brain Impair. 2001;2(2):81-96.

20. Bosscher RJ, Smit JH, Kempen GI. Expectations of general self-efficacy in elderly persons: investigating psychometric charachteristics of the General Self-Efficacy Scale. Ned Tijdschr Psychol. 1997;52:239-248.

21. Sherer MM. The Self-efficacy Scale: construction and validation. Psychol Rep. 1982;51(2):663-671. 
22. Sherer M, Bergloff P, Boake C, High W, Levin E. The Awareness Questionnaire: factor structure and internal consistency. Brain Inj. 1998;12(1):63-68.

23. Sherer M, Hart T, Nick TG. Measurement of impaired self-awareness after traumatic brain injury: a comparison of the patient competency rating scale at the awareness questionnaire. Brain Inj. 2003;17(1):25-37.

24. Burgess PW, Alderman N, Evans J, Emslie H, Wilson BA. The ecological validity of tests of executive function. J Int Neuropsychol Soc. 1998;4(6):547-558

25. Zigmond AS, Snaith RP. The Hospital Anxiety and Depression Scale. Acta Psychiatr Scand. 1983;67(6):361-370.

26. De Bie SE. Standaardvragen 1987: Voorstellen voor uniformering van vraagstellingen naar achtergrondkenmerken en interviews (Standard questions 1987: Proposal for uniformization of questions regarding background variables and interviews). Leiden: Leiden University Press; 1987.

27. Dikmen SS, Machamer JE, Powell JM, Temkin NR. Outcome 3 to 5 years after moderate to severe traumatic brain injury. Arch Phys Med Rehabil. 2003;84(10):1449-1457.

28. Prati G, Pietrantoni L, Cicognani E. Self-efficacy moderates the relationship between stress appraisal and quality of life among rescue workers. Anxiety Stress Coping. 2009;23(4):463-470.

29. Deno M, Tashiro M, Miyashita M, et al. The mediating effects of social support and self-efficacy on the relationship between social distress and emotional distress in head and neck cancer outpatients with facial disfigurement. Psychooncology. 2012;21(2):144-152.

30. Kristofferzon M-L, Lindqvist R, Nilsson A. Relationships between coping, coping resources and quality of life in patients with chronic illness: a pilot study. Scand J Caring Sci. 2011;25(3):476-483.

31. Hesselink AE, Penninx BW, Schlösser MA, et al. The role of coping resources and coping style in quality of life of patients with asthma or COPD. Qual Life Res. 2004;13(2):509-518.

32. Brands IM, Wade DT, Stapert SZ, van Heugten CM. The adaptation process following acute onset disability: an interactive two-dimensional approach applied to acquired brain injury. Clin Rehabil. 2012;26(9):840-852.

33. Miller C, Cronan T. The effects of coping style and self-efficacy on health status and health care costs. Anxiety Stress Coping. 1998;11(4):311-325.

34. Devonport TJ. Relationships between self-efficacy, coping and student retention Soc Behav Pers. 2006;34(2):127-138.

35. Tomberg T, Toomela A, Ennok M, Tikk A. Changes in coping strategies, social support, optimism and health-related quality of life following traumatic brain injury: a longitudinal study. Brain Inj. 2007;21(5):479-488.

36. Anson K, Ponsford J. Evaluation of a coping skills group following traumatic brain injury. Brain Inj. 2006;20(2):167-178.

37. Backhaus SL, Ibarra SL, Klyce D, Trexler LE, Malec JF. Brain injury coping skills group: a preventative intervention for patients with brain injury and their caregivers. Arch Phys Med Rehabil. 2010;91(6):840-848.

38. Herrmann M, Curio N, Petz T, et al. Coping with illness after brain diseases: a comparison between patients with malignant brain tumors, stroke, Parkinson's disease and traumatic brain injury. Disabil Rehabil. 2000;22(12):539-546.

39. Wolters Gregório G, Smeets SM, Ponds RW, Van Heugten C. Passive coping is maladaptive in patients with psychiatric and behavioural problems due to acquired brain injury. Brain Impair. 2012;13:167-168.

40. Stuss DT. Adult clinical neuropsychology: lessons from studies of the frontal lobes. Annu Rev Psychol. 2002;53(1):401- 433. 



\section{Chapter 6}

\section{Influence of self-efficacy and coping on quality of life}

and social participation after acquired brain injury:

a one-year follow-up study

Published in Archives of Physical Medicine and Rehabilitation as:

Brands I, Köhler S, Stapert S, Wade D, van Heugten C. Influence of self-efficacy and coping on quality of life and social participation after acquired brain injury: a one-year follow-up study. Archives of Physical Medicine and Rehabilitation. 2014 Jun 25. [Epub ahead of print] 


\begin{abstract}
Objective: To investigate the relationships linking self-efficacy and coping to quality of life and social participation and to examine what effect self-efficacy, changes in self-efficacy, and coping style have on long-term quality of life and social participation.
\end{abstract}

Design: Prospective clinical cohort study.

Setting: General hospitals, rehabilitation centres.

Participants: Patients with newly acquired brain injury $(\mathrm{N}=148)$ were assessed at baseline (start outpatient rehabilitation or discharge hospital/inpatient rehabilitation; mean time since injury $=15$ weeks) and one year later (mean time since injury $=67$ weeks).

Interventions: Not applicable.

Main outcome measures: Quality of life was measured with the EQ-5D (EQ-5D index and EQ VAS) and the Life Satisfaction Questionnaire (liSat-9), social participation with the modified Frenchay Activities Index (Modi-FAI), coping with the Coping Inventory for Stressful Situations (CISS), self-efficacy with the TBI Self-efficacy Questionnaire (SEsx).

Results: At baseline, self-efficacy moderated the effect of emotion-oriented coping on the EQ$5 \mathrm{D}$ index and of avoidance coping on the EQ VAS. Self-efficacy mediated the relation between emotion-oriented coping and LiSat-9. An increase in self-efficacy over time predicted better scores on the EQ-5D index $(\beta=0.30)$, the EQ VAS $(\beta=0.49)$, and the LiSat-9 $(\beta=0.44)$ at follow-up. In addition, higher initial self-efficacy $(\beta=0.40)$ predicted higher LiSat-9 scores at follow-up; higher initial emotion-oriented coping $(\beta=-0.23)$ predicted lower EQ VAS scores at follow-up. Higher Modi-FAI scores at follow-up were predicted by higher self-efficacy $(\beta=$ $0.19)$ and higher task-oriented coping $(\beta=0.14)$ at baseline (combined $\left.\mathrm{R}^{2}=5.1 \%\right)$.

Conclusion: Self-efficacy and coping predict long-term quality of life but seem less important in predicting long-term social participation. High self-efficacy protects against the negative effect of emotion-oriented coping. Enhancing self-efficacy in the early stage after acquired brain injury may have beneficial long-term effects. 


\section{Introduction}

Self-efficacy and coping may play an important role in the process of adaptation to the consequences of acquired brain injury (ABI) and regaining quality of life. ${ }^{1}$ Self-efficacy refers to the belief in one's ability to achieve goals. ${ }^{2}$ Efficacy beliefs influence the activities people choose to engage in, the level of effort they spend and their perseverance in the face of difficulties. ${ }^{2}$ Self-efficacy beliefs are domain-specific but various experiences of success and failure in different domains of functioning may generate a generalized belief of self-efficacy.

As a domain-oriented concept, higher self-efficacy in maintaining balance has been associated with improved activities of daily living performance, ${ }^{3}$, better walking ${ }^{4}$ and less falling. ${ }^{5}$ In patients with traumatic brain injury (TBI), higher self-efficacy for the management of specific traumatic brain injury-related symptoms, such as cognitive, physical, emotional and social problems, was related to higher quality of life. ${ }^{6}$

As a general concept, higher general self-efficacy has been related to better quality of life and social participation in traumatic brain injury.-9 However, because all studies were conducted cross-sectionally in the chronic stage after traumatic brain injury, one cannot determine whether self-efficacy in the early stage after brain injury is predictive for better long-term quality of life and social participation. High general self-efficacy has been associated with higher use of active and problem-focused coping in acquired brain injury and healthy persons. ${ }^{10-12}$ In chronic diseases, the relation between low self-efficacy and increased use of emotion-oriented coping is well documented. ${ }^{13,14}$

The relationships between coping and self-efficacy and their relationship to psychosocial outcome have not been studied yet in acquired brain injury. Self-efficacy might influence the relation between coping and psychosocial outcome in different ways. On the one hand, the strength of the effect of coping on psychosocial outcome might be different for patients with high versus low self-efficacy. High self-efficacy may act as a buffer and protect against the negative effect of passive, emotion-oriented coping styles on quality of life, ${ }^{15-18}$ whereas this protective effect might be absent when self-efficacy is low. This is called effect moderation. On the other hand, successful coping experiences might increase a patient's self-efficacy, which might, in turn, lead to better outcome. This is called effect mediation.

Therefore, the objectives of the present study were (1) to explore how self-efficacy for managing brain injury-specific symptoms contributes to the effect of coping style on quality of life and social participation in patients with acquired brain injury and (2) to investigate the influence of baseline self-efficacy, changes in self-efficacy and baseline coping style on long-term quality of life and social participation. 


\section{Method}

\section{Patients}

Between January 2011 and January 2012, rehabilitation physicians and neurologists of the participating institutes (two rehabilitation centres and two hospitals in the South of the Netherlands) recruited patients eligible for participation in this study. Patients were included consecutively upon return to the home environment, either at the start of outpatient neurorehabilitation or at discharge home from hospital or inpatient neurorehabilitation.

Inclusion criteria were: (1) age $\geq 18$ years; (2) newly acquired, non-progressive brain injury of any aetiology confirmed by neurological and/or neuroimaging data; (3) for patients recruited at the start of outpatient rehabilitation maximum time since injury was 4 months.

Exclusion criteria were: (1) any premorbid progressive brain disease; (2) insufficient command of the Dutch language; (3) inability to complete questionnaires based on clinical judgement (aphasia, severe cognitive impairment).

The medical ethics committees of Maastricht University Medical Centre and all participating hospitals and rehabilitation centres approved this study. All patients gave written informed consent.

\section{Measures}

To measure self-efficacy, we used the 13-item TBI Self-efficacy Questionnaire (SEsx) ${ }^{6}$, which contains four subscales (Social, Physical, Cognitive, Emotional) measuring self-efficacy for obtaining help and emotional support, managing physical symptoms, managing and compensating for cognitive symptoms, and managing emotional symptoms, respectively. Items are rated on a 10 -point scale $(1=$ not at all confident to $10=$ totally confident). Subscale scores are summed to a total score. Higher scores indicate greater self-efficacy. We carried out a formal translation procedure to obtain a Dutch version. Using our data, we found good internal reliability (Cronbach's a .81-.95).

Basic coping strategies were measured using the Coping Inventory for Stressful Situations (CISS). ${ }^{19}$ We used the Dutch validated version. ${ }^{20}$ The 48 -item CISS has three scales: Taskoriented (CISS-T), Emotion-oriented (CISS-E) and Avoidance (CISS-A). The Avoidance scale contains two subscales: Social Diversion and Distraction. Item scores $(1=$ not at all to 5 = very much) are summed per scale; higher scores indicate a greater use of that particular coping style. Psychometric properties of the CISS for use in patients with acquired brain injury have been shown to be good. ${ }^{21}$ Because confirmatory factor analysis showed a threefactor structure (CISS-T, CISS-E, CISS-A), ${ }^{21}$ we did not use the avoidance subscales. 
The 9-item Life Satisfaction Questionnaire (LiSat-9) was used as a generic instrument for measuring quality of life. ${ }^{22}$ We used the Dutch version. ${ }^{23,24}$ One public domain and eight specific fields are assessed. The mean of all item scores $(1=$ very unsatisfactory to $6=$ very satisfactory) was calculated. Higher scores indicate better general quality of life. Using our data, we found good internal reliability (Cronbach's $\alpha=.83$ ). To measure health-related quality of life, the EQ-5D ${ }^{25,26}$ was used, which consists of the 5-item EQ-5D index and a visual analogue scale (EQ VAS). The Dutch version has good psychometric properties. ${ }^{27}$ The five EQ-5D index items are summarized into one weighted overall score ranging from 0 to 1.00 (death to full health). The EQ VAS ranges from 0 to 100 (worst to best imaginable health state).

Social participation was measured with the modified Frenchay Activities Index (ModiFAI). The original FAI is a 15-item measure developed for patients with stroke, assessing the frequency of performance of activities such as housekeeping, recreation, transportation, and work during the last 3 to 6 months. ${ }^{28}$ We used the Dutch adapted version, Modi-FAI, which covers a more circumscribed period spanning the past four weeks with answering categories adapted correspondingly. ${ }^{29}$ Psychometric properties have been shown to be good. ${ }^{29,30}$ Items are scored on a 4-point scale. Higher scores indicate a higher level of participation (maximum score $=45)$.

Data on age, sex and diagnosis were extracted from the medical files. Level of educational attainment was asked during baseline interview and classified according to a three-level system often used in the Netherlands: primary education (low), junior vocational training (medium) and senior vocational or academic training (high), corresponding to $8.6 \pm 1.9,11.4$ \pm 2.5 , and $15.2 \pm 3.3$ years of full-time education, respectively. ${ }^{31}$ 


\section{Procedure}

After inclusion, patients were contacted. A telephone interview with the first author or research assistant was planned when the patient had been at home for at least 2 to 4 weeks. During this interview the Modi-FAI was completed and patients were asked about the three most stressful situations that they had encountered as a consequence of their brain injury during the previous two weeks. For each of the three stressful situations, a separate coping questionnaire (CISS) was prepared in which the instruction for completion was made specific: 'How much do you engage in these types of activities when you are confronted with...(one of three situations)?'. After the interview, each patient received three situation-specific coping questionnaires (CISS) by post along with the questionnaires about self-efficacy (SEsx) and quality of life (EQ-5D and LiSat-9) to complete via self-report.

One year ( \pm 4 weeks) after inclusion, patients were contacted again to plan the telephone interview. During this interview the Modi-FAI was completed and the patient again identified three brain injury-related stressful situations of importance at that time. Afterward, the same set of questionnaires (CISS, SEsx, EQ-5D, LiSat-9) was sent to complete via self-report.

If a participant requested a live interview or asked for assistance to complete the questionnaires, a face-to-face appointment with the first author or research assistant was arranged (baseline: $\mathrm{n}=26(18 \%)$, follow-up: $\mathrm{n}=26(18 \%))$.

\section{Data analysis}

The CISS completed for the first stressful situation was used in all analyses reported in this article. CISS results for the second and third situation (collected for a different research purpose) were not included to avoid problems of intercorrelation. Using paired sample t-tests, baseline and follow-up scores of all outcome variables, self-efficacy, and coping style were compared. EQ-5D scores of our study sample were compared with the EQ-5D scores of the general Dutch population (EQ-5D index $=0.843$, EQ VAS $=81.36)^{26,32}$ using one-sample t-tests.

To answer our first research question about the relationships between baseline coping style and self-efficacy and their relationship to baseline quality of life and participation, we first selected from the clinical variables (SEsx, CISS-T, CISS-E, CISS-A) those variables that had an independent effect on each outcome variable (EQ-5D index, EQ VAS, LiSat-9 and Modi-FAI). Therefore, we conducted four hierarchical multiple regression analyses. After entering demographic variables, clinical variables were tested separately and those showing associations at a p-value $<.10$ were retained. Then, we tested whether the relation between coping and outcome was dependent on the level of self-efficacy (moderation). For each 
outcome variable, demographic variables, retained clinical variables, and their respective interaction terms (SEsx x coping style) were entered into the regression model. Evidence for moderation was indicated by a significant interaction term. In the absence of moderation, we tested whether self-efficacy mediated the relationship between coping style and outcome variable using structural equation modelling (SEM). All the variables that were present in the multivariable regression model to test for moderation were now included into the SEM model (except the respective non-significant interaction terms). Evidence for mediation was indicated by a significant indirect pathway between coping style and outcome variable.

To answer our second research question whether baseline self-efficacy (SEsx), changes in self-efficacy ( $\triangle$ SEsx), and baseline coping style (CISS- T, CISS-E, CISS-A) were predictive for quality of life and social participation at follow-up, four hierarchical multiple regressions were carried out with EQ-5D index, EQ VAS, LiSat-9 and Modi-FAI as outcome variables. Because we had no prespecified prediction hypothesis, we used a stepwise approach to enter the independent variables into the regression models. First, all demographic variables and the baseline scores of the respective outcome variables were entered. Second, the predictors were tested separately, and those showing associations at a p-value $<.10$ were retained in the full multivariable model. Finally, in a backward selection procedure, any clinical variable in the full multivariable model that was not significant at a p-value $<.05$ was manually removed. All analyses were carried out in Stata 12.1, using two-sided hypothesis testing with an alpha-level of .05 .

\section{Results}

Initially 190 patients were approached, of whom 37 refused to participate. Of the 153 patients willing to participate, we excluded 5 patients because of non-matching inclusion criteria. Overall, 148 patients (78 \%) underwent baseline assessment, of whom 143 participated in follow-up assessment. Too much burden was the reason for all dropouts. Table 1 presents the demographic and injury-related characteristics of the sample at baseline. At follow-up, mean (SD) time since injury was 67 (9.12) weeks. 
Table 1. Patient characteristics at baseline $(\mathrm{N}=148)$

\begin{tabular}{llccc}
\hline & & Mean & SD & Range \\
\hline Age (years) & & 56 & 12.3 & $19-84$ \\
Time since injury (weeks) & & 15.1 & 9.6 & $2.0-43.7$ \\
\hline & & $\mathrm{n}$ & $\%$ & \\
\hline Sex (male) & & 95 & 64.2 & \\
Educational level & Low & 41 & 27.7 & \\
& Medium & 61 & 41.2 & \\
Type of lesion & High & 46 & 31.1 & \\
& Infarction & 98 & 66.2 & \\
& SAH & 10 & 6.8 & \\
& ICH & 9 & 6.1 & \\
& Diffuse vascular lesions & 2 & 1.4 & \\
& TBI & 14 & 9.5 & \\
& Anoxic encephalopathy & 3 & 2.0 & \\
& Tumour benign & 5 & 3.4 & \\
& Meningitis/encephalitis & 1 & 0.7 & \\
& Other & 6 & 4.1 & \\
\hline
\end{tabular}

Note. SAH, subarachnoid haemorrhage; ICH, intracerebral haemorrhage; TBI, traumatic brain injury

All clinical variables are described in Table 2. Compared with the general population in the Netherlands, our study sample showed for both measurements significantly lower EQ-5D index scores $\left(\mathrm{t}_{147}=-6.07, \mathrm{p}<.001\right.$ and $\mathrm{t}_{142}=-4.02, \mathrm{p}<.001$, respectively) and lower EQ VAS scores $\left(\mathrm{t}_{147}=-11.16, \mathrm{p}<.001\right.$ and $\mathrm{t}_{141}=-7.85, \mathrm{p}<.001$, respectively).

Table 2. Descriptive data of all clinical variables

\begin{tabular}{lcccccc}
\hline & \multicolumn{2}{c}{ Baseline } & \multicolumn{2}{c}{ 1-year follow-up } & & \\
& Mean & SD & Mean & SD & t & $\mathrm{p}$ \\
\hline SEsx & 83.98 & 22.37 & 87.40 & 21.29 & 2.14 & $.013^{*}$ \\
CISS-T & 49.98 & 10.69 & 49.35 & 12.39 & -0.12 & .91 \\
CISS-E & 34.75 & 12.93 & 33.56 & 11.68 & -1.48 & .14 \\
CISS-A & 39.20 & 12.21 & 41.09 & 12.10 & 1.58 & .12 \\
Modi-FAI & 19.21 & 6.97 & 27.27 & 6.92 & 15.16 & $<.001^{*}$ \\
LiSat-9 & 4.49 & 0.73 & 4.54 & 0.85 & 0.85 & .40 \\
EQ-5D index & 0.74 & 0.20 & 0.78 & 0.19 & 2.51 & $.013^{*}$ \\
EQ VAS & 66.37 & 16.35 & 71.01 & 15.72 & 3.32 & $.001^{*}$ \\
\hline
\end{tabular}

Note. SEsx, TBI Self-efficacy Questionnaire total score; CISS-T, Coping Inventory for Stressful Situations Task-oriented scale; CISS-E, Coping Inventory for Stressful Situations Emotion-oriented scale; CISS-A, Coping Inventory for Stressful Situations Avoidance scale; Modi-FAI, modified Frenchay Activities Index; LiSat-9, Life Satisfaction Questionnaire; VAS, visual analogue scale

* Associations remaining significant after Benjamini-Hochberg correction for multiple comparisons $(.013<.025, .013<.01875, .001<.0125, .0009<.00625)$ 


\section{Relationships linking self-efficacy and coping to outcome at baseline}

SEsx scores moderated the relation between EQ-5D index scores and CISS-E scores, as indicated by a significant interaction term (Table 3 ). This means that the effect of emotionoriented coping on quality of life diminishes with increasing levels of self-efficacy (Figure 1).

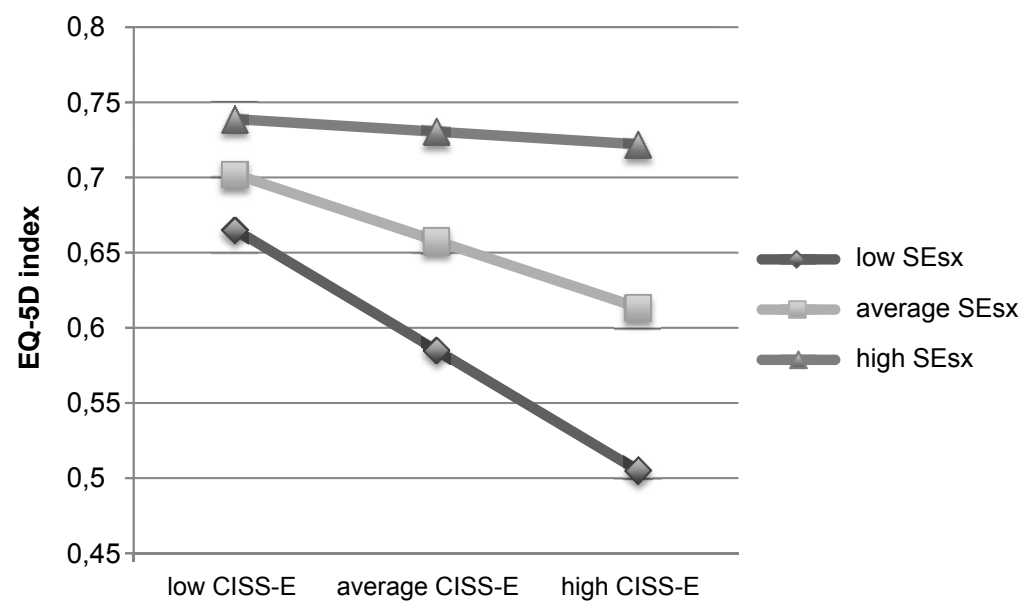

Figure 1. The moderating effect of self-efficacy (SEsx) on the relation between emotion-oriented coping (CISS-E) and EQ-5D index

Note. Low represents scores $-1 \mathrm{SD}$, average represents mean scores, high represents scores $+1 \mathrm{SD}$

SEsx, TBI Self-efficacy Questionnaire total score; CISS-E, Coping Inventory for Stressful Situations Emotion-oriented scale

For EQ VAS scores, the multivariable regression model (Table 3) showed that SEsx scores moderated both the relation between CISS-E and EQ VAS and the relation between CISS-A and EQ VAS, as indicated by significant interaction terms. This means that the contribution of avoidance coping to EQ VAS scores reduces with increasing levels of self-efficacy (Figure 2). Furthermore, the effect of emotion-oriented coping on quality of life decreases with increasing levels of self-efficacy (Figure 3). 
Table 3. Hierarchical regressions of the association between clinical variables and quality of life and social participation at baseline

\begin{tabular}{lcccccccc}
\hline & \multicolumn{5}{c}{ Crude $^{2}$ model $^{\mathrm{a}}$} & \multicolumn{5}{c}{${\text { Multivariable } \text { model }^{\mathrm{b}}}$} \\
& $\mathrm{B}$ & $\mathrm{SE}$ & $\beta$ & $\mathrm{p}$ & $\mathrm{B}$ & $\mathrm{SE}$ & $\beta$ & $\mathrm{p}$ \\
\hline EQ-5D index & & & & & & & & \\
CISS-T & -0.0003 & 0.0017 & -0.01 & .87 & & & & \\
CISS-A & 0.0003 & 0.0015 & 0.02 & .82 & & & & \\
SEsx & 0.0045 & 0.0007 & 0.48 & $<.001$ & -0.001177 & 0.0016 & -0.12 & .52 \\
CISS-E & -0.0073 & 0.0013 & -0.46 & $<.001$ & -0.0138 & 0.0035 & -0.87 & $<.001$ \\
SEsx x CISS-E & & & & & 0.000124 & 0.00004 & 0.55 & .003 \\
EQ VAS & & & & & & & & \\
CISS-T & 0.21 & 0.13 & 0.13 & 0.13 & & & & \\
SEsx & 0.46 & 0.05 & 0.63 & $<.001$ & 0.58 & 0.17 & 0.80 & .001 \\
CISS-E & -0.53 & 0.11 & -0.42 & $<.001$ & -0.69 & 0.26 & -0.55 & .008 \\
CISS-A & 0.23 & 0.12 & 0.17 & 0.056 & 1.20 & 0.36 & 0.89 & .001 \\
SEsx x CISS-E & & & & & 0.0065 & 0.003 & 0.36 & .038 \\
SEsx x CISS-A & & & & & -0.011 & 0.004 & -0.90 & .007 \\
LiSat-9 & & & & & & & & \\
CISS-T & 0.0045 & 0.006 & 0.07 & .46 & & & & \\
CISS-A & 0.00058 & 0.005 & 0.01 & .91 & & & & \\
SEsx & 0.018 & 0.002 & 0.56 & $<.001$ & 0.0122 & 0.006 & 0.38 & .042 \\
CISS-E & -0.022 & 0.005 & -0.39 & $<.001$ & -0.0155 & 0.0127 & -0.27 & .23 \\
SEsx x CISS-E & & & & & 0.00013 & 0.00015 & 0.16 & .40 \\
Modi-FAI & & & & & & & & \\
CISS-T & 0.073 & 0.053 & 0.11 & .17 & & & & \\
CISS-E & -0.056 & 0.046 & -0.11 & .23 & & & & \\
SEsx & 0.055 & 0.026 & 0.18 & .038 & 0.085 & 0.079 & 0.28 & .29 \\
CISS-A & 0.105 & 0.047 & 0.19 & .028 & 0.18 & 0.19 & 0.32 & .33 \\
SEsx x CISS-A & & & & & -0.00088 & 0.0021 & -0.17 & .68 \\
\hline
\end{tabular}

Note. B, unstandardized regression coefficient; SE, standard error; $\beta$, standardized regression coefficient; SEsx, TBI Self-efficacy Questionnaire total score; CISS-T, Coping Inventory for Stressful Situations Task-oriented scale; CISS-E, Coping Inventory for Stressful Situations Emotion-oriented scale; CISS-A, Coping Inventory for Stressful Situations Avoidance scale; Modi-FAI, Modified Frenchay Activities Index; LiSat-9, Life Satisfaction Questionnaire; VAS, visual analogue scale

a based on separate models for each clinical variable adjusted for demographic variables

${ }^{b}$ based on the model in which all clinical variables with associations at a p-value $<.10$, when tested separately, were retained together with their respective interaction terms to test for effect moderation 


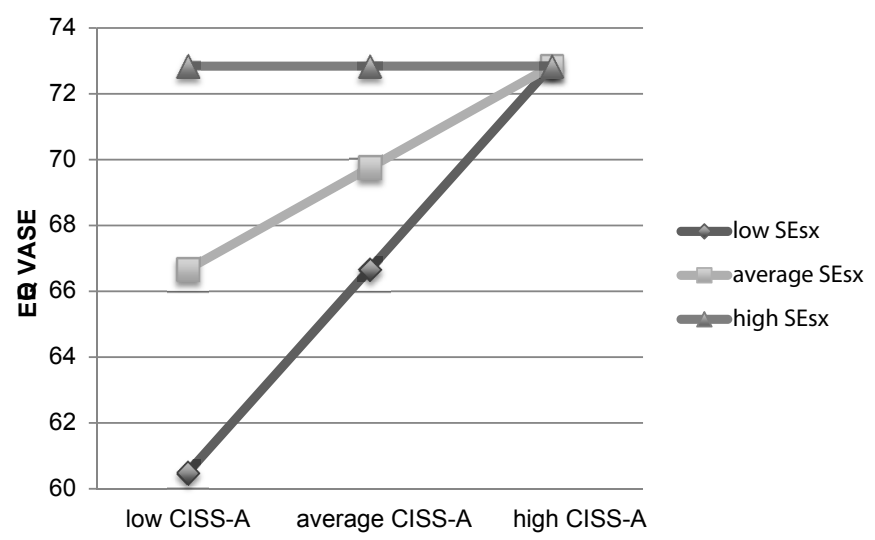

Figure 2. The moderating effect of self-efficacy (SEsx) on the relation between avoidance coping (CISS-A) and EQ VAS

Note. Low represents scores $-1 \mathrm{SD}$, average represents mean scores, high represents scores $+1 \mathrm{SD}$ SEsx, TBI Self-efficacy Questionnaire total score; CISS-A, Coping Inventory for Stressful Situations Avoidance scale; VAS, visual analogue scale

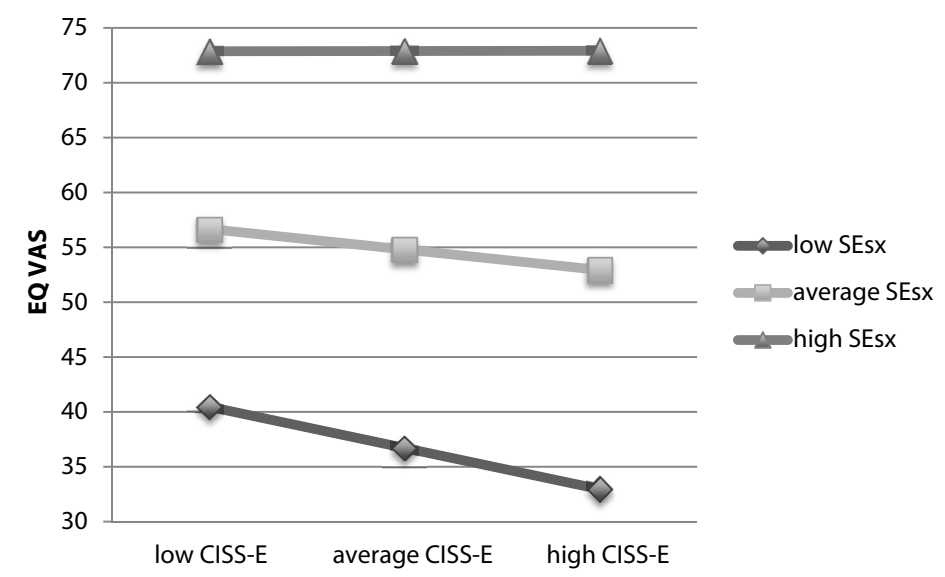

Figure 3. The moderating effect of self-efficacy (SEsx) on the relation between emotion-oriented coping (CISS-E) and EQ VAS

Note. Low represents scores $-1 \mathrm{SD}$, average represents mean scores, high represents scores $+1 \mathrm{SD}$

SEsx, TBI Self-efficacy Questionnaire total score; CISS-E, Coping Inventory for Stressful Situations Emotion-oriented scale; VAS, visual analogue scale

In contrast, SEsx scores did not moderate the relation between CISS-E and LiSat-9 scores, as indicated by a non-significant interaction term (Table 3). Therefore, the effect of emotionoriented coping on LiSat-9 did not differ between those with high self-efficacy and those with low self-efficacy. The structural equation model (Figure 4), however, revealed that the effect of CISS-E on LiSat-9 scores was completely mediated by its association with SEsx scores, 
as indicated by a non-significant direct effect of CISS-E on LiSat-9 scores and a significant indirect association between CISS-E and LiSat-9 scores $(\beta=-.30, \mathrm{p}<.001)$.

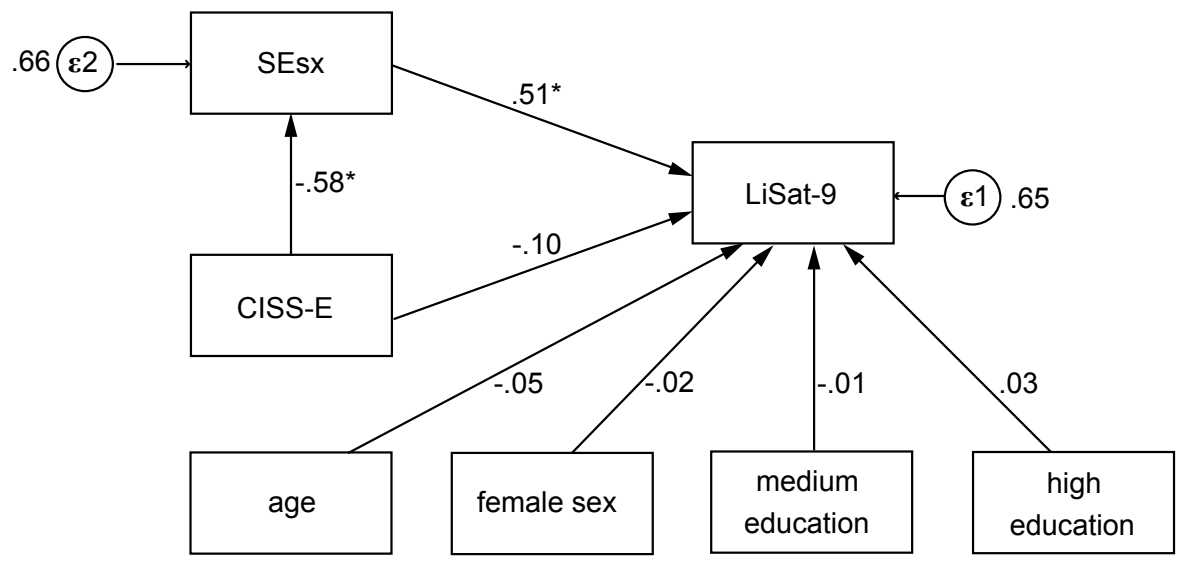

Figure 4. The mediating effect of self-efficacy (SEsx total score) on the relation between emotionoriented coping (CISS-E) and LiSat-9 scores: final model showing standardized regression coefficients for direct paths

Note. $\varepsilon$, error variance; ${ }^{\star} \mathrm{p}<.001$

SEsx, TBI Self-efficacy Questionnaire total score; CISS-E, Coping Inventory for Stressful Situations Emotion-oriented scale; LiSat-9, Life Satisfaction Questionnaire

For baseline Modi-FAI scores, a significant effect of CISS-A scores $(\beta=.19, \mathrm{p}=.025)$ and SEsx scores $(\beta=.18, \mathrm{p}=.037)$ was observed, next to an effect of sex (female versus male: $\beta=.32, \mathrm{p}<.001$ ). The interaction term (CISS-A x SEsx) was non-significant, indicating absence of moderation (Table 3). Furthermore, CISS-A scores were not significantly related to SEsx scores $(\beta=-.06, p=.46)$, so there was no evidence that SEsx scores mediated the relationship between CISS-A and Modi-FAI scores.

\section{Prediction of one-year quality of life and social participation}

In Table 4, the final hierarchical regression models are listed for each outcome variable. Higher $\Delta$ SEsx scores (an increase in self-efficacy as measured from baseline to followup) significantly predicted EQ-5D index scores at follow-up, accounting for $8.5 \%$ of the total explained variance (i.e. 43.5\%). Higher EQ VAS scores at follow-up were significantly predicted by higher $\Delta$ SEsx scores and by lower baseline CISS-E scores, jointly accounting for $23.1 \%$ of the total explained variance (i.e. 51.5\%). Higher baseline SEsx scores and higher $\Delta$ SEsx scores were predictive for higher LiSat-9 scores at follow-up, jointly accounting for $16.4 \%$ of the total explained variance (i.e. 58.0\%). Higher baseline SEsx scores and higher baseline CISS-T scores significantly predicted higher Modi-FAI scores at follow-up, but they jointly accounted for only $5.0 \%$ of the total explained variance (i.e. $48.9 \%$ ). 
Table 4. Prediction models based on stepwise hierarchical regressions of the association between baseline clinical and demographic variables and quality of life and social participation at one-year follow-up

\begin{tabular}{|c|c|c|c|c|c|}
\hline & B & $\beta$ & $95 \%$ CI for B & $\mathrm{p}$ & $\mathrm{R}^{2}(\%)$ \\
\hline EQ-5D index Follow-up & & & & & 43.5 \\
\hline Age & -0.0009 & -0.07 & $-0.003-0.001$ & .33 & \\
\hline Sex & -0.002 & -0.004 & $-0.054-0.050$ & .95 & \\
\hline Education medium & -0.035 & -0.09 & $-0.097-0.026$ & .26 & \\
\hline Education high & 0.021 & 0.05 & $-0.042-0.085$ & .61 & \\
\hline EQ-5D index baseline & 0.60 & 0.66 & $0.47-0.72$ & $<.001$ & 33.3 \\
\hline$\Delta$ SEsx & 0.0028 & 0.30 & $0.0016-0.0041$ & $<.001$ & 8.5 \\
\hline EQ VAS Follow-up & & & & & 51.5 \\
\hline Age & 0.077 & 0.06 & $-0.092-0.25$ & .37 & \\
\hline Sex & 0.63 & 0.02 & $-3.68-4.93$ & .77 & \\
\hline Education medium & -1.90 & -0.06 & $-6.87-3.06$ & .45 & \\
\hline Education high & -1.15 & -0.03 & $-6.55-4.24$ & .67 & \\
\hline EQ VAS baseline & 0.53 & 0.56 & $0.40-0.66$ & $<.001$ & 26.9 \\
\hline CISS-E baseline & -0.28 & -0.23 & $-0.45--0.10$ & .002 & 2.1 \\
\hline$\Delta$ SEsx & 0.39 & 0.48 & $0.29-0.49$ & $<.001$ & 21.1 \\
\hline LiSat-9 Follow-up & & & & & 58.0 \\
\hline Age & -0.0009 & -0.01 & $-0.009-0.007$ & .82 & \\
\hline Sex & 0.27 & 0.15 & $0.056-0.47$ & .01 & \\
\hline Education medium & -0.28 & -0.16 & $-0.52--0.036$ & .02 & \\
\hline Education high & -0.15 & -0.08 & $-0.41-0.099$ & .23 & \\
\hline LiSat-9 baseline & 0.63 & 0.55 & $0.47-0.79$ & $<.001$ & 40.7 \\
\hline SEsx baseline & 0.015 & 0.40 & $0.009-0.021$ & $<.001$ & 1.8 \\
\hline$\Delta$ SEsx & 0.019 & 0.44 & $0.013-0.024$ & $<.001$ & 14.6 \\
\hline Modi-FAI Follow-up & & & & & 48.9 \\
\hline Age & -0.048 & -0.08 & $-0.12-0.028$ & .22 & \\
\hline Sex & 2.16 & 0.15 & $0.11-4.21$ & .04 & \\
\hline Education medium & 1.64 & 0.12 & $-0.60-3.87$ & .15 & \\
\hline Education high & 3.63 & 0.24 & $1.28-5.98$ & .003 & \\
\hline Modi-FAI baseline & 0.50 & 0.49 & $0.36-0.63$ & $<.001$ & 26.5 \\
\hline CISS-T baseline & 0.093 & 0.14 & $0.011-0.18$ & .027 & 2.0 \\
\hline SEsx baseline & 0.058 & 0.19 & $0.017-0.099$ & .006 & 3.0 \\
\hline
\end{tabular}

Note. B, unstandardized regression coefficient; $\beta$, standardized regression coefficient; CI, confidence interval; $\mathrm{R}^{2}$, coefficient of determination

SEsx, TBI Self-efficacy Questionnaire total score; $\Delta$ SEsx, SEsx at follow-up minus SEsx at baseline; CISS-T, Coping Inventory for Stressful Situations Task-oriented scale; CISS-E, Coping Inventory for Stressful Situations Emotion-oriented scale; Modi-FAI, Modified Frenchay Activities Index; LiSat-9, Life Satisfaction Questionnaire; VAS, visual analogue scale 


\section{Discussion}

In this prospective cohort study of 148 patients with newly acquired brain injury, we showed that patients who became more self-efficacious in managing their brain injury-related symptoms over time showed better health-related quality of life (EQ-5D index and EQ VAS scores) and general quality of life (LiSat-9) after one year. In addition, patients with higher initial self-efficacy also displayed better long-term general quality of life (LiSat-9). We confirmed the association between emotion-oriented coping and poor quality of life and showed that high self-efficacy protected against this negative influence of emotion-oriented coping. Initial coping and self-efficacy were far less important in predicting long-term social participation.

Our results build on earlier findings. We showed that even in the subacute stage after acquired brain injury (mean time since injury $=15$ weeks), patients who were more self-efficacious had higher quality of life and better social participation. In the chronic stage after brain injury, this positive association was already known., ${ }^{6,9}$

Furthermore, increasing self-efficacy seemed to mitigate the negative influence of emotionoriented coping on health-related quality of life, suggesting that high self-efficacy has a protective effect. This stress-buffering effect of high self-efficacy is well documented in healthy people ${ }^{33}$ and patients with cancer. ${ }^{34} \mathrm{~A}$ similar protective effect of high self-efficacy was found in patients with alcohol dependence. ${ }^{35}$ As self-efficacy increased, the negative influence of coping strategies characterized by unrealistic thinking, which was associated with higher alcohol use and dependence symptoms, diminished. ${ }^{35}$ However, in patients with rheumatoid arthritis, the strength of the relation between coping and anxiety and depression did not vary in magnitude depending on level of self-efficacy. ${ }^{36}$

Patients using more emotion-oriented coping had lower general quality of life (LiSat-9). Testing effect mediation showed that this was because these patients had lower self-efficacy. In patients with osteoarthritis, a slightly resembling pathway was described. Self-efficacy for dealing with pain and arthritis symptoms together with well-being mediated the relation between emotion-focused coping and health care use. ${ }^{37}$

Increased use of avoidance coping in the subacute stage was associated with higher health status (EQ VAS) in case of low self-efficacy and with higher social participation. Our findings might seem to contradict previous studies showing a negative association between passive, avoidant coping and outcome. ${ }^{17,38,39}$ Yet, avoidance measured with the CISS refers to actively seeking social support and distraction, whereas in most other coping questionnaires avoidance is associated with a non-productive, passive, internalizing attitude. ${ }^{40}$ 
Our study offers important new insights with regard to the predictive quality of self-efficacy in acquired brain injury. We showed that patients who became more self-efficacious in managing their brain injury-related symptoms over the course of one year showed better quality of life. Higher initial self-efficacy also influenced better long-term general quality of life (LiSat-9). Furthermore, we found that patients with high initial emotion-oriented coping showed worse long-term health status (EQ VAS). This negative predictive influence of emotion-oriented coping on quality of life is well known. ${ }^{17,41}$

\section{Clinical implications}

Early monitoring of self-efficacy for managing brain injury-related symptoms might identify patients at risk of worse outcome. Furthermore, our findings suggest that promoting selfefficacy in the early stage after acquired brain injury might give rise to better long-term quality of life and social participation. According to Bandura, self-efficacy is not a trait but a generative capability in which mastery of skills is essential next to a strong belief in what can be achieved using these skills. ${ }^{2}$ Hence, skills training, referential comparison with others, verbal feedback and learning control over stress and fatigue could be used to create strong domain-specific efficacy beliefs. ${ }^{2}$ In acquired brain injury, cognitive behavioural therapy, mindfulness-based training, or individualised self-management workbooks have been successful in increasing domain-specific self-efficacy. ${ }^{42-44}$

\section{Study limitations}

We did not investigate the influence of type of injury, injury severity or lesion location. Our choice not to limit inclusion criteria for this study to one specific diagnosis was to increase generalizability and validity and recognizes that severity, localization and type of brain injury do not seem to influence coping. ${ }^{15,45-47}$ Regarding self-efficacy we assumed independence of injury characteristics. Our results cannot be extrapolated to the whole acquired brain injury population because we did not include people who required long-term residential care but we think our study sample is representative of the acquired brain injury population that is discharged home. Furthermore, our predictive model is a first exploration and needs confirmation in a second sample.

\section{Conclusion}

We showed in patients with acquired brain injury that increasing levels of self-efficacy for managing brain injury-specific symptoms over time might give rise to better long-term psychosocial outcome and that high self-efficacy protected against the negative effect of emotion-oriented coping on quality of life. For clinical practice, we suggest monitoring and promotion of self-efficacy in an early stage. 


\section{References}

1. Brands IM, Wade DT, Stapert SZ, van Heugten CM. The adaptation process following acute onset disability: an interactive two-dimensional approach applied to acquired brain injury. Clin Rehabil. 2012;26(9):840-852.

2. Bandura A. Self-efficacy : the exercise of control. New York: W.H. Freeman and Company; 1997.

3. Hellstrom K, Lindmark B, Wahlberg B, Fugl-Meyer AR. Self-efficacy in relation to impairments and activities of daily living disability in elderly patients with stroke: a prospective investigation. $J$ Rehabil Med. 2003;35(5):202-207.

4. Bonetti D, Johnston M. Perceived control predicting the recovery of individual-specific walking behaviours following stroke: testing psychological models and constructs. Br J Health Psychol. 2008;13(Pt 3):463-478.

5. Belgen B, Beninato M, Sullivan PE, Narielwalla K. The association of balance capacity and falls self-efficacy with history of falling in community-dwelling people with chronic stroke. Arch Phys Med Rehabil. 2006;87(4):554-561.

6. Cicerone KD, Azulay J. Perceived self-efficacy and life satisfaction after traumatic brain injury. $J$ Head Trauma Rehabil. 2007;22(5):257-266.

7. Rutterford NA, Wood RL. Evaluating a theory of stress and adjustment when predicting longterm psychosocial outcome after brain injury. J Int Neuropsychol Soc. 2006;12(3):359-367.

8. Wood RL, Rutterford NA. Demographic and cognitive predictors of long-term psychosocial outcome following traumatic brain injury. J Int Neuropsychol Soc. 2006;12(3):350-358.

9. Dumont C, Gervais M, Fougeyrollas P, Bertrand R. Toward an explanatory model of social participation for adults with traumatic brain injury. J Head Trauma Rehabil. 2004;19(6):431-444.

10. Devonport TJLAM. Relationships between self-efficacy, coping and student retention Soc Behav Pers. 2006;34(2):127-138.

11. Trouillet R, Gana K, Lourel M, Fort I. Predictive value of age for coping: the role of self-efficacy, social support satisfaction and perceived stress. Aging Ment Health. 2009;13(3):357-366.

12. Brands I, Köhler S, Stapert S, Wade D, van Heugten C. How flexible is coping after acquired brain injury? A 1-year prospective study investigating coping patterns and influence of self-efficacy, executive functioning and self-awareness. J Rehabil Med. 2014;46(9):869-875.

13. Kristofferzon M-L, Lindqvist R, Nilsson A. Relationships between coping, coping resources and quality of life in patients with chronic illness: a pilot study. Scand J Caring Sci. 2011;25(3):476-483.

14. Hesselink AE, Penninx BW, Schlösser MA, et al. The role of coping resources and coping style in quality of life of patients with asthma or COPD. Qual Life Res. 2004;13(2):509-518.

15. Anson K, Ponsford J. Coping and emotional adjustment following traumatic brain injury. J Head Trauma Rehabil. 2006;21(3):248-259.

16. Moore AD, Stambrook M. Coping following traumatic brain injury (TBI): derivation and validation of TBI sample Ways of Coping-Revised subscales. Can J Rehabil. 1994;4:122-129.

17. Wolters G, Stapert S, Brands I, van Heugten C. Coping following acquired brain injury: predictors and correlates. J Head Trauma Rehabil. 2011;26(2):150-157.

18. Dawson DR, Schwartz ML, Winocur G, Stuss DT. Return to productivity following traumatic brain injury: cognitive, psychological, physical, spiritual, and environmental correlates. Disabil Rehabil. 2007;29(4):301-313.

19. Endler NS, Parker JD. Coping Inventory for Stressful Situations (CISS): manual. Toronto: MultiHealth Systems; 1990.

20. De Ridder DT, Van Heck GL. Coping inventory for stressful situations. CISS Handleiding. Lisse: Swets Test Publishers; 2004. 
21. Brands IM, Köhler S, Stapert SZ, Wade DT, van Heugten CM. Psychometric properties of the coping inventory for stressful situations (ciss) in patients with acquired brain injury. Psychol Assess. 2014;26(3):848-856.

22. Fugl-Meyer AR, Branholm IB, Fugl-Meyer KS. Happiness and domain specific life satisfaction in adult northern Swedes. Clin Rehabil. 1991;5:25-33.

23. Post MW, de Witte LP, van Asbeck FW, van Dijk AJ, Schrijvers AJP. Predictors of health status and life satisfaction in spinal cord injury. Arch Phys Med Rehabil. 1998;79(4):395-401.

24. Visser-Meily A, Post M, Schepers V, Lindeman E. Spouses' quality of life 1 year after stroke: prediction at the start of clinical rehabilitation. Cerebrovasc Dis. 2005;20(6):443-448.

25. Brooks R. EuroQol: the current state of play. Health Policy. 1996;37(1):53-72.

26. EuroQuol Group. EuroQol - a new facility for the measurement of health-related quality of life. Health Policy. 1990;16(3):199-208.

27. Szende A, Oppe M, Devlin NJ. EQ-5D Value Sets: Inventory, Comparative Review and User Guide. Dordrecht, The Netherlands: Springer; 2007.

28. Holbrook M, Skilbeck CE. An activities index for use with stroke patients. Age Ageing. 1983;12(2):166-170.

29. Post MWM, De Witte LP. Good inter-rater reliability of the Frenchay Activities Index in stroke patients. Clin Rehabil. 2003;17(5):548-552.

30. Schuling J, de Haan R, Limburg M, Groenier KH. The Frenchay Activities Index. Assessment of functional status in stroke patients. Stroke. 1993;24(8):1173-1177.

31. De Bie SE. Standaardvragen 1987: Voorstellen voor uniformering van vraagstellingen naar achtergrondkenmerken en interviews (Standard questions 1987: Proposal for uniformization of questions regarding background variables and interviews). Leiden: Leiden University Press; 1987.

32. EuroQuol Group. Measuring self-reported population health: an international perspective based on EQ-5D. Available at http://www.euroqol.org/fileadmin/user_upload/Documenten/PDF/ Books/Measuring_Self-Reported_Population_Health_-_An_International_Perspective_based_ on_EQ-5D.pdf. Accessed August 24, 2014

33. Prati G, Pietrantoni L, Cicognani E. Self-efficacy moderates the relationship between stress appraisal and quality of life among rescue workers. Anxiety Stress Coping. 2009;23(4):463-470.

34. Deno M, Tashiro M, Miyashita M, et al. The mediating effects of social support and self-efficacy on the relationship between social distress and emotional distress in head and neck cancer outpatients with facial disfigurement. Psychooncology. 2012;21(2):144-152.

35. Levin C, Ilgen M, Moos R. Avoidance coping strategies moderate the relationship between selfefficacy and 5-year alcohol treatment outcomes. Psychol Addict Behav. 2007;21(1):108-113.

36. Lowe R, Cockshott Z, Greenwood R, et al. Self-efficacy as an appraisal that moderates the copingemotion relationship: associations among people with rheumatoid arthritis. Psychol Health. 2008;23(2):155-174.

37. Miller C, Cronan T. The effects of coping style and self-efficacy on health status and health care costs. Anxiety Stress Coping. 1998;11(4):311-325.

38. Wolters G, Stapert S, Brands I, Van Heugten C. Coping styles in relation to cognitive rehabilitation and quality of life after brain injury. Neuropsychol Rehabil. 2010;20(4):587-600.

39. Wolters Gregório G, Smeets SM, Ponds RW, Van Heugten C. Passive coping is maladaptive in patients with psychiatric and behavioural problems due to acquired brain injury. Brain Impair. 2012;13:167-168.

40. Wolters Gregório G, Brands I, Stapert S, Verhey FR, van Heugten CM. Assessments of coping after acquired brain injury: a systematic review of instrument conceptualization, feasibility, and psychometric properties. J Head Trauma Rehabil. 2014;29(3):E30-E42. 
41. Wolters Gregorio G, Gould KR, Spitz GB, van Heugten CM, Ponsford JL. Changes in selfreported pre- to postinjury coping styles in the first 3 years after traumatic brain injury and the effects on psychosocial and emotional functioning and quality of life. J Head Trauma Rehabil. 2014;29(3):E43-E53.

42. Jones F, Mandy A, Partridge C. Changing self-efficacy in individuals following a first time stroke: preliminary study of a novel self-management intervention. Clin Rehabil. 2009;23(6):522-533.

43. Azulay J, Smart CM, Mott T, Cicerone KD. A pilot study examining the effect of mindfulnessbased stress reduction on symptoms of chronic mild traumatic brain injury/postconcussive syndrome. J Head Trauma Rehabil. 2013;28(4):1117-1127.

44. Backhaus SL, Ibarra SL, Klyce D, Trexler LE, Malec JF. Brain injury coping skills group: a preventative intervention for patients with brain injury and their caregivers. Arch Phys Med Rehabil. 2010;91(6):840-848.

45. Finset A, Andersson S. Coping strategies in patients with acquired brain injury: relationships between coping, apathy, depression and lesion location. Brain Inj. 2000;14(10):887-905.

46. Herrmann M, Curio N, Petz T, et al. Coping with illness after brain diseases: a comparison between patients with malignant brain tumors, stroke, Parkinson's disease and traumatic brain injury. Disabil Rehabil. 2000;22(12):539-546.

47. Curran CA, Ponsford JL, Crowe S. Coping strategies and emotional outcome following traumatic brain injury: a comparison with orthopedic patients. J Head Trauma Rehabil. 2000;15(6):12561274. 


\section{Chapter 7}

Life goal attainment in the adaptation process after acquired brain injury: the influence of self-efficacy and of flexibility and tenacity in goal pursuit

Published in Clinical Rehabilitation as:

Brands I, Stapert S, Köhler S, Wade D, van Heugten C. Life goal attainment in the adaptation process after acquired brain injury: the influence of self-efficacy and of flexibility and tenacity in goal pursuit. Clinical Rehabilitation. 2014 Sep 16. [Epub ahead of print] 


\section{Abstract}

Objective: To investigate attainment of important life goals and to examine whether selfefficacy, tenacity in goal pursuit and flexibility in goal adjustment contribute to adaptation by affecting levels of emotional distress and quality of life in patients with newly acquired brain injury.

Method: Data were collected from a prospective clinical cohort study of 148 patients assessed after discharge home (mean time since injury $=15$ weeks) and one year later. At followup, attainment of life goals (set at baseline) and satisfaction with attainment was scored (10-point scale) and patients were asked how they adjusted unattained goals. Emotional distress was measured with the Hospital Anxiety and Depression Scale (HADS), quality of life with the Life Satisfaction Questionnaire (LiSat-9), self-efficacy with the TBI Self-efficacy Questionnaire (SEsx) and tenacity and flexibility with the Assimilative/Accommodative Coping Questionnaire (AACQ). Random effects regression analyses and structural equation modelling were used.

Results: In total, only $13 \%$ of initial life goals were achieved in one year. Patients who maintained efforts to reach their original goals had higher average levels of tenacity, but did not differ in level of self-efficacy compared with patients that disengaged. Patients with higher self-efficacy were more successful in attaining important life goals, which correlated with higher quality of life. Patients with higher self-efficacy, higher tenacity in goal pursuit, and higher flexibility in goal adjustment were less emotionally distressed, again correlating with higher quality of life.

Conclusion: To optimise adaptation it seems appropriate to promote self-efficacy and both tenacity and flexibility during rehabilitation treatment. 


\section{Introduction}

Acquired brain injury (ABI) causes impairments in various domains of functioning, which often remain indefinitely. ${ }^{1}$ The adaptation process after acquired brain injury is theoretically characterized by finding a balance between achieving maximal restoration of function and adjusting to various long-term limitations. ${ }^{2}$ An important aspect in this process of adaptation is building a new perspective about life, altering expectations about the future and rebuilding or restoring one's self-concept and/or self-image. ${ }^{2}$ Gracey et al. ${ }^{3}$ describe this process as the reduction of the social, interpersonal and personal discrepancies between the experienced self post-injury and the pre-injury or aspired self. Negative changes in self-concept content are associated with lower well-being and increased psychosocial burden., ${ }^{4,5}$

Reformulation of goals is an essential part in the reduction of self-discrepancies. ${ }^{3}$ Goals are central to some influential theories developed to explain human behaviour. ${ }^{6-8}$ In line with these theories, we formulated the process of adaptation in terms of discrepancy reduction between one's life goals and one's actual performance. ${ }^{2}$ Based on accomplishments and failures experienced in managing one's day-to-day problems associated with acquired brain injury, one learns if one's long-term higher order life goals are attainable. ${ }^{2}$ So, a continuous process of evaluation takes place in which the size of the goal-performance discrepancy is a major determinant of goal revision. Furthermore, the experienced rate of progress towards one's goals is compared to an expected rate of progress, which engenders positive or negative emotions. ${ }^{6}$ Increased well-being has been associated with successful pursuit of meaningful and attainable goals in patients with acquired brain injury. ${ }^{9}$ Negative emotions arise when goal attainment is unsatisfactory. This can lead to increased efforts to catch up but also to frustration when anticipated goals appear to be unreachable. ${ }^{6}$ Thus, finding the proper balance between tenacious goal pursuit and flexible goal adjustment ${ }^{8}$ is crucial in gaining emotional stability and preventing striving towards the unattainable, ending up in frustration. ${ }^{2}$ For example, emotional well-being and quality of life was highest in individuals showed high levels of both tenacity and flexibility..$^{10,11}$

Self-efficacy refers to the belief in one's capabilities in achieving goals. ${ }^{12}$ Efficacy beliefs influence the activities people choose to engage in, the level of effort they spend and their perseverance in the face of difficulties. ${ }^{12}$ In the healthy population, individuals with a low level of self-efficacy disengage at an earlier level of task difficulty compared with highly selfefficacious individuals. ${ }^{13}$ Higher self-efficacy has been associated with better quality of life and social participation in patients with traumatic brain injury. ${ }^{14-17}$ 
The aim of the present study was to test if life goal attainment is related to adaptation after acquired brain injury, as this is the central assumption in our theoretical model, ${ }^{2}$ and to explore the role of self-efficacy and tenacity and flexibility in goal pursuit on adaptation. First we examined (1) success in attainment of important life goals and satisfaction with attainment; (2) how patients adjusted life goals if unattained, and (3) whether type of goal adjustment was dependent on level of goal attainment and satisfaction, self-efficacy, tenacity in goal pursuit and flexibility in goal adjustment. Second, we examined whether self-efficacy for managing brain injury-specific symptoms, tenacity and flexibility and long-term goal attainment contributed to good adaptation by affecting levels of emotional distress and quality of life. We hypothesized that one year post-discharge home (1) the majority of patients do not adapt their important unattained life goals, (2) in patients with higher self-efficacy, goal attainment is more successful, less emotional stress is perceived and quality of life is better, and (3) in patients with higher flexibility and tenacity adaptation is more successful.

\section{Method}

\section{Patients}

Between January 2011 and January 2012, rehabilitation physicians and neurologists of the participating institutes (two rehabilitation centres and two hospitals in the South of the Netherlands) recruited patients who were eligible for participation in this prospective clinical cohort study. Patients were included consecutively upon return to the home environment, either at the start of outpatient neurorehabilitation or at discharge home from hospital or inpatient neurorehabilitation.

The inclusion criteria were: (1) age $\geq 18$ years; (2) newly acquired, non-progressive brain injury of any aetiology confirmed by neurological and/or neuroimaging data with impairments and disabilities in at least one domain of functioning at the time of inclusion, likely to persist for at least a few months; (3) for patients recruited at the start of an outpatient rehabilitation programme maximum time since injury was 4 months.

Exclusion criteria were: (1) any premorbid progressive brain disease; (2) insufficient command of the Dutch language; (3) inability to complete questionnaires based on clinical judgement (aphasia, severe cognitive impairment).

This study was approved by the medical ethics committees of Maastricht University Medical Centre and all participating hospitals and rehabilitation centres. All patients provided written informed consent. 


\section{Measures}

To measure self-efficacy for managing brain injury-specific symptoms, we used the 13-item TBI Self-efficacy Questionnaire (SEsx) ${ }^{14}$, which contains four subscales: social (4 items), physical (1 item), cognitive (4 items) and emotional (4 items) measuring self-efficacy for obtaining help and emotional support, managing physical symptoms, managing and compensating for cognitive symptoms, and managing emotional symptoms, respectively. Items scores ( $1=$ not at all confident to $10=$ totally confident $)$ are summed per subscale. Subscale scores are summed to a total score (range 10 to 130). Higher scores indicate greater self-efficacy. We carried out a formal translation procedure to obtain a Dutch version. Using our data, we found good internal reliability (Cronbach's a .81 - .95).

To measure tenacity in goal pursuit and flexibility in goal adjustment, we used the Assimilative/ Accommodative Coping Questionnaire (AACQ). ${ }^{8,18}$ We used the Dutch translation ${ }^{18}$ of the original German version of the questionnaire. ${ }^{8}$ The Tenacity scale (Tenacious Goal Pursuit, TGP) measures the tendency to maintain a chosen course of action, to persist in goal pursuit even in the face of setbacks and obstacles. The Flexibility scale (Flexible Goal Adjustment, FGA) measures the tendency to adjust to situational constraints and describes processes related to disengagement from blocked goals, reorientation, and acceptance. Each scale consists of 15 direct- and reverse-keyed answers rated on a 5-point scale $(0=$ completely agree to $4=$ completely disagree). Higher scores indicate a greater tendency towards tenacity or flexibility. Using our data, we found good internal reliability (Cronbach's $\alpha$ : TGP $=.81$, $\mathrm{FGA}=.79$ ).

The Hospital Anxiety and Depression Scale (HADS) was used as a general measure of emotional distress. The HADS contains 14 items, scored on a 4-point scale (range 0-3) that form two subscales: Anxiety and Depression (7 items per subscale). ${ }^{19}$ HADS subscale scores $\geq 8$ might indicate the presence of depression or anxiety. A Dutch version was validated by Spinhoven et al. ${ }^{20}$ Using our data, we found good internal reliability (Cronbach's $\alpha$ : HADSanxiety $=.85$, HADS-depression $=.84$ ).

The 9-item Life Satisfaction Questionnaire (LiSat-9) was used as a generic instrument for measuring quality of life. ${ }^{21}$ We used the Dutch version. ${ }^{22,23}$ One global domain (general quality of life) and eight specific fields are assessed. The mean of all item scores $(1=$ very unsatisfactory to $6=$ very satisfactory) is calculated. Higher scores indicate better general quality of life. Using our data, we found good internal reliability (Cronbach's a .83).

Attainment of life goals and satisfaction with goal attainment was rated on a 10 -point scale $(0$ $=$ completely not reached to $10=$ completely reached and $0=$ completely unsatisfied to $10=$ 
completely satisfied, respectively). The way in which patients adjusted their life goals in case of a goal attainment score < 10 was classified into four categories: (1) maintained original goal (maintain), (2) made original goal easier as to a level that was judged attainable (easier), (3) stopped striving towards original goal as current level of attainment was accepted as sufficient (accept), (4) abandoned original goal (abandon).

Data on age, sex and diagnosis were extracted from the medical files. Level of educational attainment was recorded during baseline interview and classified according to a three-level system often used in the Netherlands: primary education (low), junior vocational training (medium) and senior vocational or academic training (high), corresponding to $8.6 \pm 1.9,11.4$ \pm 2.5 , and $15.2 \pm 3.3$ years of full-time education, respectively. ${ }^{24}$

\section{Procedure}

After inclusion, patients were contacted. A telephone interview with the first author or research assistant was planned when the patient had been at home for at least 2-4 weeks. During the telephone interview, patients were asked what were their three most important, most valuable life goals, based on their current situation to achieve in about a year. Goals were specified and made measurable but were not reviewed clinically to measure likelihood of achievement; for example goals such as 'I want to return to my prior work for 20 hours per week and do my original tasks with no adaptations in difficulty and complexity' or 'I want to be a member of my athletics club again and run once a week $10 \mathrm{~km}$ at low speed (beginners level instead of advanced level)' might have been judged by the assessor as impossible, but they were still recorded. After the interview, each patient received the questionnaires about self-efficacy (SEsx), tenacity/flexibility (AACQ), emotional distress (HADS) and quality of life (LiSat-9) by post to complete via self-report.

One year ( \pm 4 weeks) after inclusion, patients were contacted again to plan the follow-up telephone interview. During this telephone interview attainment of the patient's initial life goals was reviewed. Each of three initial goals was read to the patient and he/she was asked to describe the actual level of achievement in detail. For each initial goal the investigator, in accordance with the patient, rated to what extent the goal was attained (from 0 to 10), next the patient rated how satisfied he/she was with the actual level of achievement (from 0 to 10$)$. If the initial goal was not reached (score $<10$ ) patients were asked to indicate in what way they adjusted their initial goal: four answering categories were presented, (maintain, easier, accept, abandon) of which one had to be selected. After the interview, the same set of questionnaires about self-efficacy, tenacity/flexibility, emotional distress and quality of life was sent to complete via self-report. 
If during the telephone interview a participant requested a live interview or asked for assistance to complete the questionnaires, a face-to-face appointment with the first author or research assistant was arranged ( $n=26,18 \%$ of cases at baseline; $n=26,18 \%$ of cases at follow-up).

\section{Data analysis}

Paired sample t-tests were used to compare baseline and follow-up scores of all clinical variables.

Differences in self-efficacy (SEsx), flexibility (FGA) and tenacity (TGP), life goal attainment and satisfaction with attainment according to the type of goal adjustment (maintain, easier, accept, abandon) were tested using random effects regression analysis. This approach was chosen in order not to restrict analysis to a particular life goal, and hence accounted for the fact that repeated measures were taken from individuals when asking patients to define three different life goals. Thus, analyses made full use of all available data, but they were adjusted for the fact that repeated measures are correlated within individuals, yielding pooled effect estimates. Five random effects regressions were conducted with SEsx, FGA, TGP, life goal attainment and satisfaction scores as dependent variables, respectively. Demographic variables (age, sex and education) and goal adjustment were entered as independent variables.

To test which clinical variables (SEsx, FGA, TGP, 3 goal attainment scores) contributed to successful adaptation as measured in terms of emotional distress (HADS) and quality of life (LiSat-9) at one-year follow-up, structural equation modelling (SEM) was performed. Both direct and indirect pathways were specified to test for possible effect mediation. To reduce the number of variables, a single 'goal attainment' score was constructed by factorizing the three separate goal attainment scores into a single continuous factor using a maximum likelihood estimator. An initial model was specified based on our theoretical assumptions on the direct and indirect paths between variables to influence HADS and LISat-9 scores. The initial model was re-specified based on consecutive removal of paths that did not contribute significantly $(\mathrm{p}<.10)$. This was executed in a 1-to-1 backward fashion. Model fit was assessed after each step by inspecting the model chi-square $\left(\chi_{M}^{2}\right)$ next to the root mean square error of approximation (RMSEA) and the Comparative Fit Index (CFI). For the RMSEA ${ }^{25}$, scores $\leq 0.08$ indicate acceptable fit, and scores $\leq 0.05$ indicate good fit. The $\mathrm{CFI}^{26}$ ranges from 0 to 1 with scores $\geq$ 0.90 indicating acceptable fit, and scores $\geq 0.95$ indicating good fit. All analyses were carried out in Stata 12.1 (StataCorp LP, Texas), using two-sided hypothesis testing with an alpha-level of .05 . 


\section{Results}

Initially, 190 patients were approached, 37 refused to participate. Of the 153 patients willing to participate, we excluded 5 patients because of non-matching inclusion criteria. Overall, 148 patients (78 \%) underwent baseline assessment, of which 143 participated in follow-up assessment. Too much burden was the reason for all dropouts. Table 1 shows the demographic and injury-related characteristics of the sample at baseline. At follow-up, mean time since injury was 67 weeks $(S D=9.12)$. Description of all clinical variables is summarized in Table 2. HADS-D scores were above cut-off indicative for depression in $37 \%$ of patients at baseline and in 32\% at follow-up. For HADS-A, 32\% of patients scored above the cut-off for anxiety at both measurements. Compared with baseline scores, average HADS and SEsx scores had improved at one-year follow-up (Table 2).

Table 1. Patient characteristics at baseline $(\mathrm{N}=148)$

\begin{tabular}{llccc}
\hline & & Mean & SD & Range \\
\hline Age (years) & & 56 & 12.3 & $19-84$ \\
Time since injury (weeks) & & 15.1 & 9.6 & $2.0-43.7$ \\
\hline & & $\mathrm{n}$ & $\%$ & \\
\hline Sex (male) & Low & 95 & 64.2 & \\
Educational level & Medium & 41 & 27.7 & \\
& High & 61 & 41.2 & \\
Type of lesion & Infarction & 46 & 31.1 & \\
& SAH & 98 & 66.2 & \\
& ICH & 10 & 6.8 & \\
& Diffuse vascular lesions & 9 & 6.1 & \\
& TBI & 2 & 1.4 & \\
& Anoxic encephalopathy & 14 & 9.5 & \\
& Tumour benign & 3 & 2.0 & \\
& Meningitis/encephalitis & 5 & 3.4 & \\
& Other & 1 & 0.7 & \\
\hline
\end{tabular}

Note. SAH, subarachnoid haemorrhage; ICH, intracerebral haemorrhage; TBI, traumatic brain injury

Table 2. Descriptive data of all clinical variables

\begin{tabular}{lllllcc}
\hline & Baseline & \multicolumn{7}{c}{ 1-year Follow-up } & $\mathrm{t}$ & $\mathrm{p}$ \\
& Mean & SD & Mean & SD & 2.14 & .03 \\
\hline SEsx & 83.98 & 22.37 & 87.40 & 21.29 & 1.92 & .06 \\
FGA & 36.85 & 8.59 & 38.13 & 8.54 & -1.45 & .15 \\
TGP & 35.35 & 9.46 & 34.22 & 8.83 & -2.19 & .03 \\
HADS & 11.87 & 7.34 & 10.76 & 7.70 & 0.85 & .39 \\
LiSat-9 & 4.49 & 0.73 & 4.54 & 0.85 & 03 \\
\hline
\end{tabular}

Note. SEsx, TBI Self-efficacy Questionnaire; FGA, Flexible Goal Adjustment; TGP, Tenacious Goal Pursuit; HADS, Hospital Anxiety and Depression Scale; LiSat-9, Life Satisfaction Questionnaire 


\section{Life goal attainment at one-year follow-up}

In total 426 goals were evaluated at follow-up. At one-year follow-up, full goal attainment was reached in $13 \%$ of initial goals. From the unattained initial life goals (score $\leq 9$ ), $58 \%$ were maintained as originally formulated, $31 \%$ were no longer striven for as the current level of attainment was accepted as sufficient, $9 \%$ were made easier so as to bring aspirations to a realistic level, and 2\% were abandoned. In Table 3, mean SEsx, FGA and TGP scores are given according to level of goal attainment and type of goal adjustment.

Table 3. Self-efficacy, flexibility in goal adjustment and tenacity in goal pursuit as related to type of goal adjustment and level of goal attainment at one-year follow-up

\begin{tabular}{|c|c|c|c|c|c|}
\hline \multirow{3}{*}{$\begin{array}{l}\text { GAdj } \\
\text { GA }\end{array}$} & \multirow{3}{*}{$\begin{array}{c}\text { Full GA } \\
\text { Mean (SD) }\end{array}$} & Maintain & Easier & Accept & Abandon \\
\hline & & \multicolumn{4}{|c|}{ Incomplete GA } \\
\hline & & Mean (SD) & Mean (SD) & Mean (SD) & Mean (SD) \\
\hline GA & $10(0.00)$ & $5.79(2.50)$ & $6.36(1.60)$ & $5.88(2.95)$ & $1.86(2.61)$ \\
\hline Satisfaction & $9.17(1.00)$ & $6.04(2.25)$ & $6.64(1.64)$ & $6.79(1.94)$ & $4.43(2.44)$ \\
\hline SEsx & $99.44(19.30)$ & $86.88(21.08)$ & $85.42(21.77)$ & $83.91(19.32)$ & $69.86(33.89)$ \\
\hline FGA & $39.78(8.08)$ & $37.61(8.74)$ & $38.36(11.42)$ & $38.34(6.98)$ & $33.71(11.61)$ \\
\hline TGP & $36.70(9.10)$ & $35.13(8.99)$ & $33.79(8.98)$ & $31.54(7.62)$ & $33.29(11.41)$ \\
\hline
\end{tabular}

Note. GAdj, goal adjustment; GA, goal attainment

Full GA: maximum score $(=10)$ on life goal attainment score

Incomplete GA: score $0-9$ out of 10 on life goal attainment score

Types of goal adjustment: Maintain, maintain original goal; Easier, decrease difficulty of original goal; Accept, accept actual level of goal attainment and stop striving; Abandon, abandon original goal

Separate linear random effect regressions were then run to investigate whether SEsx scores, TGP and FGA scores and attainment and satisfaction scores differed according to the type of goal adjustment in patients which did not attain their original life goals. There were no significant differences in SEsx scores and FGA scores across types of goal adjustment. Yet, compared with patients who maintained striving towards their original unmet goal, those who accepted their actual level of goal attainment and stopped striving showed significantly lower TGP scores $(\mathrm{b}=-1.31,95 \% \mathrm{CI}-2.38$ to $-0.25, \mathrm{p}=.016)$. In addition, those who abandoned their original goal were less successful in actual level of goal attainment $(b=-3.97,95 \% \mathrm{CI}$ -5.62 to $-2.33, \mathrm{p} \leq .001)$ and less satisfied with their goal attainment $(\mathrm{b}=-1.27,95 \% \mathrm{CI}$ -2.55 to $-0.002, \mathrm{p}=.050)$ compared with those who maintained striving towards their unmet original goals. 
Adaptation at one-year post-discharge home: influence of self-efficacy, tenacity and flexibility and goal attainment on emotional distress and quality of life

Structural equation modelling (SEM) was used to test for direct and indirect effects of SEsx, TGP and FGA scores on goal attainment and adaptation outcome variables at follow-up. The initial theoretical model is shown in Figure 1. Model fit was high $\left(\chi_{M}^{2}=9.61\right.$ with 10 degrees of freedom, $\mathrm{RMSEA}=0.00, \mathrm{CFI}=1.00$ ), which is explained by the close fit for the measurement part of the SEM that generates the goal attainment factor (for an explanation see Appendix 1).

Finally, a more parsimonious, reduced model (Figure 2) was obtained after consecutive backward removal of non-significant paths $\left(\chi_{M}^{2}=11.43\right.$ with 15 degrees of freedom, RMSEA $=0.00$, CFI $=1.00)$. By combining the estimates of direct and indirect pathways in the final model, the total effect of each variable (SEsx, FGA, TGP, goal attainment and HADS) on LiSat-9 was calculated. Examination of direct, indirect and total effects suggested that higher LiSat-9 scores were directly dependent on lower HADS scores $(\beta=-0.45, \mathrm{p}<.001)$, higher goal attainment factor $(\beta=0.35, \mathrm{p}<.001)$, and higher FGA scores $(\beta=0.14, \mathrm{p}=.048)$. While higher SEsx scores had no such direct effect, they had an indirect (i.e. mediated) effect on LiSat-9 scores via their association with higher goal attainment scores and lower HADS scores, thus explaining their significant total effect $(\beta=0.39, \mathrm{p}<.001)$. Similarly, higher TGP scores did not show a direct effect on LiSat-9, but a significant total effect $(\beta=0.13, \mathrm{p}<.001)$ because of their association with lower HADS scores. Next, higher FGA scores had both a direct effect on LiSat-9 scores $(\beta=0.14, \mathrm{p}=.048)$ and an indirect effect via lower HADS scores (total effect: $\beta=0.24, p=.001$ ). As no indirect paths were specified for goal attainment and HADS scores in the final model, their direct effects equalled their total effect.

For the adaptation outcome variables, $63 \%$ of the observed variance in HADS scores and 56\% of the observed variance in LiSat-9 scores were explained by these associations. 


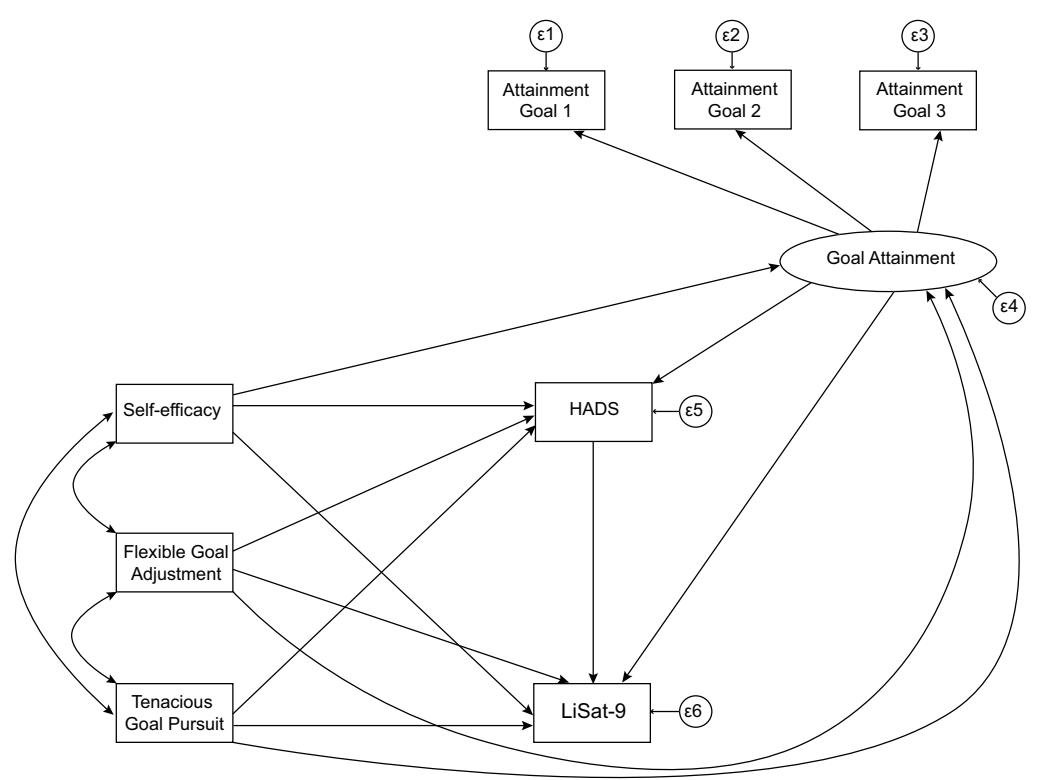

Figure 1. Structural equation model of direct and indirect effects of self-efficacy, tenacity and flexibility and goal attainment on emotional distress and quality of life: initial model

Note. HADS, Hospital Anxiety and Depression Scale; LiSat-9, Life Satisfaction Questionnaire; $\varepsilon$, error variance.

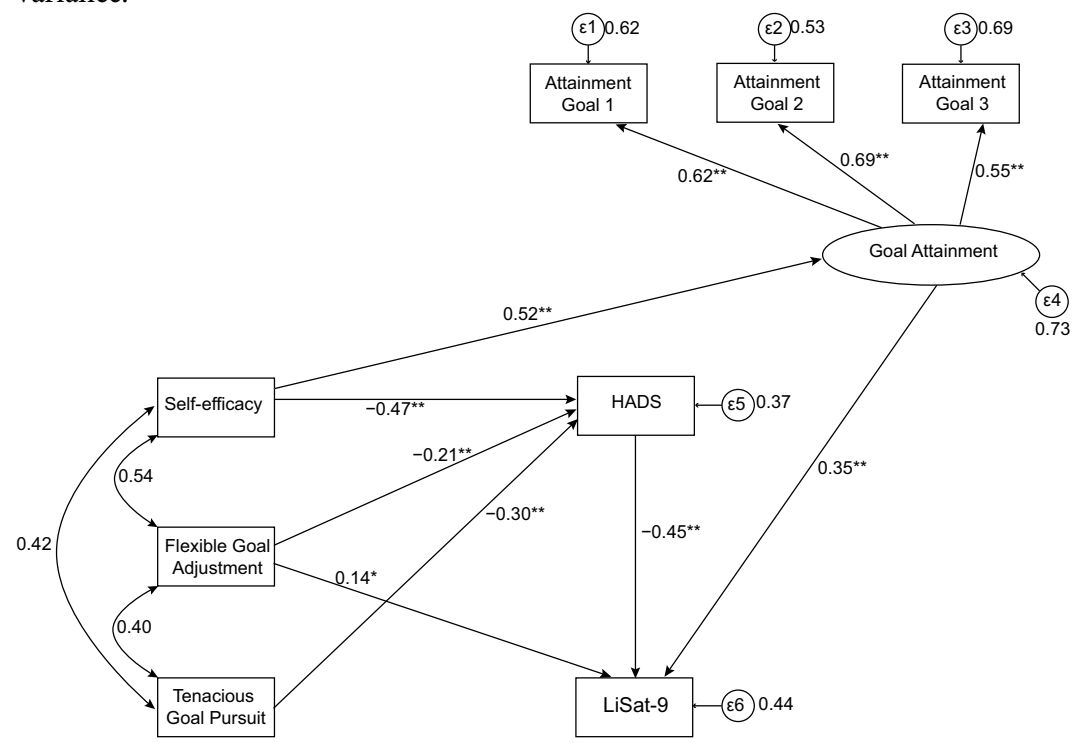

Figure 2. Structural equation model of direct and indirect effects of self-efficacy, tenacity and flexibility and goal attainment on emotional distress and quality of life: final reduced model showing standardized regression coefficients for direct paths

Note. HADS, Hospital Anxiety and Depression Scale; LiSat-9, Life Satisfaction Questionnaire; $\varepsilon$, error variance

${ }^{*} \mathrm{p}<.05 ;{ }^{* *} \mathrm{p} \leq .001$ 


\section{Discussion}

In this clinical study of patients with newly acquired brain injury, we found that only a minority of important life goals were completely met one year after discharge home. We showed that high self-efficacy for the management of brain injury-specific symptoms, high tenacity and flexibility in goal pursuit and successful attainment of important life goals were associated with better adaptation one year after discharge home.

When important life goals were not met one year post-discharge home, the majority of patients either continued striving towards their original goal, as we expected or accepted their current level of goal attainment as final, and stopped striving. Life goals appeared to be completely abandoned only if attainment was very low. Patients who continued striving towards their original life goals were more tenacious in goal pursuit than those who applied types of adjustment indicating partial disengagement. However, the patients who sustained effort did not have higher levels of self-efficacy although it is theoretically assumed that higher tenacity is associated with higher self-efficacy. ${ }^{27}$ Flexibility in goal pursuit was not linked to the way patients adjusted to unmet life goals.

At one year post-discharge home, patients who were more self-efficacious in managing their brain injury-related symptoms experienced less emotional distress and were more successful in attaining important life goals, which in turn correlated with better quality of life reflecting better adaptation. These findings are in line with the theory of Bandura in which higher selfefficacy is linked to better performance attainment. ${ }^{12}$ Self-efficacy also showed to be a reliable predictor of adjustment in patients with multiple sclerosis. ${ }^{28}$ The association between life goal attainment and higher quality of life mirrors earlier findings in brain injury. ${ }^{9,29,30}$ The stressbuffering effect of self-efficacy is also well documented in healthy people ${ }^{31}$ and in patients with cancer. ${ }^{32,33}$

Better adaptation was also present in patients with higher tenacity in goal pursuit and higher flexibility in goal adjustment as they experienced lower emotional distress, which was again related to higher quality of life. Tenacity and flexibility did not play a role in goal attainment but being flexible in goal adjustment was directly related to better quality of life, independent of goal attainment per se. These findings are in line with the theoretical model that we proposed $^{2}$ and with other models. ${ }^{6,27}$ Both assimilative and accommodative processes are activated by perceived goal-performance discrepancies, which is equivalent to the level of goal attainment in our model, in order to reduce these perceived discrepancies. ${ }^{27}$ Assimilative processes consist of corrective interventions that are initiated to maximize the likelihood of goal achievement. Accommodative processes constitute of rescaling ambitions and acceptance 
of the situation. ${ }^{27}$ Both processes also engender an emotional response. ${ }^{2,6,27}$ The adaptation process after acquired brain injury is presumably characterized by finding a balance between achieving maximal restoration of function and adjusting to various long-term limitations. ${ }^{2}$ Our findings indicate that at one-year post-injury both assimilative and accommodative processes are into play simultaneously and seem to act complementarily and synergistically to create emotional stability. ${ }^{2}$ Similar to our findings, in patients with stroke one-year postonset, quality of life was found highest in the presence of high levels of both tenacity and flexibility. ${ }^{11}$ Also in patients with a lower limb amputation (mean time since amputation = 32 weeks), better quality of life was associated with higher tenacity and flexibility. ${ }^{34}$ However, better acceptance was only related to higher flexibility in goal adjustment in patients with spinal cord injury in the chronic stage (mean time since injury $=8.5$ years) ${ }^{35}$, suggesting that, possibly, with ongoing time the tendency towards flexibility might become more important.

Self-efficacy for managing brain injury-related symptoms was moderately correlated with both tenacity and flexibility. This corresponds to our theoretical assumptions ${ }^{2}$ that both assimilative and accommodative tendencies represent different means to exert self-control.

Our findings suggest that therapeutic attempts to enhance self-efficacy related to the management of brain injury-specific symptoms, as well as interventions to increase tenacity in goal pursuit and flexibility in goal adjustment would be useful in improving attainment of important life goals and adaptation after acquired brain injury.

Self-efficacy does change, as we found an improvement over the course of a year, and thus interventions could well increase this potentially beneficial change. Indeed, after acquired brain injury cognitive behavioural therapy, mindfulness-based training or individualized self-management workbooks have all been successful in increasing domain-specific selfefficacy. ${ }^{36-38}$ According to Bandura ${ }^{12}$, self-efficacy beliefs are, in addition to training skills and strategies, developed by using referential comparison with significant others, positive feedback, reward and providing control over interfering emotions e.g. stress, anxiety and fatigue.

Although tenacity and flexibility are predominantly viewed as dispositional characteristics, fluctuations over the course of a lifetime were observed, which suggests that they can also be changed. ${ }^{8}$ Stimulating assimilative as well as accommodative tendencies are central to holistic rehabilitation approaches aiming at optimizing the process of adaptation after acquired brain injury. ${ }^{3}$ Various therapeutic techniques e.g. behavioural experiments and motivational interviewing are used to support patients in self-reflection, selecting logical subgoals, environmental mastery and recruiting resources, exploring alternative perspectives and reducing catastrophizing thoughts. ${ }^{3,39-41}$ 
It is well known that rehabilitation after acquired brain injury is more successful and motivation increases when personally important goals are set, which are concurrent with one's life goals. ${ }^{42-44}$ Our findings stress the importance of such an approach, as we showed that attainment of important life goals is associated with better long-term quality of life. We did not constrain goals by achievability, and interestingly the patients rarely considered that they had a major lack of achievement. Some modification of initial goals might be appropriate, but major attempts to alter patient-set goals in the early stage after brain injury, might carry the risk of demotivating the patient.

We did not formally account for type of injury, injury severity or lesion location. However, exploratory analyses did not show any influence. Our choice not to limit inclusion criteria for this study to one specific diagnosis was to increase generalizability and validity. Our results cannot be extrapolated to the whole acquired brain injury population as we did not include people who required long-term residential care but we think our study sample is representative of the acquired brain injury population that is discharged home. We did not include brain injury-related characteristics such as self-awareness and cognitive functioning in our analyses, nor did we account for classical coping styles although they are assumed of influence. ${ }^{2,3}$ Therefore our findings must be interpreted as a first exploration and testing of the relationships between a set of variables, that are presumed to be involved in the adaptation process after acquired brain injury. ${ }^{2}$ As a consequence of testing our model at only one point in time (at one-year follow-up), estimation of reciprocal effects (e.g. a pathway from HADS towards SEsx or from goal attainment towards SEsx) was not possible. ${ }^{45}$

\section{Conclusions}

In patients with acquired brain injury, one year after discharge home, the majority of important life goals is not met and striving for continued. Compared with patients who apply types of goal adjustment pointing towards disengagement, patients who sustain effort to reach their initial life goals, have higher tenacity but do not differ in level of self-efficacy. Furthermore, we showed that high self-efficacy for the management of brain injury-specific symptoms, high tenacity in goal pursuit, high flexibility in goal adjustment and successful attainment of important life goals is associated with better adaptation after acquired brain injury. For clinical practice, we stress the importance of promoting self-efficacy and both assimilative and accommodative qualities during rehabilitation treatment. 


\section{Clinical messages}

- One year after acquired brain injury, only a minority of important life goals are completely met.

- Life goals are completely abandoned, only if attainment is very low.

- Patients with high self-efficacy are more successful in attainment of life goals.

- Major modification of initial goals might demotivate the patient. 
Appendix 1. Model building process

The initial theoretical SEM (see Figure 1 in main text) falls apart in a structural part (the paths including observed/manifest variables) and a measurement part (the factor analysis that constructs the latent continuous goal attainment variable). Model fit of that initial theoretical model: $\chi_{M}^{2}=9.61$ with 10 degrees of freedom, $\mathrm{RMSEA}=0.00, \mathrm{CFI}=1.00$. This very close fit seems mainly driven by a close fit for the measurement part, with an acceptable fit for the structural part. Below is a more detailed account of the model building process for the two parts of that full SEM model.

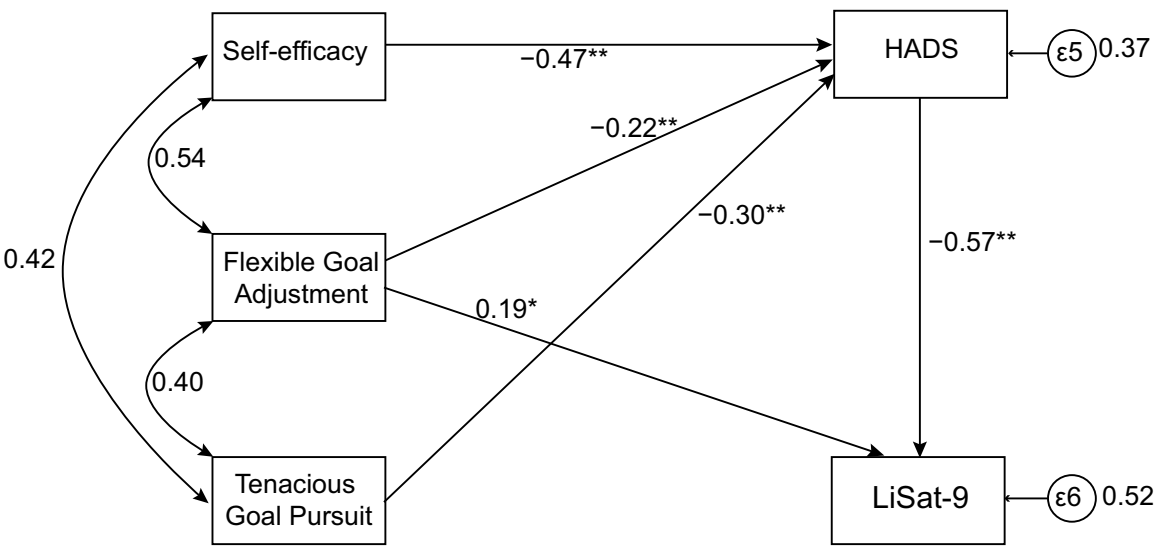

Appendix-Figure 1. Structural part only (Model fit: $\chi_{M}^{2}=3.96$ with 2 degrees of freedom, RMSEA = $0.083, \mathrm{CFI}=0.992$ )

Note. $\varepsilon$, error variance

${ }^{*} \mathrm{p}<.05 ;{ }^{* *} \mathrm{p} \leq .001$

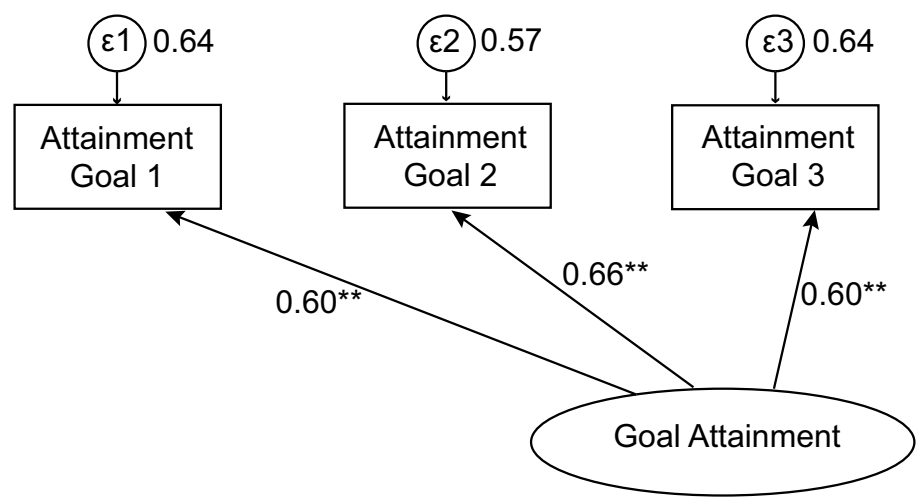

Appendix-Figure 2. Measurement part only (Model fit: RMSEA $=0.000$, CFI $=1.000$ )

Note. $\varepsilon$, error variance

${ }^{\star} \mathrm{p}<.05 ;{ }^{* *} \mathrm{p} \leq .001$ 


\section{References}

1. Dikmen SS, Machamer JE, Powell JM, Temkin NR. Outcome 3 to 5 years after moderate to severe traumatic brain injury. Arch Phys Med Rehabil. 2003;84(10):1449-1457.

2. Brands IM, Wade DT, Stapert SZ, van Heugten CM. The adaptation process following acute onset disability: an interactive two-dimensional approach applied to acquired brain injury. Clin Rehabil. 2012;26(9):840-852.

3. Gracey F, Evans JJ, Malley D. Capturing process and outcome in complex rehabilitation interventions: a "Y-shaped" model. Neuropsychol Rehabil. 2009;19(6):867-890.

4. Cantor JB, Ashman TA, Schwartz ME, et al. The role of self-discrepancy theory in understanding post-traumatic brain injury affective disorders: a pilot study. I Head Trauma Rehabil. 2005;20(6):527-543.

5. Doering BK, Conrad N, Rief W, Exner C. Living with acquired brain injury: self-concept as mediating variable in the adjustment process. Neuropsychol Rehabil. 2011;21(1):42-63.

6. Carver CS, Scheier MF. On the self-regulation of behaviour. 2005 ed. Cambridge: Cambridge university Press; 1998.

7. Bandura A. Social Foundations of Thought and Action. Englewood Cliffs, NJ: Prentice-Hall; 1986.

8. Brandtstadter J, Renner G. Tenacious goal pursuit and flexible goal adjustment: explication and age-related analysis of assimilative and accommodative strategies of coping. Psychol Aging. 1990;5(1):58-67.

9. Conrad N, Doering BK, Rief W, Exner C. Looking beyond the importance of life goals. The personal goal model of subjective well-being in neuropsychological rehabilitation. Clin Rehabil. 2010;24(5):431-443.

10. Kelly RE, Wood AM, Mansell W. Flexible and tenacious goal pursuit lead to improving well-being in an aging population: a ten-year cohort study. Int Psychogeriatr. 2013;25(01):16-24.

11. Darlington A-S, Dippel DW, Ribbers GM, van Balen R, Passchier J, Busschbach JJ. Coping strategies as determinants of quality of life in stroke patients: a longitudinal study. Cerebrovasc Dis. 2007;23(5-6):401-407.

12. Bandura A. Self-efficacy: the exercise of control. New York: W.H. Freeman and Company; 1997.

13. Beattie S, Davies M. A test of engagement versus disengagement in catastrophe models. $\mathrm{Br} \mathrm{J}$ Psychol. 2010;101(2):361-371.

14. Cicerone KD, Azulay J. Perceived self-efficacy and life satisfaction after traumatic brain injury. $J$ Head Trauma Rehabil. 2007;22(5):257-266.

15. Rutterford NA, Wood RL. Evaluating a theory of stress and adjustment when predicting longterm psychosocial outcome after brain injury. J Int Neuropsychol Soc. 2006;12(3):359-367.

16. Wood RL, Rutterford NA. Demographic and cognitive predictors of long-term psychosocial outcome following traumatic brain injury. J Int Neuropsychol Soc. 2006;12(3):350-358.

17. Dumont C, Gervais M, Fougeyrollas P, Bertrand R. Toward an explanatory model of social participation for adults with traumatic brain injury. J Head Trauma Rehabil. 2004;19(6):431-444.

18. Aben L, Busschbach JJ. A formal translation of the Assimilation-Accomodation Coping Scale from German to Dutch. 2009 Erasmus MC Report 06.

19. Zigmond AS, Snaith RP. The hospital anxiety and depression scale. Acta Psychiatr Scand. 1983;67(6):361-370.

20. Spinhoven P, Ormel J, Sloekers PP, Kempen GI, Speckens AE, Hemert AM. A validation study of the Hospital Anxiety and Depression Scale (HADS) in different groups of Dutch subjects. Psychol Med. 1997;27(02):363-370. 
21. Fugl-Meyer AR, Branholm IB, Fugl-Meyer KS. Happiness and domain specific life satisfaction in adult northern Swedes. Clin Rehabil. 1991;5:25-33.

22. Post MW, de Witte LP, van Asbeck FW, van Dijk AJ, Schrijvers AJ. Predictors of health status and life satisfaction in spinal cord injury. Arch Phys Med Rehabil. 1998;79(4):395-401.

23. Visser-Meily A, Post M, Schepers V, Lindeman E. Spouses' quality of life 1 year after stroke: prediction at the start of clinical rehabilitation. Cerebrovasc Dis. 2005;20(6):443-448.

24. De Bie SE. Standaardvragen 1987: Voorstellen voor uniformering van vraagstellingen naar achtergrondkenmerken en interviews (Standard questions 1987: Proposal for uniformization of questions regarding background variables and interviews). Leiden: Leiden University Press; 1987.

25. Steiger JH. Structural model evaluation and modification: an interval estimation approach. Multivariate Behav Res. 1990;25:173-180.

26. Bentler PM. Comparative fit indexes in structural models. Psychol Bull. 1990;107(2):238-246.

27. Brandtstädter J, Rothermund $\mathrm{K}$. The life-course dynamics of goal pursuit and goal adjustment: a two-process framework. Dev Rev. 2002;22(1):117-150.

28. Black R, Dorstyn D. A biopsychosocial model of resilience for multiple sclerosis. J Health Psychol. 2013 Dec 12. [Epub ahead of print]

29. Doering BK, Nico C, Winfried R, Cornelia E. Life goals after brain injury in the light of the dual process approach: empirical evidence and implications for neuropsychological rehabilitation. Neuropsychol Rehabil. 2011;21(4):515-538.

30. Kuenemund A, Zwick S, Doering BK, Conrad N, Rief W, Exner C. Decline in attainability of communion and agency life goals over 2 years following acquired brain injury and the impact on subjective well-being. Neuropsychol Rehabil. 2013;23(5):678-697.

31. Prati G, Pietrantoni L, Cicognani E. Self-efficacy moderates the relationship between stress appraisal and quality of life among rescue workers. Anxiety Stress Coping. 2009;23(4):463-470.

32. Hirai K, Suzuki Y, Tsuneto S, Ikenaga M, Hosaka T, Kashiwagi T. A structural model of the relationships among self-efficacy, psychological adjustment, and physical condition in Japanese advanced cancer patients. Psychooncology. 2002;11(3):221-229.

33. Deno M, Tashiro M, Miyashita M, et al. The mediating effects of social support and self-efficacy on the relationship between social distress and emotional distress in head and neck cancer outpatients with facial disfigurement. Psychooncology. 2012;21(2):144-152.

34. Coffey L, Gallagher P, Desmond D. Goal pursuit and goal adjustment as predictors of disability and quality of life among individuals with a lower limb amputation: a prospective study. Arch Phys Med Rehabil. 2014;95(2):244-252.

35. van Lankveld W, van Diemen T, van Nes I. Coping with spinal cord injury: tenacious goal pursuit and flexible goal adjustment. J Rehabil Med. 2011;43(10):923-929.

36. Jones F, Mandy A, Partridge C. Changing self-efficacy in individuals following a first time stroke: preliminary study of a novel self-management intervention. Clin Rehabil. 2009;23(6):522-533.

37. Azulay J, Smart CM, Mott T, Cicerone KD. A pilot study examining the effect of mindfulnessbased stress reduction on symptoms of chronic mild traumatic brain injury/postconcussive syndrome. J Head Trauma Rehabil. 2013;28(4):1117-1127.

38. Backhaus SL, Ibarra SL, Klyce D, Trexler LE, Malec JF. Brain injury coping skills group: a preventative intervention for patients with brain injury and their caregivers. Arch Phys Med Rehabil. 2010;91(6):840-848.

39. Brands IM, Bouwens SF, Wolters Gregório G, Stapert SZ, van Heugten CM. Effectiveness of a process-oriented patient-tailored outpatient neuropsychological rehabilitation programme for patients in the chronic phase after ABI. Neuropsychol Rehabil. 2013;23(2):202-215.

40. Cicerone KD, Mott T, Azulay J, et al. A randomized controlled trial of holistic neuropsychologic rehabilitation after traumatic brain injury. Arch Phys Med Rehabil. 2008;89(12):2239-2249. 
41. Prigatano GP. Principles of neuropsychological rehabilitation. New York: Oxford University Press; 1999.

42. Nair KP. Life goals: the concept and its relevance to rehabilitation. Clin Rehabil. 2003;17(2):192202.

43. Nair KP, Wade DT. Changes in life goals of people with neurological disabilities. Clin Rehabil. 2003;17(7):797-803.

44. Bergquist TF, Micklewright JL, Yutsis M, Smigielski JS, Gehl C, Brown AW. Achievement of client-centred goals by persons with acquired brain injury in comprehensive day treatment is associated with improved functional outcomes. Brain Inj. 2012;26(11):1307-1314.

45. Kline RB. Principles and practice of structural equation modeling. 3rd ed. New York: The Guilford Press; 2011. 



\section{Chapter 8}

General discussion 
Chapter 8 


\section{Introduction}

The main objectives of this thesis were to develop a new theoretical model that describes the process of adaptation to the consequences of acquired brain injury within the framework of the biopsychosocial model of illness ${ }^{1}$, and, to test whether the theoretically assumed relationships between the core concepts in this new model indeed contribute to adaptation in terms of quality of life, social participation and emotional distress.

In our new model (chapter 2), we suggest a two-dimensional approach to describe the adaptation process after acquired brain injury, which is needed to capture the full complexity of this process. The two dimensions represented in our model are, on the one hand the temporal dimension which comprises the interaction of the short-term and long-term perspective in goal pursuit and/or goal revision, and on the other hand the dimension covering the interaction between behaviour and emotion.

Coping is an element in our model on adaptation, as it plays a role in dealing with the day-today hassles due to acquired brain injury. Because information on psychometric properties of instruments to measure coping in acquired brain injury was lacking, we performed a systematic review. After synthesizing and reviewing information about the conceptualization, feasibility, and psychometric properties, the COPE might be considered as a suitable instrument for use in patients with mild cognitive impairments and mild fatigue. For patients with moderate to severe cognitive impairments the brief COPE, the Coping Scale for Adults-short form and the Utrecht Coping List might be suitable. The other-report version of the Coping with Health Injuries and Problems might be a good alternative for use in patients who struggle with the commonly used self-report format of coping questionnaires. Other instruments may be used when researchers or clinicians have specific questions, such as how an individual is coping with a specific stressful situation or illness (chapter 3).

To test our model, we needed an instrument suitable for measuring situation-specific coping. For this, we selected the Coping Inventory for Stressful Situations (CISS) and we investigated its psychometric properties (construct, discriminant, convergent and divergent validity) to conclude that they were sufficient for use in the acquired brain injury population (chapter 4).

Because the new model is complex in terms of the many interacting components, meaningful parts of the model were isolated for testing (chapter 5,6,7). We found that patients with acquired brain injury made use of a rather defined and stable set of coping strategies across situations. The type of problem encountered had only little influence on patients' use of coping styles. Higher self-efficacy showed to be associated with higher use of active types 
of coping, less emotional distress, higher quality of life and more successful attainment of important long-term goals. Better adaptation was also present in patients with higher tenacity and flexibility in goal pursuit as they experienced lower emotional distress, which was again related to higher quality of life.

In the next sections, we will first evaluate the new theoretical model. Centred around three core concepts of the model i.e. self-efficacy, coping and goal pursuit, the theoretically assumed relationships in the model will be related to the result of the studies that were performed to test the model. Our findings will be discussed and reviewed against the literature. Next, our findings on the measurement of coping will be shortly discussed. This chapter ends with a critical reflection on the clinical implications of our findings and possible directions for future research.

\section{Evaluation of our interactive two-dimensional model}

\section{Self-efficacy}

According to Bandura ${ }^{2}$, self-efficacy is not a trait but a generative capability in which mastery of skills is essential, next to a strong belief in what can be achieved using these skills under a variety of circumstances. Self-efficacy beliefs are domain-specific but various and numerous experiences of success and failure in different domains of functioning may generate a generalized belief of self-efficacy.

In our two-dimensional interactive model on adaptation following acquired brain injury, we considered self-efficacy to be an important element. As self-efficacy determines the level of effort people spend in pursuing their goals and their perseverance in the face of difficulties ${ }^{2}$, we assumed a link with coping through its influence on the ability to manage stress and overcome problems. This aspect concerns the short-term perspective of the model, which is representing the day-to-day adjustment and application of strategies to manage the various problems associated with brain injury.

Furthermore, we assumed that self-efficacy would influence attainment of important life goals. Consequently, self-efficacy would be of influence on the perception of how well one is doing in terms of reducing the discrepancy between one's actual situation and the desired situation, i.e. the anticipated life goals, which in turn would elicit an emotional response. These aspects concern the long-term perspective of the model, in which the focus is on building a new perspective about life and altering expectations about the future. In addition, we also assumed a direct relationship between self-efficacy and outcome (quality of life and social participation). 
Our assumptions were based on research findings in chronic disease showing that high selfefficacy predicts better psychological functioning, improved functional status and improved health behaviour and disease management. ${ }^{3-7}$ In the chronic stage after traumatic brain injury, higher self-efficacy was associated with better quality of life and higher levels of social participation..$^{8-11}$

Concerning the influence of self-efficacy on coping, defined in our model as the way patients deal with their daily hassles due to their injury, we found in our studies that patients with higher general self-efficacy used more active forms of coping i.e. more task-oriented coping and more avoidance coping (chapter 5). Task-oriented coping aims at solving the problem. Avoidance coping refers to actively seeking social support and distraction to alleviate stress. Furthermore, we showed that higher self-efficacy for managing brain injury-specific symptoms was associated with decreased use of emotion-oriented strategies (chapter 5). Emotion-oriented coping represents ventilating of negative emotions.

Moreover, we found that higher self-efficacy for managing brain injury-specific symptoms in the subacute stage after acquired brain injury (mean time since injury $=15$ weeks) was associated with higher quality of life and social participation and protected against the negative effect of emotion-oriented coping on quality of life (chapter 6). Also in spinal cord injury, a positive association between higher general self-efficacy and better social participation and resiliency has been shown. ${ }^{12-14}$

We also showed that patients who were able, over the course of a year, to increase their level of self-efficacy for managing brain injury-specific symptoms experienced better general and health-related quality of life one-year post-discharge home. In addition, higher levels of selfefficacy in the subacute stage were predictive for better long-term general quality of life. In contrast, for predicting long-term levels of social participation, initial self-efficacy and coping styles appeared to be far less important (chapter 6). We are not aware of other longitudinal studies concerning the influence of self-efficacy on quality of life and social participation.

Concerning the influence of self-efficacy on life goal attainment and its emotional repercussions, we showed that patients with higher self-efficacy for managing brain injuryrelated symptoms were more successful in attainment of their important life goals and experienced less emotional distress at one year post-discharge home (chapter 7). Similarly, in a semi-qualitative study in patients with spinal cord injury and multiple sclerosis a positive link was found between achievement of personal important goals and general self-efficacy. ${ }^{15}$ 
We investigated how self-efficacy might influence the relationship between coping and quality of life. As explained in chapter 6, the strength of the effect might differ depending on the level of self-efficacy (moderation) or successful coping experiences might increase a patient's self-efficacy, further leading to better quality of life (mediation). Methodologically it is not possible to test for both mechanisms simultaneously. A mediator cannot be a moderator at the same time. ${ }^{16}$ So, one has to prioritize in testing these effects. As there was some evidence for a stress-buffering effect of high self-efficacy, ${ }^{17,18}$ we choose to test for moderation first. However, overall little literature was available. So, it is important to realize that the choice or preference for one of both mechanisms, largely influences interpretation of results.

In addition, it is important to bear in mind the limitations of a cross-sectional design in unravelling relationships between variables. From a theoretical point of view, ${ }^{2}$ a reciprocal relationship between self-efficacy and coping in relation to outcome is assumed: coping and self-efficacy mutually influence each other. Successful coping experiences might increase a patient's self-efficacy, which in turn might lead to more effective coping and better outcome. ${ }^{2}$ This means that coping might also have a mediating role in the relationship between selfefficacy and outcome. For example, in patients with spinal cord injury, higher general selfefficacy was associated with more use of humour as a form of coping, which was in turn related to better participation. ${ }^{12}$

So, the results of our studies confirm the relationships that were assumed in our model and our findings suggest that self-efficacy indeed seems to play a central role in the adaptation process after acquired brain injury. With regard to the short-term time perspective in our model, higher self-efficacy was related to better adaptation in terms of better quality of life and social participation through its effect on coping. With regard to the long-term time perspective in our model, higher self-efficacy was associated with better adaptation in terms of better quality of life and less emotional distress through its effect on life goal attainment. Also the direct positive relationship between self-efficacy and outcome (quality of life and social participation) was confirmed.

\section{Coping}

In our model, we define coping as the way patients deal with the daily hassles due to their injury. A large body of evidence is available showing the negative influence of passive, escapeavoidant coping styles on psychosocial outcome after acquired brain injury. ${ }^{19-23}$ Our studies are in line with these previous findings, as we found a negative influence of emotion-oriented coping on quality of life. In addition, as already described above, we showed that high selfefficacy for managing brain injury-associated symptoms protected against this negative effect. 
In contrast, the opposite reaction to stress i.e. making use of more problem-oriented and active coping styles is not invariably associated with higher quality of life. ${ }^{19,21,24,25}$ Again, our results are in line with these previous findings (chapter 6). In the subacute stage (mean time since injury = 15 weeks), we found that increased use of avoidance coping, referring to actively seeking social support and distraction, was associated with better quality of life in patients with low self-efficacy and with higher social participation. Yet, we did not find an influence of task-oriented coping on quality of life and social participation. In contrast, increased use of task-oriented coping in the subacute stage after acquired brain injury was predictive for better social participation after one year, but only to a very limited extent.

In our study on coping flexibility (chapter 5), we showed that patients with acquired brain injury seem to rely on a rather defined and stable set of coping strategies across situations. The type of problem that patients were confronted with was of limited influence on the choice of coping styles. Patients only used more task-oriented coping when confronted with cognitive problems compared to physical problems. Yet, the fact that the other problem types (emotional, behavioural and communication) were of much smaller size might have influenced detection of associations. Coping consistency (one's fixed situation-independent coping repertoire) was high for task-oriented coping. Variability in frequency of use of strategies over situations was rather low.

In the literature, the conceptualisation of coping differs depending on the theoretical foundation that serves as background. From the transactional perspective, ${ }^{24}$ coping is considered as a situation-dependent and dynamic process. In the disposition-oriented view, ${ }^{26}$ coping is conceptualised as a personality trait, which assumes that people across situations have preferences for certain coping styles. Coping can also be regarded as domain-specific. ${ }^{27}$ In this view coping is relatively stable across different stressors within one single domain but the coping repertoire used may vary between different domains.

The fact that patients with acquired brain injury seem to have a preference for a rather established set of coping strategies over situations does not seem to support a pure situationdependent nature of coping. Yet, whether coping is domain-specific remains unclear. Notwithstanding that the preference of patients for a rather defined set of coping strategies could also be interpreted as supportive for the disposition-oriented view, we think other explanations must be considered first in this patient group. The fact that flexibility is limited might be due to brain injury characteristics such as cognitive problems and self-awareness deficits. 
We examined whether brain injury-specific symptoms, such as subjective executive functioning and self-awareness, were of influence on coping and coping flexibility (chapter 5). As selfreported executive functions might be influenced by emotional distress, we corrected for this in our analyses. ${ }^{28}$ We did not find subjective executive function to influence coping variability. We showed that patients who reported higher levels of subjective executive dysfunction used more emotion-oriented coping and showed higher coping consistency for task-oriented and emotion-oriented coping. The fact that these patients make use of the same large set of strategies throughout situations might reflect problems in effective strategy selection and suggest 'trial and error' or haphazard coping. We were not able to check this assumption, as we did not measure the effectiveness of the strategies deployed in every situation. We are not aware of other studies about this topic.

Yet, as we did not test the influence of objective cognitive performance, caution in interpretation is needed. With regard to the influence of objective executive functioning on coping the findings in published research are mixed. Some authors did not find a relationship between objective executive performance and the use of coping styles, ${ }^{19,29}$ while others showed that a preference for passive escape avoidant coping was associated with worse performance in the executive control function domain. ${ }^{30-32}$ Other cognitive functions e.g. memory, attention and processing speed showed not to be associated with style of coping. ${ }^{19,29}$ So, executive functions, formally tested or self-reported (this thesis) seem particularly of influence on emotionoriented coping i.e. worse executive functioning is associated with increased escape avoidant behaviour and negative venting of emotions.

With regard to the influence of self-awareness on coping and coping flexibility, we assumed that impaired self-awareness, associated with diminished problem perception, would be associated with decreased strategy use ${ }^{33}$ and low variability (chapter 5). We did not find any relationship between self-awareness and style of coping, or coping variability and coping consistency. Yet, it is important to mention that only a very limited number (2\%) of the patients in our study showed moderate-to-severe awareness deficits, which may have been of influence in detecting associations. Anson et al. ${ }^{19}$ found that greater self-awareness of deficits were associated with increased use of coping characterized by avoidance, worry, self-blame and drug/alcohol abuse. Kortte et al. ${ }^{34}$ did not find support for the hypothesis that impaired self-awareness was associated with lower strategy use. We are not aware of studies investigating the relationship between coping flexibility and self-awareness. So, further exploration of this topic is of interest. 


\section{Goal pursuit, life goal attainment and life goal adjustment}

In our model, we assume a continuous, on-going process of evaluation: at any moment in time the actual level of attainment of one's long-term goals (which is the inverse of goal-performance discrepancy) is compared to the anticipated goals. Discrepancies between desired and actual situation are powerful motivational forces towards action, which can consist of renewed effort and/or adjustment of goals. So, the magnitude of the discrepancy will influence the extent to which one will be tenacious in goal pursuit or more prone to disengagement. At the same time, the experienced goal-performance discrepancy is compared to an expected rate of progress in goal pursuit, which generates an emotional response. Negative feelings may lead to re-engagement and efforts to catch up, but also to frustration when sustained effort does not lead to success in goal attainment. Positive feelings arise from achieving goals. We assume that one's level of self-efficacy will influence this process of evaluation; patients with higher levels of self-efficacy will have a more pronounced tendency towards tenacity. ${ }^{35}$ Furthermore, we assume that patients with impaired awareness, which is associated with inadequate problem perception and therefore inadequate evaluation of discrepancies, will experience little emotional distress and high satisfaction.

We found (chapter 7) that one year after discharge home, only a minority (13\%) of the patients' valuable and important goals in life were completely achieved. As already mentioned, patients with higher self-efficacy for managing brain injury-related symptoms were more successful in attainment of their important life goals. Higher goal attainment was directly associated with higher quality of life (chapter 7). Similarly, in patients with visual impairment, myocardial infarction or Parkinson's disease disturbances in attainment of valuable goals were associated with worse quality of life and emotional distress. ${ }^{36-38}$ Furthermore, our findings are in line with those of Schönberger et al., ${ }^{39}$ who showed that good psychological adjustment to traumatic brain injury was associated with the experience of a smaller discrepancy between present functional status and participants' desired functional status. Furthermore Schönberger et al. ${ }^{39}$ showed that this relationship was moderated by self-awareness: the patients' functional status was more strongly related to poor psychological adjustment in patients with high level of awareness of injury consequences. This latter finding supports the assumption formulated in our model that satisfaction with life might be fairly good in individuals with acquired brain injury who have limited awareness of the consequences of their injury as this might interfere with problem perception and the ability to assess goal-performance discrepancies adequately. The timeframe in which the study of Schonberger et al. ${ }^{39}$ was conducted is comparable to our study (chapter 7).

Furthermore, we showed that goal attainment was not associated with emotional distress (chapter 7). So, in patients with acquired brain injury findings are consistent with theoretical 
assumptions, which state that the rate of progress towards an anticipated goal rather than the size of the goal-performance discrepancy is responsible for generating an emotional response. ${ }^{40}$

Next, we evaluated how patients adjusted their unattained life goals (chapter 7). Of unattained life goals, the majority (58\%) was maintained as originally formulated. A smaller amount of goals $(9 \%)$ were made easier so as to bring aspirations to a more realistic level. For one third of goals the actual level of attainment was accepted as sufficient and striving for more ceased. Only a very small fraction (2\%) of goals was completely abandoned. Goals were abandoned only if attainment was extremely low.

Put differently, our observations revealed a dichotomy in type of adjustment of these goals. For one group of goals continuation of the original engagement was observed and for the other group of goals a tendency towards partial disengagement and acceptation occurred. In contrast, complete disengagement was rare.

In case of partial disengagement and acceptation, we found that ratings of satisfaction with actual level of attainment were fairly high. This might suggest that already at this point in time, for certain valuable life goals, a shift in reference point might have occurred. Internal standards and attributed values are recalibrated to avoid frustration and overwhelming negative emotions. Similarly, in patients who were on average one-year post breast cancer diagnosis and in patients who were on average six months post lower limb amputation, disengagement from unattainable goals was associated with lower levels of negative affect. ${ }^{41,42}$

Yet, a substantial amount of valuable and important life goals were maintained as originally formulated (chapter 7), which could indicate that future possibilities are still assumed favourable and aspirations remain high.

The fact that both high levels of tenacity in goal pursuit and flexibility in goal adjustment are associated with lower levels of emotional distress, which in turn is related to better quality of life, might be a reflection of the presence of both above mentioned processes, i.e. continued engagement versus partial disengagement.

The large differences in how patients adjust their unattained goals in our one-year analysis (chapter 7) might indicate that, at this point in time, awareness of the changes in all aspects of life and adjustment of expectations and hope for recovery has just started. One year, although generally considered as a long follow-up period, might be short in the context of the whole process of adaptation. Clinical experience and research findings ${ }^{43}$ rather suggest that this 
is a process that takes time, and is highly individual. Indeed, Schonberger et al. ${ }^{39}$ showed that large interindividual differences exist during the first year of rehabilitation in the level of psychological adjustment to traumatic brain injury and in the temporal development of adjustment. In addition, the qualitative study of Freeman et al. ${ }^{44}$ describes that patients with traumatic brain injury who were at least 1,5 years post-injury, were still adapting to losses and perceived changes in self-identity and social identity.

The aspect of time needs some further reflection. Our model incorporates a temporal dimension, which represents the interaction of the short-term and long-term perspective in goal pursuit and/or goal revision. On the one hand, the rate of progress over time towards anticipated goals determines whether one perceives the discrepancy between the actual and the desired situation as either favourable or unsatisfactory. On the other hand, the evaluation of and reflection on one's current state and one's aspired state and the decision on subsequent actions, is a process that needs 'a certain amount' of time. Time 'per se' is not a causal factor in inducing changes or adaptation. Also in spinal cord injury, only weak empirical support exists for the notion that longer duration of disability results in better adaptation to the condition's impact. ${ }^{45}$

Furthermore, the temporal aspect of our model is not synonymous with time since injury and as such the cyclical character of the adjustment process does fit into our model. Due to major contextual changes, e.g. marriage, birth of children, changes in employment, patients have to make adjustments in their lives at any moment, independent of time since injury. Either being confronted with problems in the acute stage after injury or facing major life events in the chronic phase requires the same kind of adaptation process as described in our model. Qualitative studies in patients with acquired brain injury and spinal cord injury showed that reconstruction of one's self-concept does not follow a linear trend, but seems to be an ongoing process leading to a state of perpetual re-evaluation and tentative balance. ${ }^{46,47}$

\section{The model as a whole}

Overall, we can state that, except for self-awareness, all the components of the model which we assumed to be of importance (self-efficacy, coping, life goal attainment, tenacity and flexibility in goal pursuit, cognitive functions) seem to play a role in the process of adaptation to the consequences of acquired brain injury, defined in terms of emotional distress, quality of life and social participation.

The results of the studies in this thesis must be considered as a first exploration on the associations between the different components of the model, but do not allow us yet to infer temporal or causal relationships concerning the mechanisms involved in goal revision. 
In other chronic diseases (such as arthritis, chronic heart failure, pulmonary disease) adaptation is often looked at from a self-management perspective. ${ }^{4,5}$ Three sets of tasks are proposed to manage illness and self-care. The first set of tasks involves the medical management of the disease (medical management). The second set of tasks involves maintaining, changing, and creating new meaningful behaviours and life goals (role or behavioural management). The third set of tasks involves dealing with the emotional sequelae of having a chronic condition and altering future perspectives (emotional management). The concept of selfefficacy is assumed to play a central role in the accomplishments of all these tasks. In the self-management model the focus is on how people can develop high levels of self-efficacy in relevant domains resulting in changes in health behaviour. The self-management model is developed to guide interventions teaching patients to take responsibility for the day-to-day management of their disease. When looking at different examples of these health promotion and patient education programmes, most deal with the medical and role management (e.g. adherence to medication use, lifestyle change, health care utilization...) and as such are rather limited in scope. ${ }^{48-50}$ So, in chronic disease self-management, in accordance with our model, self-efficacy has a central role. However, the self-management model differs from our model, as it is not a priori explanatory in nature.

Of course, our model is incomplete. For example Gracey et al. ${ }^{51}$ emphasize the role of selfconcept and self-identity and its relation to social identity in the adaptation process after acquired brain injury. Although these concepts are related to personal goals, they are not the same. Furthermore, we shortly mentioned family and social support, optimism and selfesteem as influencing factors (chapter 2) but we did not include them in our studies, at this point. With regard to life goals and self-regulation, one could also think of other components that might influence the process of adaptation, such as attainability of goals and reengagement in new valued goals. ${ }^{41,52,53}$

Is adaptation to brain injury a unique process or similar to adaptation in any other chronic disease? In our opinion, adaptation to any acute onset disability is similar in many aspects. What might be unique in the adaptation process to acquired brain injury is the presence of cognitive impairments and impaired self-awareness, as both might interfere with almost any relationship in our model.

Recently, Lennon et al. ${ }^{47}$ showed in a qualitative study that many similarities exist in the ways in which patients with acquired brain injury and patients with spinal cord injury reconstruct their sense of self after having experienced this sudden-onset life-changing injury. The differences that were observed between the two groups were supposed to be due to cognitive deficits ${ }^{47}$ although cognitive functioning was not measured either by self-report questionnaires or formal testing. 


\section{The measurement of coping}

To test our model, we needed an instrument suitable for measuring situation-specific coping in patients with acquired brain injury. We choose the 48-item Coping Inventory for Stressful Situations (CISS) and made its instruction situation-specific. Our choice was based on its feasibility (easy wording) and its excellent psychometric properties in the general population. We did not use the 21-item CISS-Situation Specific Coping ${ }^{54}$ as this questionnaire is not widely used and information on its psychometric properties is scarce..$^{54,55}$

We performed a study on the psychometric properties of the 48-item CISS, because no such information was available for acquired brain injury (chapter 4). The consistent finding of a three- to four-factor structure across studies, including ours, using various versions of the questionnaire (either the CISS-SSC or the 48-item CISS) and various instructions, suggests that all these versions of the CISS are measuring the same underlying construct.

\section{Methodological considerations}

Research must always be interpreted in the light of its methodology. In the next section we will review the strengths and limitations of our work critically.

\section{Strengths}

We asked 190 patients to participate in our study, of which only $37(19 \%)$ refused and $5(3 \%)$ showed to have non-matching inclusion criteria after check. The numbers of patients included in our analyses were large, ranging from 136 (chapter 5) to 148 (chapter 6,7). The number of patients lost to observation between baseline measurement and follow-up measurement one year later was negligible $(n=5)$.

We recruited patients after discharge home from hospital or from the rehabilitation setting, which makes our sample representative for the population of patients with acquired brain injury that return to their home environment, not requiring long-term residential care.

Consecutive recruitment of patients succeeded well in the rehabilitation settings but some gaps in recruitment appeared in the participating hospitals. We choose not to restrict our study sample to a single diagnosis (e.g. stroke or traumatic brain injury) but to include all forms of non-progressive newly acquired brain injury, because in our studies the focus is on changes (symptomatology of any kind) caused by the injury. The focus is not on a specific disease. Wade et al. ${ }^{56}$ state that, in rehabilitation research, patients should be selected and described by the clinical problem presented and that it is rarely appropriate or necessary to restrict studies to people with a specific disease diagnosis. The trade-off of this choice was that 
we might have missed effects of awareness deficits. Awareness deficits occur more frequently in patients with traumatic brain injury due to the higher incidence of frontal lobe damage. ${ }^{57}$

Since we were interested in changes in coping, self-efficacy, and goal attainment, we used longitudinal designs for all our studies. Psychometric properties of the measurement instruments that we used were good; psychometric properties of the Coping Inventory for Stressful Situations showed to be good (chapter 4), using our data internal reliability of all other scales showed to be good (chapter 6 and 7). We choose a sufficiently long follow-up period, i.e. one year to cover the emerging confrontation with long(er)-lasting impairments, as most of the recovery process occurs in the first months. ${ }^{58,59}$

The overall strength of these studies is that we conducted our research based on a theoretical model on the adaptation process after acquired brain injury. A theoretical understanding of the likely process of change is a first step in the development of interventions aiming at optimizing adjustment and adaptation. As such, our results and that of other researchers can be used to adapt and improve the model and gain insight into this complex process in a more systematic way.

\section{Limitations}

In our studies in chapter 5 and 6, the domains assessed with the Traumatic Brain Injury (TBI) Self-efficacy Questionnaire ${ }^{8}$ (managing cognitive, physical, emotional and social consequences of the injury) matched almost perfectly with the subject of coping i.e. physical, cognitive, emotional, behavioural, communicative and other problems. Yet, with regard to our study on life goal attainment (chapter 7), the self-efficacy domains captured with the TBI self-efficacy questionnaire, although spanning a broad spectrum of symptoms, might not have been sufficient with regard to all life goals. One could imagine that attainment of some life goals involve other more specific self-efficacy domains that are not included in the TBI self-efficacy questionnaire.

The amount and kind of therapy that patients have received, might be a possible confounder. Yet, our study was observational in nature and not an effect study.

In our original study design, we planned to rate the patients' perception of attainability of initial life goals as a part of the baseline interview. For each goal, patients were given a choice of 4 categories of attainability (from very likely to very unlikely). Yet, during execution of the study it became clear that patients were not capable of judging achievability in a reliable way. The majority of patients indicated that they could not assess the likelihood of attainability of their life goals. They only wished it would be very likely. So, we stopped to inventory achievability. 
A possible explanation might be that the answering categories were not distinctive enough. Maybe, this question came too early, as most patients had returned home some weeks ago and confrontation with real life problems only just started.

In our study on coping flexibility we did not include a control group of healthy subjects. So, we could not determine whether coping variability or consistency in patients with acquired brain injury differed from the healthy population.

\section{Clinical implications}

Nowadays, supported by scientific evidence mainly stemming from research on motor recovery, ${ }^{58,60}$ and based on economic motives, ${ }^{61}$ the emphasis in rehabilitation is on creating intensive but short-duration rehabilitation programs at the early stage after injury. As adaptation to acquired brain injury is a process that takes time, this approach holds the risk of leaving gaps in the more psychosocial oriented part of treatment, resulting in a suboptimal overall outcome. Therefore, it is important to identify patients at risk for worse outcome in the early stages after injury.

In this thesis, we showed that lower self-efficacy for managing brain injury-associated symptoms and making high use of emotion-oriented coping in the early stage after injury are putative risk factors for worse quality of life. In clinical practice, as well in rehabilitation as in hospital settings or in primary health care, questionnaires (e.g. the Traumatic Brain Injury Self-efficacy Questionnaire and the Coping Inventory for Stressful Situations) can be very easily used to detect these risk factors.

The results of the different studies in this thesis suggest that therapeutic attempts to enhance self-efficacy in the early stage after acquired brain injury would be appropriate. Training of skills in various domains of functioning, which is the basic component of self-efficacy, is the central part in rehabilitation programmes and therapy conducted in the hospital setting or primary health care facility. In our clinical experience with these treatment programmes, less explicit attention is paid to the second component of self-efficacy namely that of developing the firm belief or confidence that goals can be achieved through these skills, even under difficult circumstances. In our opinion, it is essential to reinforce the development of these self-beliefs explicitly. Referential comparison with others, verbal feedback and control over negative physiological and affective states (e.g. stress, fatigue) could be used to create strong efficacy beliefs in any domain of functioning. ${ }^{2}$ Recently, Aben et al. ${ }^{62}$ showed that training memory self-efficacy in patients with stroke had many beneficial effects over traditional 
memory rehabilitation treatment. The memory self-efficacy training consisted of a general theoretical introduction on memory and stroke, training internal and external compensatory memory strategies and psycho-education on the influence of mood, anxiety and memoryrelated worries on memory complaints. A positive impact on psychological aspects of quality of life was observed, even one year after the intervention. ${ }^{62}$ Furthermore, Backhaus et al. ${ }^{63}$ showed that after a 12-week coping skills training programme patients' self-efficacy in coping improved and levels of emotional distress remained stable, while they did increase in the control group. Even in sports psychology, it has been shown that track and field athletes' general self-efficacy improved through vicarious experiences, by learning control over negative emotions and by learning to deal with failure. ${ }^{64}$ Marks et al. ${ }^{4}$ made several recommendations and described specific approaches for enhancing self-efficacy in patients with chronic diseases in different settings.

As we showed an association between coping and self-efficacy, the question arises if it is sufficient to solely rely on enhancement of self-efficacy to improve coping. In our opinion, a balanced approach is needed. Enhancing self-efficacy for the management of brain injuryassociated symptoms might counter the deleterious effects of emotion-oriented coping. So, we would encourage therapeutic attempts to enhance self-efficacy for managing the various cognitive and physical symptoms and the emotional and social consequences of the injury. In addition, we think it is necessary to equip patients, who show inadequate coping, with a set of problem-solving and stress-reducing strategies. Especially in patients with impaired executive functions, it seems appropriate to teach a small but effective set of coping strategies, as problems in effective strategy selection are probably present. Training of coping skills is possible in these patients. ${ }^{25,65}$

It is well known that rehabilitation after acquired brain injury is more successful and motivation increases when personally important goals are set which are concurrent with one's life goals. ${ }^{66-68}$ Our findings stress the importance of such an approach, as we showed that attainment of important life goals is associated with better long-term quality of life.

\section{Future research directions}

As we already mentioned, the research design we used in this thesis, did not allow us to gain insight in the full temporal development of the adaptation process and in the causality of the relationships between the different elements in the adaptation process. Such insight is needed in order to further identify risk factors for unfavourable adaptation, and maybe even more important, to give further direction to treatment programmes. 
With regard to the temporal development of the adaptation process, future research should focus on two different aspects. On the one hand, it is necessary to follow cohorts of patients for many years after injury to gain insight in the long-term development of the adaptation process. On the other hand, a different kind of research design, for example multiple measurements in a rather short period of time (time series) might help to gain insight into some specific aspects of the adaptation process, e.g. what factors are responsible for goal revision, scaling back goals, finding new adaptive meanings and identities ${ }^{51}$.

We also should reflect carefully on the choice of outcome measures. In this thesis, next to social participation and emotional distress, we choose quality of life as the representation of the level of adaptation. Yet, quality of life is a very broad concept and difficult to grasp. ${ }^{69}$ According to Dijkers, ${ }^{69}$ subjective well-being represents subjective quality of life, i.e., the individual's cognitive and emotional reactions to the balance of achievements and expectations in life. In contrast, objective quality of life assesses achievement in predefined major domains of life, which are considered to be of general importance. ${ }^{69}$ Indeed, in chapter 7 we saw that both emotional distress, which is related to subjective well-being, and goal attainment contributed to quality of life. In further research, it is necessary to carefully select both primary and secondary outcome measures. ${ }^{70}$ Primary outcome measures should be very closely related to the specific changes in the process of adaptation that are of interest. Secondary outcomes should be related to more distal changes. ${ }^{70}$ For example, a very important component in the adaptation process after acquired brain injury is shifting one's reference point and recalibrating one's internal standards, which in turn influence one's aspirations and goals to pursue. When investigating the factors contributing to this shift, an example of a primary outcome measure could be the value attached to ones' life goals or the way initial goals are adjusted. Quality of life could only be a secondary outcome measure as this shift in reference point is automatically incorporated in one's ratings of quality of life.

Furthermore, as already mentioned, it would be interesting to incorporate several other variables in our model on adaptation. For example, further detailed research on the changes in self-concept, of which personally valuable goals are an important part, is needed and this comprises as well factors that contribute to the experienced discrepancy between the preinjury and post-injury self $f^{51}$ and factors that contribute to the development of positive changes in the perception of self and interpersonal relationships (personal growth). ${ }^{71,72}$ With regard to life goals and self-regulation, one could think of adding components such as attainability of goals and reengagement in new valued goals. ${ }^{41,52,53}$

With regard to interventions, the question arises if it would be possible to develop a kind of general therapy format for improvement of self-efficacy in patients with acquired brain injury after the example of Marks et al. ${ }^{4}$ and Lorig et al. ${ }^{73}$ in chronic disease. Such a general therapy 
format would have the advantage of being suitable for improving self-efficacy in any domain of functioning and would be applicable and adaptable to any kind of therapy or training in rehabilitation, hospital or primary care. 


\section{References}

1. Wade DT. Applying the WHO ICF framework to the rehabilitation of patients with cognitive deficits. In: Halligan PW, Wade DT, eds. Effectiveness of rehabilitation for cognitive deficits. Oxford: Oxford University Press; 2005.

2. Bandura A. Self-efficacy: the exercise of control. New York: W.H. Freeman and Company; 1997.

3. Hellstrom K, Lindmark B, Wahlberg B, Fugl-Meyer AR. Self-efficacy in relation to impairments and activities of daily living disability in elderly patients with stroke: a prospective investigation. $J$ Rehabil Med. 2003;35(5):202-207.

4. Marks R, Allegrante JP. A review and synthesis of research evidence for self-efficacy-enhancing interventions for reducing chronic disability: implications for health education practice (Part II). Health Promot Pract. 2005;6(2):148-156.

5. Lorig K, Holman H. Self-management education: history, definition, outcomes, and mechanisms. Ann Behav Med. 2003;26(1):1-7.

6. Lorig KR, Ritter P, Stewart AL, et al. Chronic disease self-management program: 2-year health status and health care utilization outcomes. Med Care. 2001;39(11):1217-1223.

7. O'Leary A. Self-efficacy and health: behavioral and stress-physiological mediation. Cognit Ther Res. 1992;16(2):229-245.

8. Cicerone KD, Azulay J. Perceived self-efficacy and life satisfaction after traumatic brain injury. $J$ Head Trauma Rehabil. 2007;22(5):257-266.

9. Rutterford NA, Wood RL. Evaluating a theory of stress and adjustment when predicting longterm psychosocial outcome after brain injury. J Int Neuropsychol Soc. 2006;12(3):359-367.

10. Dumont C, Gervais M, Fougeyrollas P, Bertrand R. Perceived self-efficacy is associated with social participation in adults with traumatic brain injury. Can J Occup Ther. 2005;72(4):222-233.

11. Dumont C, Gervais M, Fougeyrollas P, Bertrand R. Toward an explanatory model of social participation for adults with traumatic brain injury. J Head Trauma Rehabil. 2004;19(6):431-444.

12. Peter C, Muller R, Post MW, et al. Psychological resources, appraisals, and coping and their relationship to participation in spinal cord injury: a path analysis. Arch Phys Med Rehabil. 2014;95(9):1662-1671.

13. Geyh S, Nick E, Stirnimann D, et al. Self-efficacy and self-esteem as predictors of participation in spinal cord injury: an ICF-based study. Spinal Cord. 2012;50(9):699-706.

14. Kilic SA, Dorstyn DS, Guiver NG. Examining factors that contribute to the process of resilience following spinal cord injury. Spinal Cord. 2013;51(7):553-557.

15. Block P, Vanner EA, Keys CB, Rimmer JH, Skeels SE. Project Shake-It-Up: using health promotion, capacity building and a disability studies framework to increase self efficacy. Disabil Rehabil. 2010;32(9):741-754.

16. Jacoby J, Sassenberg K. It takes four to tango: why a variable cannot be a mediator and a moderator at the same time. Available at http://www.academia.edu/1928836/Jacoby_J._and_ Sassenberg_K._2010_._It_takes_four_to_tango_Why_a_variable_cannot_be_a_mediator_ and_a_moderator_at_the_same_time._Unpublished_manuscript. Accessed October 1, 2014

17. Prati G, Pietrantoni L, Cicognani E. Self-efficacy moderates the relationship between stress appraisal and quality of life among rescue workers. Anxiety Stress Coping. 2009;23(4):463-470.

18. Deno M, Tashiro M, Miyashita M, et al. The mediating effects of social support and self-efficacy on the relationship between social distress and emotional distress in head and neck cancer outpatients with facial disfigurement. Psychooncology. 2012;21(2):144-152.

19. Anson K, Ponsford J. Coping and emotional adjustment following traumatic brain injury. J Head Trauma Rehabil. 2006;21(3):248-259. 
20. Wolters G, Stapert S, Brands I, Van Heugten C. Coping styles in relation to cognitive rehabilitation and quality of life after brain injury. Neuropsychol Rehabil. 2010;20(4):587-600.

21. Wolters G, Stapert S, Brands I, van Heugten C. Coping following acquired brain injury: predictors and correlates. J Head Trauma Rehabil. 2011;26(2):150-157.

22. Wolters Gregorio G, Gould KR, Spitz GB, van Heugten CM, Ponsford JL. Changes in selfreported pre- to postinjury coping styles in the first 3 years after traumatic brain injury and the effects on psychosocial and emotional functioning and quality of life. J Head Trauma Rehabil. 2014;29(3):E43-E53.

23. Dawson DR, Schwartz ML, Winocur G, Stuss DT. Return to productivity following traumatic brain injury: cognitive, psychological, physical, spiritual, and environmental correlates. Disabil Rehabil. 2007;29(4):301-313.

24. Folkman S, Moskowitz JT. Coping: pitfalls and promise. Annu Rev Psychol. 2004;55(1):745-774.

25. Anson K, Ponsford J. Who benefits? Outcome following a coping skills group intervention for traumatically brain injured individuals. Brain Inj. 2006;20(1):1-13.

26. Schreurs PJ, Tellegen B, Willige GV. Health, stress and coping: the development of the Utrechtse Coping Scale. Gedrag: Tijdschrift voor psychologie. 1984;12:101-117.

27. Ptacek JT, Pierce GR. Issues in the study of stress and coping in rehabilitation settings. Rehabil Psychol. 2003;48(2):113-124.

28. Schiehser DM, Delis DC, Filoteo V, et al. Are self-reported symptoms of executive dysfunction associated with objective executive function performance following mild to moderate traumatic brain injury? J Clin Exp Neuropsychol. 2011;33(6):704-714.

29. Wolters Gregório G, Ponds RW, Smeets F, Jonker CG, Pouwels FR, van Heugten CM. Coping and executive functioning in individuals with neuropsychiatric symptoms due to acquired brain injury. 2013.

30. Krpan KM, Levine B, Stuss DT, Dawson DR. Executive function and coping at one-year post traumatic brain injury. J Clin Exp Neuropsychol. 2007;29(1):36-46.

31. Krpan KM, Stuss DT, Anderson ND. Coping behaviour following traumatic brain injury: what makes a planner plan and an avoider avoid? Brain Inj. 2011;25(10):989-996.

32. Kegel J, Dux M, Macko R. Executive function and coping in stroke survivors. NeuroRehabilitation. 2014;34(1):55-63.

33. Medley AR, Powell T, Worthington A, Chohan G, Jones C. Brain injury beliefs, self-awareness, and coping: a preliminary cluster analytic study based within the self-regulatory model. Neuropsychol Rehabil. 2010;20(6):899 - 921.

34. Kortte KB, Wegener ST, Chwalisz K. Anosognosia and denial: their relationship to coping and depression in acquired brain injury. Rehabil Psychol. 2003;48(3):131-136.

35. Brandtstädter J, Rothermund $\mathrm{K}$. The life-course dynamics of goal pursuit and goal adjustment: a two-process framework. Dev Rev. 2002;22(1):117-150.

36. McNamara PR. Life goals of patients with Parkinson's disease: a pilot study on correlations with mood and cognitive functions. Clin Rehabil. 2006;20(9):818-826.

37. Boersma SN, Maes S, van Elderen T. Goal disturbance predicts health-related quality of life and depression 4 months after myocardial infarction. Br J Health Psychol. 2005;10(4):615-630.

38. Boerner KV. Optimizing rehabilitation for adults with visual impairment: attention to life goals and their links to well-being. Clin Rehabil. 2005;19(7):790-798.

39. Schönberger M, Ponsford J, McKay A, et al. Development and predictors of psychological adjustment during the course of community-based rehabilitation of traumatic brain injury: a preliminary study. Neuropsychol Rehabil. 2014;24(2):202-219.

40. Carver CS, Scheier MF. On the self-regulation of behaviour. 2005 ed. Cambridge: Cambridge university Press; 1998. 
41. Wrosch C, Sabiston CM. Goal adjustment, physical and sedentary activity, and well-being and health among breast cancer survivors. Psychooncology. 2013;22(3):581-589.

42. Coffey LP, Gallagher P, Desmond D. A prospective study of the importance of life goal characteristics and goal adjustment capacities in longer term psychosocial adjustment to lower limb amputation. Clin Rehabil. 2014;28(2):196-205.

43. Kendall E, Catalano T, Kuipers P, Posner N, Buys N, Charker J. Recovery following stroke: the role of self-management education. Soc Sci Med. 2007;64(3):735-746.

44. Freeman A, Adams M, Ashworth F. An exploration of the experience of self in the social world for men following traumatic brain injury. Neuropsychol Rehabil. 2014, May 21. [Epub ahead of print]

45. Martz E, Livneh H, Priebe M, Wuermser LA, Ottomanelli L. Predictors of psychosocial adaptation among people with spinal cord injury or disorder. Arch Phys Med Rehabil. 2005;86(6):1182-1192.

46. Muenchberger H, Kendall E, Neal R. Identity transition following traumatic brain injury: a dynamic process of contraction, expansion and tentative balance. Brain Inj. 2008;22(12):979-992.

47. Lennon A, Bramham J, Carroll À, et al. A qualitative exploration of how individuals reconstruct their sense of self following acquired brain injury in comparison with spinal cord injury. Brain Inj. 2014;28(1):27-37.

48. Lorig K, Ritter P, Pifer C, Werner P. Effectiveness of the chronic disease self-management program for persons with a serious mental illness: a translation study. Community Ment Health J. 2014;50(1):96-103.

49. Lorig K, Ritter PL, Ory MG, Whitelaw N. Effectiveness of a generic chronic disease selfmanagement program for people with type 2 diabetes: a translation study. Diabetes Educ. 2013;39(5):655-663.

50. McCorkle R, Ercolano E, Lazenby M, et al. Self-Management: enabling and empowering patients living with cancer as a chronic illness. CA Cancer J Clin. 2011;61(1):50-62.

51. Gracey F, Evans JJ, Malley D. Capturing process and outcome in complex rehabilitation interventions: a "Y-shaped" model. Neuropsychol Rehabil. 2009;19(6):867-890.

52. Wrosch C, Scheier MF, Miller GE, Schulz R, Carver CS. Adaptive self-regulation of unattainable goals: goal disengagement, goal reengagement, and subjective well-being. Pers Soc Psychol Bull. 2003;29(12):1494-1508.

53. Conrad N, Doering BK, Rief W, Exner C. Looking beyond the importance of life goals. The personal goal model of subjective well-being in neuropsychological rehabilitation. Clin Rehabil. 2010;24(5):431-443.

54. Endler NS, Parker JD. Coping Inventory for Stressful Situations (CISS): manual. Toronto: MultiHealth Systems; 1999.

55. Cohan SL, Jang KL, Stein MB. Confirmatory factor analysis of a short form of the Coping Inventory for Stressful Situations. J Clin Psychol. 2006;62(3):273-283.

56. Wade DT, Smeets RJ, Verbunt JA. Research in rehabilitation medicine: methodological challenges. J Clin Epidemiol. 2010; 63(7):699-704.

57. Stuss DTLB. Adult clinical neuropsychology: lessons from studies of the frontal lobes. Annu Rev Psychol. 2002;53(1):401- 433.

58. Kwakkel G, Kollen BJ. Predicting activities after stroke: what is clinically relevant? Int J Stroke. 2013;8(1):25-32.

59. El Hachiouia H, van de Sandt-Koenderman MW, Dippela DW, Peter J., Visch-Brinka EG. A 3-year evolution of linguistic disorders in aphasia after stroke. J Rehabil Res 2011;34(3):214-221.

60. Kwakkel G, Wagenaar RC, Twisk JW, Lankhorst GJ, Koetsier JC. Intensity of leg and arm training after primary middle-cerebral-artery stroke: a randomised trial. The Lancet. 1999;354(9174):191196. 
61. van Eeden M, Van Heugten C, Evers S. The economic impact of stroke in The Netherlands: the restore4stroke study. BMC Public Health. 2012;12:122.

62. Aben L, Heijenbrok-Kal MH, Ponds RW, Busschbach JJ, Ribbers GM. Long-lasting effects of a new memory self-efficacy training for stroke patients: a randomized controlled trial. Neurorehabil Neur Repair. 2014;28(3):199-206.

63. Backhaus SL, Ibarra SL, Klyce D, Trexler LE, Malec JF. Brain injury coping skills group: a preventative intervention for patients with brain injury and their caregivers. Arch Phys Med Rehabil. 2010;91(6):840-848.

64. Zagórska A, Guszkowska M. A program to support self-efficacy among athletes. Scand J Med Sci Sports. 2014;24(3):121-128.

65. Anson K, Ponsford J. Evaluation of a coping skills group following traumatic brain injury. Brain Inj. 2006;20(2):167-178.

66. Nair KP. Life goals: the concept and its relevance to rehabilitation. Clin Rehabil. 2003;17(2):192202.

67. Nair KP, Wade DT. Changes in life goals of people with neurological disabilities. Clin Rehabil. 2003;17(7):797-803.

68. Bergquist TF, Micklewright JL, Yutsis M, Smigielski JS, Gehl C, Brown AW. Achievement of client-centred goals by persons with acquired brain injury in comprehensive day treatment is associated with improved functional outcomes. Brain Inj. 2012;26(11):1307-1314.

69. Dijkers MP. Quality of life after traumatic brain injury: a review of research approaches and findings. Arch Phys Med Rehabil. 2004;85(4 Suppl 2):S21-35.

70. Whyte J. Contributions of treatment theory and enablement theory to rehabilitation research and practice. Arch Phys Med Rehabil. 2014;95(1, Suppl):S17-S23.e12.

71. Hawley CA, Joseph S. Predictors of positive growth after traumatic brain injury: a longitudinal study. Brain Inj. 2008;22(5):427-435.

72. Collicutt McGrath J, Linley PA. Post-traumatic growth in acquired brain injury: a preliminary small scale study. Brain Inj. 2006;20(7):767-773.

73. Lorig K, Laurent DD, Plant K, Krishnan E, Ritter PL. The components of action planning and their associations with behavior and health outcomes. Chronic Illn. 2014;10(1):50-59. 
Summary 
Acquired brain injury refers to any non-progressive injury to the brain caused after birth. The two most common forms of acquired brain injury are strokes and traumatic brain injuries.

Chapter $\mathbf{1}$ is a general introduction to the topic of this thesis: the adaptation process after acquired brain injury. Physical, cognitive, emotional and behavioural problems are frequently present in patients with acquired brain injury and are often followed by long-lasting impairment and disability. In addition, sustaining a brain injury is usually a disruptive event and may cause major changes, not only in the life course of patients but also in their families' lives. The process of adjustment to these various changes caused by the injury is often difficult and shows an unfavourable course. The most commonly used theoretical framework to understand the process of adaptation after brain injury is 'the theory of stress and coping' by Lazarus and Folkman. This theory was developed to explain how people deal with acute stress in general. Yet, 'the theory of stress and coping' is only partially sufficient in explaining psychosocial outcome after acquired brain injury. Therefore, a new model is proposed in which the emphasis is on behavioural change.

The main objectives of this thesis were twofold:

1. To develop a new theoretical model on the adaptation process after acquired brain injury.

2. To test the main components of this model

\section{Part One. The interactive two-dimensional model on adaptation after acquired brain injury}

Chapter 2 describes the new model on the adaptation process following acquired brain injury, based on the patient's goals, the patient's abilities, and the possible discrepancy between goals and achievements, and the emotional response to the changes. The process of adaptation after acquired brain injury is characterized by a continuous interaction of two processes: achieving maximal restoration of function; and adjusting to the alterations and losses that occur in the various domains of functioning. Consequently, adaptation requires a balanced mix of restoration-oriented coping and loss-oriented coping. The commonly used framework to explain adaptation, 'the theory of stress and coping' by Lazarus and Folkman, does not capture this interactive duality. The new model additionally considers theories concerned with self-regulation of behaviour and self-efficacy, in which the setting and achievement of goals is central. The new model also incorporates the influence of self-awareness. Our model proposes the simultaneous and continuous interaction of two pathways; goal pursuit (shortterm and long-term) and/or goal revision as a result of success or failure in reducing distance between current state and expected future state, and an emotional response that is elicited by 
the experienced goal-performance discrepancies. This emotional response, in turn, influences the goals set. So, the two dimensions described in the model are, on the one hand the temporal dimension representing the interaction of the short-term and long-term perspective in goal pursuit and/or goal revision, and on the other hand the dimension covering the interaction between behaviour and emotion. This two-dimensional representation also covers the processes mentioned above; restoration of function, attempts to recover lost skills and abilities, and consideration of long-term limitations. It is proposed that adaptation centres on readjustment of long-term goals to new achievable but desired and important goals, and that this adjustment underlies re-establishing emotional stability. Finally, the new proposed model is discussed related to actual rehabilitation practice.

\section{Part Two. The measurement of coping}

Chapter 3 is a systematic review identifying the instruments used to measure coping in patients with acquired brain injury and summarizing information on the conceptualization of coping, and the feasibility and psychometric properties of the instruments. For this study, articles published between 1970 and 2011 were screened on information on both coping and brain injury. The search identified 47 instruments, of which 14 instruments were selected for further evaluation. Overall, we can conclude that information on the psychometric properties of instruments used to measure coping in patients with acquired brain injury is scarcely available. After synthesizing and reviewing information about the conceptualization, feasibility, and psychometric properties, the COPE might be considered as a suitable instrument for use in patients with mild cognitive impairments and mild fatigue. For patients with moderate to severe cognitive impairments the brief COPE, the Coping Scale for Adultsshort form and the Utrecht Coping List might be suitable. The other-report version of the Coping with Health Injuries and Problems might be a good alternative for use in patients who struggle with the commonly used self-report format of coping questionnaires. Other instruments may be used when researchers or clinicians have specific questions, such as how an individual is coping with a specific stressful situation or illness.

Chapter 4 presents a study on the psychometric properties of the Coping Inventory for Stressful Situations (CISS) in acquired brain injury. The construct, discriminant, convergent and divergent validity of the CISS in 139 patients with newly acquired brain injury was investigated. Patients were recruited at the start of outpatient neurorehabilitation (time since diagnosis $\leq 4$ months) or after discharge home from hospital or inpatient neurorehabilitation. The original three-factor solution of the CISS (Task-oriented, Emotion-oriented and Avoidance) showed borderline fit, which slightly improved after removal of three problematic 
items. We found borderline support for a four-factor model. Internal consistency was good. Discriminant validity was partially sufficient, as we found a moderate correlation between the Task-oriented and Avoidance scale. Emotion-oriented coping correlated strongly with the Anxiety and Depression subscale of the Hospital Anxiety and Depression Scale. Of the two scales of the Assimilative/Accommodative Coping Questionnaire, Tenacious Goal Pursuit correlated strongest with Task-oriented coping, whereas Flexible Goal Adjustment correlated negatively with Emotion-oriented coping. In summary, we can conclude that the psychometric properties of the CISS in patients with acquired brain injury ranged from acceptable to good. The classical three-factor structure is appropriate, but some items might be problematic in patients with acquired brain injury. Replication of the restricted threefactor model in larger samples is needed, together with further exploration of discriminant validity and the relationship of the CISS with other coping measures. For now, the use of the original CISS in patients with acquired brain injury is recommended.

\section{Part Three. Testing components of the new interactive two-dimensional model on adaptation following acquired brain injury}

Chapter 5 describes a study on coping flexibility in 136 patients with newly acquired brain injury assessed after discharge home (mean time since diagnosis $=15$ weeks) and one year later (mean time since diagnosis $=67$ weeks). Coping flexibility means that coping styles can be readily adapted to changing contextual demands. The aims of this study were (1) to explore if coping responses are adapted across situations, according to the type of problem encountered and over time; (2) to investigate coping variability (the range in frequency of use of strategies across situations) and coping consistency (one's fixed situation-independent coping repertoire, the number of strategies used throughout every situation) and its evolution over time and (3) to investigate the influence of self-reported executive functioning, selfawareness and self-efficacy on coping, variability and consistency. Situation-specific coping was measured by asking patients to complete a Coping Inventory for Stressful Situations (CISS) for each of three stressful situations that they had encountered as a consequence of their brain injury during the previous two weeks. These situations were then categorized into problem types: physical, cognitive, emotional, behavioural, communication and other. We found that patients relied on a rather defined and stable set of coping strategies, both over time and across different situations. Contrary to our expectations, the type of problem was of limited influence on patients' use of coping styles. Patients only used more task-oriented coping when confronted with cognitive problems compared to physical problems. Coping variability was limited. Reliance on emotion-oriented coping decreased over time. Higher general self-efficacy correlated with increased task-oriented coping (directed at solving the 
problem) and avoidance coping (referring to actively seeking social support and distraction), which both are needed in adapting to the consequences of acquired brain injury. Higher levels of self-efficacy for managing brain injury-specific symptoms correlated with decreased use of emotion-oriented coping (venting of negative emotions). Greater self-reported problems in executive function correlated with greater consistency for task-oriented and emotionoriented strategies. This invariable deployment of a greater amount of task and emotion strategies throughout situations might reflect problems in effective strategy selection. To optimize adjustment to the diverse consequences of acquired brain injury, we suggest training patients, especially those who experience problems in executive functioning, to use a small but effective set of coping strategies. Furthermore, these findings suggest that therapeutic attempts to enhance self-efficacy during rehabilitation would be appropriate, as this seems to promote active coping.

Chapter 6 presents the results of a study investigating (1) the relationships linking self-efficacy for the management of brain injury-specific symptoms and coping to quality of life and social participation and (2) the influence of initial self-efficacy, changes in self-efficacy and initial coping style on long-term quality of life and social participation. One hundred and forty-eight patients with newly acquired brain injury participated in this study. They were assessed after discharge home and one year later. In the subacute stage, self-efficacy influenced the relation between coping and quality of life in different ways. Increasing self-efficacy for managing brain injury-specific symptoms seemed to mitigate the negative influence of emotionoriented coping on health-related quality of life (EQ-5D index and EQ VAS), suggesting that high self-efficacy has a protective effect. Patients using more emotion-oriented coping had lower general quality of life (LiSat-9). Testing effect mediation showed that this was because these patients had lower self-efficacy for managing brain injury-specific symptoms. Increased use of avoidance coping was associated with higher health status (EQ VAS) in case of low self-efficacy and with higher social participation. Furthermore, we showed that patients who became more self-efficacious in managing their brain injury-related symptoms over the course of one year, showed better quality of life after one year. Higher initial self-efficacy also predicted higher long-term general quality of life (LiSat-9). In addition, we found that patients with high initial emotion-oriented coping showed worse long-term health status (EQ VAS). However, for predicting long-term levels of social participation, initial self-efficacy and coping styles appeared to be far less important. So, early monitoring of self-efficacy for managing brain injury-related symptoms might identify patients at risk of worse outcome, and promoting self-efficacy in the early stage after acquired brain injury might give rise to better long-term quality of life and social participation. 
Chapter 7 presents the results of a study conducted to investigate the attainment of important life goals and to examine whether self-efficacy, tenacity and flexibility in goal pursuit contribute to adaptation by affecting levels of emotional distress and quality of life. One hundred and forty-eight patients with newly acquired brain injury were assessed after discharge home and one year later. We found that only a minority of important life goals (13\%) were met one year after discharge home. Of unattained life goals, the majority (58\%) was maintained as originally formulated. A smaller amount of goals (9\%) were made easier, so as to bring aspirations to a more realistic level and for $31 \%$ of goals the actual level of attainment was accepted as sufficient and striving for ceased. Only a very small fraction (2\%) of goals were completely abandoned. Life goals appeared to be completely abandoned only if attainment was very low. Patients who maintained efforts to reach their life goals had higher average levels of tenacity, but did not differ in level of self-efficacy compared with patients that disengaged. At one year post-discharge home, patients who were more self-efficacious in managing their brain injury-related symptoms experienced less emotional distress and were more successful in attaining important life goals, which in turn correlated with higher quality of life reflecting better adaptation. Better adaptation was also present in patients with higher tenacity and flexibility in goal pursuit as they experienced lower emotional distress, which was again related to higher quality of life. Tenacity and flexibility in goal pursuit did not play a role in goal attainment, but being flexible was directly related to better quality of life, independent of goal attainment per se. For clinical practice, we stress the importance of promoting self-efficacy and both assimilative (tenacity in goal pursuit) and accommodative (flexibility in goal adjustment) qualities during rehabilitation treatment.

Chapter 8 is the general discussion, in which the findings of the different studies in this thesis are integrated. Centred around three important elements of the new interactive twodimensional model, i.e. self-efficacy, coping, and life goal attainment and adjustment, we reflect on our findings. Furthermore implications for clinical practice and future research directions are discussed. We showed that low self-efficacy for managing brain injuryassociated symptoms and making high use of emotion-oriented coping in the early stage after injury are putative risk factors for worse quality of life. In our opinion, it is important to identify patients at risk for worse outcome and unfavourable adaptation in the early stages after injury. This can be done easily by using questionnaires. The results of the different studies in this thesis also suggest that therapeutic attempts to enhance self-efficacy already in the early stage after acquired brain injury would be appropriate. The results of this thesis must be considered as a first test on the relationships between the different components of the model. So, future research is needed to provide more insight into the temporal development of the adaptation process after acquired brain injury. Another challenge could be the development of a general therapy format to improve self-efficacy in any domain of functioning, applicable to and adaptable to any kind of training in rehabilitation or to other therapy settings. 

Samenvatting 
Samenvatting 
Niet aangeboren hersenletsel (NAH) is een verzamelterm voor een aantal niet progressieve vormen van hersenletsel, ontstaan na de geboorte. De twee meest voorkomende vormen zijn CVA en traumatisch hersenletsel.

Hoofdstuk 1 is een algemene inleiding tot het onderwerp van dit proefschrift: het aanpassingsproces na doormaken van NAH. Fysieke, cognitieve, emotionele en gedragsproblemen komen frequent voor na het doormaken van $\mathrm{NAH}$, niet enkel in de acute fase maar ook in de chronische fase na letsel. Vaak is er sprake van ingrijpende veranderingen in het leven van zowel de patiënt met $\mathrm{NAH}$ als diens familie. Het aanpassen aan deze veranderingen is geen gemakkelijke opdracht en verloopt niet altijd gunstig. Om het aanpassingsproces na NAH te kunnen begrijpen en verklaren wordt tot nog toe vooral de 'stress en coping theorie' van Lazarus en Folkman over het omgaan met acute stress gebruikt. Echter, deze theorie is slechts ten dele geschikt als verklaring voor het aanpassingsproces na hersenletsel. Daarom stellen wij een nieuw theoretisch model voor waarin de nadruk ligt op aspecten van gedragsverandering die nodig zijn in het zich aanpassen aan veranderingen.

Het onderzoek dat beschreven wordt in dit proefschrift had twee belangrijke doelstellingen:

1. Het ontwikkelen en beschrijven van een nieuw theoretisch model ter verklaring van het aanpassingsproces na NAH.

2. Het testen van de belangrijkste componenten uit dit model.

\section{Deel 1. Het interactieve tweedimensionale model ter verklaring van het aanpassingsproces na NAH}

Hoofdstuk 2 beschrijft het nieuwe model waarin de volgende componenten opgenomen zijn: de doelstellingen van de patiënt, de mogelijkheden van de patiënt, de mogelijke discrepantie tussen vooropgestelde doelen en behaald resultaat en de emotionele respons als reactie op alle veranderingen. Het aanpassingsproces na NAH wordt gekenmerkt door een continue interactie van twee processen: enerzijds is er het streven naar maximaal functieherstel en anderzijds is het nodig om zich aan te passen aan de blijvende beperkingen die aanwezig kunnen zijn in diverse domeinen van functioneren. Aanpassen vereist dus een mix van coping gericht op herstel en coping gericht op aanpassen aan verlies. Echter, in het meest gebruikte theoretische raamwerk om het aanpassingsproces na NAH te verklaren, de 'stress en coping theorie' van Lazarus en Folkman, is deze typische interactie tussen beide processen onvoldoende vervat. In het nieuwe model zijn theorieën over zelfregulatie van gedrag en zelfeffectiviteit, waarbij het stellen en behalen van doelen centraal staat, geïncorporeerd en wordt ook de invloed van ziekte-inzicht meegenomen. De centrale assumptie is dat er sprake is 
van een simultane en continue interactie van twee paden: enerzijds het nastreven van doelen zowel voor de korte als de lange termijn, waarbij deze doelen al dan niet bijgesteld worden op basis van de mate van succes in het bereiken van de gewenste situatie en anderzijds de emotionele respons die voortkomt uit de discrepantie tussen wat men wil (doel) en wat men kan (prestatie). Deze emotionele respons is vervolgens weer van invloed op de doelen die men zich stelt. De twee dimensies beschreven in het model behelzen enerzijds de tijdsdimensie, die bestaat uit de interactie van het korte en lange termijnperspectief in het nastreven en bijstellen van doelen en anderzijds de dimensie betreffende de interactie tussen gedrag en emotie. In deze tweedimensionale representatie passen ook de eerder beschreven processen die deel uitmaken van het gehele aanpassingsproces: streven naar maximaal functieherstel en het aanpassen aan blijvende beperkingen. Centraal in het aanpassingsproces staat het bijstellen van het lange termijn perspectief waarbij het van belang is om te komen tot realistische en/ of nieuwe doelen voor de lange termijn die tegelijkertijd waardevol zijn. We veronderstellen dat hiermee ook stabiliteit op emotioneel vlak gegenereerd wordt. In dit hoofdstuk wordt vervolgens ook besproken hoe het voorgestelde model kan gelinkt worden aan de huidige werkwijze in de revalidatie.

\section{Deel 2. Het meten van coping}

Hoofdstuk 3 beschrijft een systematisch literatuuroverzicht van meetinstrumenten die gebruikt worden om coping te meten bij patiënten met $\mathrm{NAH}$ waarbij informatie over de conceptualisatie van coping, de toepasbaarheid en de psychometrische eigenschappen van deze meetinstrumenten in deze populatie zijn samengevat. Hiervoor werden artikelen gepubliceerd tussen 1970 en 2011 gescreend op de aanwezigheid van informatie over zowel coping als hersenletsel. Uiteindelijk werden 47 meetinstrumenten geïdentificeerd waarvan er 14 werden geselecteerd voor verdere evaluatie. De algemene conclusie is dat er weinig gegevens beschikbaar zijn over de psychometrische eigenschappen van deze meetinstrumenten in de NAH populatie. De gegevens over conceptualisatie van coping, toepasbaarheid en psychometrische eigenschappen samenvattend, lijkt de COPE een geschikt meetinstrument voor NAH patiënten met lichte cognitieve stoornissen en lichte vermoeidheidsklachten. Voor patiënten met matige tot ernstige cognitieve stoornissen lijken de 'brief COPE', de Coping Scale for Adults-short form en de Utrechtse Coping Lijst het meest geschikt. De versie voor naasten (other-report version) van de Coping with Health Injuries and Problems lijkt geschikt om coping te meten bij patiënten die niet in staat zijn om zelf vragenlijsten betrouwbaar in te vullen. Andere meetinstrumenten kunnen gebruikt worden wanneer onderzoekers of clinici specifieke vragen hebben, zoals bijvoorbeeld hoe een individu omgaat met een specifieke situatie of ziekte. 
Hoofdstuk 4 beschrijft de resultaten van een studie naar de psychometrische eigenschappen van de Coping Inventory for Stressful Situations (CISS) in een groep van 139 patiënten met recent NAH. Gegevens werden verzameld bij start poliklinische revalidatie (tijd sinds diagnose $\leq 4$ maanden) of na ontslag naar huis uit ziekenhuis of klinische revalidatie. De constructvaliditeit, discriminante, convergente en divergente validiteit van de CISS werd onderzocht. De oorspronkelijke drie-factor structuur van de CISS (taakgerichte coping, emotiegerichte coping en vermijdingsgerichte coping) werd bevestigd, zij het nipt (borderline fit). Model fit verbeterde licht na verwijderen van drie items met lage gestandaardiseerde factorwaarde $(<.40)$. Ook voor een vier-factor structuur werd een nipte model fit gevonden. Interne consistentie was goed. Discriminante validiteit voldeed slechts ten dele gezien de matig sterke correlatie tussen taakgerichte en vermijdingsgerichte coping. Emotiegerichte coping toonde een sterke correlatie met zowel de Angst subschaal als de Depressie subschaal van de Hospital Anxiety and Depression Scale. Uit de Assimilative/Accommodative Coping Questionnaire, correleerde de subschaal 'Tenacious Goal Pursuit' het sterkst met taakgerichte coping, terwijl de subschaal 'Flexible Goal Adjustment' een negatieve correlatie met emotiegerichte coping vertoonde. Samenvattend kan gesteld worden dat de psychometrische eigenschappen van de CISS bij patiënten met NAH acceptabel tot goed zijn. De oorspronkelijke drie-factor structuur is passend, hoewel sommige items mogelijk problematisch zijn. Replicatie van het beperkte drie-factor model (zonder de problematische items) in grotere groepen patiënten met $\mathrm{NAH}$ is nodig, naast verdere exploratie van de discriminante validiteit en de relatie van de CISS tot andere coping instrumenten. Op dit moment lijkt bij patiënten met NAH het gebruik van de oorspronkelijke versie van de CISS aangewezen.

\section{Deel 3. Het testen van het nieuwe interactieve tweedimensionale model ter verklaring van het aanpassingsproces na $\mathrm{NAH}$}

Hoofdstuk 5 beschrijft een studie naar coping flexibiliteit bij136 patiënten met recent NAH. Metingen werden verricht bij ontslag naar huis (gemiddelde tijd sinds letsel $=15$ weken) en een jaar later (gemiddelde tijd sinds letsel $=67$ weken). Coping flexibiliteit betekent een flexibele inzet van coping strategieën, aangepast aan de contextuele vereisten. De doelen van deze studie waren (1) exploreren of patiënten het gebruik van coping strategieën aanpassen aan de situatie, het type probleem of over verloop van tijd; (2) onderzoeken van variabiliteit en consistentie in coping en (3) van de invloed van zelf-gerapporteerd executief functioneren, ziekte-inzicht en zelf-effectiviteit op coping, coping variabiliteit en consistentie. Coping variabiliteit is de range in frequentie van gebruik van strategieën over situaties. Coping consistentie is iemands vaste, niet situatie-afhankelijke coping repertoire, het aantal coping strategieën dat in elke situatie wordt gebruikt. Aan alle patiënten werd gevraagd om drie 
stressvolle situaties te beschrijven waarmee ze, ten gevolge van het hersenletsel, werden geconfronteerd tijdens de afgelopen twee weken. Voor elke situatie werd een CISS vragenlijst ingevuld. Deze situaties werden vervolgens gecategoriseerd in probleem types: fysiek, cognitief, emotioneel, gedrag, communicatie en overig. Deze studie liet zien dat patiënten gebruik maken van een relatief vaste set coping strategieën, ongeacht situatie en tijd. Het type probleem bleek slechts een beperkte invloed te hebben op het gebruik van coping stijlen. Enkel voor cognitieve problemen was de inzet van taakgerichte coping hoger dan voor fysieke problemen. Coping variabiliteit was beperkt. Het gebruik van emotiegerichte coping nam af over de tijd. Een hogere mate van algemene zelf-effectiviteit correleerde met een grotere inzet van taakgerichte coping (gericht op oplossen van het probleem) en vermijdingsgerichte coping (gericht op het actief zoeken van sociale steun en afleiding). Beide coping stijlen zijn nodig in het aanpassen aan de gevolgen van hersenletsel. Een grotere zelf-effectiviteit in het omgaan met hersenletsel-specifieke symptomen correleerde met een lager gebruik van emotiegerichte coping (ventileren van negatieve emoties). Een hogere mate van zelfgerapporteerde problemen in executieve functies correleerde met een grotere consistentie in taak- en emotiegerichte coping. De inzet van een uitgebreider invariabel repertoire aan strategieën suggereert mogelijk problemen in het effectief selecteren van strategieën. Om het aanpassingsproces aan de diverse gevolgen van NAH te bevorderen, lijkt het aangewezen om vooral patiënten met problemen in executief functioneren, te trainen in het gebruik van een beperkte maar effectieve set van coping strategieën. Daarenboven lijkt het bevorderen van zelf-effectiviteit tijdens het revalidatieproces aangewezen aangezien hierdoor het gebruik van actieve copingstijlen toeneemt.

In Hoofdstuk 6 worden de resultaten gepresenteerd van een studie naar (1) de invloed van zelf-effectiviteit in het managen van hersenletsel-specifieke symptomen op de relatie tussen coping en kwaliteit van leven en sociale participatie en (2) de invloed van de initiële mate van zelf-effectiviteit en copingstijl en verandering in zelf-effectiviteit op kwaliteit van leven en sociale participatie een jaar later. Aan deze studie namen 148 patiënten met recent NAH deel. Metingen werden verricht bij ontslag naar huis en een jaar later. In de subacute fase na $\mathrm{NAH}$ was er verschil in hoe de mate van zelf-effectiviteit de relatie tussen coping en kwaliteit van leven beïnvloedde. Een hogere mate van zelf-effectiviteit in het omgaan met hersenletselspecifieke symptomen bleek de negatieve invloed van emotiegerichte coping op gezondheidsgerelateerde kwaliteit van leven (EQ-5D index en EQ VAS) te milderen, hetgeen suggereert dat een hoge mate van zelf-effectiviteit een beschermend effect heeft. Patiënten die meer gebruik maakten van emotiegerichte coping ervaarden een lagere algemene kwaliteit van leven (LiSat-9). Testen voor effect mediatie toonden aan dat dit was omdat deze patiënten een lagere zelf-effectiviteit in het omgaan met hersenletsel-specifieke symptomen hadden. Het gebruiken van meer vermijdingsgerichte coping was geassocieerd met een hogere 
gezondheids-gerelateerde kwaliteit van leven (EQ VAS) bij patiënten met een lage zelfeffectiviteit en met een hogere mate van sociale participatie. Verder bleek dat patiënten wiens mate van zelf-effectiviteit voor het managen van hersenletsel-specifieke symptomen toenam over de loop van het jaar, een hogere kwaliteit van leven rapporteerden. Een hogere mate van zelf-effectiviteit in de subacute fase was voorspellend voor een betere algemene kwaliteit van leven (LiSat-9) een jaar later. Patiënten die in de subacute fase in hoge mate gebruik maakten van emotiegerichte coping rapporteerden na een jaar een lagere gezondheids-gerelateerde kwaliteit van leven (EQ VAS). Echter, in het voorspellen van sociale participatie na een jaar bleken de initiële mate van zelf-effectiviteit en coping stijl van beperkt belang. Het vroegtijdig monitoren van de mate van zelf-effectiviteit in het managen van hersenletsel-specifieke symptomen kan mogelijk helpend zijn in het identificeren van patiënten die risico lopen op een slechtere uitkomst. Het lijkt dus aangewezen om al in de vroege fase na NAH zelfeffectiviteit te bevorderen aangezien hiermee de kans op een betere kwaliteit van leven en een hogere mate van sociale participatie op de lange termijn toeneemt.

Hoofdstuk 7 beschrijft een studie waarin het behalen van belangrijke levensdoelen werd onderzocht en werd nagegaan of zelf-effectiviteit en vasthoudendheid en flexibiliteit in het nastreven van doelen bijdragen tot het aanpassingsproces in termen van kwaliteit van leven en emotioneel welbevinden. Aan deze studie namen 148 patiënten met recent NAH deel. Metingen werden verricht bij ontslag naar huis en een jaar later. Uit deze studie bleek dat slechts een beperkt aantal (13\%) belangrijke levensdoelen behaald werd na een jaar. Van de niet behaalde doelen werd 58\% behouden zoals oorspronkelijk geformuleerd. Een klein aantal (9\%) doelen werd gemakkelijker gemaakt en teruggebracht tot een realistischer ambitieniveau. Voor 31\% van de niet behaalde doelen werd de actuele prestatie als voldoende beoordeeld en werd niet verder gestreefd naar het oorspronkelijk gestelde einddoel. Slechts een fractie van de niet behaalde doelen (2\%) werd helemaal verlaten en dit bleek enkel het geval wanneer succes zeer beperkt was. Patiënten die hun oorspronkelijke doelen bleven nastreven, hadden gemiddeld een hogere mate van vasthoudendheid maar verschilden niet in mate van zelf-effectiviteit ten opzichte van patiënten die hun oorspronkelijke doel niet verder nastreefden. Patiënten met een hogere mate van zelf-effectiviteit in het managen van hersenletsel-specifieke symptomen waren een jaar na ontslag naar huis succesvoller in het bereiken van hun doelen en ervaarden een hogere mate van emotioneel welbevinden, hetgeen verder correleerde met een betere kwaliteit van leven en dus een gunstiger aanpassingsproces. Ook bij patiënten met een hogere mate van zowel vasthoudendheid als flexibiliteit in het nastreven van doelen was er sprake van een gunstiger aanpassingsproces aangezien zij een groter emotioneel welbevinden vertoonden, hetgeen correleerde met een betere kwaliteit van leven. Vasthoudendheid en flexibiliteit speelden geen rol in het behalen van doelen maar flexibiliteit was wel geassocieerd met een betere kwaliteit van leven, onafhankelijk van de mate 
van succes in het behalen van doelen. In de klinische praktijk lijkt het dus belangrijk om zowel zelf-effectiviteit te bevorderen als vasthoudendheid en flexibiliteit.

Hoofdstuk 8 is de algemene discussie waarin over de belangrijkste bevindingen uit dit proefschrift wordt gereflecteerd. Drie hoofdcomponenten van het nieuwe interactieve tweedimensionale model, nl. zelf-effectiviteit, coping en doelen, worden hierbij centraal geplaatst. Ook worden toepassingen voor de klinische praktijk en ideeën voor verder onderzoek aangereikt. Dit proefschrift toont dat een lage zelf-effectiviteit voor het managen van hersenletsel-specifieke symptomen en in hoge mate gebruik maken van emotiegerichte coping in de subacute fase na NAH potentiele risicofactoren zijn voor een slechtere uitkomst op de langere termijn. Daarom is het, naar onze mening, van belang om in een vroegtijdig stadium deze factoren te screenen om zo patiënten met een hoger risico op een slechtere uitkomst te identificeren. Screening kan gebeuren door middel van vragenlijsten. De resultaten van verschillende studies in dit proefschrift suggereren ook dat therapeutische interventies gericht op het bevorderen van zelf-effectiviteit in een vroeg stadium na NAH een gunstige impact kunnen hebben op het aanpassingsproces. De studies in dit proefschrift zijn een eerste stap in het testen van de diverse relaties tussen de componenten in het nieuw ontwikkelde model. Verder onderzoek is nodig naar het verloop van het aanpassingsproces in de tijd. Een ander uitdaging is het ontwikkelen van een algemeen behandelformat ter bevordering van zelf-effectiviteit gericht op om het even welk domein van functioneren en toepasbaar in elke vorm van training of therapiesetting. 
Valorization 


\section{Relevance}

Acquired brain injury (ABI) refers to any non-progressive injury to the brain caused after birth. The two most common forms of acquired brain injury are strokes and traumatic brain injuries (TBI).

The overall annual incidence rate worldwide of stroke is around $0.20-0.25 \%$, the total annual prevalence rate is around $0.5 \% .{ }^{1}$ After discharge from hospital, more than $50 \%$ of stroke survivors return to their home environment. ${ }^{2}$ For traumatic brain injury, the incidence rate for the European population is $0.24 \%$ with 66000 deaths per year.,

Physical, cognitive, emotional and behavioural problems are frequently present in patients with acquired brain injury and are often followed by long-lasting impairment and disability. ${ }^{5-8}$ In addition, sustaining a brain injury is usually a disruptive event and may cause major changes, not only in the life course of patients but also in their families' lives. ${ }^{9,10}$ The process of adjustment to these various changes caused by the injury is often difficult and shows an unfavourable course. ${ }^{11}$ Even long after the occurrence of acquired brain injury, large groups of patients report symptoms of anxiety and depression ${ }^{12-14}$, restrictions in their level of social participation ${ }^{8}$ and worse quality of life ${ }^{15}$ and well-being ${ }^{16}$ compared with the general population. Furthermore, the poor employment outcomes following brain injury impacts upon self-identity, autonomy and emotional well-being. ${ }^{17}$

The substantial clinical burden of acquired brain injury also involves considerable health care $\operatorname{costs}^{18,19}$, e.g. in Western society approximately $3-4 \%$ of total health care expenditures are spent on stroke. ${ }^{20}$ In 2010, in the Netherlands total costs per capita (including direct healthcare costs, direct non-medical costs and indirect costs associated with patient's production loss) were estimated at $€ 2422$ million for stroke and at $€ 1360$ million for traumatic brain injury. ${ }^{21}$ The European per capita cost was estimated at $€ 64$.1 billion for stroke and $€ 33.0$ billion for traumatic brain injury. ${ }^{21}$

So, from as well a clinical as a societal perspective it is important to gain insight into the determinants of successful adaptation to the consequences of acquired brain injury. A theoretical understanding of the likely process of change and an understanding of the mechanisms involved is essential as a first step in the development of interventions directed at optimizing adjustment and adaptation to brain injury. ${ }^{11,22,23}$ In our research, we proposed a new theoretical model to explain the adaptation process after acquired brain injury and we tested whether the theoretically assumed relations between the core concepts in this new model indeed contribute to adaptation in terms of life goal attainment, quality of life, social participation and emotional distress. 
We focused on determinants that were likely to be amenable for change, such as self-efficacy and coping flexibility. Not all determinants of outcome can be target for therapy, e.g. older age is a predictor for worse outcome in stroke ${ }^{24}$ or longer duration of post-traumatic amnesia is a predictor for worse outcome in traumatic brain injury ${ }^{25}$. Self-efficacy and coping flexibility (both concepts belong to 'personal factors' in the international classification of functioning, disability and health (WHO ICF ${ }^{26}$ ) have, not yet, received major attention in research on outcome after acquired brain injury.

In the process of testing the model, we investigated the psychometric properties of the Coping Inventory for Stressful Situations (CISS), a questionnaire to measure coping, as it was never validated for use in acquired brain injury. We concluded that the psychometric properties of the CISS were sufficient for use in the acquired brain injury population.

Our research revealed that patients with acquired brain injury made use of a rather defined and stable set of coping strategies across situations. The type of problem encountered had only little influence on patients' use of coping styles. Higher self-efficacy showed to be associated with using more active types of coping, less emotional distress, higher quality of life and more successful attainment of important long-term goals. Better adaptation was also present in patients with higher tenacity and flexibility in goal pursuit as they experienced lower emotional distress, which was again related to higher quality of life.

So, the results of our research enable us to detect patients at risk for worse outcome and give direction to the development of interventions to optimize the adjustment process and outcome. In addition, this knowledge serves economical interests, as it might be helpful in reducing long-term health care costs.

\section{Target groups}

The results of this research are relevant to patients and their families and to the various stakeholders involved in dealing with patients with acquired brain injury.

Patients and their families will benefit from this research through optimization of existing interventions and development of new treatment procedures, leading to better outcome in terms of life goal attainment, emotional distress and quality of life.

The results of this research are immediately relevant to the different health care professionals (psychologists, physiotherapists, occupational therapists, cognitive rehabilitation therapists, 
social workers...) in primary care settings, hospitals and rehabilitation centres, as well as to rehabilitation physicians involved in dealing with acquired brain injury. Patients at risk for worse outcome can be identified through early inventory of coping styles and level of selfefficacy, which can be, at the same time, targets for treatment.

Recently the Dutch government has identified the development towards a participation society ('participatie samenleving') as one of the major targets. In this regard, the results of this research are highly relevant for policy makers and health insurance companies. We have shown that specific personal factors, such as self-efficacy and coping have an important impact on how well one adapts to the consequences of acquired brain injury in terms of participation and quality of life. This means that it is not enough to solely address the somatic aspects or disease-related factors during acute care and rehabilitation after acquired brain injury. To improve outcome and participation in society, it is also of importance to address these personal factors during treatment, as well in primary care as during rehabilitation and other settings involved in integrated care pathways. Insurance companies and policy makers need to be more aware of this.

In addition, the detection of patients at risk for worse outcome and the development of interventions to optimize the adjustment process and participation might be helpful in reducing long-term health care costs.

\section{Activities and products}

In this thesis we showed that lower self-efficacy for managing brain injury-associated symptoms and making high use of emotion-oriented coping in the early stage after injury are putative risk factors for worse quality of life. In clinical practice, as well in rehabilitation and hospitals as in primary health care, questionnaires (e.g. the Traumatic Brain Injury Selfefficacy Questionnaire and the Coping Inventory for Stressful Situations) can very easily be used to detect these risk factors.

Through the systematic review that we performed, information on instruments used to measure coping after acquired brain injury, as well as information about their conceptualisation, their psychometric properties and feasibility came available. Furthermore, we showed that the Coping Inventory for Stressful Situation (CISS) has sound psychometric properties in the acquired brain injury population. This knowledge serves clinicians and researchers in their choice of coping measurement instruments for this population. 
So, to make sure that screening of coping style and level of self-efficacy will be implemented in clinical practice, information must become readily available for clinicians. Not only scientific publications are necessary but also the organisation of workshops and symposia in which the scientific knowledge is communicated but also practical information is given, e.g. availability of questionnaires, how to use these questionnaires etc.

The results of the different studies in this thesis suggest that therapeutic attempts to enhance self-efficacy already in the early stage after acquired brain injury would be appropriate. Training of skills in various domains of functioning, which is the basic component of self-efficacy, is the central part in rehabilitation programmes and therapy conducted in the hospital setting or primary health care facility. In our clinical experience with these treatment programmes, less explicit attention is paid to the second component of self-efficacy namely that of developing the firm belief or confidence that goals can be achieved through these skills, even under difficult circumstances. In our opinion, it is essential to reinforce the development of these self-beliefs explicitly. Referential comparison with others, verbal feedback and control over negative physiological and affective states (e.g. stress, fatigue) could be used to create strong efficacy beliefs in any domain of functioning. ${ }^{27}$ Recently, Aben et al. ${ }^{28}$ showed that training memory self-efficacy in patients with stroke had many beneficial effects over traditional memory rehabilitation treatment. The memory self-efficacy training consisted of a general theoretical introduction on memory and stroke, training internal and external compensatory memory strategies and psycho-education on the influence of mood, anxiety and memoryrelated worries on memory complaints. A positive impact on psychological aspects of quality of life was observed, even one year after the intervention. ${ }^{28}$

The next challenge is to broaden the target of the self-efficacy intervention to different domains of functioning and to do this in the most efficient way, with regard to patient burden and health care costs. So, an interesting path is to develop and test a kind of general therapy format for improvement of self-efficacy in patients with acquired brain injury after the example of Marks et al. ${ }^{29}$ and Lorig et al. ${ }^{30}$ in patients with chronic disease. A general therapy format would have the advantage of being suitable for improving self-efficacy in any domain of functioning and would be applicable and adaptable to any kind of therapy or training in rehabilitation, hospital or primary care. This general therapy format could be the application of a systematic and stepwise approach in training skills, whatever they are (cognitive skills, physical skills...). Important components are goal setting, incremental learning strategies that involve instructions in a multimodal way (e.g. verbal, visual, kinaesthetic...), feedback on performance achievements, reinterpretation of symptoms and promotion of generalization. This stepwise approach is rather a refinement of the actual training methodology that is used in e.g. physical therapy, cognitive rehabilitation therapy, occupational therapy, and speech 
therapy, which could be an advantage in further implementation in clinical practice.

Our research findings confirm the involvement of the main components that we assumed to be of importance in our theoretical model on the adaptation process after acquired brain injury. As such our model has stood the first test. Further research conducted to gain insight into the determinants of successful adaptation to the consequences of acquired brain injury should capitalize upon these findings.

\section{Innovation}

Our research is innovative in several aspects. The research in this thesis is based on a newly developed theoretical model explaining the adaptation process after acquired brain injury. This process is complex and involves many components. Very few theoretical models were available to explain this process and we concluded that they were only partially sufficient. Model development is important because it helps to gain insight into a complex process in a more systematic way. Moreover, as already mentioned, the theoretical understanding of the likely process of change is a first step in the development of interventions aiming at optimizing adjustment and adaptation.

The strength of our new model is that it integrates theories about human behaviour and behavioural change as adaptation to brain injury is about making major adjustments in various domains of functioning and participation. Furthermore, our model is in line with the biopsychosocial model ${ }^{11,31}$ of human functioning in the context of disease or illness as we emphasize that in the process of adjustment to the consequences of acquired brain injury, the physical, psychological, emotional and social aspects involved are all interlinked. Our new model is applicable independent of time since injury, and as such relevant in every stage after acquired brain injury, from acute to chronic. The incorporation of the concept of self-efficacy is new, as is the description of the adaptation process in a goal-oriented way, which provides a link to clinical practice, especially in rehabilitation where goal setting and goal planning are essential.

Although this new model describes the adaptation process after acquired brain injury, we assume it is generic and applicable to various chronic diseases when the brain injury-specific factors such as self-awareness and cognitive impairments are left out.

Our research findings are relevant for clinical practice as they give direction to the development of new treatments (see activities and products). 


\section{Schedule and implementation}

Dissemination of knowledge is needed at several levels. All findings of this thesis are available to the scientific and clinical community as published articles to date. In addition, we presented our work at international and national conferences (IBIA San Francisco 2014, WCNR Istanbul 2014, WTH teamdag Eindhoven 2014). For patients and their families the information should be spread through magazines edited by patient organisations, rehabilitation centres etc.

In clinical guidelines (e.g. 'richtlijn Beroerte'), more attention should be paid to the contribution of psychosocial aspects and personal factors to outcome after acquired brain injury. In this thesis we showed that lower self-efficacy for managing brain injury-associated symptoms and making high use of emotion-oriented coping in the early stage after injury are putative risk factors for worse quality of life. Concerning the negative effect of emotion-oriented coping on psychosocial outcome, ample evidence is available. Yet, replication of findings with regard to the influence of self-efficacy is necessary.

The development of a generic intervention to optimize self-efficacy is a large project that must be carefully considered and planned. The instruments used to measure self-efficacy should be reviewed. Furthermore, information on the psychometric properties of these instruments and their feasibility is needed. Based on this information, suitable instruments can be identified and/or additional work (e.g. validation) can be started. The design of the intervention should be considered carefully. In this process, clinical practitioners of various backgrounds should be involved to make sure that the intervention fits into existing practice without lengthening the number of therapy sessions, adds the missing elements, and is feasible. Ultimately, this should result in a therapy protocol and instruction booklet. A pilot study should be conducted to check feasibility of the intervention and feasibility and responsiveness of the self-efficacy questionnaires. Next, a full study should be designed to test the effectiveness of the intervention. If positive, widespread use of this intervention must be promoted through education and instruction of the health care professionals involved in treatment of patients with acquired brain injury. 


\section{References}

1. Wolfe CD. The impact of stroke. Br Med Bull. 2000 2000;56(2):275-286.

2. Scholte op Reimer W. Proceedings of the Mixed Methods Symposium. November 28, 2008; Amsterdam.

3. Andlin-Sobocki P, Jonsson B, Wittchen HU, Olesen J. Cost of disorders of the brain in Europe. Eur J Neurol. 2005;12(S1):1-27.

4. Tagliaferri F, Compagnone C, Korsic M, Servadei F, Kraus J. A systematic review of brain injury epidemiology in Europe. Acta Neurochir (Wie). 2006;148(3):255-268.

5. Dikmen S, Machamer J, Temkin N. Psychosocial outcome in patients with moderate to severe head injury: 2-year follow-up. Brain Inj. 1993;7(2):113-124.

6. Dikmen SS, Machamer JE, Powell JM, Temkin NR. Outcome 3 to 5 years after moderate to severe traumatic brain injury. Arch Phys Med Rehabil. 2003;84(10):1449-1457.

7. McCarthy ML, Dikmen SS, Langlois JA, Selassie AW, Gu JK, Horner MD. Self-reported psychosocial health among adults with traumatic brain injury. Arch Phys Med Rehabil. July 2006;87(7):953-961.

8. Gadidi V, Katz-Leurer M, Carmeli E, Bornstein NM. Long-term outcome poststroke: predictors of activity limitation and participation restriction. Arch Phys Med Rehabil. 2011;92(11):18021808.

9. Visser-Meily A, Post M, Schepers V, Lindeman E. Spouses' quality of life 1 year after stroke: prediction at the start of clinical rehabilitation. Cerebrovasc Dis. 2005;20(6):443-448.

10. Peters LC, Stambrook M, Moore AD, Esses L. Psychosocial sequelae of closed head injury: effects on the marital relationship. Brain Inj. 1990;4(1):39-47.

11. Gracey F, Evans JJ, Malley D. Capturing process and outcome in complex rehabilitation interventions: a "Y-shaped" model. Neuropsychol Rehabil. 2009;19(6):867-890.

12. Bergersen H, Frøslie KF, Stibrant Sunnerhagen K, Schanke A-K. Anxiety, depression, and psychological well-being 2 to 5 years poststroke. J Stroke Cerebrovasc Dis. 2010;19(5):364-369.

13. Gould KR, Ponsford JL, Johnston L, Schönberger M. Course of psychiatric disorders following traumatic brain injury. Brain Inj. 2010;24(3):337.

14. Whelan-Goodinson R, Ponsford J, Johnston L, Grant F. Psychiatric disorders following traumatic brain injury: their nature and frequency. J Head Trauma Rehabil. 2009;24(5):324-332.

15. Andelic N, Hammergren N, Bautz-Holter E, Sveen U, Brunborg C, Roe C. Functional outcome and health-related quality of life 10 years after moderate-to-severe traumatic brain injury. Acta Neurol Scand. 2009;120(1):16-23.

16. Clarke P, Marshall V, Black SE, Colantonio A. Well-being after stroke in Canadian seniors. Findings from the Canadian Study of Health and Aging. Stroke. 2002;33:1016-1021.

17. Ownsworth $\mathrm{T}$, McKenna $\mathrm{K}$. Investigation of factors related to employment outcome following traumatic brain injury: a critical review and conceptual model. Disabil Rehabil. 2004;26(13):765783.

18. Evers SM, Struijs JN, Ament AJ, Van Genugten ML, Jager JH, Van Den Bos GA. International comparison of stroke cost studies. Stroke 2004;35:1209-1215.

19. Berg J, Tagliaferri F, Servadei F. Cost of trauma in Europe. Eur J Neurol 2005;12(S1):85-90.

20. Struijs JN, Van Genugten ML, Evers SM, Ament AJ, Baan CA, Van Den Bos GA. Future costs of stroke in the Netherlands: the impact of stroke services. Int J Technol Assess Health Care. 2006;22:518-524.

21. Gustavsson A, Svensson M, Jacobi F, et al. Cost of disorders of the brain in Europe 2010. Eur Neuropsychopharmacol. 2011;21(10):718-779. 
22. Whyte J, Hart T. It's more than a black box; it's a russian doll: defining rehabilitation treatments. Am J Phys Med Rehabil. 2003;82(8):639-652.

23. Craig P, Dieppe P, Macintyre S, Michie S, Nazareth I, Petticrew M. Developing and evaluating complex interventions: the new Medical Research Council guidance. BMJ. 2008:337:a1655.

24. Meijer R, Ihnenfeldt DS, van Limbeek J, Vermeulen M, de Haan RJ. Prognostic factors in the subacute phase after stroke for the future residence after six months to one year. A systematic review of the literature. Clin Rehabil. 2003;17(5):512-520.

25. Ponsford J, Draper K, Schönberger M. Functional outcome 10 years after traumatic brain injury: its relationship with demographic, injury severity, and cognitive and emotional status. $J$ Int Neuropsychol Soc. 2008;14(02):233-242.

26. WHO. International classification of functioning, disability and health. Geneva, World Health Organization, 2001. Available at http://www3.who.int/icf/icftemplate.cfm.

27. Bandura A. Self-efficacy: the exercise of control. New York: W.H. Freeman and Company; 1997.

28. Aben L, Heijenbrok-Kal MH, Ponds RW, Busschbach JJ, Ribbers GM. Long-lasting effects of a new memory self-efficacy training for stroke patients: a randomized controlled trial. Neurorehabil Neural Repair. 2014;28(3):199-206.

29. Marks R, Allegrante JP. A review and synthesis of research evidence for self-efficacy-enhancing interventions for reducing chronic disability: implications for health education practice (Part II). Health Promot Pract. 2005;6(2):148-156.

30. Lorig K, Laurent DD, Plant K, Krishnan E, Ritter PL. The components of action planning and their associations with behavior and health outcomes. Chronic Illn. 2014;10(1):50-59.

31. Wade DT. Applying the WHO ICF framework to the rehabilitation of patients with cognitive deficits. In: Halligan PW, Wade DT, eds. Effectiveness of rehabilitation for cognitive deficits. Oxford: Oxford University Press; 2005. 


\section{Dankwoord}


Dankwoord 
Ik heb het werken aan dit proefschrift als heel stimulerend, boeiend en uitdagend ervaren. Ik kijk met ontzettend veel plezier terug op deze periode. In dit dankwoord wil ik graag een aantal mensen noemen die een bijzondere rol gespeeld hebben in het tot stand komen van dit proefschrift.

I was very privileged to have such a fantastic promotion team: both my promotores Caroline van Heugten and Derick Wade and both my co-promotores Sven Stapert and Sebastian Köhler. It was a pleasure to work with you all.

Dear Derick, your help and guidance in crystallizing ideas, shaping thoughts and your assistance in the description of the model was of great value. I have learned a lot from you about writing and succinct formulation. I greatly appreciate your critical appraisal and your way of giving feedback. Thank you so much.

Beste Caroline, van jou heb ik in dit traject 'het onderzoek als vak' geleerd. Ik apprecieer ontzettend je positief kritische houding waarbij je heel systematisch aangeeft waar verbeteringen nodig zijn en andere gezichtspunten aanreikt. Het was heel prettig om met jou samen te werken. Ik hoop dat we dit in de toekomst nog kunnen doen.

Beste Sven, dank voor je klinische inbreng, het brainstormen en meedenken in het ontwikkelen van het model maar ook voor je steun, de gezellige babbel en je vermogen tot relativeren.

Beste Seb, je bent pas in een later stadium het team komen vervoegen als 'statisticus'. Ik heb ontzettend veel van je geleerd, niet enkel wat betreft statistiek maar ook in interpretatie en schrijven. Het was ontzettend stimulerend en prettig om met jou te werken.

Veel dank ben ik ook verschuldigd aan alle patiënten en hun families die bereid waren om geheel belangeloos mee te werken aan dit onderzoek.

John, ik kon me geen betere onderzoeksassistent wensen! Dankzij jouw inzet en enthousiasme is het verzamelen van data een succes geworden. Ook jouw klinische kennis van hersenletsel was een grote meerwaarde voor de kwaliteit van de interviews. Dennis, dank je wel voor je hulp in de beginfase van het onderzoek. 
Vele centra en ziekenhuizen hebben meegewerkt aan dit onderzoek waarbij ik vele mensen wil bedanken:

- Revalidatiecentrum Blixembosch Eindhoven, in het bijzonder Hanneke Pijlman, Danielle Driessen, Anneke van Druenen, Barbara Oomen, Cindy Peters, Judith van Loon, Carla van de Griend, Noortje Beekwilder, Sonja Beukelaars en alle dames van het medisch secretariaat Neurologie

- Revalidatiecentrum Leijpark Tilburg, in het bijzonder Christa van Stuivenberg, Iris Heijnen, Anita Tinga, Nienke Doorneveld, Karlijn Smulders en Loes Burgers

- Orbis Medisch Centrum Sittard, in het bijzonder Pieter Struyf, Roger Haenen, Roger Nieling en Fergus Rooijer

- Atrium Medisch Centrum Heerlen, in het bijzonder Erwin Drossaer

- Maxima Medisch Centrum Veldhoven, in het bijzonder Jose Hofstede en Timothy van Esch

Heel speciaal wil ik Vincent Buitendijk, raad van bestuur Libra Revalidatie \& Audiologie, danken voor de gelegenheid die ik van hem heb gekregen om dit onderzoek te doen. Ook al mijn collega's, Ben van den Brand en Gerard Hermans, dank voor jullie betrokkenheid en steun. Sharif, bedankt voor het maken van de folders en het printen van alle materiaal.

Nico en Ron, bedankt voor de informatica-technische ondersteuning, het bouwen van de database, de praktische tips, het installeren van software. Geweldig dat dit altijd à la minute mogelijk was.

Gisela, het was heel aangenaam om met jou samen te werken en samen te schrijven.

Jan Worst, ik ben ontzettend blij dat jij bereid was om mij wegwijs te maken in structural equation modeling. Door jouw uitleg over de basisbeginselen werd wat eerst chaos was, logisch en zag ik door de bomen het bos weer! Prof. Nikolik, I am very grateful for your advice and for all the helpful articles on SEM that you sent me.

Een speciale dank je wel is er ook voor mijn paranimfen, Bert Ter Mors en Nathalie Lemmens. Bert, jouw vriendschap betekent heel veel voor mij. Het deed heel veel deugd om regelmatig met jouw van gedachten te wisselen, te reflecteren maar ook gewoon te lachen. Nathalie, immer mijn getuige op belangrijke momenten, ook nu weer. Dat doet veel plezier.

Linde, mijn nichtje, ik ben ontzettend blij met je prachtige omslagontwerp. Dank je wel!

Mams en paps, dank je wel voor de kansen die ik van jullie kreeg. 
Dirk, Arnout en Ewald, de drie belangrijkste mannen in mijn leven. Dank jullie wel voor alle praktische hulp, de humor, de steun, de plagerijen, de belangstelling...

Arnout en Ewald, ik ben een heel trotse mama. Dirk, jij bent mijn liefste. 



\section{Curriculum Vitae}


Curriculum vitae 


\section{Curriculum Vitae}

Ingrid Brands was born on May 24, 1968 in Maaseik, Belgium. She graduated magna cum laude from Medical School at the University of Leuven, Belgium in 1993.

Between 1993 and 1998 she fulfilled her training in Physical Medicine and Rehabilitation at the University of Leuven (Prof. dr. R. Lysens), the Sint Maartenskliniek, Nijmegen (Drs. R.A.J. Rijken) and the Sint Maartens Gasthuis, Venlo (Drs. J. Strijckers).

From 1998 on, she worked as a rehabilitation physician at Blixembosch Rehabilitation Centre in Eindhoven, part of Libra Rehabilitation \& Audiology. In 2010 she started her PhD project, which resulted in this thesis. Currently, she combines her clinical work in Blixembosch with research activities at Libra and she is senior researcher at the Rotterdam Neurorehabilitation Research programme (Prof. dr. G. Ribbers, Rijdam Rehabilitation Centre and Erasmus Medical Centre Rotterdam). Since many years, she is medical advisor to 'Hersenletselteam Zuidoost Brabant' and since 2012, she is secretary of the Traumatic Brain Injury Special Interest Group of the Dutch Association of Physical Medicine and Rehabilitation. 



\section{List of publications}


List of publications 


\section{List of publications}

1. Wolters G, Stapert S, Brands I, Van Heugten C. Coping styles in relation to cognitive rehabilitation and quality of life after brain injury. Neuropsychological Rehabilitation. 2010;20(4):587-600.

2. Wolters G, Stapert S, Brands I, Van Heugten C. Coping following acquired brain injury: predictors and correlates. Journal of Head Trauma Rehabilitation. 2011;26(2):150-157.

3. Wolters Gregório G, Stapert S, Brands I, van Heugten C. Coping styles within the family system in the chronic phase following acquired brain injury: its relation to families' and patients' functioning. Journal of Rehabilitation Medicine. 2011;43(3):190-196.

4. Copingstijlen van patiënten met hersenletsel en familieleden in een revalidatiesetting Gisela Wolters Gregório, Sven Stapert, Ingrid Brands en Caroline van Heugten. Neuropraxis. 2011;15(3):67-75.

5. Brands IM, Wade DT, Stapert SZ, van Heugten CM. The adaptation process following acute onset disability: an interactive two-dimensional approach applied to acquired brain injury. Clinical Rehabilitation. 2012; 26(9): 840-852.

6. Brands I, Bouwens S, Wolters Gregório G, Stapert S, van Heugten C. Effectiveness of a process-oriented patient-tailored outpatient neuropsychological rehabilitation programme for patients in the chronic phase after acquired brain injury. Neuropsychological Rehabilitation. 2013;23(2):202-215.

7. Wolters Gregório G, Brands I, Stapert S, Verhey FR, van Heugten CM. Assessments of coping after acquired brain injury: a systematic review of instrument conceptualization, feasibility, and psychometric properties. Journal of Head Trauma Rehabilitation. 2014;29(3):30-42.

8. Brands IMH, Köhler S, Stapert SZ, Wade DT, van Heugten CM. Psychometric properties of the Coping Inventory for Stressful Situations (CISS) in patients with acquired brain injury. Psychological Assessment. 2014;26(3):848-856.

9. Brands I, Köhler S, Stapert S, Wade D, van Heugten C. How flexible is coping after acquired brain injury? A 1-year prospective study investigating coping patterns and influence of self-efficacy, executive functioning and self-awareness. Journal of Rehabilitation Medicine. 2014;46(9):869-875.

10. Brands I, Köhler S, Stapert S, Wade D, van Heugten C. Perceived self-efficacy and coping in acquired brain injury: relations with quality-of-life and social participation after 1 year. Brain Injury. 2014;28(5-6):658-659. (abstract IBIA 2014)

11. Brands I, Köhler S, Stapert S, Wade D, van Heugten C. Influence of self-efficacy and coping on quality of life and social participation after acquired brain injury: a 1-year follow-up study. Archives of Physical Medicine and Rehabilitation. 2014, Jun 25. [Epub ahead of print]

12. Brands I, Stapert S, Köhler S, Wade D, van Heugten C.Life goal attainment in the adaptation process after acquired brain injury: the influence of self-efficacy and of flexibility and tenacity in goal pursuit. Clinical Rehabilitation. 2014, Sep 16. [Epub ahead of print] 


\section{Abstracts}

1. Claessens G, Stapert S, Brands I, van Heugten C. The effect of cognitive performances and cognitive rehabilitation after brain injury on coping styles, and the ifluences of changes in coping styles on quality of life. First meeting of the Federation of the European Societies of Neuropsychology (FESN), Edinburgh 2008

2. Wolters-Gregório G, Stapert S, Brands I, van Heugten C. Cognitive performance and coping styles after acquired brain injury. Second meeting of the Federation of the European Societies of Neuropsychology (FESN), Amsterdam 2010

3. Wolters-Gregório G, Stapert S, Brands I, Visser-Meily J, van Heugten C. Coping styles of patients and the family system in relation to cognitive rehabilitation and quality of life after brain injury. $6^{\text {th }}$ World Congress for NeuroRehabilitation (WCNR), Vienna 2010

4. Brands I, Köhler S, Stapert S, Wade D, van Heugten C. How flexible is coping after acquired brain injury: a one-year prospective study. $8^{\text {th }}$ World Congress for NeuroRehabilitation (WCNR), Istanbul 2014

5. Brands I, Köhler S, Stapert S, Wade D, van Heugten C. Perceived self-efficacy and coping in acquired brain injury: relations with quality-of-life and social participation after 1 year. 10 ${ }^{\text {th }}$ World Congress on Brain Injury (IBIA), San Francisco 2014 
